\author{
UNIVERSIDADE DE SÃO PAULO \\ ESCOLA DE ENGENHARIA DE SÃO CARLOS \\ DEPARTAMENTO DE ENGENHARIA MECÂNICA
}

ROMEU RONY CAVALCANTE DA COSTA

\title{
APLICABILIDADE DE MODELOS CONSTITUTIVOS PARA ANALISAR O COMPORTAMENTO MECÂNICO DE UM BIOPOLÍMERO
}



ROMEU RONY CAVALCANTE DA COSTA

\section{APLICABILIDADE DE MODELOS CONSTITUTIVOS PARA ANALISAR O COMPORTAMENTO MECÂNICO DE UM BIOPOLÍMERO}

Tese apresentada à Escola de Engenharia de São Carlos, da Universidade de São Paulo, como parte dos requisitos para a obtenção do título de Doutor em Engenharia Mecânica.

Área de concentração: Engenharia mecânica.

Orientador: Prof.Titular Benedito de Moraes Purquerio. 
AUTORIZO A REPRODUÇÃO E DIVULGAÇÃO TOTAL OU PARCIAL DESTE TRABALHO, POR QUALQUER MEIO CONVENCIONAL OU ELETRÔNICO, PARA FINS DE ESTUDO E PESQUISA, DESDE QUE CITADA A FONTE.

Ficha catalográfica preparada pela Seção de Tratamento da Informação do Serviço de Biblioteca - EESC/USP

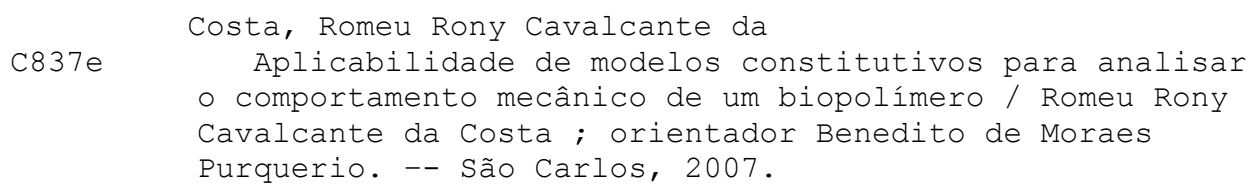

Tese (Doutorado-Programa de Pós-Graduação em Engenharia Mecânica. Área de Concentração: Projeto Mecânico) -- Escola de Engenharia de São Carlos da Universidade de São Paulo, 2007.

1. Métodos dos elementos finitos. 2. Modelos de materiais poliméricos 3. Viscoelasticidade. 4. Viscoplasticidade. . 5. Biopolímero. 6. Ensaios mecânicos. I. Título. 


\section{Candidato: Engenheiro ROMEU RONY CAVALCANTE DA COSTA}

Tese defendida e julgada em 05/07/2007 perante a Comissão Julgadora:

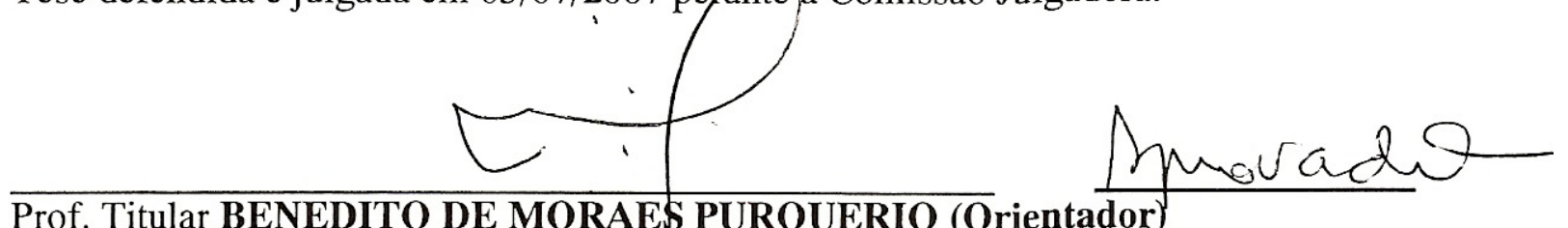

Prof. Titular BENEDITO DE MORAES PURQUERIO (Orientador)

(Escola de Engenharia de São Carlos/USP)

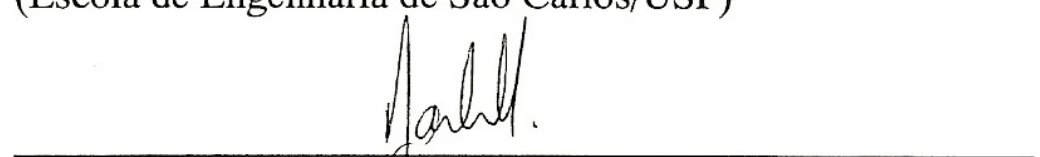

Prof. Associado JONAS DE CARVALHO

(Escola de Engenharia desSão Carlos/USP)

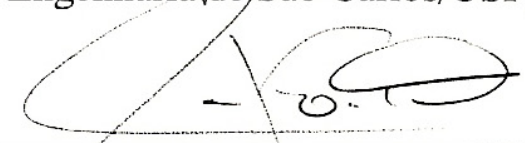

\section{Prof. Dr. CARLOS ALBERTO FORTULAN}

(Escola de Engenharia de Sầo Carlos/USP)

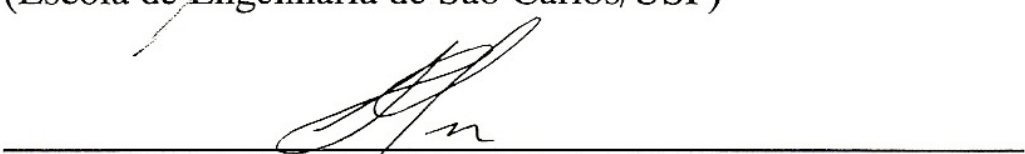

Dr. SALVADOR CLARO NETO

(Instituto de Química de São Carlos/USP)

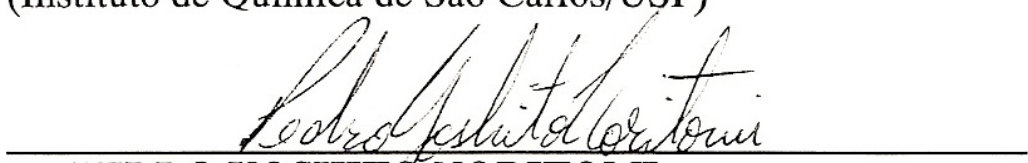

Dr. PEDRO YOSHITO NORITOMI

(Centro de Pesquisas Renato Archer/CenPRA)
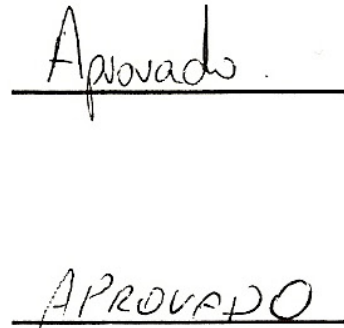
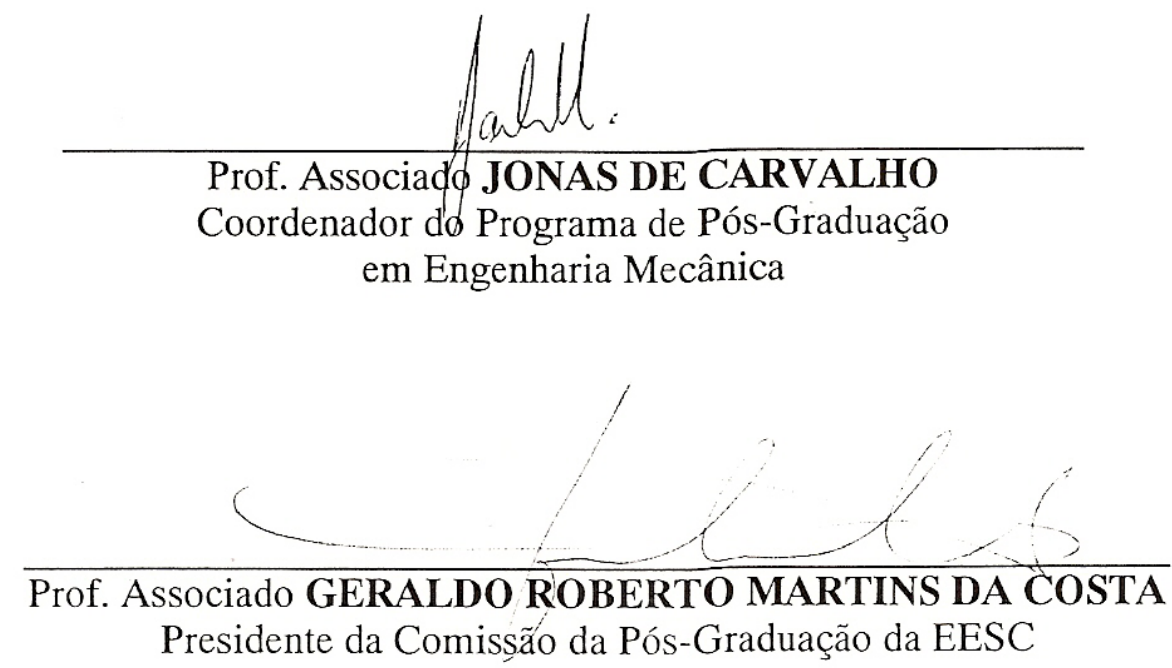

Ao Senhor Deus, toda glória.

Nada há melhor para o homem do que comer, beber e fazer que a sua alma goze o bem do seu trabalho. No entanto, vi também que isto vem da mão de Deus, [Eclesiastes 2:24]. 



\section{DEDICATÓRIA}

À minha amada esposa Alzeni por conceder tamanho e privilegiado amor, confiança e atenção a mim dedicados.

À minha mãe Maria Lúcia e irmãos pelo amor, carinho e cuidado dispensados. 



\section{AGRADECIMENTOS}

Ao SENHOR meu DEUS por ter me concedido saúde, proteção, superação em suportar os momentos de dor e ausência dos familiares, pois tudo isso faz parte da vida e por esta agradeço-O por este imenso privilégio concedido;

A minha esposa Alzira Alzeni, pelo amor transmitido através do imenso apoio e solidariedade nos momentos difíceis;

A minha família pela paciência, amor, incentivo e esperança;

Ao Professor Benedito de Moraes Purquerio pelo auxílio, amizade e por ter se disposto a orientar esse trabalho;

Aos Professores Jonas de Carvalho e Carlos Alberto Fortulan pela amizade;

Ao Professor Volnei Tita pela amizade, disposição e auxílio constante na revisão e contribuição científica no meu processo de formação;

Ao grande amigo Rodrigo Bresciani Canto pela atenção, amizade e discussões de grande importância para o bom andamento do trabalho;

Aos Professores Neilor César dos Santos, Amauri Bravo Ferneda pela amizade e discussões;

Ao Professor Sérgio Persival Baroncini Proença pela constante disponibilidade e auxílio no transcorrer desta pesquisa;

A todos os amigos do LTC pelo excelente ambiente de trabalho que sempre proporcionaram e que sempre mantiveram: Rogério Ikegami, Zilda Silveira, Henrique Monaretti, Ricardo Angélico, Cláudia Camilo, Thaís Samed, Roni Carvalho, Marcio Marques, Maria Alejandra, Cassius Riul;

Ao Professor Gilberto Orivaldo Chierice e ao Doutor Salvador Claro Neto do Instituto de Química de São Carlos da Universidade de São Paulo (Departamento de Química e Física Molecular) pela cessão do biopolímero da mamona e pelo auxílio; 
Aos Professores Dirceu Spinelli e Waldek Bose Filho do Departamento de Engenharia de Materiais, Aeronáutica e Automobilística por terem disponibilizarem a máquina de ensaios EMIC para a execução dos ensaios;

Ao Professor Belo por disponibilizar gentilmente o equipamento de aquisição HBM.

Ao Professor Carlos De Marqui Junior pela amizade, disposição, auxílio e orientação no uso do sistema de aquisição HBM;

Ao Mestre José Cláudio Azevedo (Claudião Bigode) pela disposição e auxílio na preparação dos experimentos;

Ao Professor Benedito Di Giacomo por ceder às dependências do Laboratório de Metrologia para a realização das medições;

Ao Professor Elias Hage da Universidade Federal de São Carlos (Departamento de Engenharia de Materiais) por ter cedido à máquina de ensaios INSTRON para a realização de ensaios e ao Dr. Leonardo Bresciani Canto pelo auxílio na operação da mesma;

Ao Dr. Luiz Vareda pelo grande auxílio prestado na parte experimental com strain gages.

Ao pessoal do LAMAFE: José Carlos, Luiz Neves, Adão, Botelho por todo o auxílio na usinagem de peças, aplicadores, moldes, matrizes, medições e etc.

Ao pessoal das secretarias: Maragno, Cristina, Margareth, Vilma, Ana Paula e seus auxiliares por todo apoio que sempre deram e pela amizade;

Ao CNPq pela bolsa de estudos que me foi concedida;

À USP por toda a infra-estrutura de trabalho disponibilizada. 


\section{RESUMO}

Este trabalho aborda o estudo de modelos constitutivos a fim de analisar o comportamento mecânico de um biopolímero derivado de óleo de mamona (Ricinus communis). A importância deste trabalho se dá ao fato de: servir como roteiro de ensaio de materiais poliméricos; completar caracterização do material estudado além do regime viscoelástico, bem como aplicação da análise do comportamento do material além do regime viscoelástico linear. A aplicação dos modelos avaliados via Método dos Elementos Finitos (MEF) exigiu o levantamento das propriedades e do comportamento mecânico do biopolímero, bem como a preparação dos ensaios, com as devidas especificações sugeridas pela ASTM (American Society for Testing and Materials) para cada tipo de ensaio. Assim, foram obtidos os corposde-prova (CDP) para a realização dos ensaios mecânicos quase-estáticos de tração, compressão e flexão (monotônicos e cíclicos), bem como, ensaio para análise dinâmicomecânica (Dynamic Mechanical Analysis - DMA) para a obtenção de propriedades associada às parcelas viscosas do material. Com estes foram obtidos parâmetros inerentes a cada tipo de ensaio, permeados com uma cuidadosa revisão bibliográfica sobre as implicações para a realização de cada ensaio. Uma outra etapa foi a verificação de modelos de plastificação baseados na teoria de von Mises, Drucker-Prager e de viscoelasticidade implementados no programa comercial ABAQUS ${ }^{\circledR}$. Sendo que o objetivo maior foi a comparação dos resultados experimentais obtidos com os modelos em MEF. Os resultados para tração monotônica obtiveram erro de $0,61 \%$, os resultados de compressão monotônica apresentaram erro de $1,5 \%$ e as simulações para os carregamentos cíclicos de tração e compressão não foram tão bons quanto os anteriores. Por isso se justifica a criação do modelo fenomenológico utilizando os parâmetros do material que foram identificados.

Palavras-chave: Métodos dos elementos finitos; modelos de materiais; viscoelasticidade; viscoplasticidade; biopolímero; ensaios mecânicos. 



\section{ABSTRACT}

This work develops the study involving constitutive models with the objective to analyze the mechanical behavior of a biopolymer obtained from the Castor Oil Polyurethane (Ricinus communis). The importance of this work is due to the fact that: serves as a test script for the use of polymer materials; complete the characterization of the material studied beyond the viscoelastic realm, as well as the application of the analysis of the behavior of the material beyond the linear viscoelastic domain. The application of the evaluated models by way of the Finite Element Method (FEM), required the gathering of the properties and mechanical behavior of the biopolymer, as well as the preparation of the tests, with the required specifications suggested by the ASTM (American Society for Testing and Materials) for each type of test. Therefore, there were obtained the body-tests in order to run the mechanical quasi-static traction tests, tensile, compression and flexion (monotonic and cyclical) dynamicmechanical analysis (DMA) in order to obtain the properties associated with the viscous parts of the material. With these the inherent parameters were obtained for each specimen, permeated with a careful biographical revision of the implications for the experimenting of each specimen. Another phase was the verification of laminated models based on the theory by Von Mises, Drucker-Prager a dn of the viscoelasticity implemented in the commercial program ABAQUS $®$. The main objective being the comparison of the experimental results obtained with the models in FEM. The results for the monotonic traction obtained a error of $0,61 \%$, the results of monotonic comparison presented an error of $1,5 \%$ and the simulations for the cyclical charges of traction and compression were not as good as the former. Therefore it justifies the creation of the phenomenological model utilizing the parameters of the materials that were identified.

Keywords: Finite element method; material models; viscoelasticity; viscoplasticity; biopolymer; experimental tests. 



\section{LISTA DE FIGURAS}

Figura 2.1 - Comportamento do material sob ensaio com deslocamento controlado.

Figura 2.2 - Comportamento hiper-elástico sob carregamento e descarregamento: curva

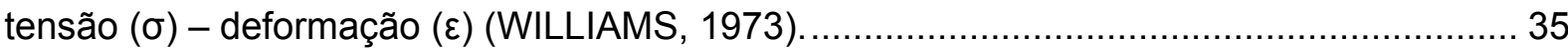

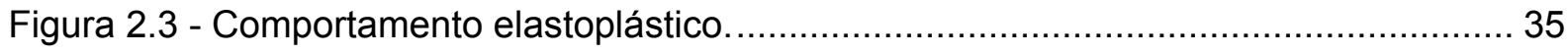

Figura 2.4 - Característica do comportamento visco-elastoplástico. ................................... 36

Figura 2.5 - Comportamento viscoelástico sob carregamento: Entrada (tensão x tempo);

Saída (deformação x tempo) (McCRUM et al, 1992). ................................................... 37

Figura 2.6 - Representação esquemática da deformação de um polímero em nível molecular (YOUNG e LOVELL, 1991).

Figura 2.7 - Comportamento do biopolímero: (a) sob tração; (b) sob compressão, (SILVESTRE FILHO, 2001). 40

Figura 2.8 - Efeito da taxa de deformação.

Figura 2.9 - Representação esquemática da resposta (R) para entrada (I) de polímeros visco-elásticos: Fluência e Relaxação. (YOUNG e LOVELL, 1991).................................... 42

Figura 2.10 - Superfície: tensão-deformação-tempo (p-e-t)(WILLIAMS, 1973).................... 43

Figura 2.11 - O fenômeno de Recovery: (a) tensão x tempo; (b) deformação x tempo (WILLIAMS, 1973).

Figura 2.12 - Modelo elástico, Lemaitre e Chaboche (1990).............................................. 50

Figura 2.13 - Modelo plástico perfeito, Lemaitre e Chaboche (1990)................................. 51

Figura 2.14 - Modelo viscoso, Lemaitre e Chaboche (1990)............................................ 51

Figura 2.15 - Modelo elastoplástico perfeito de Saint-Venant, Lemaitre e Chaboche (1990).

Figura 2.16 - Modelo viscoelástico (modelo de Maxwell), Lemaitre e Chaboche (1990). ..... 52 Figura 2.17 - Modelo viscoelástico (modelo de Kelvin - Voigt), Lemaitre e Chaboche (1990).

Figura 2.18 - Modelo proposto por Bardenhagen et al (1997) ......................................... 53

Figura 2.19 - Resultados obtidos pelo modelo proposto por Bardenhagen et al (1997)...... 54 Figura 2.20 - Técnica de homogeneização e EVR (VAN DER SLUIS, SCHREUR e MEIJER, 1999). 55

Figura 2.21 - Representação da micro-estrutura do polietileno de alta densidade (NIKOLOV

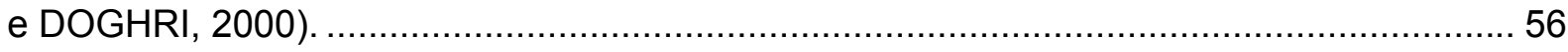

Figura 2.22 - Modelo proposto por Nikolov e Doghri (2000)........................................... 56

Figura 2.23 - Modelo proposto por Bardella (2001) ...................................................... 57 
Figura 3.1 - Molde aberto em silicone para obtenção de corpos-de-prova. .......................... 61

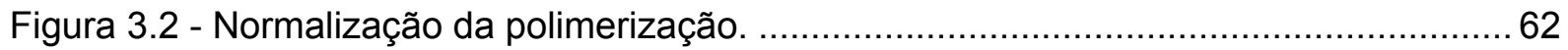

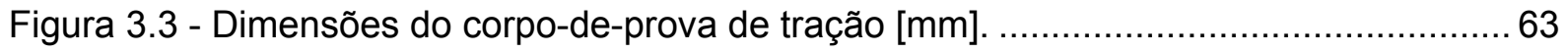

Figura 3.4 - Corpo-de-prova instrumentado com strain gage e extensômetro para ensaio de

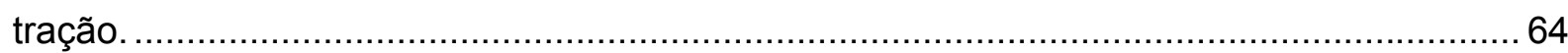

Figura 3.5 - Curva força-tempo-deslocamento segundo carregamento de fluência.............. 67

Figura 3.6 - Curva força-tempo-deslocamento segundo carregamento de relaxação............ 68

Figura 3.7- Curva tensão-deformação: (a) sem perda de energia; (b) com perda de energia.

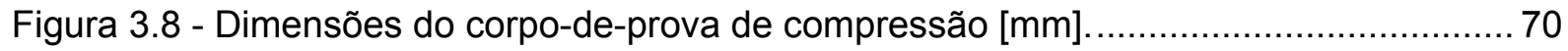

Figura 3.9 - Corpo-de-prova instrumentado com strain gage para ensaio de compressão...71

Figura 3.10 - Dispositivo de compressão com superfície específica para este material. ......72

Figura 3.11 - Dimensões do corpo-de-prova de flexão [mm] ........................................... 73

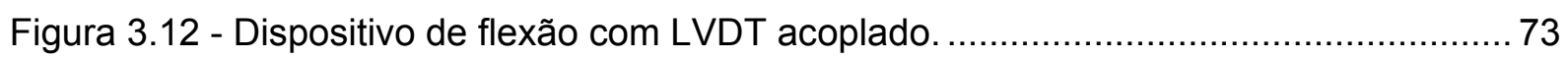

Figura 3.13 - Esquema da máquina de ensaio de DMA. .............................................. 76

Figura 3.14 - Tensão alternada medida com atraso de um ângulo de fase em relação a uma deformação alternada aplicada (McCRUM et al.,1992).................................................. 76

Figura 3.15 - Porção do CDP de tração utilizado na simulação. .......................................... 79

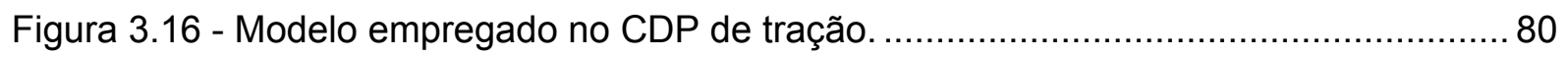

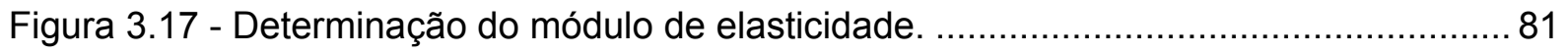

Figura 3.18 - Corpo-de-prova com as condições contorno aplicadas. ................................... 83

Figura 3.19 - Procedimento de ajuste dos coeficientes ao modelo de Drucker-Prager......... 86

Figura 3.20 - Malha do modelo do CDP de compressão................................................. 88

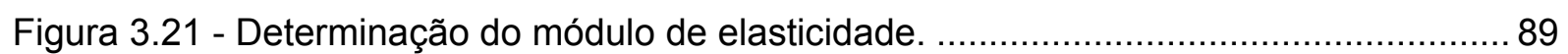

Figura 3.22 - Aplicador de carga, CDP de compressão e condições de contorno. ...............90

Figura 3.23 - Curva do coeficiente de atrito pela taxa de escorregamento; HIBBIT et al (2000). 92

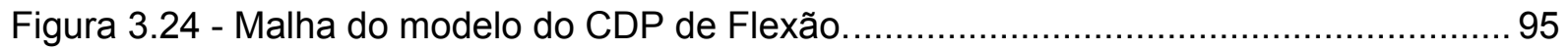

Figura 4.1 - Deformações medidas com extensômetro sob diferentes velocidades. ............ 99

Figura 4.2 - Curvas (a) força-deslocamento e (b) tensão-deformação verdadeira (ensaio de tração). 102

Figura 4.3 - Curva deformação transversal-verdadeira x deformação longitudinal verdadeira (Coeficiente de Poisson médio). 104

Figura 4.4 - Comparação entre as formas de cálculo das tensões. .................................... 106

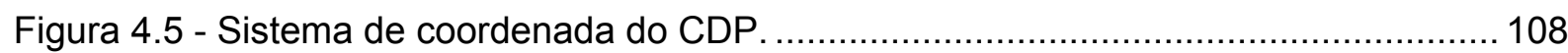

Figura 4.6- Curva tensão - tempo - deformação (Resposta viscoelástica linear para 4 passos de carga). 
Figura 4.7 - Isócronas(deformação verdadeira-tensão verdadeira) para determinação da linearidade do material.

Figura 4.8 - Curva tensão-tempo-deformação, representando a mudança de fase do material.

Figura 4.9 - Curvas força-tempo versus deslocamento-tempo. 115

Figura 4.10 - Curvas tensão -tempo- deformação com ciclos de relaxação de tensão....... 116

Figura 4.11 - Ciclos de relaxação de tensão sob tração. 117

Figura 4.12 - Isócronas do material sob relaxação de tensão. 119

Figura 4.13 - Histerese no ciclo de carregamento e descarregamento. 120

Figura 4.14 - Curvas tensão-deformação para determinação da energia dissipada. 120

Figura 4.15 - Sentido de carregamento e descarregamento no CDP de tração. 122

Figura 4.16 - Curva tensão verdadeira-deformação verdadeira. 124

Figura 4.17 - Representação da redução do comprimento do CDP.................................. 125

Figura 4.18 - Curvas tensão-deformação compressiva obtidas de duas formas. ................ 126

Figura 4.19 - Sistema de orientação das deformações principais. 128

Figura 4.20 - Resposta viscoelástica não-linear de uma série de passos de carga de compressão.

Figura 4.21 - Curvas isócronas de compressão para determinação da viscoelasticidade (Deformação -Tensão).

Figura 4.22 - Curvas de fluência para ensaio de compressão.

Figura 4.23 - Curvas do ensaio em fluência compressiva, com patamares de recuperação.

Figura 4.24 - Relaxação de tensão na compressão. 134

Figura 4.25 - Isócronas do material sob relaxação de tensão (tensão-Deformação). 136

Figura 4.26 - Comparação entre a forma de carregamento e descarregamento dos ensaios de compressão e tração. 137

Figura 4.27 - Curvas tensão-deformação para determinação da energia dissipada. 138

Figura 4.28 - Esquema do dispositivo de flexão. 139

Figura 4.29 - Curvas de (a) força-deslocamento e (b) tensão-deformação sob flexão. ...... 140 Figura 4.30 - Curvas (a) Tensão-deformação, (b) Tensão-tempo-deformação em flexão. . 141 Figura 4.31 - Módulo de elasticidade: curvas parcela elástica (E')-Tempo e parcela viscosa (E')-Tempo. 143

Figura 4.32 - Módulo de elasticidade complexo $\left(E^{*}\right)$ : curva parcela viscosa-parcela elástica.

Figura 4.33 - Fator de amortecimento $(\tan \delta)$-tempo.

Figura 4.34 - Módulo de cisalhamento: parcela elástica e parcela viscosa. 145

Figura 4.35 - Módulo de cisalhamento complexo $\left(\mathrm{G}^{*}\right)$. 
Figura 4.36 - Superfície de plastificação de Drucker-Prager. ............................................ 147

Figura 4.37 - Curvas de tensão-deformação elastoplástica. ........................................... 148

Figura 4.38 - Cuvas de tensão-deformação viscoelastoplástica....................................... 149

Figura 4.39 - Comparação das curvas deformação-tempo teórico-experimental. ............... 150

Figura 4.40 - Comparação teórico-experimental de curvas deformação-tempo.................. 152

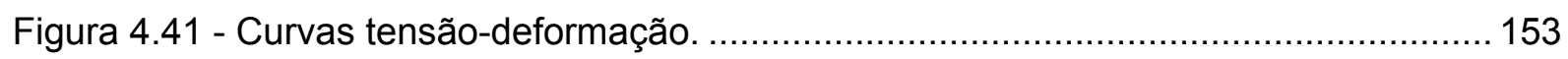

Figura 4.42 - Comparação das curvas tensão-deformação teórico-experimental em compressão.

Figura 4.43 - Comparação das curvas deformação-tempo teórico-experimental de compressão. 155

Figura 4.44 - Comparação das curvas teórico-experimental em flexão monotônica. 157

Figura 4.45 - Comparação das curvas teórico-experimental em flexão cíclica. 158 


\section{LISTA DE TABELAS}

Tabela 3.1 - Relações para a determinação das propriedades viscoelásticas...................... 78

Tabela 4.1 - Propriedades do material obtidas por tração obtidas por três métodos. ......... 107

Tabela 4.2 - Resultado do cálculo da variação volumétrica. ............................................ 109

Tabela 4.3 - Propriedades do ensaio de fluência em tração para as curvas isócronas. ..... 111

Tabela 4.4 - Propriedades de relaxação de tensão na tração para as curvas isócronas.... 118

Tabela 4.5 - Propriedades do material sob compressão.............................................. 127

Tabela 4.6 - Resultado do cálculo da variação volumétrica no CDP de compressão. ......... 128

Tabela 4.7 - Propriedades compressivas do ensaio de fluência para as curvas isócronas. 130

Tabela 4.8 - Propriedades do material na relaxação de tensão na compressão. ................ 135

Tabela 4.9 - Valores dos parâmetros de Drucker-Prager.............................................. 147

Tabela 4.10 - Propriedades do material para entrada no Abaqus..................................... 154 



\section{LISTA DE ABREVIATURA E SIGLAS}

\begin{tabular}{|c|c|}
\hline ASTM & American Society for Testing and Materials \\
\hline DMA & Dynamic Mechanical Analysis - Análise dinâmica mecânica \\
\hline MEF & Método dos Elementos Finitos \\
\hline CDP & Corpo-de-prova \\
\hline GQATP & Grupo de Química Analítica e Tecnologia de Polímeros \\
\hline FDA & Food and Drug Administration \\
\hline$\dot{\varepsilon}$ & Taxa de Deformação \\
\hline Creep & Fenômeno de Fluência \\
\hline Relaxation & Fenômeno de Relaxação de Tensão \\
\hline Recovery & Recuperação \\
\hline$\mu \mathrm{m}$ & Micrometro \\
\hline $\mathrm{J}_{2}$ & Segundo Invariante das Tensões Desviadoras \\
\hline$E$ & Módulo de Elasticidade ou Módulo de Young \\
\hline$\sigma$ & Tensão \\
\hline$\varepsilon$ & Deformação \\
\hline$\sigma_{\mathrm{s}}$ & Tensão ao escoamento \\
\hline$\eta$ & Viscosidade do Material \\
\hline${ }^{\circ} \mathrm{C}$ & Graus Celsius \\
\hline Strain-gage & Extensômetro de folha \\
\hline Extensômetro & Extensômetro tipo clipe \\
\hline$v$ & Coeficiente de Poisson \\
\hline$D(t)$ & Flexibilidade à Fluência \\
\hline$\varepsilon(\mathrm{t})$ & Deformação em Função do Tempo \\
\hline$\tau_{1}$ & Tempo \\
\hline $\mathrm{T}$ & Tempo \\
\hline$\Delta \sigma$ & Variação de Tensão \\
\hline$Q^{*}$ & Energia Dissipada à Tração \\
\hline $\mathrm{E}_{\mathrm{c}}$ & Módulo de Elasticidade à Compressão \\
\hline$\sigma_{\mathrm{e}}$ & Tensão de Escoamento à Compressão \\
\hline$\sigma_{c}$ & Limite de Resistência à Compressão \\
\hline LVDT & Transdutor de Deslocamento Linear Variável \\
\hline$\sigma^{f}$ & Tensão à Flexão \\
\hline$E^{f}$ & Módulo de Elasticidade Transversal \\
\hline$\gamma$ & Deformação ao Cisalhamento \\
\hline $\mathrm{E}^{\mathrm{t}}$ & Módulo de Elasticidade à Tração \\
\hline$\sigma_{\mathrm{AV}}$ & Tensão Verdadeira Atuante \\
\hline$\varepsilon_{\mathrm{e}}$ & Deformação Elástica \\
\hline$\varepsilon_{\mathrm{p}}$ & Deformação Plástica \\
\hline$\varepsilon_{\mathrm{t}}$ & Deformação Total \\
\hline
\end{tabular}





\section{SUMÁRIO}

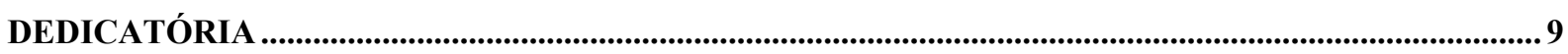

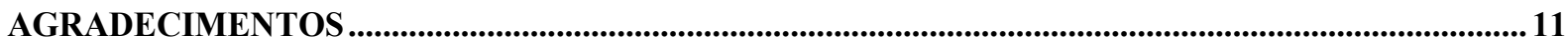

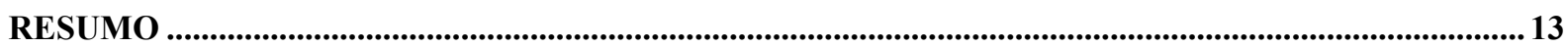

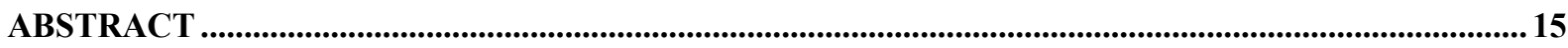

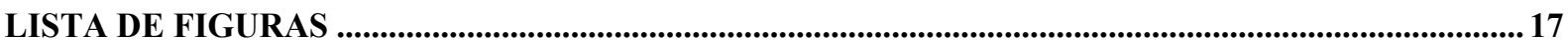

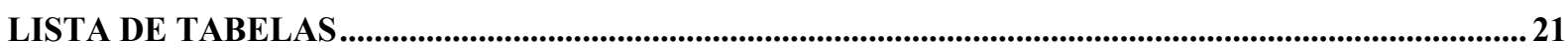

LISTA DE ABREVIATURA E SIGLAS............................................................................................. 23

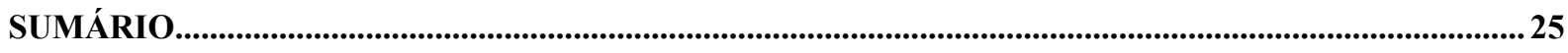

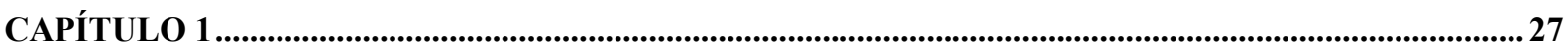

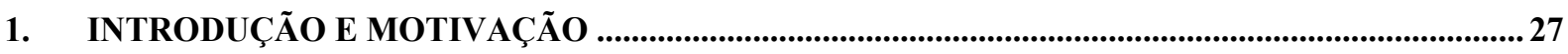

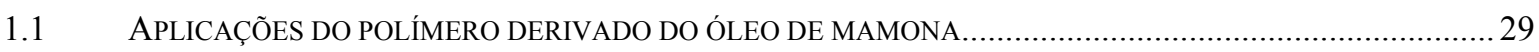

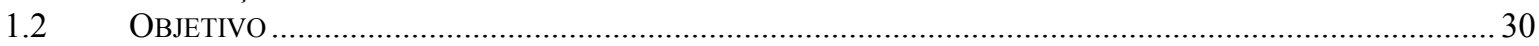

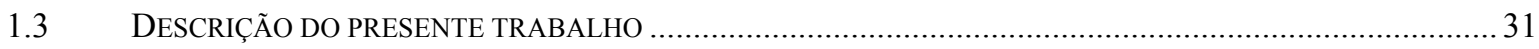

CAPÍTULO 2

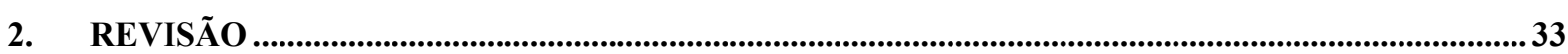

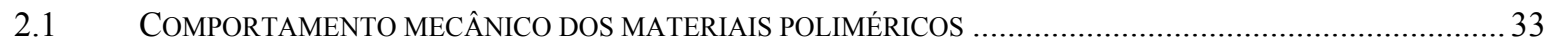

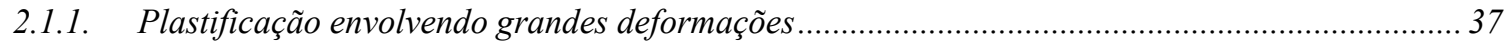

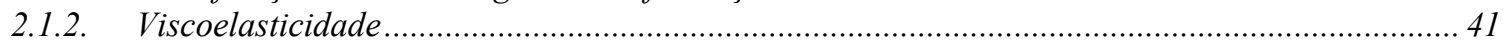

2.2 ENSAIOS MECÂNICOS EM MATERIAIS POLIMÉRICOS.............................................................................. 44

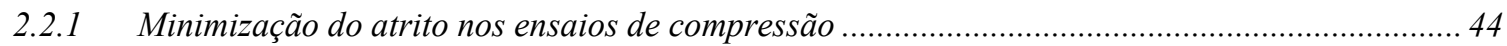

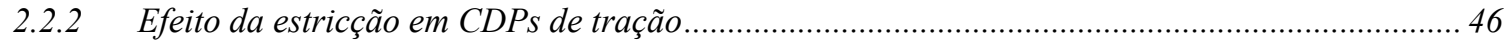

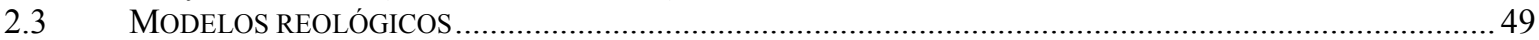

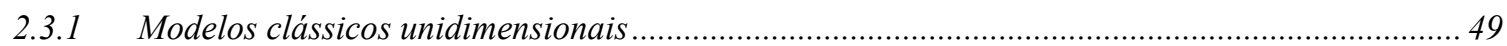

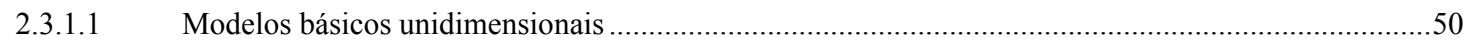

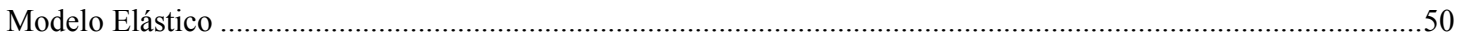

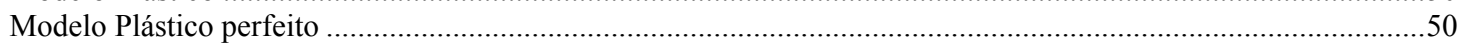

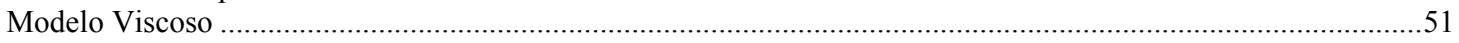

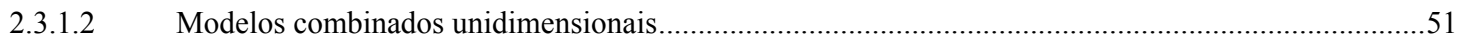

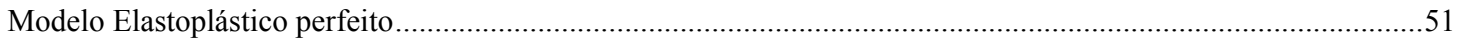

Modelo Viscoelástico de Maxwell ................................................................................................................52

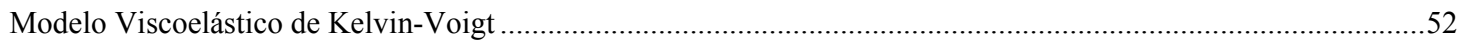

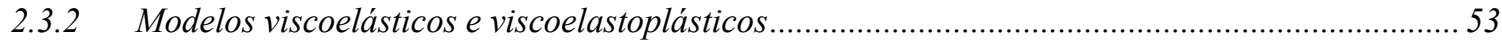

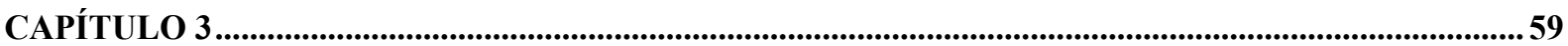

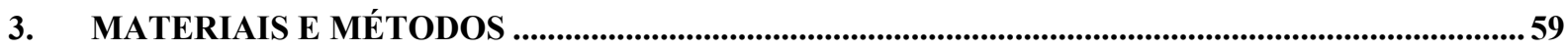

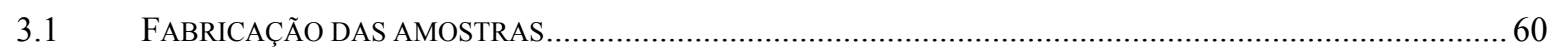

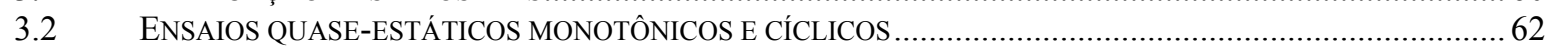

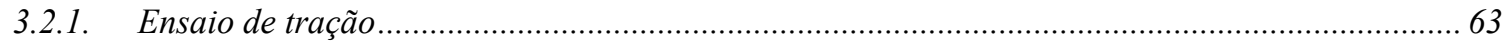

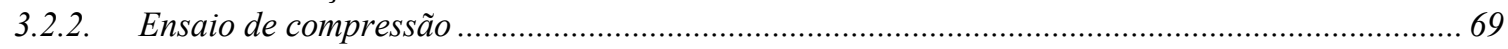

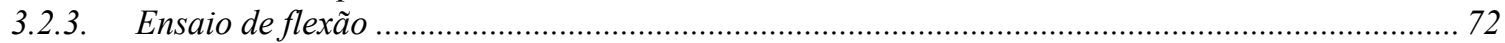

3.3 ANÁLISE DINÂMICO-MECÂNICA (DYNAMIC MECHANICAL ANALYSIS -DMA) ……………………….... 75

3.4 METODOLOGIA EMPREGADA NA SIMULAÇÃO NUMÉRICA ………..................................................... 78

3.4.1. Metodologia empregada na simulação do ensaio de tração .......................................................... 79

3.4.1.1. Metodologia empregada na simulação do ensaio monotônico de tração................................. 81

3.4.1.2. Metodologia empregada na simulação do ensaio cíclico de fluência em tração ....................... 84

3.4.2. Metodologia empregada na simulação do ensaio de compressão.............................................. 88

3.4.2.1. Metodologia empregada na simulação do ensaio monotônico de compressão .........................................

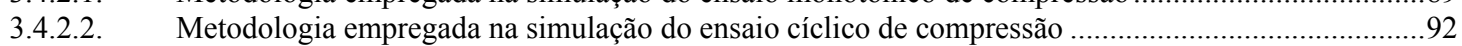

3.4.3. Metodologia empregada na simulação do ensaio de flexão …………………………………..... 94

3.4.3.1. Metodologia empregada na simulação monotônica do ensaio de flexão ................................................95 
3.4.3.2. Metodologia empregada na simulação cíclica do ensaio de flexão................................................. 96

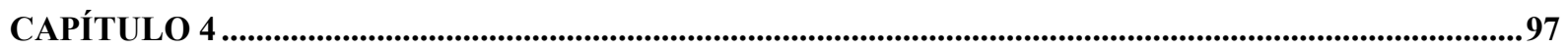

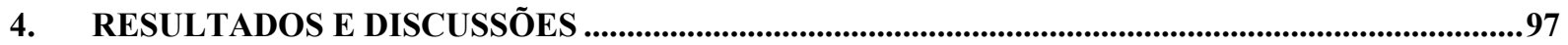

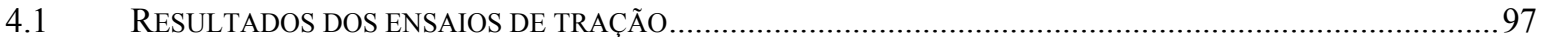

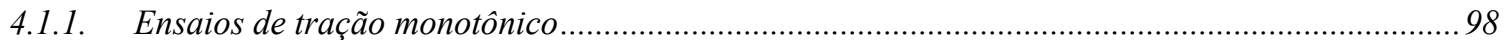

4.1.2. Ensaios de tração cíclicos de fluência ......................................................................................... 110

4.1.3. Ensaios de tração cíclicos de relaxação de tensão...................................................................... 116

4.1.4. Ensaios cíclicos de tração para avaliação da energia dissipada ..........................................119

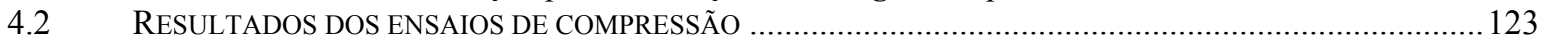

4.2.1. Ensaios de compressão monotônico ....................................................................................... 123

4.2.2. Ensaios de compressão cíclicos de fluência ..................................................................... 128

4.2.3. Ensaios de compressão cíclicos de relaxação ..................................................................... 133

4.2.4. Ensaios cíclicos de compressão para avaliação da energia dissipada .................................... 136

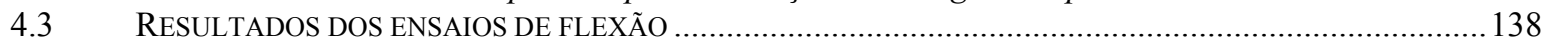

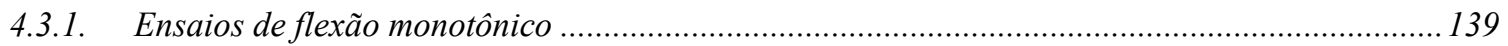

4.3.2. Ensaios de relaxação de tensão sob flexão ...................................................................... 141

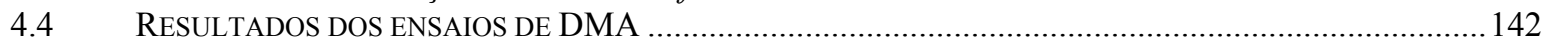

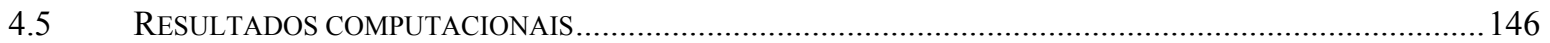

4.5.1. Cálculo dos parâmetros de Drucker-Prager ................................................................. 146

4.5.2. Resultados computacionais dos ensaios de tração monotônico ................................................. 147

4.5.3. Resultados computacionais dos ensaios de tração cíclicos de fluência......................................150

4.5.4. Resultados computacionais dos ensaios de compressão monotônico.......................................... 152

4.5.5. Resultados computacionais dos ensaios de compressão cíclicos de fluência ............................. 155

4.5.6. Resultados computacionais dos ensaios de flexão monotônico ............................................. 156

4.5.7. Resultados computacionais dos ensaios de flexão cíclicos de relaxação .................................... 157

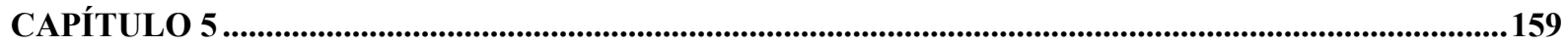

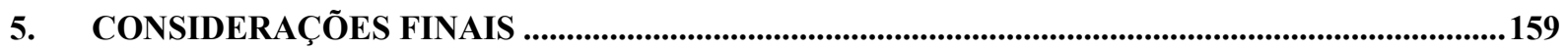

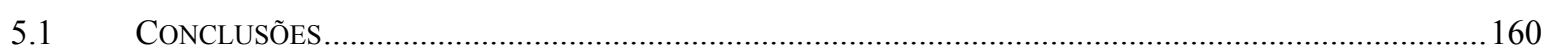

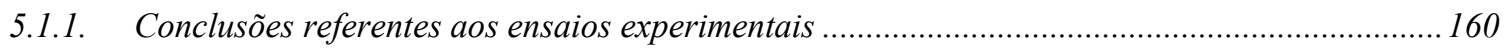

5.1.2. Conclusões referentes às simulações computacionais............................................................ 163

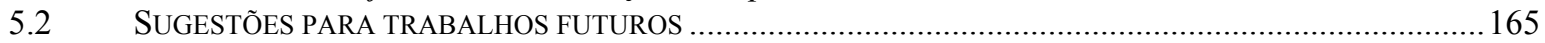

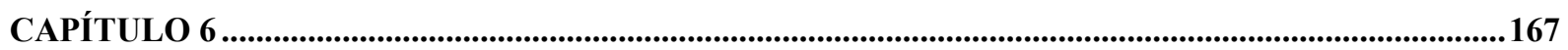

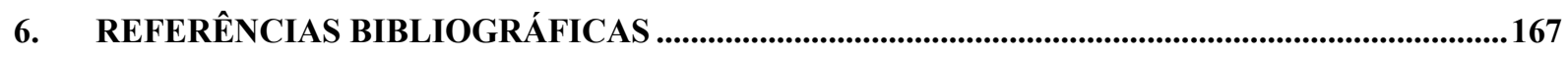




\section{Introdução e motivação}

O desenvolvimento de novos materiais tem trazido benefícios para os mais variados seguimentos da sociedade. Dentre a gama de materiais desenvolvidos se destaca os biopolímeros, como exemplo pode-se citar a poliuretana derivada do óleo de mamona (Ricinus communis) que vem sendo desenvolvida pelo Grupo de Química Analítica e Tecnologia de Polímeros (GQATP) do Instituto de Química da USP em São Carlos desde 1984.

Esses biomateriais servem como alternativa para suprir a carência da área médica no que tange aos requisitos de materiais implantáveis tais como: biocompatibilidade, elevado desempenho estrutural, integridade estrutural, etc., para que possam garantir a uma prótese as funções para as quais a mesma foi projetada. Além das aplicações médicas esta poliuretana tem um vasto campo de aplicações, como será visto no Item 1.1.

Apesar de existirem trabalhos, no que se refere aos estudos de caracterização, como de Claro Neto (1997) que aborda os ensaios de DMA e ensaios de tração e compressão quase-estáticos preliminares, Varoto et al. (1999), que aborda a questão da capacidade de amortecimento, e de Silvestre Filho (2001), que apresenta alguns resultados de ensaios de tração e flexão, percebeu-se que os trabalhos relacionados ao biopolímero em questão abordaram até o limite de escoamento (regime viscoelástico linear), principalmente no que 
se refere ao estudo mais completo que vise prever o comportamento em serviço de estruturas ósseas (humanas) constituídas por esse material. Acredita-se que o pouco investimento em tais estudos se deva as pressões exercidas pelos fabricantes (representantes do interesse financeiro) de componentes metal/cerâmica que detém grande parte do mercado das órteses/próteses, corroborado com o fato deste biopolímero ter sido certificado pelo U.S. FDA (Food and Drug Administration) apenas em 2003.

Então, para se aprofundar no estudo de estruturas humanas (ossos) mais complexas produzida com esse material, necessita-se do pleno conhecimento do comportamento do mesmo quando solicitado das formas mais variadas. Por isso, uma parcela importante deste trabalho consistiu na realização e na análise de ensaios de tração, compressão e flexão até o regime viscoplástico, bem como, na análise dinâmico-mecânica (DMA). De posse dos dados experimentais, procedeu-se a utilização de ferramentas computacionais baseadas no Método dos Elementos Finitos (MEF) para a verificação das respostas dos modelos existentes. Utilizou-se assim, os modelos de plastificação de von Mises, Drucker-Prager, Drucker-Prager creep e outros modelos viscoelásticos implementados no programa ABAQUS $^{\circledR}$.

O trabalho traz como originalidade o estudo do comportamento do material mediante as mais variadas condições de carregamento, sejam, estáticas (tração, compressão, flexão) ou dinâmicas (DMA), bem como a seleção do modelo de material (implementado no programa Abaqus $®)$ que melhor represente o comportamento fenomenológico do material, além do comportamento viscoelástico que até o presente fora abordado nos trabalhos anteriores. Também, este trabalho resultou em um pedido de patente referente às condições do ensaio de compressão. 


\subsection{Aplicações do polímero derivado do óleo de mamona}

O polímero derivado do óleo de mamona possui variadas aplicações, tais como: aglomerante para concreto (SILVA, 1996); adesivos para madeira (JESUS, 1998); na fabricação de isoladores elétricos (MURAKAMI, 2002); matriz em compósitos de fibras vegetais (SILVA, 2003). Nas áreas médica/ odontológica muitos pesquisadores, tais como Ohara et al (1995) e Ignácio et al (1996) estudaram a biocompatibilidade da PU na forma de cimento ósseo em coelhos; próteses dentárias (VIANNA, 1997); preenchimento de falha óssea (IGNÁCIO, 1999); no estudo da biocompatibilidade como cimento ósseo (PASCON, 1999). Assim, investigaram seus aspectos de biocompatibilidade em organismos vivos, os quais não apresentaram reações adversas (IGNÁClO et al, 1996).

Como prótese, desenvolveu-se um pré-projeto de prótese de quadril por Silvestre Filho (2001) e que foi reavaliado por Ferneda (2006); luvas de soquetes intrapatelares (BONINI, 2004); cilindros de PU enriquecido com carbonato de cálcio para a obtenção de porosidade e radio-densidade foram implantados em patas de coelhos. Os resultados apresentaram propriedades de biocompatibilidade, de osteo-condução e osteoindução, bem como serviram para a verificação da resistência mecânica do material implantado, sendo estes resultados de grande interesse para aplicação em cirurgia ortopédica (IGNÁCIO et al, 1997).

Por fim, foram aplicadas em seres humanos em cirurgia de cranioplastia, próteses de mandíbula, placas de contenção de hérnia de disco (ARA, 1999), e na avaliação da biocompatibilidade do "Fio Lifting Biológico" - fio serrilhado de poliuretana de óleo de mamona - e sua eficácia no rejuvenescimento facial (DONTOS, 2005).

Diante desse contexto, várias pesquisas em novos materiais estão sendo realizadas com a finalidade de verificar as propriedades de biocompatibilidade. Com isso, contribuições científicas, visando o desenvolvimento de componentes biomecânicos em forma de 
próteses/ órteses para serem apresentadas à sociedade com o intuito de minimizar o efeito dos danos causados por enfermidades naturais ou por meio de acidentes. Esse panorama motivou o desenvolvimento do presente trabalho que visa especificamente fazer com que haja um maior entendimento teórico do biopolímero, e o mesmo possa ser utilizado no projeto de componentes capazes de suportar o esforço para os quais forem requisitados. Para que essa contribuição seja concretizada busca-se realizar os objetivos propostos a seguir.

\subsection{Objetivo}

Em virtude do vasto campo de aplicação desse material, o pesquisador se sentiu motivado para realização deste trabalho, tendo em vista a necessidade de um estudo mais rigoroso sobre o comportamento mecânico desse polímero sob regime elástico, viscoelástico e visco-elastoplástico.

Com base nas justificativas apresentadas na introdução, verifica-se que o principal objetivo do presente projeto consiste em verificar se modelos constitutivos de material citados na literatura são capazes de representar, de forma coerente, o comportamento mecânico de estruturas fabricadas a partir do biopolímero. Entretanto, devido à complexidade e extensão do objetivo principal optou-se por dividi-lo em objetivos específicos:

a) Realizar revisão bibliográfica a fim de obter informações de modelos constitutivos aplicados a polímeros, e assim, selecionar os modelos que serão avaliados;

b) Realizar ensaios experimentais capazes de fornecer parâmetros para os modelos de materiais selecionados; 
c) Analisar o desempenho dos modelos selecionados, confrontando os resultados numéricos via MEF com os resultados experimentais de tração, compressão, flexão por 3 pontos e DMA;

d) Apresentar conclusões sobre o desempenho dos modelos avaliados;

e) Apresentar propostas para os trabalhos futuros.

\subsection{Descrição do presente trabalho}

Com base nos objetivos específicos propostos, o desenvolvimento do trabalho está estruturado da seguinte forma:

\section{- Capítulo 2 - Revisão bibliográfica}

Apresenta uma revisão sobre o comportamento mecânico dos materiais poliméricos quando solicitados com carregamentos específicos. Em seguida, há uma revisão sobre a plastificação envolvendo grandes deformações. A terceira parte aborda o regime viscoelástico de materiais poliméricos. A quarta parte apresenta uma revisão sobre os problemas típicos da realização do ensaio de compressão e como os mesmos foram solucionados por alguns pesquisadores. A quinta parte há uma revisão sobre o problema da estricção em CDPs (corpos-de-prova)de tração. Por fim, há uma abordagem sobre alguns modelos matemáticos da literatura. 


\section{- Capítulo 3 - Materiais e métodos}

Está dividido em quatro partes principais. A primeira consta da descrição do processo de obtenção dos CDPs. A segunda parte consta dos ensaios quase-estáticos e suas variações quanto ao tipo (tração, compressão ou flexão) e quanto à forma de aplicação do carregamento (monotônicos ou cíclicos). A terceira parte apresenta o ensaio de DMA. A quarta parte apresenta a metodologia empregada na avaliação dos modelos de material estudados.

\section{- Capítulo 4 - Resultados e discussão}

Está dividido em duas partes. A primeira apresenta e discute todos os resultados experimentais obtidos em cada tipo de ensaio e formas de aplicação de carregamento. A segunda parte trata dos resultados das simulações numéricas obtidas via MEF com base em modelos de material.

\section{- Capítulo 5 - Considerações finais}

Este capítulo contém uma descrição sobre as vantagens e limitações das respostas obtidas pelos modelos estudados, bem como trabalhos futuros que podem ser realizados.

\section{- Capítulo 6 - Referências bibliográficas}

Contém as fontes das referências bibliográficas utilizadas no trabalho. 


\section{Revisão}

\subsection{Comportamento mecânico dos materiais poliméricos}

O comportamento mecânico dos materiais pode ser classificado em dependente ou independente do tempo. Sabendo disso, pode-se verificar o comportamento através de alguns tipos de ensaio, tais como: ensaio de DMA, ensaios de compressão e tração com passos de carregamento e descarregamento, etc. Por conveniência, neste trabalho utilizouse ensaio de tração com deslocamento controlado com o qual se obteve o histórico do comportamento do material, o qual é mostrado através das curvas força-tempo versus deslocamento-tempo, Figura 2.1. Nota-se que, com a evolução do tempo, enquanto o nível de deslocamento quase permanece constante, a força sofre uma redução acentuada. 


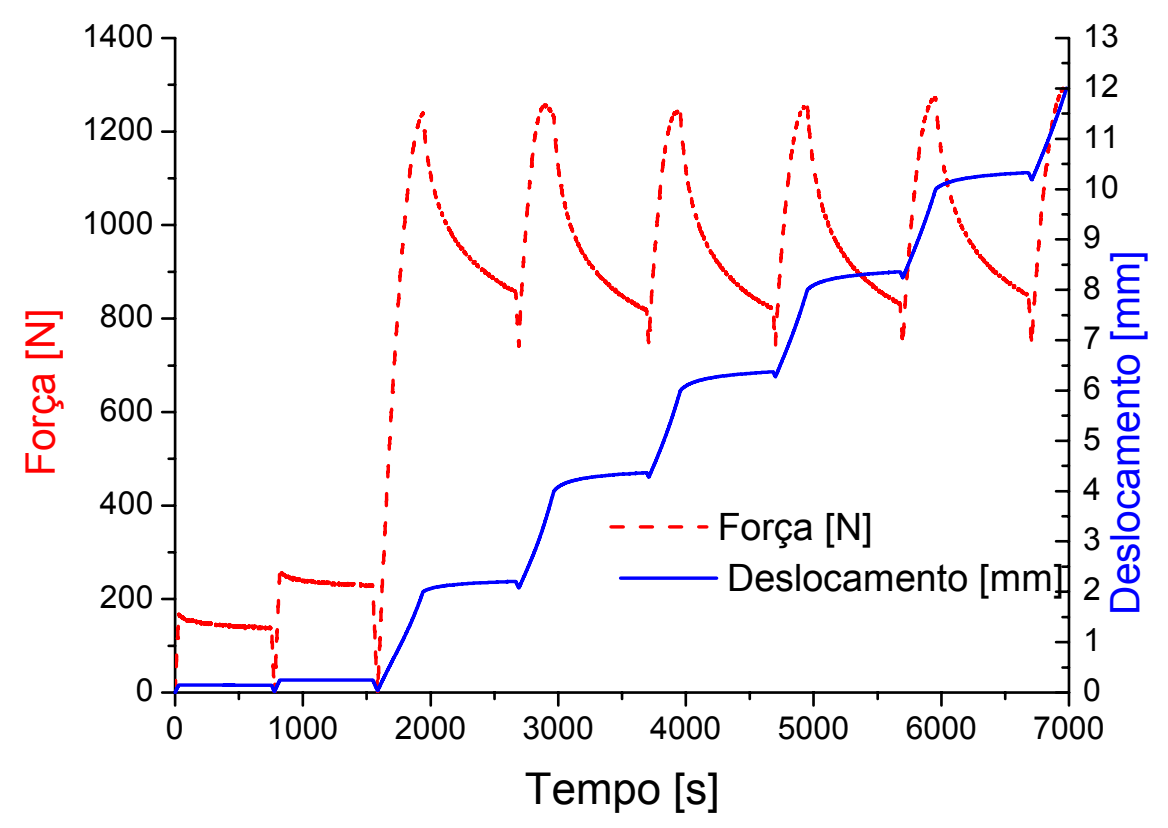

Figura 2.1 - Comportamento do material sob ensaio com deslocamento controlado.

Segundo Williams (1973), todos os materiais se encontram entre o sólido rígido e o fluido perfeito. Esse comportamento depende, muitas vezes, da temperatura. A variação da temperatura é de suma importância para os materiais poliméricos, para os quais há uma temperatura particular, chamada de temperatura de transição vítrea, acima da qual o polímero se comporta como elastômero, Figura 2.2, ou seja, exibem um comportamento hiperelástico sem ponto de limite de tensão de escoamento determinado e sem deformação permanente, este é um exemplo de independência do tempo. Porém, neste trabalho os ensaios foram realizados a temperatura ambiente em virtude de Claro Neto (1997) ter realizado ensaios considerando o efeito da temperatura. De acordo com Meyers e Chawla (1999) comportamento elástico de materiais poliméricos é muito mais difícil de descrever do que dos metais ou cerâmicas, por causa da sua forte dependência da temperatura e do tempo. Os materiais com comportamento dependente do tempo são chamados de viscoelásticos ou anelásticos. 


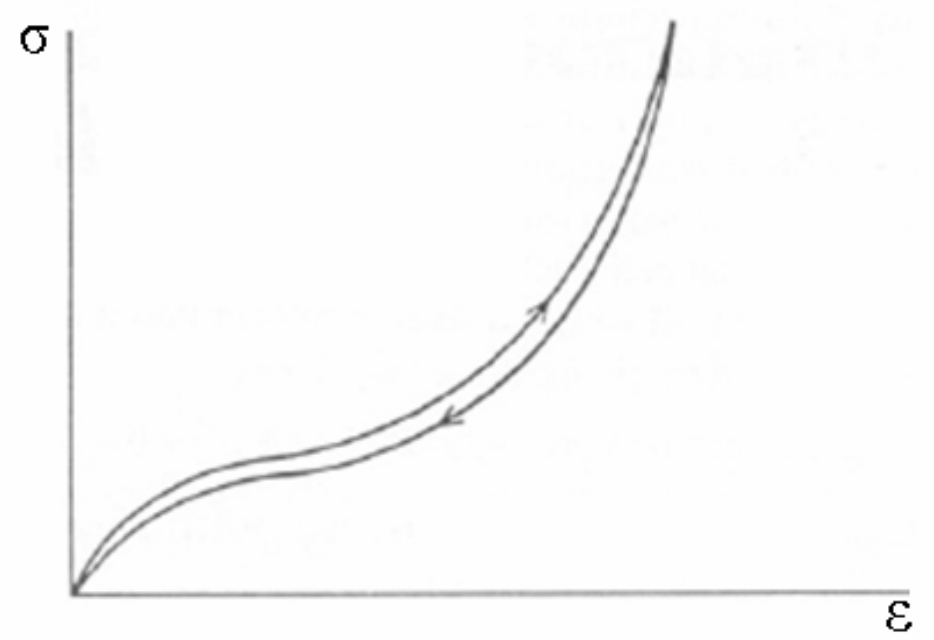

Figura 2.2 - Comportamento hiper-elástico sob carregamento e descarregamento: curva tensão $(\sigma)$ deformação $(\varepsilon)$ (WILLIAMS, 1973).

Na Figura 2.3 mostra um material com comportamento linear-elástico até o ponto A, após este ponto há uma perda da linearidade através do processo de escoamento, quando descarregado, há uma deformação residual e, neste estado de deformação, tanto no descarregamento como no re-carregamento, tem-se uma inclinação paralela à inclinação do regime elástico. O comportamento apresentado na Figura 2.3 é de um material elastoplástico.

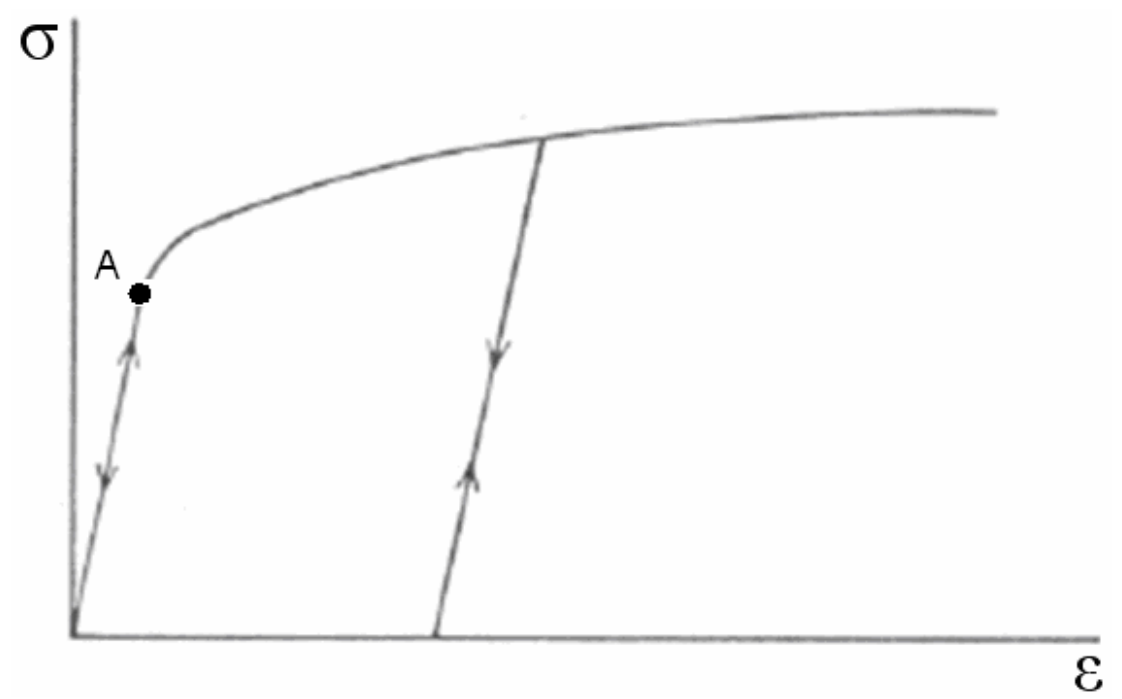

Figura 2.3 - Comportamento elastoplástico. 
Na Figura 2.4, é apresentado um material que está abaixo da temperatura de transição vítrea, por isso exibe um comportamento similar aos materiais elastoplásticos, porém com uma não-linearidade acentuada após o ponto "A". A partir deste ponto, ao sofrer descarregamento, apresenta uma deformação residual (deformação plástica). Todavia, durante o descarregamento e o re-carregamento há formação de um laço histerético, em virtude do efeito viscoso que faz com que haja um atraso na resposta do material, impedindo-o de retornar com a mesma inclinação da região elástica. Assim, essa forma de resposta é de material visco-elastoplástico.

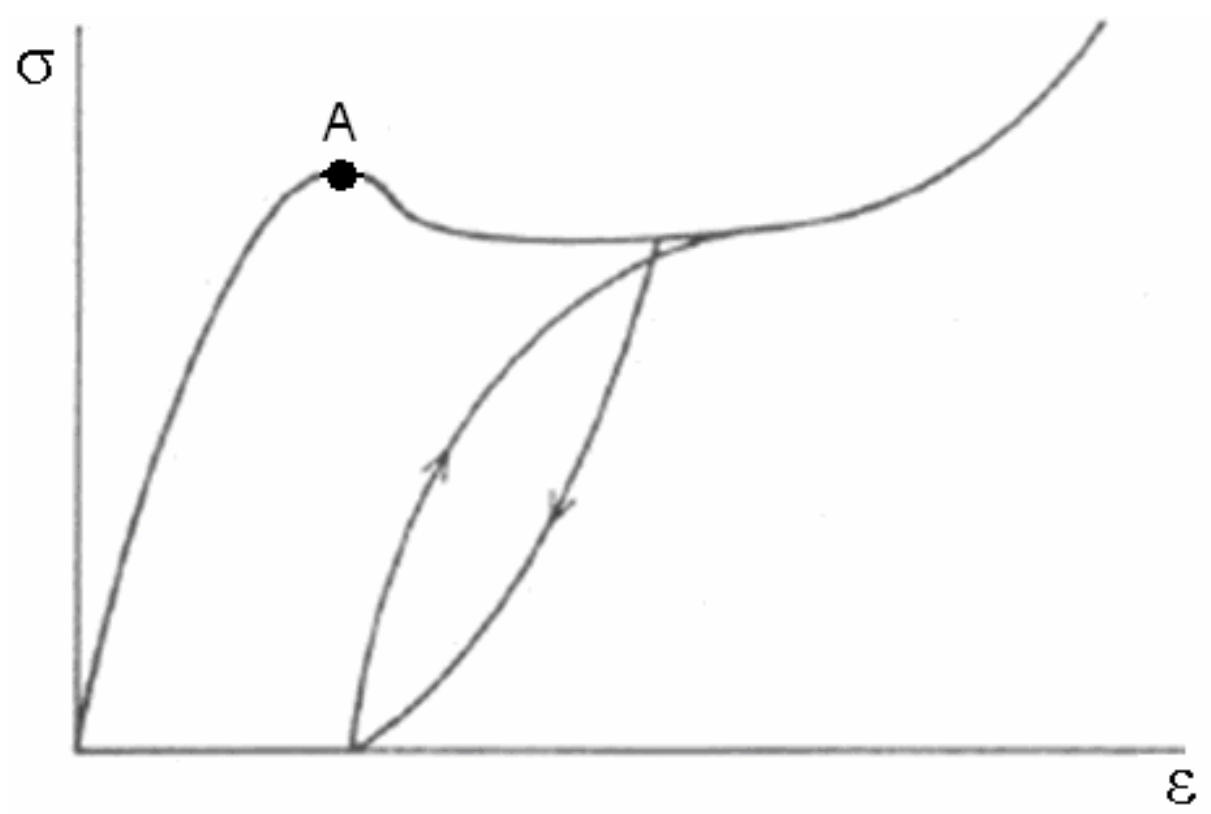

Figura 2.4 - Característica do comportamento visco-elastoplástico.

Vale ressaltar que para deformações abaixo de $0,5 \%$ muitos materiais poliméricos podem ser descritos como linearmente viscoelásticos, mas acima desse valor eles são nãolineares (WILLIAMS, 1973). Para ilustrar melhor o efeito viscoso a Figura 2.5 apresenta uma curva de tensão-tempo como dado de entrada e uma curva de deformação-tempo como dado de saída, a qual evidencia o efeito viscoso como dependente do tempo. 
Entrada

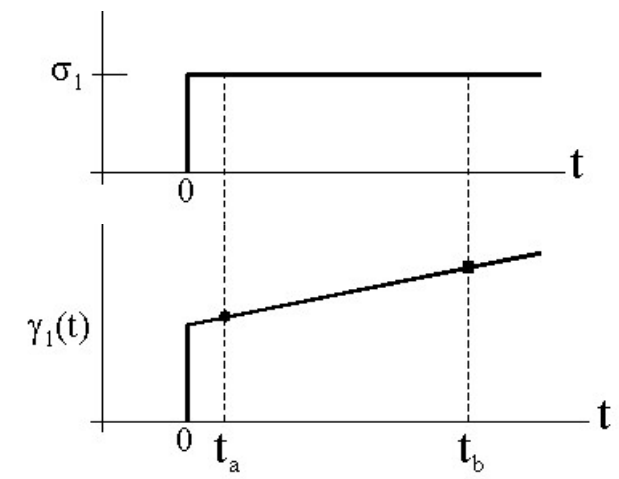

Figura 2.5 - Comportamento viscoelástico sob carregamento: Entrada (tensão x tempo); Saída (deformação x tempo) (McCRUM et al, 1992).

\subsubsection{Plastificação envolvendo grandes deformações}

Segundo Young e Lovell (1996, p. 367), certos polímeros são passíveis de suportar uma forma localizada de deformação plástica conhecida como crazing. Para tal é necessário um estado de tensão hidrostática, que promova um aumento significativo no volume. Surgem assim, pequenas falhas iniciadas nas superfícies do CDP e orientadas perpendicularmente ao eixo de carregamento.

Shackelford (1996) classifica os polímeros como termoplásticos e termofixos e mostra que a diferença principal entre ambos está no comportamento frente ao aquecimento. Os termoplásticos se fundem como um líquido viscoso, enquanto os termofixos sofrem decomposição térmica (MEYERS e CHAWLA, 1999).

Os polímeros termoplásticos consistem de cadeias moleculares lineares ou ramificadas que, ao serem aquecidos sofrem alteração em sua consistência de sólido rígido para líquido viscoso. Posteriormente, eles são moldados, geralmente sob pressão, e após adquirirem a forma desejada são resfriados, voltando ao estado sólido rígido. Neste caso, não ocorrem reações químicas ou decomposição, podendo assim ser re-aquecidos repetidamente (McCRUM et al, 1992). 
Por outro lado, os polímeros termofixos podem sofrer reações químicas quando aquecido ou ainda se decompor antes do processo de fusão. Este fenômeno ocorre porque neste tipo de polímero durante o processo de polimerização são formadas ligações cruzadas covalentes entre as cadeias moleculares adjacentes, desenvolvendo uma estrutura tridimensional.

Para os polímeros termofixos as ligações cruzadas, à medida que se formam, causam diminuição da mobilidade das cadeias moleculares. Essa pequena mobilidade das cadeias poliméricas faz com que os mecanismos físicos para a criação de deformação permanente ocorram de forma diferente em materiais poliméricos e em materiais metálicos. Para os materiais metálicos a deformação plástica deve-se a presença de discordâncias na estrutura cristalina do metal, com isso, há redução da estabilidade em nível da microestrutura, facilitando o escorregamento relativo entre planos atômicos, para determinar outra posição de equilíbrio, criando o fenômeno conhecido por deslocação. Tal mecanismo de deformação é irreversível e não implica em ruptura de ligações ou variações no volume da estrutura. Entretanto, para polímeros, a explicação do fenômeno de plastificação está associada à orientação das cadeias moleculares.

A Figura 2.6 mostra que, a princípio na fase A, a estrutura polimérica idealizada ainda não se deformou. $\mathrm{Na}$ fase $\mathrm{B}$, ocorre um determinado escorregamento das moléculas, deformando a estrutura cristalina que iniciará sua organização na fase C. Finalmente, na fase D, a estrutura estará completamente re-arranjada e alinhada em relação ao carregamento aplicado. Este processo de alinhamento das cadeias moleculares altera a estrutura interna e proporciona uma variação no módulo de elasticidade do material. Sendo assim, a deformação plástica nos materiais poliméricos ocorre sem existir a quebra das moléculas, mas apenas uma mudança de orientação das mesmas, colocando-se de forma paralela ou perpendicular em relação ao eixo da cadeia molecular (YOUNG e LOVELL, 1991). Além disso, o processo de encruamento ocorre de forma diferente para carregamento uniaxial de tração e uniaxial de compressão. No primeiro caso de carregamento, há uma 
orientação uniaxial das cadeias poliméricas, mas no segundo caso, há uma orientação molecular planar (BOYCE e ARRUDA, 1990).

Segundo Bardella (2001), polímeros apresentam duas fontes distintas de resistências. A primeira fonte é a rotação das cadeias moleculares (isto ocorre quando o material é tensionado), o que pode ser responsável pelo amolecimento (softening) do material, quando este ultrapassa o limite de escoamento. A segunda fonte é a orientação de encruamento (hardening), que é devida à tentativa de alteração da configuração de entropia do material. Esta observação feita por Bardella (2001) é corroborada com os trechos (B, C, D) da Figura 2.6.

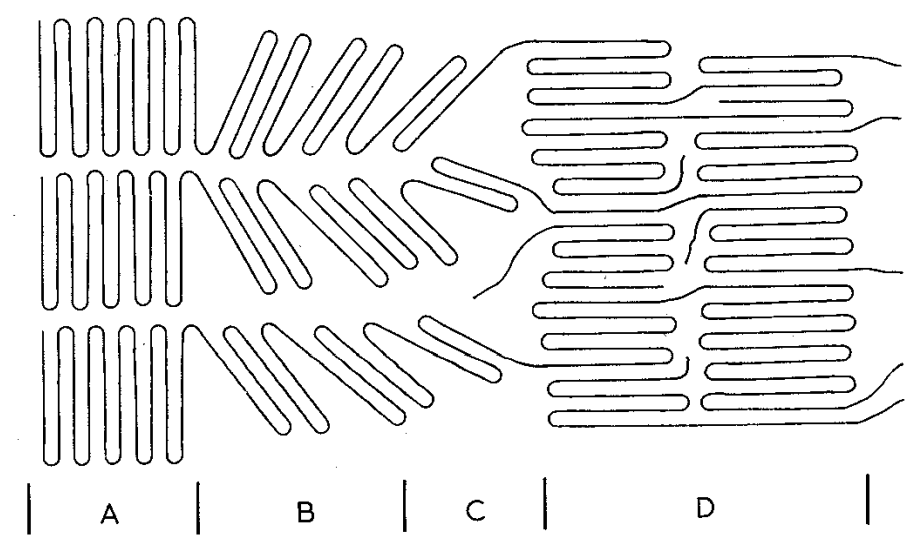

Figura 2.6 - Representação esquemática da deformação de um polímero em nível molecular (YOUNG e LOVELL, 1991).

Deve-se ressaltar que o biopolímero à base de óleo de mamona é classificado como um polímero termofixo, contendo ligações cruzadas. Portanto, a estrutura tridimensional molecular formada é quem irá determinar o comportamento deste material frente às diversas formas de carregamentos. Os resultados preliminares, obtidos por Silvestre Filho (2001) mostram que o biopolímero, a ser avaliado no presente trabalho, possui um comportamento dúctil tanto sob tração (Figura 2.7a) como sob compressão (Figura 2.7b), podendo atingir cerca de $33 \%$ de deformação nominal no limite de ruptura à tração e $16 \%$ no limite de ruptura à compressão. Apesar do autor não ter mostrado a realização dos ciclos de 
carregamento e descarregamento e de não ter calculado os valores de tensão e deformação verdadeiros, nota-se que o biopolímero apresenta plastificação com níveis elevados de deformação permanente.

Outro aspecto que deve ser considerado durante a plastificação dos materiais poliméricos é a variação de volume. Ao contrário dos materiais metálicos, que não sofrem variação volumétrica, os materiais poliméricos apresentam coeficiente de Poisson próximo a 0,5 durante a plastificação. Além disso, estes materiais terão seu processo de escoamento influenciado não somente pelas tensões desviadoras, mas também pelas tensões hidrostáticas. Tal fenômeno é descrito na literatura e pode ser encontrado no trabalho desenvolvido por G'Sell et al (2002).

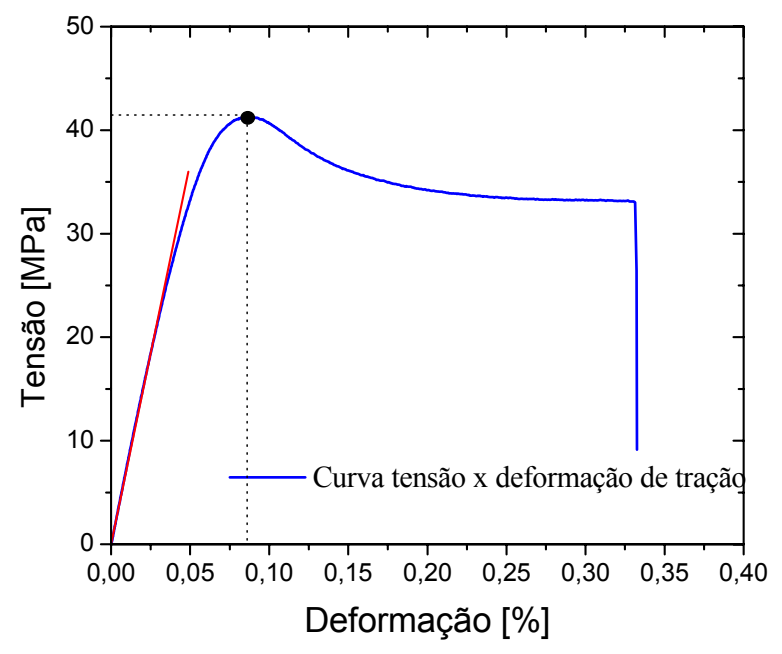

(a)

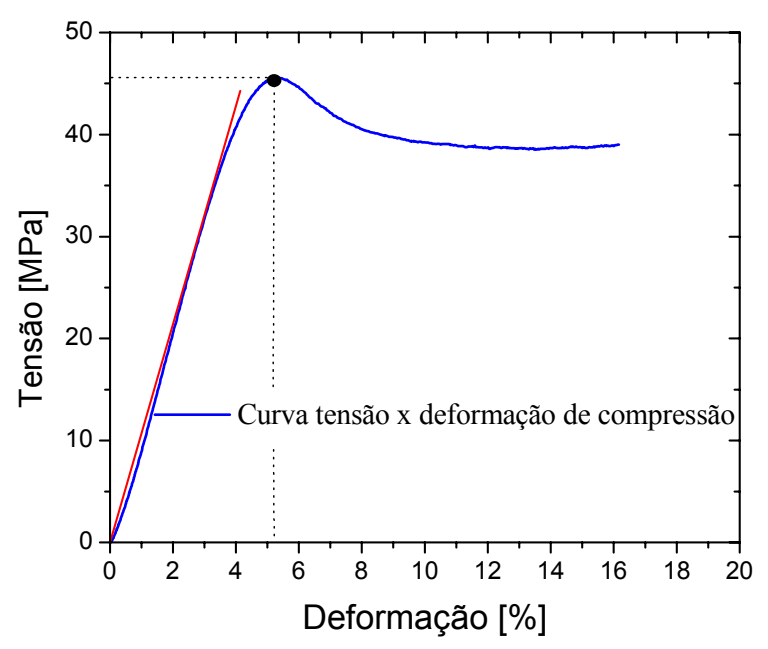

(b)

Figura 2.7 - Comportamento do biopolímero: (a) sob tração; (b) sob compressão, (SILVESTRE FILHO, 2001).

Por fim, assim como os materiais metálicos, os materiais poliméricos possuem comportamento influenciado pela taxa de deformação. Essa taxa é definida como a variação da deformação em função do tempo $(\dot{\varepsilon}=\mathrm{d} \varepsilon / \mathrm{dt})$, e é convencionalmente expressa em $\left[\mathrm{s}^{-1}\right]$. Dessa forma, os valores de tensão de escoamento e de resistência do material dependem da velocidade de deformação aplicada no mesmo. A Figura 2.8 mostra que o aumento da 
taxa de deformação pode elevar os valores de tensão de escoamento e de ruptura do material.

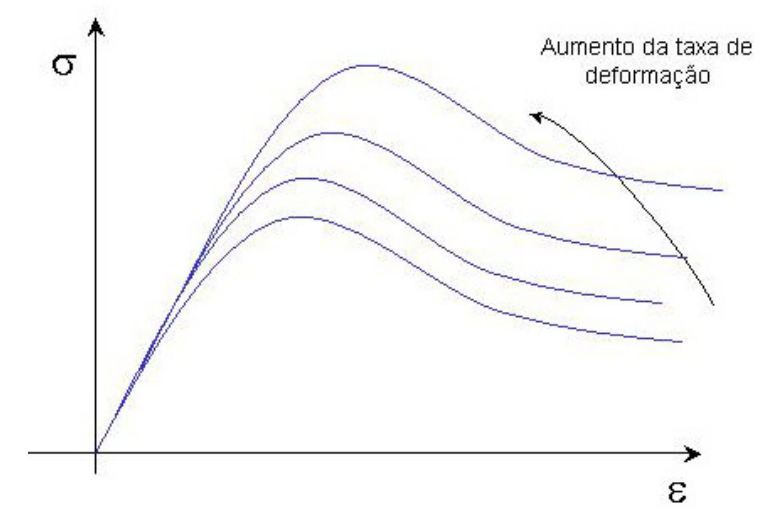

Figura 2.8 - Efeito da taxa de deformação.

\subsubsection{Viscoelasticidade}

Segundo Malvern (1969), o comportamento viscoelástico é a combinação dos mecanismos elásticos associados aos viscosos, sendo intensamente marcante nos polímeros. Assim, durante a deformação, a resistência ao escoamento ou fluxo (viscosidade) e os efeitos elásticos influenciam o comportamento desses materiais.

Segundo a literatura o comportamento viscoelástico é caracterizado por dois fenômenos:

a) O fenômeno de Fluência (“Creep”);

b) O fenômeno de Relaxação de Tensões ("Stress Relaxation").

O fenômeno de fluência é observado normalmente como sendo um aumento na deformação, em função do tempo, quando o material é mantido numa tensão constante, abaixo da sua tensão de escoamento (Figura 2.9). A maioria dos materiais exibe esse 
fenômeno; nos metais é mais notado sob altas temperaturas e nos polímeros à temperatura ambiente. Pode ser recuperável ou não, dependendo da natureza do processo de deformação interna. Nota-se que este tipo de fenômeno não ocorreria para um material puramente elástico, pois o nível de deformação seria atingido imediatamente e se manteria constante ao longo do tempo (linha tracejada).

Entrada

Fluência (Creep)

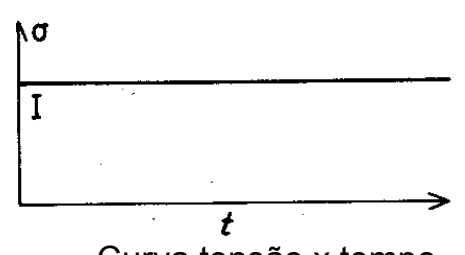

Curva tensão $\mathrm{x}$ tempo

Entrada

Relaxação (Relaxation)

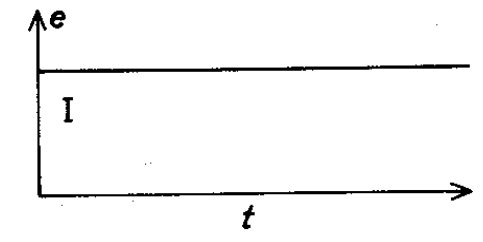

Curva deformação $\mathrm{x}$ tempo
Saída

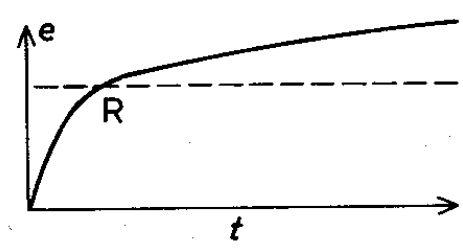

Curva deformação $x$ tempo

Saída

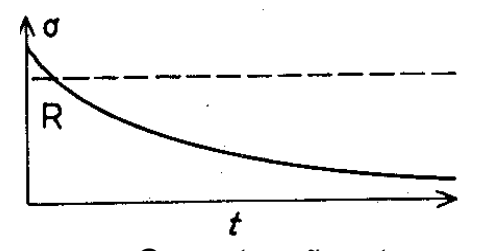

Curva tensão $\mathrm{x}$ tempo

Figura 2.9 - Representação esquemática da resposta (R) para entrada (I) de polímeros viscoelásticos: Fluência e Relaxação. (YOUNG e LOVELL, 1991).

Por outro lado, o fenômeno de relaxação é observado normalmente como sendo uma redução na tensão, em função do tempo, quando o material é mantido num nível de deformação constante (Figura 2.9). Nota-se que este tipo de fenômeno não ocorreria para um material puramente elástico, pois o nível de tensão se manteria constante (linha tracejada). Vale ressaltar que a combinação das curvas de tensão-deformação-tempo para o fenômeno de fluência e relaxação fornecerá a superfície demonstrada na Figura 2.10. 


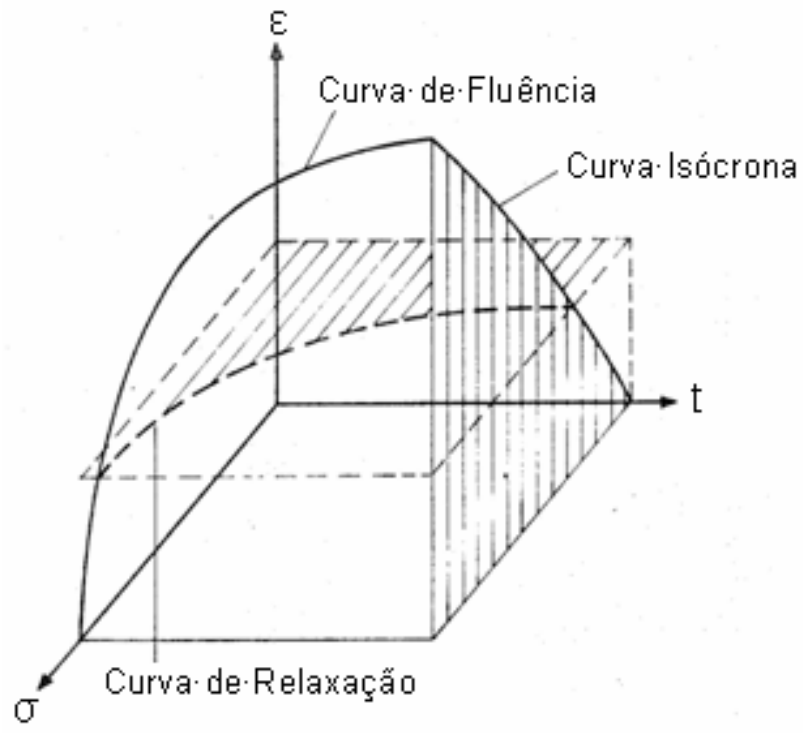

Figura 2.10 - Superfície: tensão-deformação-tempo (p-e-t)(WILLIAMS, 1973).

Um outro fenômeno apresentado pelos materiais viscoelásticos é conhecido como "Recovery" (Recuperação) e ocorre quando certo nível de tensão é reduzido ou removido integralmente (Figura 2.11a). Sendo assim, as deformações recuperam níveis compatíveis com a tensão aplicada em função do tempo (Figura 2.11b). Nota-se que para materiais puramente elásticos, a recuperação dos valores de deformação compatível com o nível de tensão seria imediata (linha tracejada).

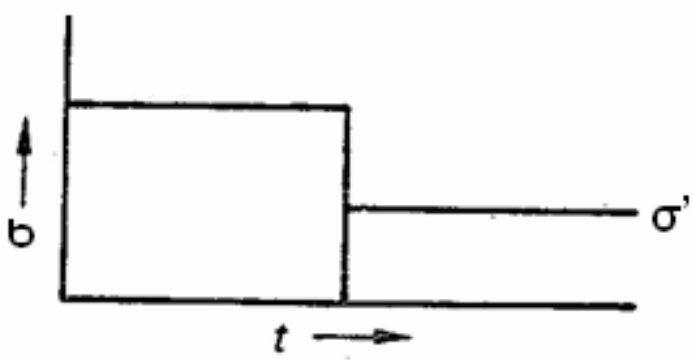

(a)

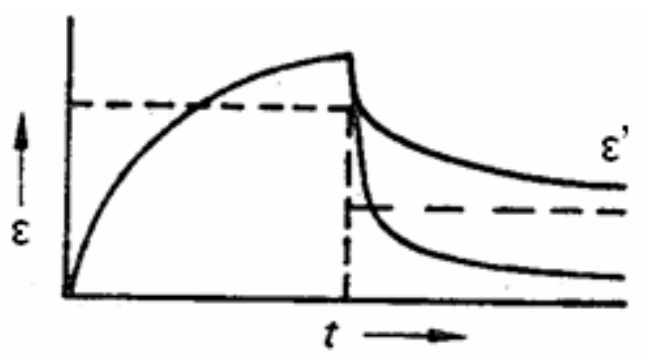

(b)

Figura 2.11 - O fenômeno de Recovery: (a) tensão x tempo; (b) deformação x tempo (WILLIAMS, 1973). 


\subsection{Ensaios mecânicos em materiais poliméricos}

Uma das maneiras mais comuns de prever o comportamento mecânico de materiais poliméricos é através de ensaios baseados em normas, como as da ASTM. Porém, essas normas não abordam procedimentos de como solucionar alguns problemas específicos inerentes à realização dos ensaios. Por isso, procurou-se em literatura específica os procedimentos de realização empregados em cada tipo de ensaio, como pode ser visto nos itens seguintes.

\subsubsection{Minimização do atrito nos ensaios de compressão}

O estudo sobre como melhor obter dados consistentes num ensaio de compressão é tradicionalmente expresso na literatura, em virtude das dificuldades de realização deste ensaio quanto a manter o carregamento uniaxial. A busca incessante pela diminuição do efeito de Saint Venant, ou seja, a influência da interface entre o aplicador de força e o corpode-prova (CDP), que produz o embarrilamento, pode ser observada em diversos artigos. Assim, para evitar o fenômeno de embarrilamento, Boyce e Arruda (1990, p.1290) utilizaram folhas finas de teflon entre o CDP e o aplicador de força da máquina de ensaio, segundo estes pesquisadores a introdução de uma a duas folhas de teflon foram suficientes para eliminar o embarrilamento.

Odom e Adams (1994, p.104) afirmam que são necessários dois tipos de CDP. Um com uma relação entre comprimento e diâmetro $(/ / d)$ igual a 2 é recomendado para a obtenção de valores de resistência, enquanto que para a determinação de valores de módulo de elasticidade seria necessário um outro com a relação de 2,75 , para evitar os efeitos de restrição da deformação nos seus extremos. 
Com o intuito de evitar instabilidades em polímeros em altas deformações, como por exemplo, cisalhamento, flambagem e embarrilamento, Ravi-Chandar e MA (2000, p.333) realizaram o ensaio de compressão através da técnica de compressão confinada do CDP. Tal procedimento realmente elimina tais instabilidades geradas durante o experimento, como o embarrilamento, porém não é possível que se meça a deformação diretamente no CDP. Além disso, o atrito entre a parede interna do dispositivo e o diâmetro externo do CDP pode gerar dados não tão precisos.

Khan e Zhang (2001, p.1169) comprimiram os CDPs entre placas feitas em aço VascoMax C-35 tratados termicamente para obtenção de sua dureza máxima. Para reduzir o coeficiente de atrito entre as faces do CDP e os aplicadores de força foi empregado um lubrificante de silicone de alto vácuo.

Frachon (2002, p.60) menciona a utilização de uma folha de grafite entre os aplicadores de força e o CDP, para assim eliminar efeitos indesejáveis gerados pelo atrito e um estado de tensões diferente do uniaxial.

Wu et al. (2004) analisaram o comportamento de vários tecidos moles (pele de porco, cérebro de porco e gordura do calcanhar humano) através do Método dos Elementos Finitos (MEF). Neste trabalho foram feitas várias simulações da compressão de CDPs cilíndricos não-confinados, variando-se o coeficiente de atrito entre os espécimes e os aplicadores de força.

An e Vegter (2005, p.152) utilizaram um filme de $25 \mu \mathrm{m}$ de teflon (PTFE) misturado com óleo mineral (Quaker N6130) entre as placas aplicadoras de força e o corpo de prova. Relataram ainda que a expansão dos CDPs cilíndricos ensaiados sob compressão se deu uniformemente em todas as direções radiais sem observação de embarrilamento. Salientaram também que os CDPs, com rugosidade elevada danificam o filme de teflon e, portanto, estes devem ter um bom acabamento superficial. O encruamento do material não influencia no atrito e a contribuição do atrito na tensão de escoamento é função da geometria inicial e do grau de deformação. 
Portanto, a realização do ensaio de compressão não é uma tarefa simples por envolver diversas variáveis a serem controladas.

Tendo em vista o variado campo de aplicação do biopolímero em questão, o levantamento das propriedades mecânicas de maneira consistente se tornou um importante alicerce para o desenvolvimento do presente trabalho, bem como, desta pesquisa.

No presente trabalho, a abordagem desse problema se deu na melhoria do acabamento superficial dos aplicadores de carga e dos CDPs, para assim, atingir os resultados esperados.

\subsubsection{Efeito da estricção em CDPs de tração}

O ensaio de tração é uma forma conveniente para determinar as propriedades mecânicas de um material. Porém, na realização do mesmo existem várias implicações, tais como as instabilidades advindas do problema da estricção da seção transversal do CDP sob solicitação, principalmente a estricção que antecede a ruptura (chamada de estricção localizada). Por tanto, há vários estudos relacionados a esse tema, principalmente relacionados ao CDP de seção circular.

Hart (1955) elaborou um modelo para deformação uniaxial da linha de deformação de Luder, a qual é o modo característico da deformação na vizinhança do ponto de escoamento, para muitos metais que exibem este ponto.

Bridgman (1964) desenvolveu um método de aproximação através da medição do raio de curvatura gerada pela estriç̧ão dentro do comprimento de medição das deformações. Para tanto, ele tratou esse raio como parâmetro experimentalmente determinado, dessa forma não houve um aprofundamento de uma teoria que abordasse esse raio em termos dos parâmetros plásticos fundamentais do material. 
Chen (1971) analisou o processo de estricção de um CDP de tração (axissimétrico) através da teoria de fluxo $\mathrm{J}_{2}$ (segundo invariante das tensões desviadoras) generalizada para grandes deformações, solucionando as equações que governam o fenômeno através de um tipo de aproximação baseada no princípio variacional. Devido ao comportamento plástico do material, são consideradas as não-linearidades físicas e geométricas. Contudo, as respostas obtidas por esse processo não foram conclusivas porque as técnicas numéricas empregadas precisavam ser melhoradas.

No trabalho de Needleman (1972), fêz-se uma comparação com a fórmula desenvolvida por Bridgman (1964), a qual necessitava de cada estágio do histórico de deformação, da área atual, do raio de curvatura na estricção e da carga total, enquanto que a desenvolvida por Needleman era suprida por sua formulação. Esta fórmula apresentou bons resultados para os estágios iniciais da estricção, porém para estágios mais avançados a formulação fornecia resultados com valores menores do que o real.

Norris et al (1978) apresentou uma forma de cálculo computacional iterativo que permitia correções dos dados do ensaio de tração simples para validar uma curva universal de tensão de escoamento para grandes deformações. Com isso, por meio de sua formulação, tomou-se o estado da deformação na fratura, para comparar com os valores obtidos por Bridgman (1964), bem como outros pesquisadores que realizaram este tipo de cálculo (NEEDLEMAN 1972; CHEN, 1971). Assim, encontraram-se consideráveis diferenças da solução de Bridgman, concluindo que a sua formulação subestima em $23 \%$ a tensão no estado tri-axial atingido durante o processo de falha na estricção do CDP, enquanto que a formulação apresentada por Norris et al (1978) apresentou valores 52\% maiores do que os calculados por Bridgman.

Gillis e Jones (1979) estenderam o estudo sobre a estricção para os CDPs de tração tipo gravata (flat sheet), em virtude de uma necessidade tecnológica sobre o entendimento das instabilidades plásticas decorrentes do processo de estampagem. É sabido que a estricção de um CDP dúctil de tração antes de fraturar é a forma mais familiar de 
instabilidade plástica, na qual ocorre a localização da deformação. Os resultados desta análise são similares em forma, embora não em detalhes, àquelas de uma análise prévia para barras de tração circular.

Ling (1996) desenvolveu um método para predizer a relação tensão-deformação verdadeira a partir dos dados da relação tensão-deformação de engenharia, esse método se utiliza da média ponderada dos limites superior e inferior (método das médias ponderadas) de curvas tensão-deformação. Segundo Ling (1996), o método de correção de Bridgman se mostrou inapropriado para o uso em CDPs prismático e, por outro lado, o método das médias ponderadas não se aplica na predição da deformação em fratura. Para este nível de deformação, o autor sugere o método convencional envolvendo a medição da área da seção transversal mínima.

Zhang at al (1999) analisaram o comportamento da estricção em CDP de seção retangular em material isotrópico através de um extensivo estudo numérico tridimensional. Por meio deste, estabeleceram uma relação aproximada entre a redução de área da seção transversal mínima e a medida da redução da espessura. Porém, destaca-se que este modelo proposto é válido apenas para materiais isotrópicos e com 0,3 de coeficiente de Poisson.

Mikkelsen (1999) utilizou um modelo bidimensional em elementos finitos para estudar o efeito da estricção no CDP de tração uniaxial com seção transversal retangular, comparando sua resposta com um modelo tridimensional. Com isso ele concluiu que seu modelo apresenta vantagem na execução computacional em relação ao tridimensional e que seu modelo é utilizável não somente para aplicações simples, mas em análise do comportamento após ter iniciado a estricção em estruturas de paredes finas, o qual representa bem o caso de estampagem de chapas metálicas.

Cabezas e Calentano (2004) propuseram uma metodologia numérico-experimental a fim de originar os parâmetros elásticos e de encruamento que caracterizam a resposta do material. Essa metodologia aplicada a CDPs prismáticos é essencialmente uma extensão da 
metodologia aplicada a CDPs cilíndricos. Os autores realizaram a simulação do processo de deformação através de uma formulação em elementos finitos baseada na elastoplasticidade com grandes deformações e, finalmente, validaram os resultados numéricos com os experimentais, podendo estimar o desempenho da metodologia proposta para análise tridimensional de CDPs prismáticos. Além disso, discutiram a faixa de aplicabilidade das condições do estado plano de tensões.

Assim, como visto neste item e no anterior a obtenção dos parâmetros do comportamento mecânico dos materiais não é tarefa simples, dependendo das propriedades que se deseja, em virtude das inúmeras variáveis que envolvem os ensaios mecânicos.

\subsection{Modelos reológicos}

Nesta sessão serão apresentados os modelos clássicos e os modelos que são originados a partir da combinação desses modelos clássicos. Estes modelos são encontrados na literatura e abordam a modelagem viscoelástica e visco-elastoplástica.

\subsubsection{Modelos clássicos unidimensionais}

Os modelos reológicos clássicos se dividem em modelos básicos e modelos combinados. Os modelos básicos simulam o comportamento elástico, plástico e o viscoso separadamente. Enquanto, os modelos combinados simulam o comportamento elastoplástico, viscoelástico, viscoplástico e o elastoviscoplástico. 


\subsubsection{Modelos básicos unidimensionais}

\section{Modelo Elástico}

O modelo elástico é caracterizado pelo fato da deformação ser essencialmente reversível, ou seja, um corpo quando carregado dentro do limite de escoamento apresenta certo nível de deformação e ao se retirar esse carregamento o corpo não apresenta deformação residual, ou seja, o corpo retorna ao nível inicial. O comportamento elástico é representado por uma mola, Figura 2.12 .

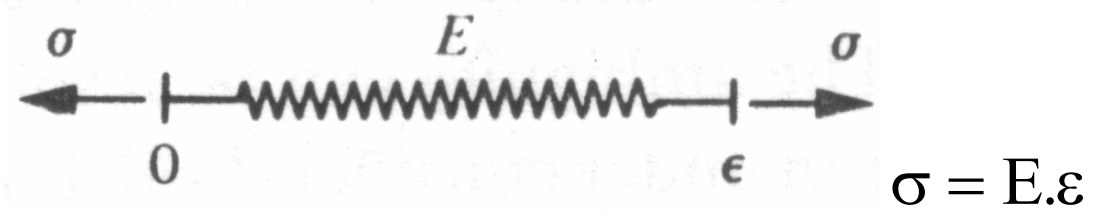

Figura 2.12 - Modelo elástico, Lemaitre e Chaboche (1990).

\section{Modelo Plástico perfeito}

O modelo plástico perfeito é caracterizado pelo fato de toda deformação ser residual quando o corpo é aliviado da carga que estava submetido, ou seja, quando o corpo é carregado além do limite de escoamento apresenta certo nível de deformação e ao se retirar esse carregamento o corpo apresenta deformação permanente. O comportamento plástico é representado por um bloco que desliza sobre uma superfície, como pode ser visto na Figura 2.13. 


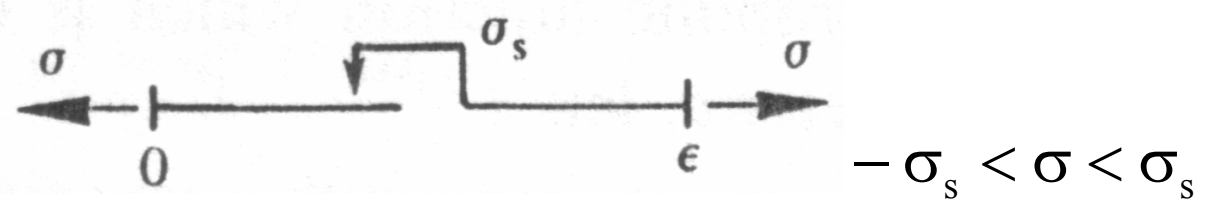

Figura 2.13 - Modelo plástico perfeito, Lemaitre e Chaboche (1990).

\section{Modelo Viscoso}

Este modelo viscoso é representado por um amortecedor, Figura 2.14, o qual caracteriza a resposta em função do tempo. Apesar de esse comportamento ser uma característica inerente dos líquidos alguns sólidos apresentam esse mesmo comportamento, mesmo que as tensões permaneçam constantes.

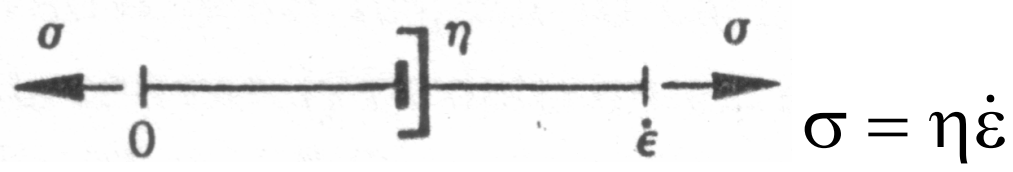

Figura 2.14 - Modelo viscoso, Lemaitre e Chaboche (1990).

\subsubsection{Modelos combinados unidimensionais}

\section{Modelo Elastoplástico perfeito}

O modelo elastoplástico perfeito é o modelo de Saint-Venant, o qual consiste de uma mola linear em série com um bloco que desliza sobre uma superfície, Figura 2.15. 


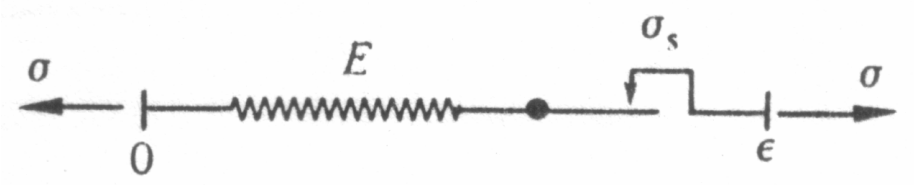

Figura 2.15 - Modelo elastoplástico perfeito de Saint-Venant, Lemaitre e Chaboche (1990).

\section{Modelo Viscoelástico de Maxwell}

Este modelo consiste da associação em série de uma mola com um amortecedor,

Figura 2.16.

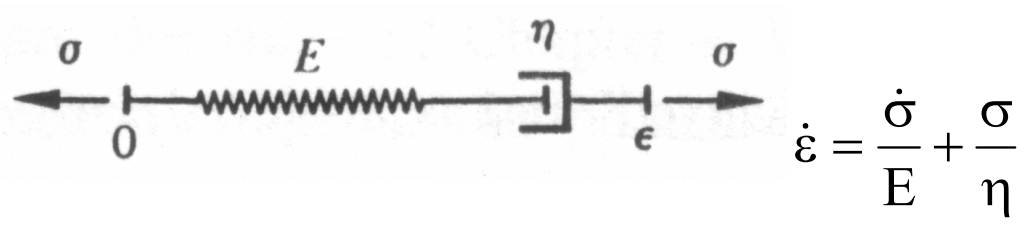

Figura 2.16 - Modelo viscoelástico (modelo de Maxwell), Lemaitre e Chaboche (1990).

\section{Modelo Viscoelástico de Kelvin-Voigt}

Este modelo consiste da associação em paralelo de uma mola com um amortecedor, Figura 2.17, a fim de representar a igualdade de deformação, enquanto que a tensão é a soma das tensões atuantes nos dois elementos.

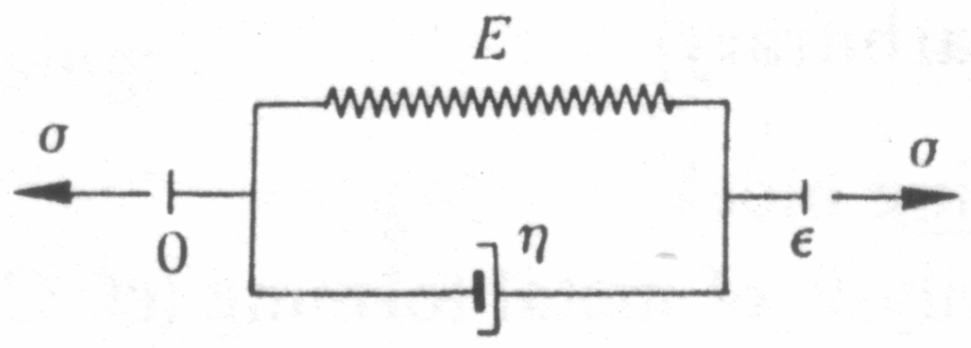

Figura 2.17 - Modelo viscoelástico (modelo de Kelvin - Voigt), Lemaitre e Chaboche (1990). 
Com esses modelos clássicos os autores contemporâneos fazem associações de forma a representar o comportamento dos materiais da melhor maneira possível, como pode ser visto nas seções seguintes.

\subsubsection{Modelos viscoelásticos e viscoelastoplásticos}

Bardenhagen, Stout e Gray (1997) apresentaram uma metodologia geral capaz de realizar uma análise tridimensional com deformações finitas e modelos constitutivos viscoplásticos empregados em materiais poliméricos. O desenvolvimento da mesma tem como ponto de partida um modelo unidimensional constituído por um elemento elástico e um elemento dissipador (amortecedor) (Figura 2.18) capaz de representar tanto o fenômeno de fluência como o de relaxação. No entanto, a viscosidade associada ao elemento dissipador é tratada como não-Newtoniana, ou seja, a mesma varia em função do tempo.

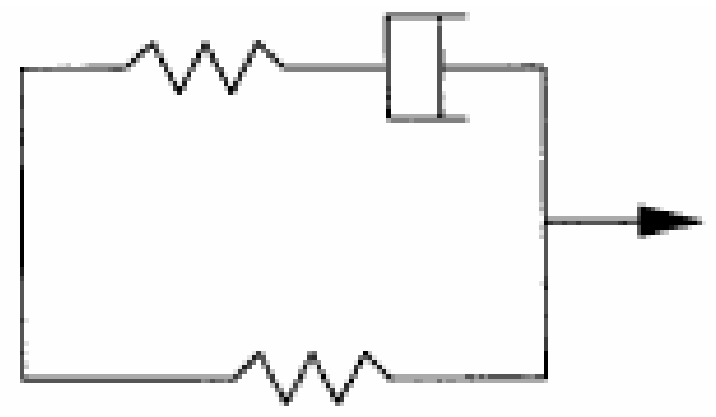

Figura 2.18 - Modelo proposto por Bardenhagen et al (1997).

A modelagem tridimensional proposta pelos autores pode ser facilmente generalizada e incorporar um número arbitrário de processos inelásticos, representando assim, mecanismos de deformação micro-estrutural que ocorrem em diferentes escalas de tempo. 
Vale ressaltar ainda, que estudos de casos envolvendo fluência e relaxação são discutidos e detalhados para o modelo unidimensional, além disso, os resultados obtidos pelo mesmo foram validados através resultados experimentais. As Figuras 2.19 (a) e (b) mostram os resultados experimentais comparados aos resultados do modelo para o fenômeno de relaxação.
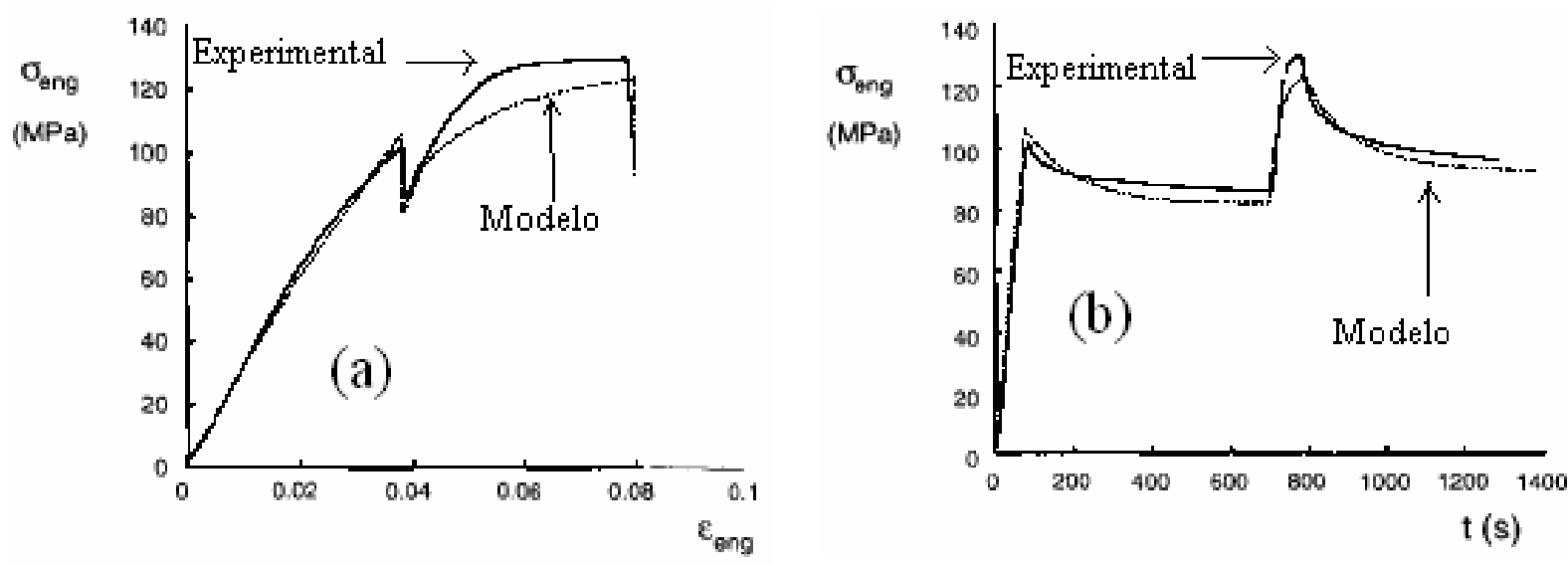

Figura 2.19 - Resultados obtidos pelo modelo proposto por Bardenhagen et al (1997).

Por fim, os autores concluíram que a metodologia possibilita uma abordagem flexível para modelar o comportamento de materiais poliméricos sobre uma ampla faixa de carregamentos.

Van Der Sluis, Schreur e Meijer (1999) empregando o modelo de Perzynas, juntamente como uma técnica de homogeneização, simularam o comportamento viscoelástico de polímeros heterogêneos que possuem propriedades mecânicas melhoradas, tais como, alta resistência, alta rigidez ou alta tenacidade. Vale ressaltar que o método de homogeneização proposto permite que um material heterogêneo seja substituído por um meio homogêneo contínuo equivalente. Sendo assim, recorrendo ao método dos elementos finitos, os pesquisadores verificaram o comportamento mecânico de um Elemento Volumétrico Representativo (EVR) o qual é definido geometricamente pela micro-estrutura do material em análise (Figura 2.20). 


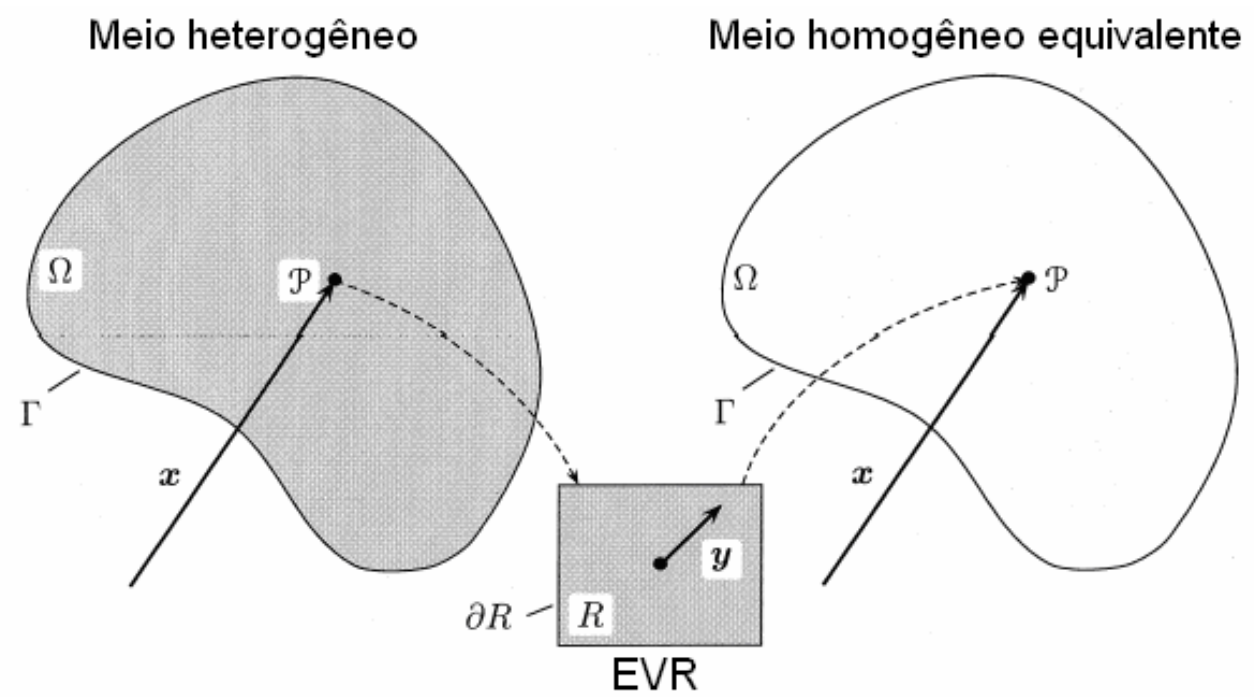

Figura 2.20 - Técnica de homogeneização e EVR (VAN DER SLUIS, SCHREUR e MEIJER, 1999).

Deve-se destacar que para suas análises, os autores fizeram uso do modelo de Perzynas, tendo este sido alimentado adequadamente por um dado grupo de parâmetros. A estratégia de homogeneização proposta possibilitou uma alternativa para obter os parâmetros associados a um modelo constitutivo que representa um meio homogêneo contínuo equivalente.

Finalmente, a fim de validar tal estratégia, os autores realizaram a análise de uma placa perfurada submetida a diferentes tipos de carregamento. Posteriormente o modelo descrito anteriormente foi melhorado por Van Der Sluis et al. (2000), discutindo sobre a distribuição uniforme e a distribuição irregular dos constituintes micro-estruturais.

Nikolov e Doghri (2000) apresentaram um modelo constitutivo baseado em micromecânica, capaz de simular o comportamento visco-elástico do polietileno de alta densidade sob pequenas deformações. Vale ressaltar que a micro-estrutura do polietileno consiste de lamelas cristalinas empacotadas de maneira muito próxima que são separadas por camadas de polímero amorfo. Assim, este polímero semi-cristalino foi modelado como um material que possui inclusões orientadas aleatoriamente, consistindo assim de lamelas paralelas empilhadas contendo camadas amorfas adjacentes (Figura 2.21). 


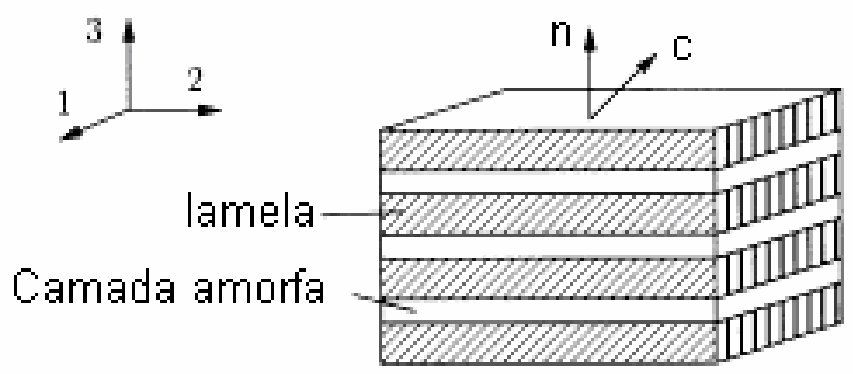

Figura 2.21 - Representação da micro-estrutura do polietileno de alta densidade (NIKOLOV e DOGHRI, 2000).

Com base nesse modelo micro-mecânico, os autores obtiveram os parâmetros $E_{a}, G_{a}$ e $\eta_{a}$ que estão associados a um modelo visco-elástico unidimensional, mostrado na Figura 2.22, o qual consiste do elemento Hookeano (mola) em paralelo com o modelo de Maxwell.

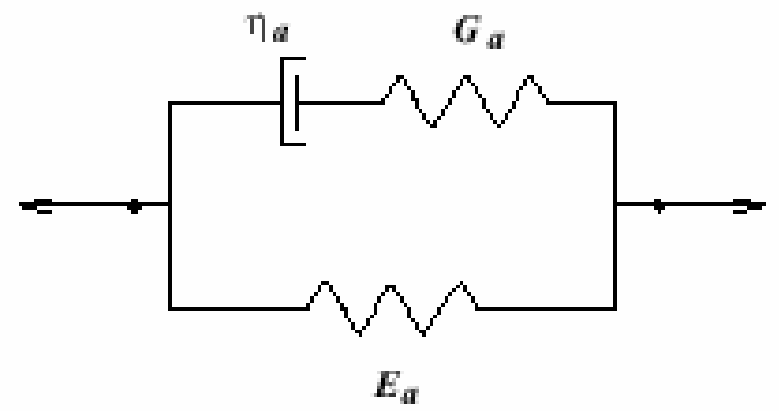

Figura 2.22 - Modelo proposto por Nikolov e Doghri (2000)

Al-Haik et al. (2001) estudaram compósitos poliméricos e inicialmente obtiveram as propriedades viscoplásticas para vários carregamentos e faixas de temperatura para esses materiais. Posteriormente um modelo constitutivo visco-elastoplástico de Gates foi empregado para representar o comportamento desses compósitos. Vale destacar que este modelo está baseado num conceito de "overstress" o qual é apropriado para as propriedades elásticas de materiais compósitos.

Os parâmetros associados ao modelo foram obtidos com base em ensaios experimentais de relaxação de carregamento. 
Com este modelo, os autores puderam prever o fenômeno de fluência em curtos períodos de tempo e sob baixas temperaturas. Porém, com o aumento da temperatura ou com o aumento do tempo para a análise da Fluência, verificou-se que o resultado do modelo divergiu dos resultados experimentais.

Bardella (2001) propôs um modelo constitutivo que descreve a visco-elasticidade das resinas epóxis (Figura 2.23).

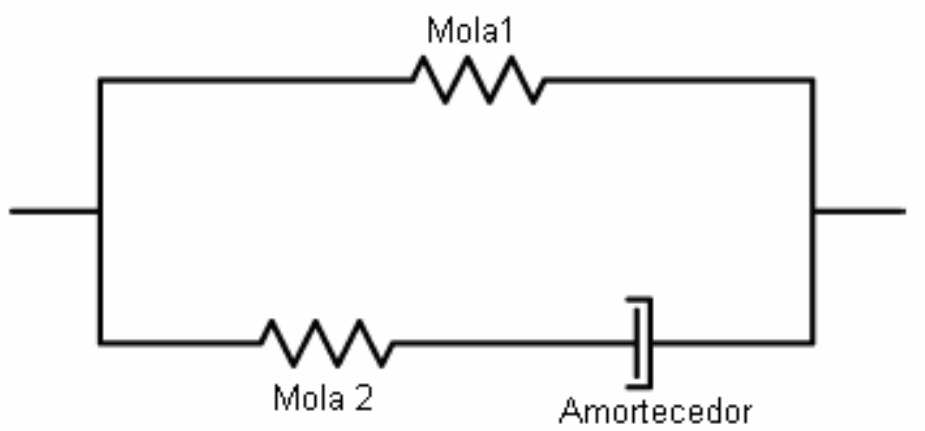

Figura 2.23 - Modelo proposto por Bardella (2001).

O autor mostrou, através de resultados experimentais, que há ocorrência de comportamento não-linear, visco-elástico quando este polímero sofre a ação de carregamento cíclico. Sendo assim, recorrendo à técnica de mínimos quadrados, o autor identificou os parâmetros associados ao modelo proposto e simulou o comportamento cíclico desse polímero.

Drozdov e Gupta (2003) realizaram ensaios uniaxiais de tração com diferentes taxas de deformação e sob temperatura ambiente em amostras de polipropileno e polietileno de baixa densidade com diferentes pesos moleculares. Os autores propuseram equações constitutivas derivadas do comportamento visco-plástico de polímeros semi-cristalinos para deformações finitas. Essas equações dependem de três parâmetros que são ajustados em função dos resultados experimentais. Por fim, os autores mostram que o modelo proposto fornece resultados coerentes com os resultados experimentais. 
Drozdov e Christiansen (2003) realizaram ensaios experimentais cíclicos uniaxiais sob temperatura ambiente em polietileno de baixa densidade, porém com diferentes taxas de deformação. Um modelo constitutivo foi proposto a partir do comportamento viscoplástico de um polímero semicristalino sob pequenas deformações. As equações constitutivas foram determinadas por cinco parâmetros que foram identificados através do ajuste do modelo com base nas curvas experimentais tensão-deformação.

Conclui-se assim, diante dos trabalhos apresentados, que são necessários ensaios experimentais específicos, principalmente envolvendo ciclos de carregamento e descarregamento, a fim de que sejam obtidos os parâmetros associados ao modelo viscoelástico ou visco-elastoplástico empregado. Dessa forma, segue no próximo capítulo a descrição detalhada dos ensaios experimentais realizados, com a finalidade de obter os parâmetros do modelo de material que será utilizado bem como avaliar a capacidade do mesmo em representar os fenômenos de fluência e de relaxação. 


\section{Materiais e métodos}

A poliuretana derivada do óleo da mamona é objeto deste estudo em virtude de seu potencial em serviço, conforme foi visto na revisão, desta forma escolheu-se uma das várias configurações dessa poliuretana para o desenvolvimento deste estudo. A poliuretana estudada é constituída de dois componentes (para a configuração utilizada) denominados de pré-polímero 329L e o poliol 471. A obtenção do polímero se dá através da mistura desses dois componentes a uma razão estequiométrica de 1 (uma) parte do pré-polímero para 0,7 (parte) do poliol em massa. O produto foi cordialmente cedido pelo Grupo de Química Analítica e Tecnologia de Polímeros (GQATP) do Instituto de Química da USP em São Carlos. Maiores informações sobre essa poliuretana se encontram em Claro Neto (1997). 


\subsection{Fabricação das amostras}

A fabricação dos corpos-de-prova foi realizada no Laboratório de Tribologia e Compósitos do Departamento de Engenharia Mecânica (EESC-USP). As amostras foram divididas nos seguintes tipos:
a) CDP de tração (40 CDPs);
b) CDP de compressão (40 CDPs);
c) CDP de flexão (15 CDPs);
d) CDP de DMA (Dynamic mechanical analysis) (15 CDPs).

O procedimento de obtenção dos CDPs foi realizado em sala com controle de umidade $\left(40 \%\right.$ de umidade relativa do ar) e temperatura (aproximadamente $20^{\circ} \mathrm{C}$ ). $\mathrm{Na}$ ausência desse controle ocorrem dificuldades na manipulação da mistura, porque em ambiente com umidade relativa superior à supracitada promove-se um aumento excessivo na formação de bolhas. Nesta condição, a umidade do meio é absorvida reagindo com o pré-polímero, liberando $\mathrm{CO}_{2}$ para o meio gerando bolhas.

A ocorrência de bolhas prejudica a qualidade dos CDPs, pois, formam-se vazios indesejáveis nos mesmos. Também, teve-se o cuidado com o tempo de manipulação da mistura, devido ao início da polimerização (tempo de gel), que é de aproximadamente 20 minutos para o volume de polímero manipulado na obtenção dos CDPs. Assim, para a obtenção dos CDPs, procedeu-se da seguinte forma:

a) Em uma balança eletrônica OHAUS ${ }^{\circledR}$, modelo TS4000D com capacidade de $4000 \mathrm{~g}$ e sensibilidade de $0,01 \mathrm{~g}$, o pré-polímero e o poliol foram pesados a uma razão de 1:0,7 em massa, respectivamente; 
b) Misturaram-se, em recipiente plástico e agitado por um bastão de vidro, as duas partes dos materiais conforme foram pesados (item anterior) por aproximadamente 2 (dois) minutos, a fim de promover a homogeneização, sendo esta realizada à pressão atmosférica e temperatura ambiente;

c) A mistura ficou durante 5 minutos em uma câmara de vácuo (constituída por um dessecador acoplado a uma bomba de vácuo da marca PFEIFFER BALZERS ${ }^{\circledR}$ com capacidade de pressão de $10^{-4}$ [mbar] e uma vazão de ar de $8\left[\mathrm{~m}^{3} / \mathrm{h}\right]$ ) com a finalidade de reduzir a quantidade de bolhas introduzidas pelo processo de homogeneização do material;

d) A mistura foi vertida em moldes abertos fabricados em silicone, Figura 3.1;

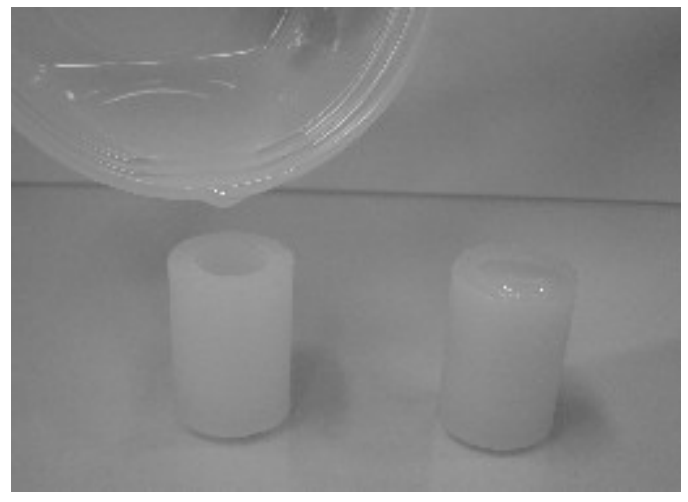

(a) CDP de compressão

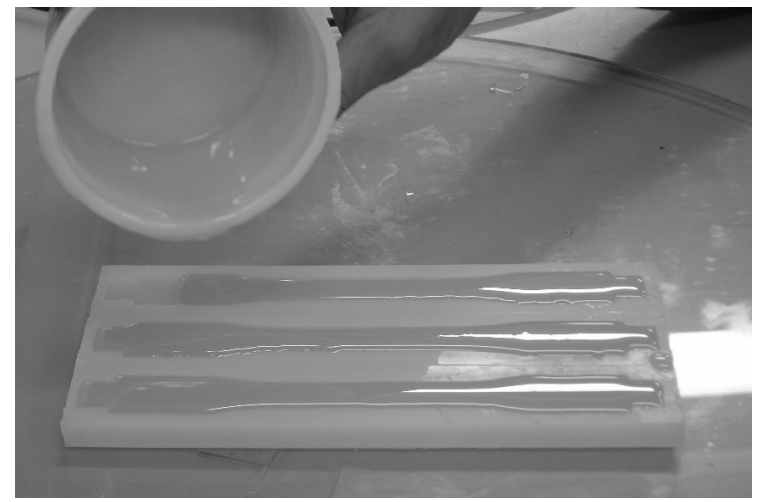

(b) CDP de tração

Figura 3.1 - Molde aberto em silicone para obtenção de corpos-de-prova.

e) Transcorrido o tempo de 8 horas da moldagem, os CDPs atingiam certo nível de polimerização a ponto de permitir a desmoldagem, em seguida foi feita sua identificação, constando de: data da moldagem, numeração própria e o tipo de ensaio a que se destinava;

f) Após 48 horas da moldagem os CDPs eram enviados para um forno microcontrolado (Figura 3.2) e submetidos a uma temperatura de $80^{\circ} \mathrm{C}$ por 3 (três) horas. Tal processo foi particularmente denominado como normalização da polimerização. Isto foi realizado com o intuito de promover a polimerização 
remanescente. Porém, segundo o Grupo de Química Analítica e Tecnologia de Polímeros (GQATP), nem todas as ligações cruzadas possíveis foram efetuadas, pois essas ligações podem ocorrer enquanto houver isocianato livre no polímero, mas com um grau de dificuldade maior com o passar do tempo, ou seja, quanto mais "velho" (elevado tempo pós-cura), mais polimerizado estará o material;

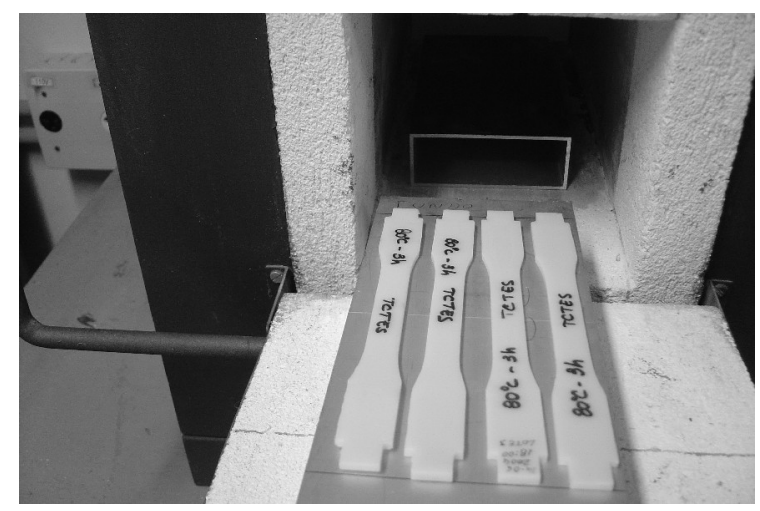

Figura 3.2 - Normalização da polimerização.

g) Por fim, as amostras passaram por um ajuste dimensional, a fim de conferir uma uniformização na largura e na espessura para os CDPs de tração e flexão, removendo algumas, através do uso de lixas, rebarbas inerentes ao processo de moldagem. Os CDPs de compressão sofreram um processo de faceamento para garantir o paralelismo do topo e da base do cilindro e, assim, possibilitar um carregamento uniaxial de compressão.

\subsection{Ensaios quase-estáticos monotônicos e cíclicos}

Para a realização dos ensaios quase-estáticos convencionais (tração, compressão e flexão), foram seguidas as normas propostas pela ASTM (American Society for Testing and Materials) para os ensaios de tração, compressão e flexão, aplicadas a materiais 
poliméricos. Procedeu-se assim, os ensaios para obter as propriedades do material e, por conseqüência, obtiveram-se as curvas: força-deslocamento, tensão-deformação, forçatempo, tensão-tempo, deslocamento-tempo, deformação-tempo.

\subsubsection{Ensaio de tração}

Para o ensaio de tração foi seguida a ASTM D638M - 96 (Tipo I), a qual sugere o corpo-de-prova do tipo gravata, Figura 3.3, sob uma velocidade de ensaio de 5 [ $\mathrm{mm} / \mathrm{min}$ ] (equivalente a uma taxa de deformação de $1,67.10^{-3}\left[\mathrm{~s}^{-1}\right]$ ). Porém, após alguns ensaios essa velocidade foi diminuída para 0,8 [mm/min] (equivalente a uma taxa de deformação de $2,67.10^{-4}\left[\mathrm{~s}^{-1}\right]$ ) devido às características viscoelásticas (fluência e relaxação) acentuadas do material.

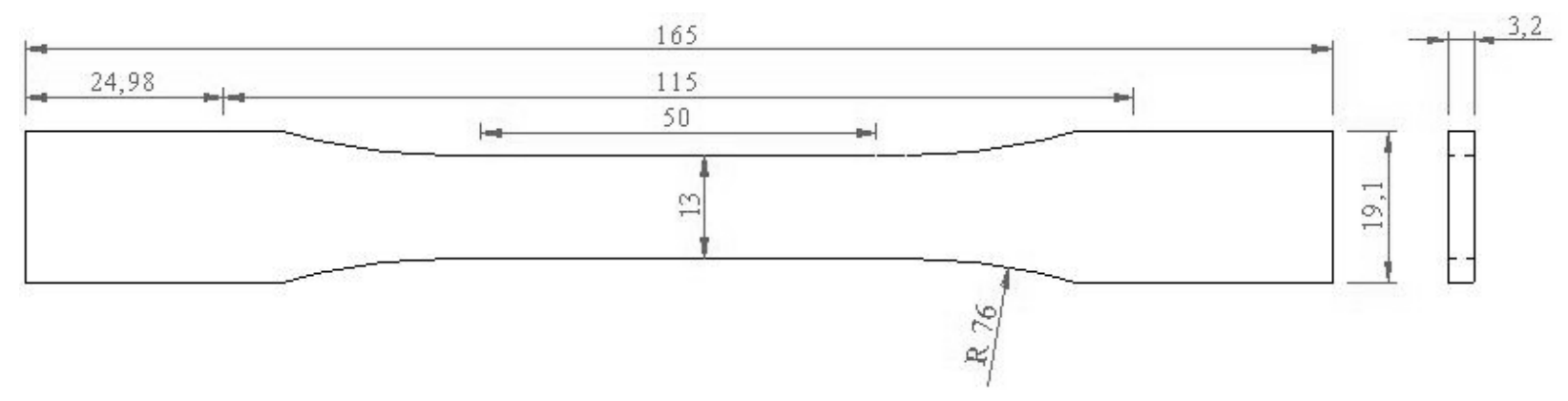

Figura 3.3 - Dimensões do corpo-de-prova de tração [mm].

Os ensaios foram divididos em quatro modalidades:

a) Ensaio monotônico de tração;

b) Ensaio de fluência (creep);

c) Ensaio de relaxação de tensão (stress relaxation); 
d) Ensaios cíclicos de tração para avaliação da energia dissipada através da histerese do material.

Os equipamentos utilizados nos ensaios foram: uma máquina EMIC modelo DL10000, instalada no Departamento de Materiais, Aeronáutica e Automobilística (EESC USP), interligada ao sistema de coleta de dados Test Works ${ }^{T M}$ e um extensômetro tipo clipe para medir a elongação dos corpos-de-prova no sentido longitudinal, bem como, uma máquina Universal de Ensaios Instron 5500R, instalada no Departamento de Engenharia de Materiais (DEMA-UFSCar).

Numa outra etapa dos ensaios, com a finalidade de melhorar a qualidade dos dados obtidos, bem como a medição da deformação transversal, o CDP foi instrumentado por meio de colagem de extensômetros tipo folha (strain gage) com a seguinte classificação: strain gage biaxial KFEL-2-120-D34 e o strain gage uniaxial o KFEL-2-120-C1, que podem medir deformações de até 15\% (KYOWA 2004a, p35), como pode ser visto na Figura 3.4. Para a aquisição de dados via strain gages foi utilizado um sistema de aquisição da Hottinger Baldwin Messetechnik GmbH (HBM), modelo MGCplus com AB22A / AB32. Os strain gages foram colados no sentido longitudinal e no sentido transversal (largura) do CDP, a fim de determinar o coeficiente de Poisson.

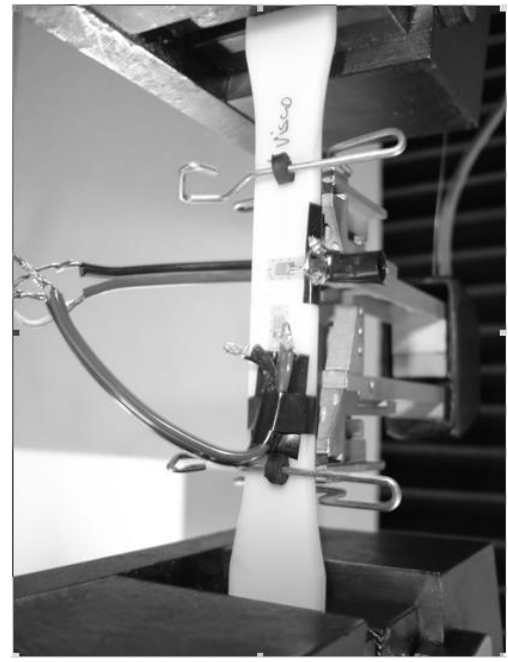

(a) CDP instrumentado

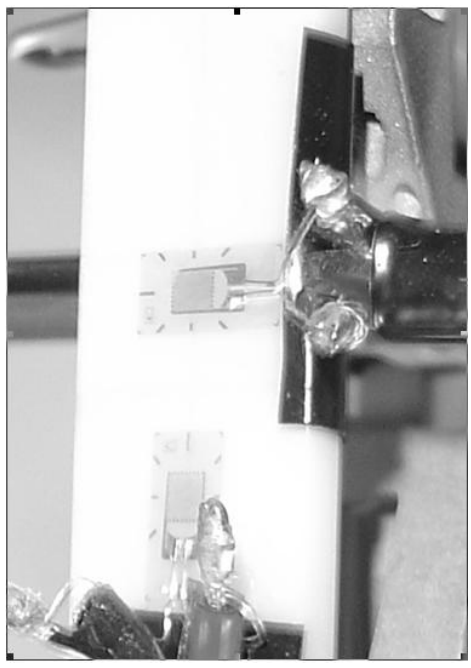

(b) Detalhe do CDP instrumentado

Figura 3.4 - Corpo-de-prova instrumentado com strain gage e extensômetro para ensaio de tração. 
Foram realizados os ensaios monotônicos a fim de se determinar: o módulo de elasticidade $(E)$, o coeficiente de Poisson, a tensão de escoamento e o limite de resistência à tração.

Os ensaios cíclicos para fluência foram realizados executando o controle de força por meio da máquina de ensaio. Este tipo de ensaio além auxiliar nas análises das curvas carga-deslocamento, tensão-deformação, também auxilia na definição mais precisa do instante em que o material perde a linearidade de resposta, com isso, tem-se a definição do módulo de elasticidade e a flexibilidade à fluência que é dada em função do tempo (creep compliance, $\mathrm{D}(\mathrm{t}))$. Esta flexibilidade admite que a deformação após um dado tempo $\left(\varepsilon_{(\mathrm{t})}\right)$ seja relacionada à tensão aplicada, para um material viscoelástico, através da seguinte expressão:

$$
\varepsilon_{(\mathrm{t})}=\mathrm{D}(\mathrm{t}) \sigma
$$

O fundamento da teoria da viscoelasticidade é baseado no princípio da superposição de Boltzmann (YOUNG e LOVELL, 1991). A hipótese básica, desse princípio, é que durante a deformação viscoelástica na qual a tensão aplicada é variada periodicamente, a deformação total pode ser determinada pela soma algébrica das deformações, produzida para cada passo de carga.

O uso do princípio da superposição pode ser demonstrado por considerar a deformação de creep causada por uma série de passos de carga, Figura 3.5.

Havendo um incremento de tensão aplicado em um tempo $\tau_{1}$, então a deformação devido a este incremento no tempo " $\mathrm{t}$ " é dada por:

$$
\varepsilon_{1}(\mathrm{t})=\Delta \sigma \mathrm{D}(\mathrm{t})\left(\mathrm{t}-\tau_{1}\right)
$$

No caso em que mais incrementos de tensão (positivo ou negativo) forem aplicados, então o princípio assume que a contribuição de cada incremento (i) de deformação é aditiva: 


$$
\varepsilon(\mathrm{t})=\sum_{\mathrm{n}=0}^{\mathrm{n}} \mathrm{D}(\mathrm{t}-\tau) \Delta \sigma_{\mathrm{n}}
$$

É possível representar esse somatório na forma integral, tal que:

$$
\varepsilon(\mathrm{t})=\int_{-\infty}^{\mathrm{t}} \mathrm{D}(\mathrm{t}-\tau) \mathrm{d} \sigma(\mathrm{t})
$$

A integral tem seu limite inferior em "- $\infty$ " e o superior em "t". Isto é feito para varrer todo o histórico de deformação viscoelástica ao qual a amostra é submetida, para saber como esse afetará o comportamento subseqüente. Esta equação pode ser usada para determinar a deformação após qualquer histórico geral de carregamento. Frequentemente esse histórico de deformação é expresso como função de $\tau$, com isso têm-se:

$$
\varepsilon(\mathrm{t})=\int_{-\infty}^{\mathrm{t}} \mathrm{D}(\mathrm{t}-\tau) \frac{\mathrm{d} \sigma(\tau)}{\mathrm{d} \tau} \mathrm{d} \tau
$$

O uso do princípio da superposição de Boltzmann pode ser visto pela consideração específica de um simples exemplo. Um caso trivial é o simples passo de carga de $\sigma_{0}$ no tempo $\tau=0$. É evidente, entretanto, que a distensão extra ou a recuperação que resulta de cada evento de carregamento ou descarregamento é independente do histórico de carregamento prévio e é considerado pelo princípio da superposição como uma série de eventos separados, que somados fornecem a deformação total do CDP.

Durante esses ensaios, os CDPs são solicitados de acordo com o seguinte procedimento, Figura 3.5: 
a) A velocidade de aplicação de força igual a 37,5 [N/s] até o CDP atingir patamar ou nível de força especificado (neste caso tem-se 250 [N], para o primeiro patamar);

b) Atingido este patamar, faz-se com que a máquina mantenha o nível de força por um dado intervalo de tempo para, assim, medir parâmetros de fluência associados ao material;

c) Após esse período, reinicia-se o carregamento (ou descarregamento) até outro patamar com a mesma velocidade de carregamento, mantendo o mesmo período de tempo para o processo de fluência;

d) Repetem-se os três passos anteriores até que seja atingida a quantidade de patamares ou ciclos estipulados, onde estes ciclos envolvem carregamento (recarregamento), descarregamento (onde há recuperação do material).

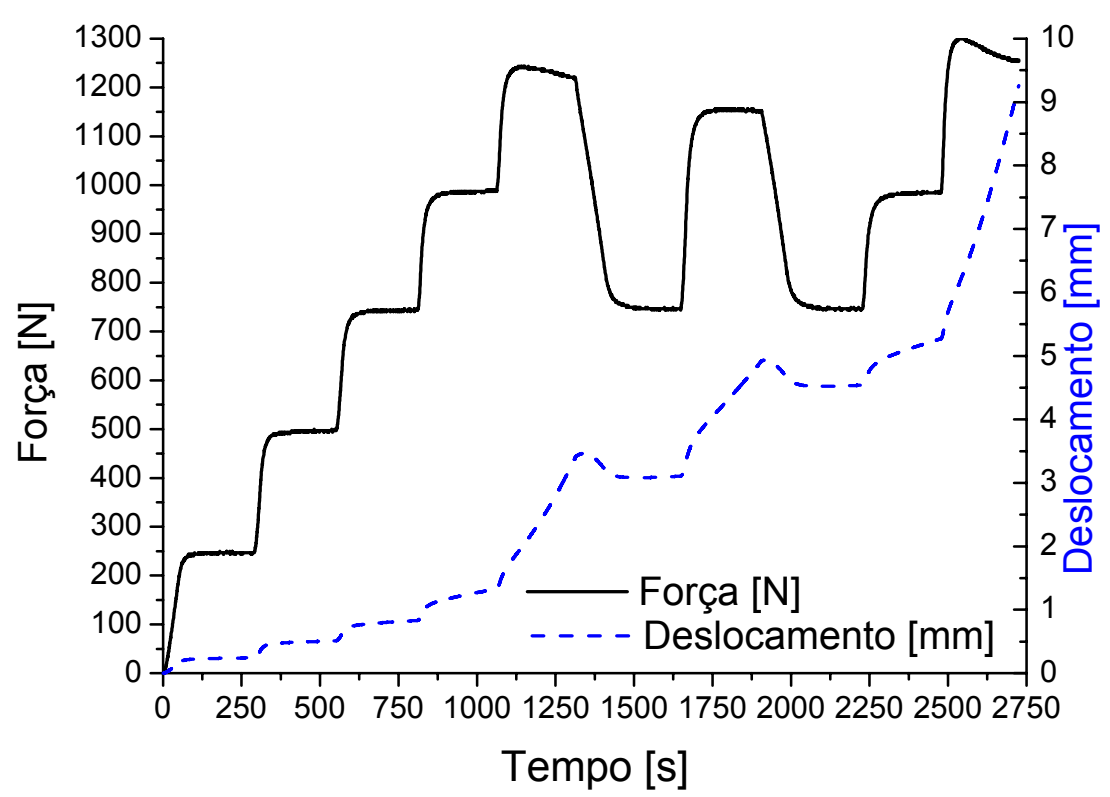

Figura 3.5 - Curva força-tempo-deslocamento segundo carregamento de fluência. 
Os ensaios cíclicos de relaxação foram realizados através do controle interno do deslocamento do travessão da máquina. Durante esses ensaios, os CDPs são solicitados de acordo com o seguinte procedimento, Figura 3.6:

a) O deslocamento do travessão da máquina de ensaio se dá com velocidade igual a $0,8[\mathrm{~mm} / \mathrm{min}]\left(\dot{\varepsilon}=2,67.10^{-4}\left[\mathrm{~s}^{-1}\right]\right)$ até o CDP atingir patamar ou nível de elongação especificado;

b) Atingido este patamar, faz-se com que a máquina mantenha este nível de elongação para, assim, medir parâmetros de relaxação associados ao material por um dado intervalo de tempo até que o nível de força atinja um valor estabelecido;

c) Após este período, reinicia-se o deslocamento do travessão até outro patamar de elongação ou descarregamento do CDP, com a mesma velocidade de ensaio, mantendo o mesmo período de tempo para todos os processos de relaxação;

d) Repetem-se os três passos anteriores até que seja atingida a quantidade de patamares ou ciclos estipulados, onde estes ciclos envolvem carregamento (recarregamento), descarregamento (onde há recuperação do material).

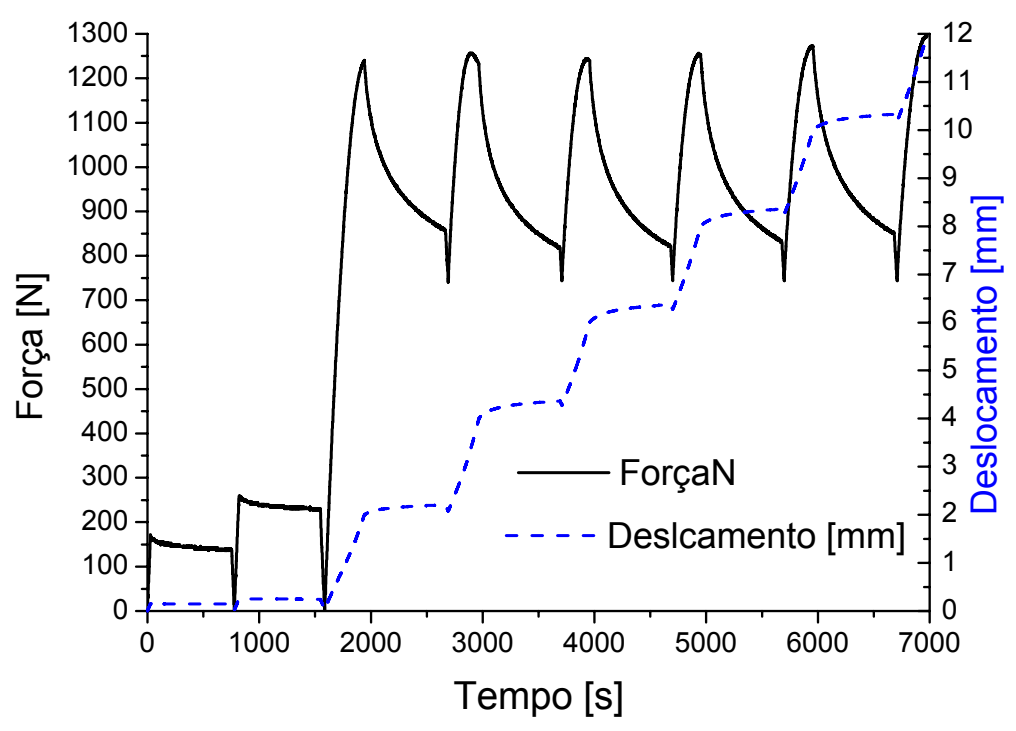

Figura 3.6 - Curva força-tempo-deslocamento segundo carregamento de relaxação. 
Os ensaios para a verificação da energia dissipada foram realizados controlando a máquina através do deslocamento do travessão com velocidade de 0,8 [ $\mathrm{mm} / \mathrm{min}]$, realizando ciclos de carregamento, descarregamento e recarregamento, sem que o material sofra fluência ou relaxação de tensão, de maneira que seja revelada a histerese do material, para que a área dos laços histeréticos seja mensurada. As áreas desses laços revelam a perda de energia por unidade de volume em cada ciclo ( $Q^{*}$, energia dissipada à tração), segundo Meyers e Chawla (1999). Essa energia é dissipada como calor por ciclo, quando o material tem o comportamento elástico essa perda de energia é zero (Figura $3.7 a$ ), porque a trajetória de carregamento é a mesma do descarregamento. Porém, quando o comportamento do material é viscoso há uma perda de energia por ciclo, como ilustra a Figura 3.7b.

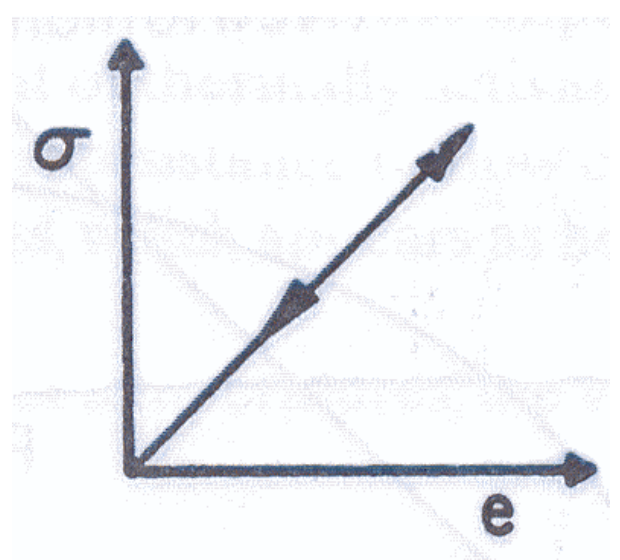

(a) Comportamento elástico

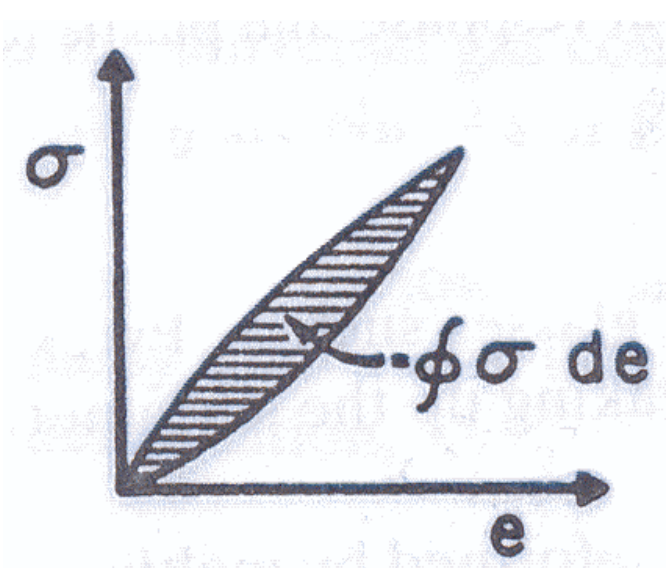

(b) Comportamento viscoso

Figura 3.7- Curva tensão-deformação: (a) sem perda de energia; (b) com perda de energia.

\subsubsection{Ensaio de compressão}

Para o ensaio de compressão foi seguida a ASTM D695-96, a qual sugere o corpode-prova cilíndrico de 12,7 [mm] de diâmetro e 25,4 [mm] de comprimento, Figura 3.8, sob uma velocidade de ensaio de 1,3 [mm/ min]. Após alguns ensaios, essa velocidade foi 
reduzida para 0,8 [mm/min] devido às características viscoelásticas (fluência e relaxação) acentuadas do material.

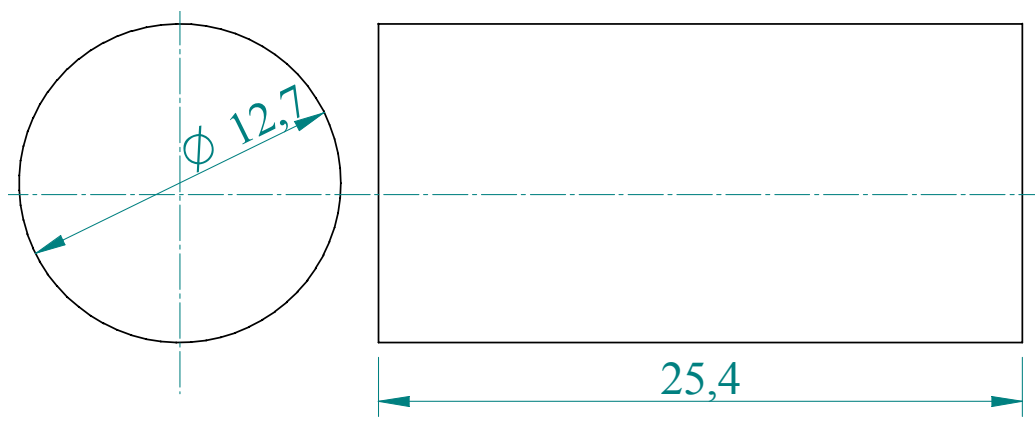

Figura 3.8 - Dimensões do corpo-de-prova de compressão [mm].

Os ensaios foram divididos em quatro modalidades:

$>$ Ensaio monotônico de compressão;

$>$ Ensaio de fluência (creep) a compressão;

$>$ Ensaio de relaxação de tensão (stress relaxation) na compressão;

> Ensaios cíclicos de compressão para avaliação da energia dissipada através da histerese do material.

Os equipamentos utilizados nos ensaios foram: uma máquina EMIC, instalada no Departamento de Materiais, Aeronáutica e Automobilística (EESC - USP), interligada ao sistema de coleta de dados Test Works ${ }^{T M}$. Porém, como a máquina não dispunha de sistema capaz de medir deformação localmente no CDP para o ensaio de compressão (como no caso da tração, para o qual há um extensômetro tipo clipe), a não ser a medida do deslocamento do travessão, fez-se necessário o uso de extensômetros tipo folha (strain gage) com a seguinte classificação: strain gage biaxial KFEL-2-120-D34 e o strain gage uniaxial o KFEL-2-120-C1 (Figura 3.9), que podem medir deformações de até 15\% (KYOWA 2004a, p35). 
Para a aquisição de dados via strain gages foi utilizado um sistema da Hottinger Baldwin Messetechnik GmbH (HBM), modelo MGCplus com AB22A / AB32. Estes strain gages foram colados no sentido longitudinal e no sentido transversal do CDP.

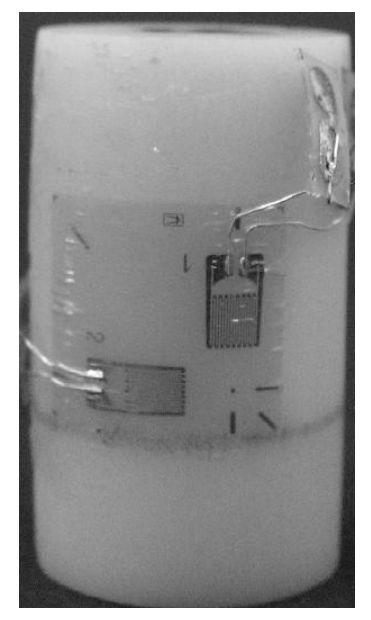

Figura 3.9 - Corpo-de-prova instrumentado com strain gage para ensaio de compressão.

Ressalta-se que os aplicadores de carga de compressão da máquina se mostraram ineficientes para a realização destes ensaios, tendo em vista o embarrilamento e flexão que eram exibidos pelos corpos-de-prova em virtude da rugosidade superficial daqueles aplicadores. Assim, foi etapa fundamental, para obtenção de dados consistentes e livres dos efeitos supracitados, a fabricação de novos aplicadores de carga que atendessem às expectativas, ou seja, minimização do embarrilamento e flexão até o nível de deformação de $15 \%$, limite de medição com strain gages. Porém, ressalta-se que com o auxílio de tal dispositivo, chegou-se à deformação qualitativa de mais de $50 \%$ de deformação, Figura 3.10, medida esta, efetuada através de um paquímetro. 

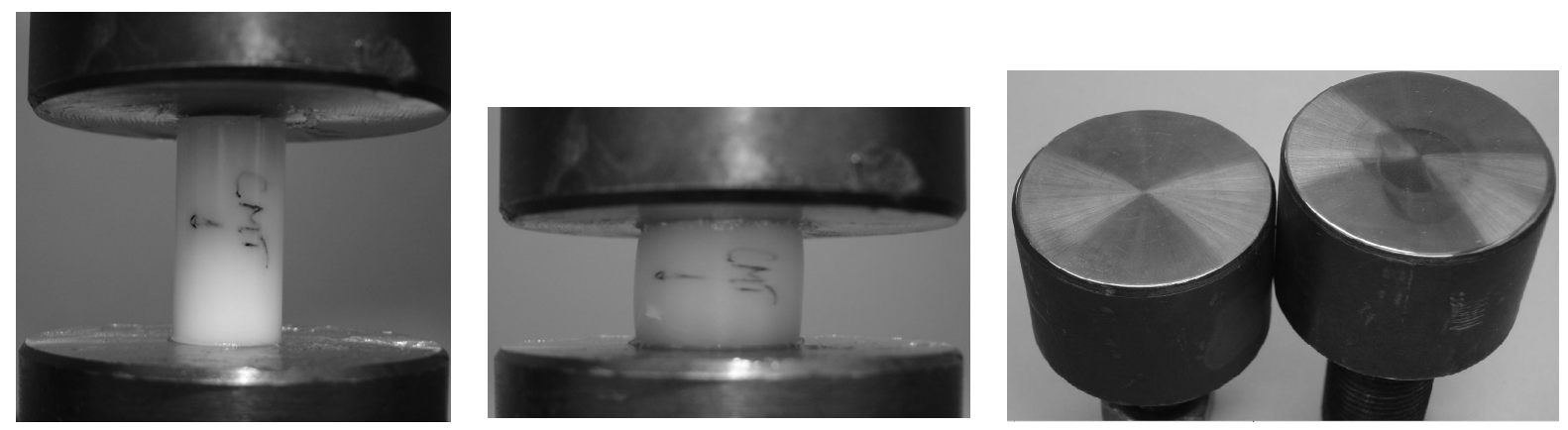

Figura 3.10 - Dispositivo de compressão com superfície específica para este material.

Inicialmente foram realizados os ensaios monotônicos a fim de levantar: o módulo de elasticidade $(E c)$, a tensão de escoamento $\left(\sigma_{e}\right)$ e o limite de resistência à compressão $\left(\sigma_{c}\right)$.

Os ensaios cíclicos de compressão, empregados para medir parâmetros associados à fluência (creep) e a relaxação (stress relaxation), são similares aos ensaios de tração, ou seja, foram seguidos os mesmos procedimentos.

\subsubsection{Ensaio de flexão}

Para o ensaio de flexão por três pontos, foram adotadas as dimensões especificadas pela ASTM D790-96a (Método I), a qual sugere o corpo-de-prova prismático de acordo com a Figura 3.11, porém a velocidade do ensaio foi de $0,8[\mathrm{~mm} / \mathrm{min}]\left(\dot{\varepsilon}=2,67.10^{-4}\left[\mathrm{~s}^{-1}\right]\right)$.

Deve-se ressaltar que as curvas força-deslocamento geradas pelo ensaio de flexão serão utilizadas para validar a consistência do modelo de material em representar o comportamento do biopolímero, não sendo assim empregadas para a caracterização do mesmo, tendo em vista que o ensaio de flexão serve como exemplo de aplicação. 


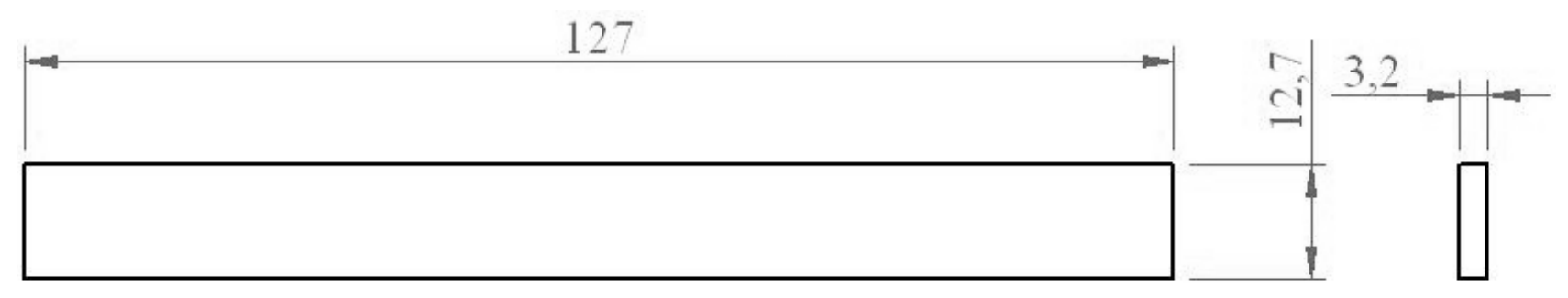

Figura 3.11 - Dimensões do corpo-de-prova de flexão [mm].

Os equipamentos utilizados nos ensaios foram: a máquina EMIC, já mencionada e um LVDT (Linear variable displacement transducer - transdutor de deslocamento linear variável). Cujos dados foram coletados pelo sistema de aquisição da Hottinger Baldwin Messetechnik GmbH (HBM), modelo MGCplus com AB22A / AB32. A montagem do dispositivo de flexão com o LVDT está na Figura 3.12. Este dispositivo foi montado de tal maneira que os apoios distavam 51 [mm] (comprimento útil de medição da flexão) um do outro, sendo que, o ponto de aplicação de carga está no centro desse comprimento e os apoios foram projetados especialmente para a adaptação do LVDT.

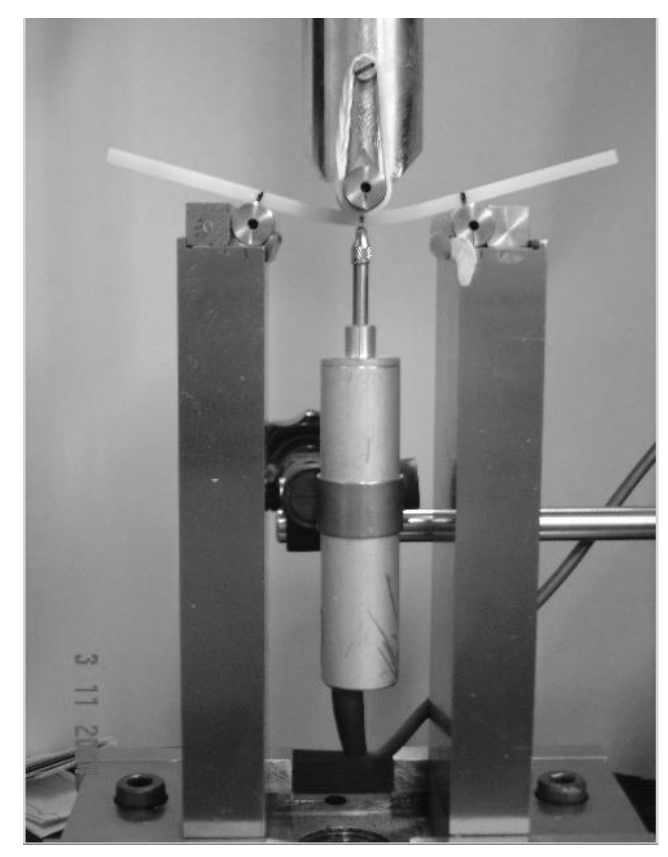

Figura 3.12 - Dispositivo de flexão com LVDT acoplado. 
Além dos ensaios monotônicos de flexão, realizaram-se também ensaios cíclicos segundo os mesmos procedimentos empregados para os ensaios de tração.

O procedimento de cálculo das propriedades do material sob flexão segue a hipótese de Bernoulli-Navier, que a secção inicialmente plana permanece plana e ortogonal ao eixo deslocado. Com isso, pode-se calcular a deformação e a contribuição das tensões de tração (abaixo da linha neutra) e de compressão (acima da linha neutra) no CDP de flexão, Figura 3.12.

O cálculo segue o seguinte procedimento:

a) Tensão devido ao carregamento de flexão $\left(\sigma^{f}\right)$;

$$
\sigma^{f}=\frac{3 P L}{2 b t^{2}}
$$

Sendo que:

$\mathrm{P}=$ carga concentrada no centro do CDP;

$L$ = distância entre os apoios (span);

$\mathrm{t}=$ espessura da amostra

$b=$ largura da amostra

b) Módulo de elasticidade transversal $\left(E^{f}\right)$, devido ao carregamento de flexão;

$$
\mathrm{E}^{\mathrm{f}}=\frac{\mathrm{PL}^{3}}{4 \mathrm{bt}^{3} \mathrm{y}}
$$

Sendo que:

y - a flecha medida pelo LVDT. 
A deformação do CDP sob flexão é dada por:

$$
\varepsilon^{\mathrm{f}}=\frac{\mathrm{PLt}}{8 \mathrm{E}^{\mathrm{f}} \mathrm{I}}
$$

Sendo que:

$\mathrm{I}=$ momento de inércia da viga.

Os ensaios de flexão foram realizados segundo os mesmos procedimentos dos ensaios de tração e compressão, ou seja:

$>$ Ensaios monotônicos de flexão;

D Ensaios cíclicos para avaliação da fluência em flexão;

D Ensaios cíclicos para avaliação da relaxação em flexão.

\subsection{Análise dinâmico-mecânica (Dynamic mechanical analysis - DMA)}

O ensaio de DMA (Dynamic Mechanical Analysis) foi realizado em CDP prismático com $60[\mathrm{~mm}]$ de comprimento, 12,7 [mm] de largura, 3,5 [mm] de espessura e sob uma freqüência de oscilação de $1[\mathrm{~Hz}]$ em temperatura ambiente, sendo as medidas realizadas no equipamento da Dupont Instruments modelo Dyamic mechanical Analyser 983 acoplado ao sistema analisador de dados Thermal Analyst 2000. O CDP foi engastado no "braço motor" e no "braço movido" da máquina de ensaio de DMA, conforme Figura 3.13. Foi empregado um movimento oscilatório senoidal como sinal de entrada do sistema com uma freqüência angular $\omega$ por meio do braço motor, sendo este responsável por gerar uma deformação cisalhante segundo a expressão: 


$$
\gamma=\gamma_{\mathrm{o}} \operatorname{sen}(\omega . \mathrm{t})
$$

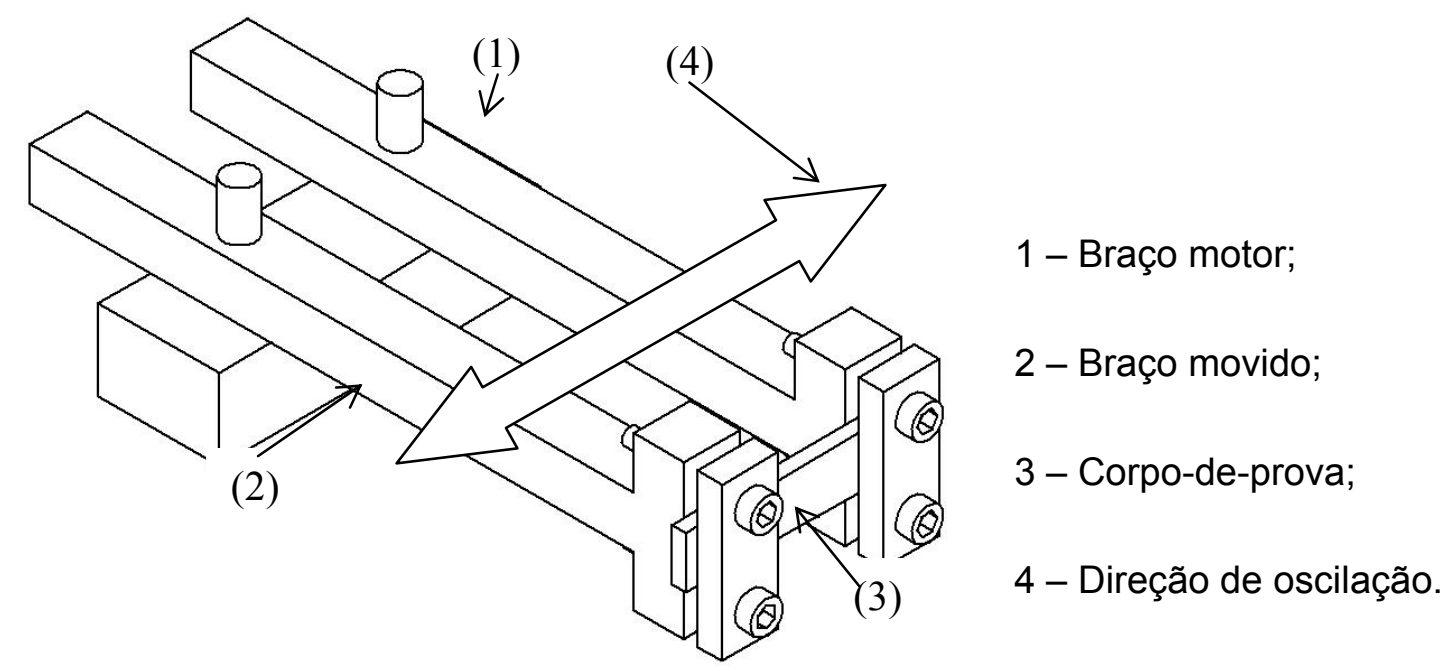

Figura 3.13 - Esquema da máquina de ensaio de DMA.

Obteve-se como sinal de saída uma tensão senoidal, porém fora de fase com a deformação (por um ângulo de fase $\delta$ ), sendo essa tensão expressa por:

$$
\sigma=\sigma_{\mathrm{o}} \operatorname{sen}(\omega \mathrm{t}+\delta)
$$

A defasagem, ou atraso, da deformação em relação à tensão por um ângulo de fase $\delta$ pode ser representado por meio da Figura 3.14.

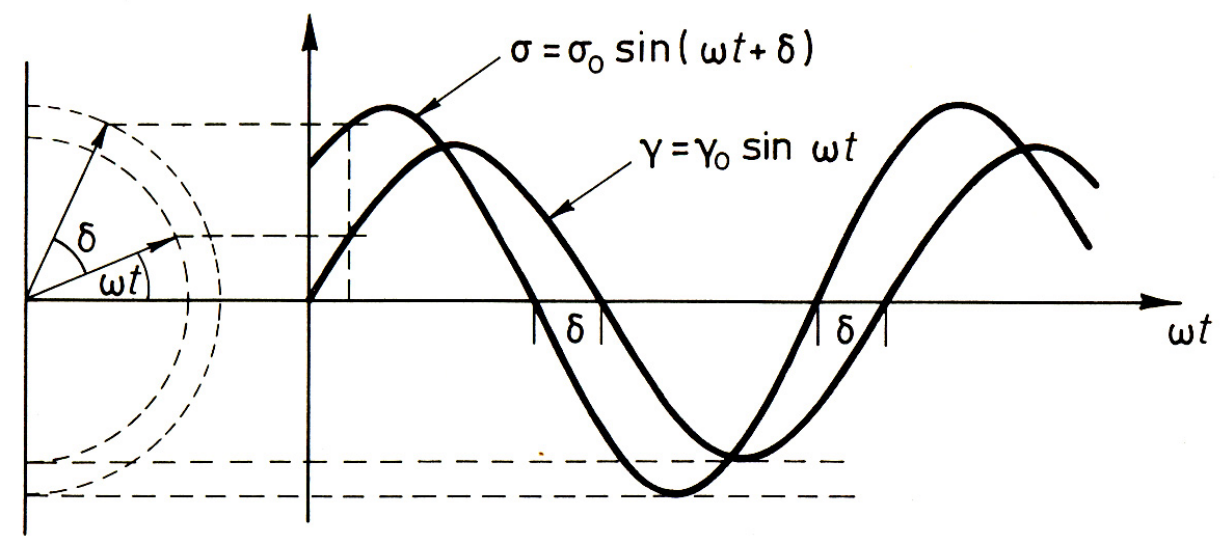

Figura 3.14 - Tensão alternada medida com atraso de um ângulo de fase em relação a uma deformação alternada aplicada (McCRUM et al.,1992). 
Expandindo a equação (3.8), obtêm-se duas componentes da tensão, uma em fase com a deformação $\left(\sigma_{0} \cos \delta\right)$ e a outra defasada em $90^{\circ}\left(\sigma_{0} \operatorname{sen} \delta\right)$ com a deformação.

$$
\sigma=\left(\sigma_{0} \cos \delta\right) \operatorname{sen} \omega t+\left(\sigma_{0} \operatorname{sen} \delta\right) \cos \omega t
$$

A relação entre a tensão e a deformação neste caso dinâmico pode ser definida por:

$$
\sigma=\gamma_{\mathrm{o}}\left[\mathrm{G}^{\prime} \operatorname{sen} \omega \mathrm{t}+\mathrm{G}{ }^{\prime} \cos \omega \mathrm{t}\right]
$$

Sendo que:

$$
\begin{aligned}
& G^{\prime}=\frac{\sigma_{0}}{\gamma_{0}} \cos \delta \\
& G^{\prime \prime}=\frac{\sigma_{0}}{\gamma_{0}} \sin \delta
\end{aligned}
$$

Assim, separaram-se os módulos de elasticidade e de cisalhamento em parte real (E' ou G', em fase) e complexa (E” ou G”, imaginária, fora de fase), sendo que a componente em fase é o módulo de armazenamento devido a característica elástica e a componente fora de fase é o módulo de perda devido a característica viscosa. Dentre essas propriedades, elásticas e viscosas (complexas), pode ser determinado o fator de dissipação ou tangente

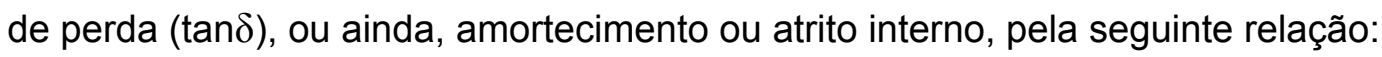

$$
\tan \delta=\frac{E^{\prime \prime}}{E^{\prime}}=\frac{G^{\prime \prime}}{G^{\prime}}
$$

Finalmente, é exposta na Tabela 3.1 uma série de relações possíveis para os cálculos das propriedades viscoelásticas que podem ser obtidas por meio desse ensaio. 
Tabela 3.1 - Relações para a determinação das propriedades viscoelásticas.

\begin{tabular}{|c|c|c|}
\hline Propriedade Visco-Elástica & Parcela Real (Elástica) & Parcela Imaginária (Viscosa) \\
\hline Módulo de Elasticidade & $\mathrm{E}^{\prime}=|\sigma / \varepsilon| \cos \delta$ & $\mathrm{E}^{\prime \prime}=|\sigma / \varepsilon| \operatorname{sen} \delta$ \\
\hline Módulo ao Cisalhamento & $\mathrm{G}^{\prime}=|\tau / \gamma| \cos \delta$ & $\mathrm{G}^{\prime \prime}=|\tau / \gamma| \operatorname{sen} \delta$ \\
\hline \multirow{2}{*}{ Flexibilidade } & $\mathrm{D}^{\prime}=|\varepsilon / \sigma| \cos \delta$ & $\mathrm{D}^{\prime \prime}=|\varepsilon / \sigma| \operatorname{sen} \delta$ \\
\cline { 2 - 3 } & $\mathrm{D}^{\prime}=\mathrm{E}^{\prime} /\left(\mathrm{E}^{\prime 2}+\mathrm{E}^{\prime \prime^{2}}\right)$ & $\mathrm{D}^{\prime \prime}=\mathrm{E}^{\prime \prime} /\left(\mathrm{E}^{\prime 2}+\mathrm{E}^{\prime 2}\right)$ \\
\hline
\end{tabular}

O equipamento utilizado nos ensaios foi um analisador da Du Pont Instruments modelo DMA983 interligado a um sistema de coleta de dados, os quais estão instalados no Instituto de Química de São Carlos da Universidade de São Paulo (Departamento de Química e Física Molecular).

Por fim, deve-se destacar que o equipamento de DMA também possibilita a realização de ensaios de Fluência e de Relaxação de tensão.

\subsection{Metodologia empregada na simulação numérica}

Após finalizar os ensaios quase-estáticos e dinâmicos, seguiram-se as simulações computacionais via elementos finitos. As simulações foram realizadas empregando o programa comercial ABAQUS ${ }^{\circledR}$ versão 6.5.

Os resultados numéricos foram confrontados com os experimentais, a fim de verificar as potencialidades e limitações dos modelos de material implementados no programa comercial ABAQUS $^{\circledR}$ versão 6.5 para representar o comportamento do polímero da mamona frente às solicitações de ensaio de tração e compressão, monotônicos e cíclicos. Detalhes sobre a comparação entre resultados computacionais e experimentais são apresentados no Capítulo 4. 


\subsubsection{Metodologia empregada na simulação do ensaio de tração}

Com o intuito de simular os ensaios de tração na região de medição tais como foram realizados, inicialmente baseou-se nas medidas de deformações efetuadas com extensômetro que cobria uma região de 50 [mm] (gage length). Isto fez com que na simulação do modelo do CDP fosse contemplada somente a região coberta pelo extensômetro durante o ensaio. Então, devido à simetria do modelo do corpo-de-prova considerou-se apenas $1 / 8$ da região de ensaio, ou seja, metade do comprimento (25 [mm]), metade da largura $(6,5[\mathrm{~mm}])$ e metade da espessura $(1,65[\mathrm{~mm}])$, aplicando as condições de contorno apropriadas, Figura 3.16. Dessa forma, foi possível utilizar na simulação os dados de deformação dos CDPs obtidos com base nos extensômetros. Também, para que a simulação pudesse refletir o comportamento de estricção do CDP, fez-se uma redução no sentido da largura como mostrado na Figura 3.15.

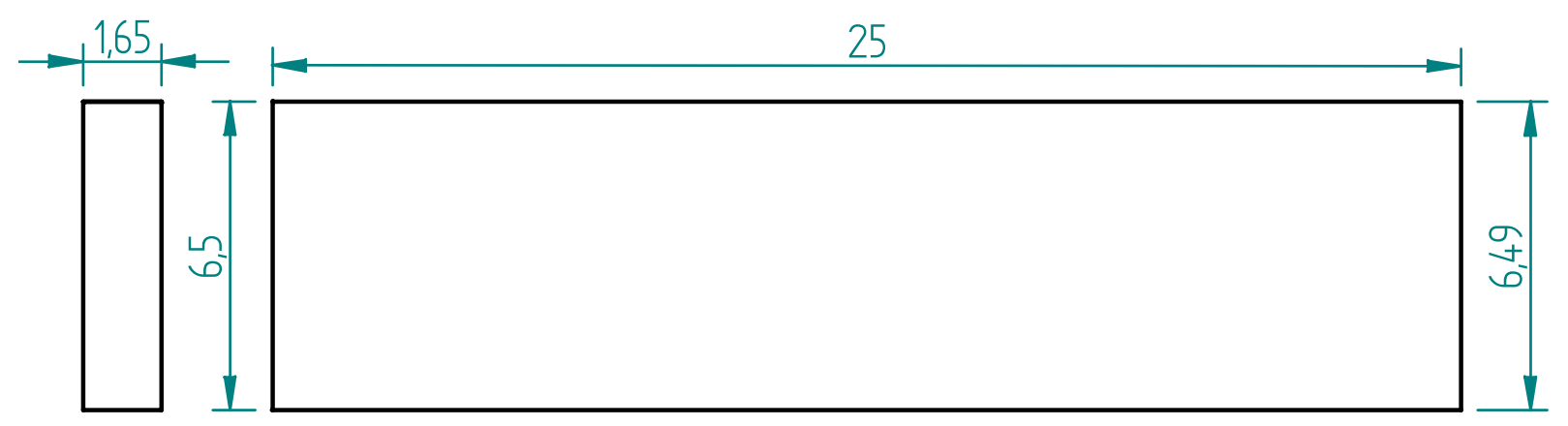

Figura 3.15 - Porção do CDP de tração utilizado na simulação.

O modelo de tração é constituído por elementos do tipo C3D8R, ou seja, são elementos tridimensionais retangulares que possuem 8 nós e 3 graus de liberdade cada um (translação em x, y e z coordenadas globais), bem como, interpolação linear, Figura 3.16. 


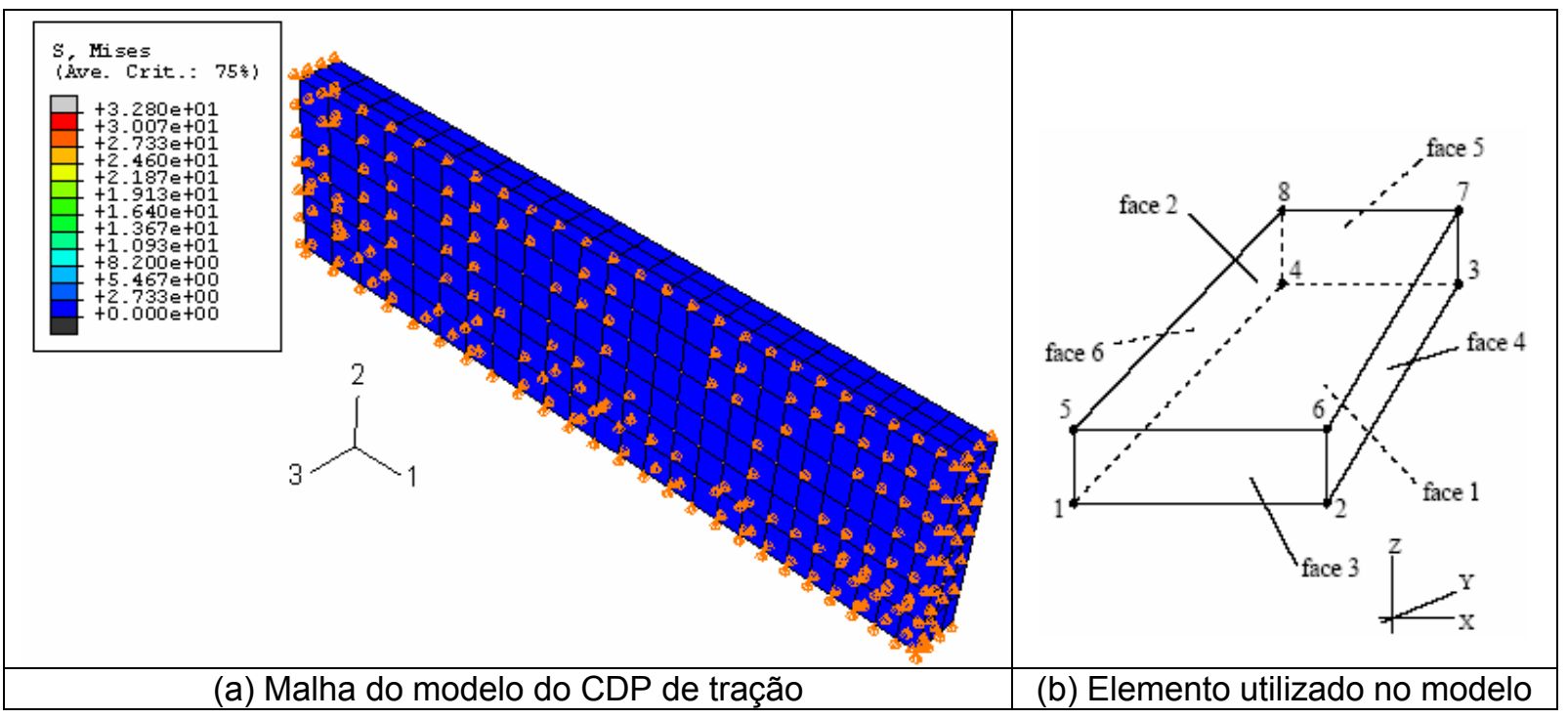

Figura 3.16 - Modelo empregado no CDP de tração.

A escolha desse elemento permitiu o uso da integração reduzida, a qual tem algumas vantagens, tais como: as deformações e tensões são calculadas nas localizações que provêem uma ótima exatidão; o número reduzido de pontos de integração diminui o tempo de CPU e o tamanho de armazenamento. A desvantagem é que o procedimento de integração reduzida pode admitir modos de deformação que não cause deformação nos pontos de integração, esses modos criam elementos com posição deficiente e causa um fenômeno chamado de "hourglassing", esse fenômeno promove a propagação da deformação através da malha o que leva a solução inexata. Por isso, para prevenir estas deformações excessivas foi escolhido, no momento de configurar a simulação, o controle "hourglass" que promove uma pequena rigidez artificial ao elemento. 


\subsubsection{Metodologia empregada na simulação do ensaio monotônico de tração}

Para a simulação foram tomados os resultados provenientes dos ensaios monotônicos medidos com extensômetro, para tanto, procedeu-se da seguinte forma para estabelecer os parâmetros necessários:

a) Foram utilizados dois modelos de plasticidade: 1) o modelo clássico de plasticidade em metais, usando a superfície de escoamento de von Mises para encruamento isotrópico; 2) o modelo de Drucker-Prager;

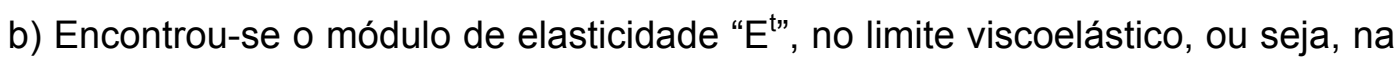
iminência em que a curva tensão-deformação perde completamente a linearidade, ponto "A" na Figura 3.17;

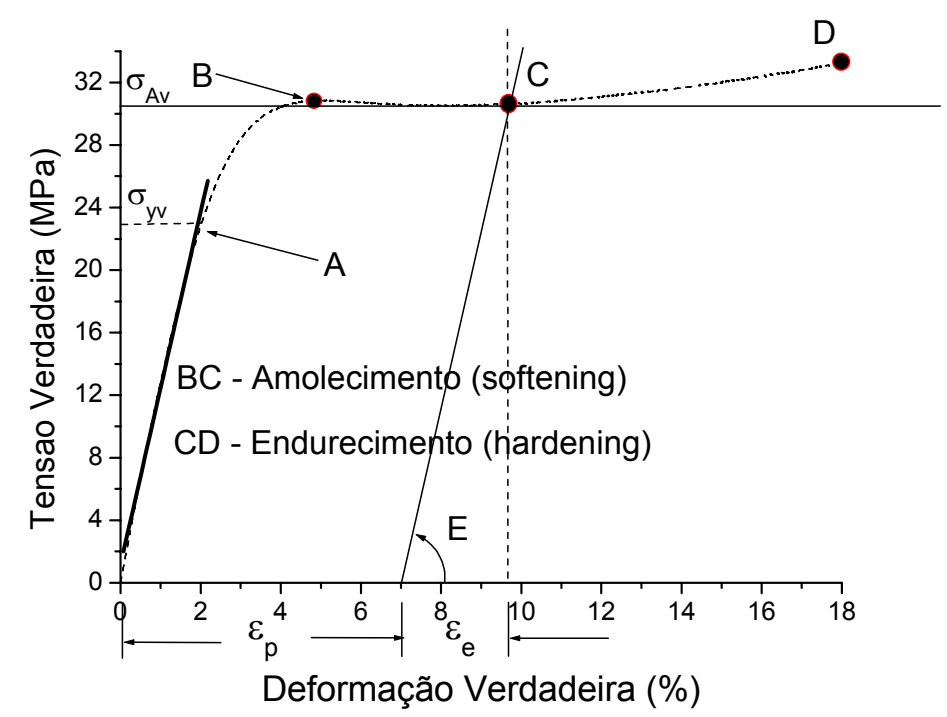

Figura 3.17 - Determinação do módulo de elasticidade.

c) O coeficiente de Poisson foi obtido por meio da razão entre a deformação transversal e a deformação longitudinal, as quais foram obtidas inicialmente com 
extensômetros da máquina de ensaio universal Instron 5500R (instalada no DEMA) e posteriormente com auxílio dos strain gages;

d) A determinação da deformação plástica se deu por meio da equação: $\varepsilon_{\mathrm{p}}=\varepsilon_{\mathrm{t}}-\varepsilon_{\mathrm{e}}$. Sendo que $\varepsilon_{\mathrm{e}}=\sigma_{\mathrm{Av}} / \mathrm{E}^{\mathrm{t}}$. Onde $\sigma_{\mathrm{Av}}$ é a tensão verdadeira atuante (encruamento); $\varepsilon_{t}$ é deformação verdadeira total medida aplicada no modelo de von Mises, enquanto que para o modelo de Drucker-Prager os dados utilizados foram os do início do escoamento, ou seja, quando a tensão atingiu $\sigma_{\mathrm{yv}}$;

e) O preenchimento da tabela de entrada de dados do ABAQUS refere-se à deformação plástica, com isso, seguiu-se a equação do item anterior, ou seja, preenche a tabela apenas com os dados plásticos escolhendo-se alguns pontos da curva tensão-deformação, excluindo a parcela do amolecimento (softening), quando a simulação do comportamento elasto-plástico. Fez-se uma idealização para a obtenção dos dados de acordo com a Figura 3.17, na qual estão evidenciados os pontos C-D que delimitam a curva idealizada que exprime os dados elásticos e plásticos necessários para a simulação;

f) As condições de contorno foram aplicadas nas devidas faces $(1,2,3,4)$ da Figura 3.18, para que as condições de simetria fossem válidas e não permitisse movimento de corpo rígido, assim, as condições de contorno foram distribuídas nas faces do CDP da seguinte forma: face (1) não era permitida se deslocar na direção (1); face (2) não era permitida se deslocar na direção (2); face (3) não era permitida se deslocar na direção (3) e na face (4) impôs-se o deslocamento prescrito de 4 [mm] na direção (1); 


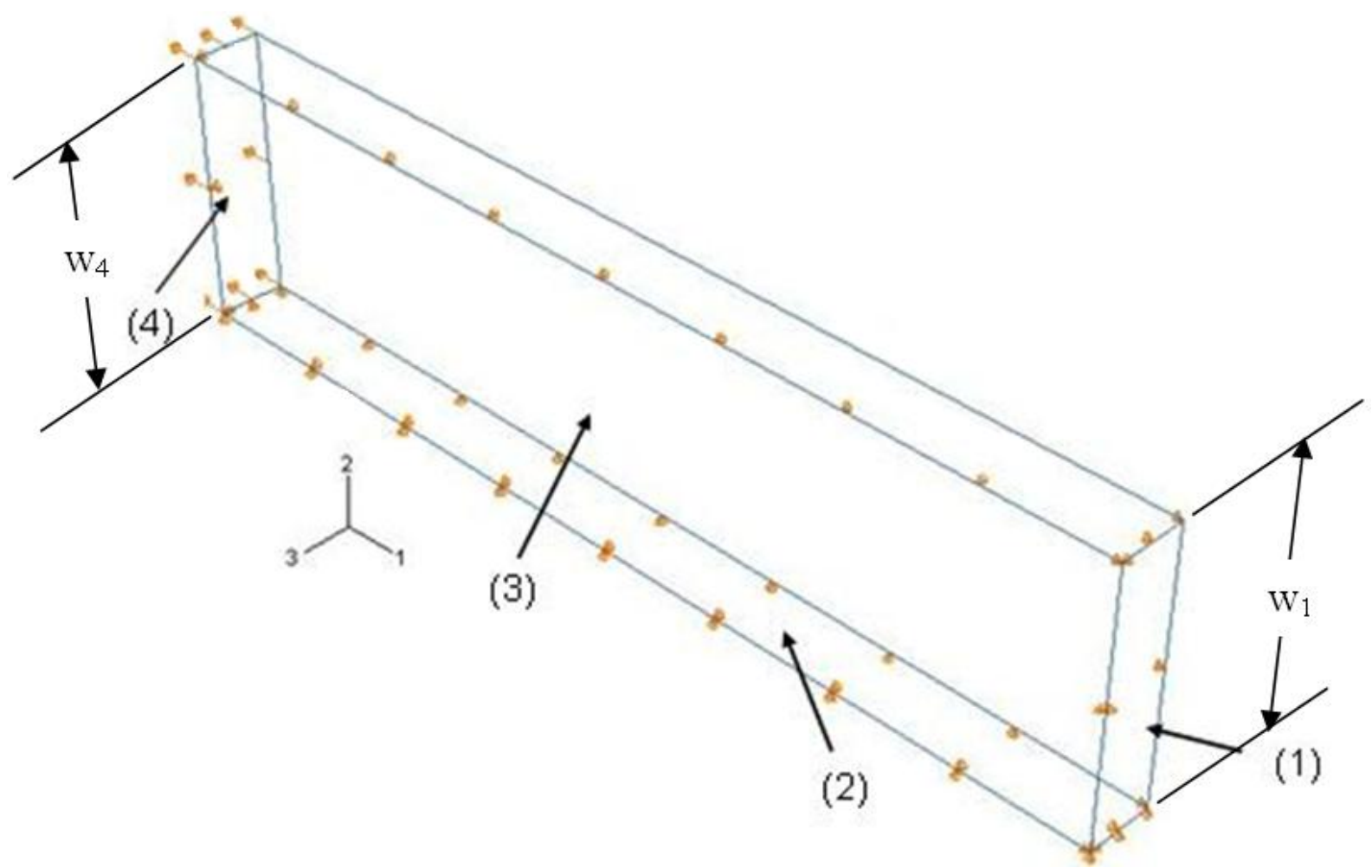

Figura 3.18 - Corpo-de-prova com as condições contorno aplicadas.

g) Para que houvesse a simulação do efeito da estricção se fez necessária uma redução na largura do modelo do CDP, no sentido da face (4) para face (1) (Figura 3.18), a qual passou de 6,50 [mm] $\left(\mathrm{w}_{4}\right)$ para 6,49 $[\mathrm{mm}]\left(\mathrm{w}_{1}\right)$.

Em seguida foram realizadas outras simulações para a verificação do modelo viscoplástico existente no $A B A Q U S^{\circledR}$, para tais simulações foram necessários os seguintes dados:

1- As propriedades elásticas de tração, $E^{t}$ e v;

2- As propriedades plásticas, ou seja, tensão e deformação no regime plástico com encruamento isotrópico;

3- Os parâmetros viscosos ("A", "n", "m" e "f") são definidos por meio de calibração. A calibração para os três primeiros parâmetros é feita através de tentativa, sendo que: o parâmetro " $A$ " para este modelo tem unidade [Newton.metro.segundo] e os parâmetros "n" e "m" são constantes. O parâmetro "f" é calibrado através da realização de ensaio do material sob várias taxas de 
deformação (Figura 4.1). Isto se fez necessário para determinar o momento no qual o módulo instantâneo não mais variava $\left(E=E^{e}+E^{v}, E^{e}\right.$ é o módulo elástico e $\mathrm{E}^{\mathrm{v}}$ é o módulo viscoso). Na Figura 4.1, considerando-se como referência a curva sob a taxa de deformação de $2,67.10^{-4}\left[\mathrm{~s}^{-1}\right](0,8$ [mm/min]) para um módulo instantâneo " $E$ "' igual a 1,47 [GPa] e a curva com taxa de deformação de $0,133\left[\mathrm{~s}^{-1}\right]$ (400 [mm]/min) como a taxa mais elevada cujo módulo instantâneo foi de 1,64 [GPa]. Escolheu-se o modelo viscoplástico, utilizando a lei de deformação (Law strain). O valor de "f" é determinado pela seguinte expressão

$$
f=\frac{E-E^{e}}{E}
$$

\subsubsection{Metodologia empregada na simulação do ensaio cíclico de fluência em tração}

Para a simulação do ensaio de fluência em tração, primeiramente foram analisados os 3 modelos de Drucker-Prager creep implementados no programa ABAQUS ${ }^{\circledR}$, segundo Hibbitt et al(2002):
a) Time hardening (encruamento por tempo);
b) Strain hardening (encruamento por deformação);
c) Singh-Mitchell. 
Para a verificação de quanto esses modelos eram capazes de representar o comportamento do material frente às solicitações de fluência, necessitou-se dos seguintes dados:

a) As propriedades elásticas de tração, E e v;

b) Os parâmetros de Drucker-Prager, ou seja, o ângulo de atrito, a razão da tensão de fluxo (para o caso de fluência é indicado que a razão da tensão de fluxo "K" seja igual a 1) e o ângulo de dilatação $(\psi)$, que no caso é igual ao ângulo de atrito ( $\beta$ ) para o caso de fluxo associado;

c) O critério de cisalhamento configurado para linear, sendo que a opção padrão implica em ter o critério de plastificação de Drucker-Prager para escoamento linear, requerido na utilização do comportamento de fluência;

d) A excentricidade do potencial de fluxo igual a 0,1, para quando o modelo é exponencial e o fluxo é associado. A excentricidade significa a taxa com que a curva se aproxima da assíntota.

Para Drucker-Prager creep time hardening, o modelo é expresso da seguinte forma:

$$
\dot{\varepsilon}^{c r}=A \cdot\left(\sigma^{c r}\right)^{n} t^{m} \rightarrow \varepsilon^{c r}=A \cdot\left(\sigma^{c r}\right)^{n} \frac{t^{m+1}}{m+1}+\varepsilon_{0}^{c r}
$$

Sendo os coeficientes $A, n$ e $m$ ajustados pelo usuário para que a curva teórica levantada pelo modelo se aproxime o máximo possível da curva experimental. Esse ajuste se deu segundo o procedimento ilustrado pela Figura 3.19. 


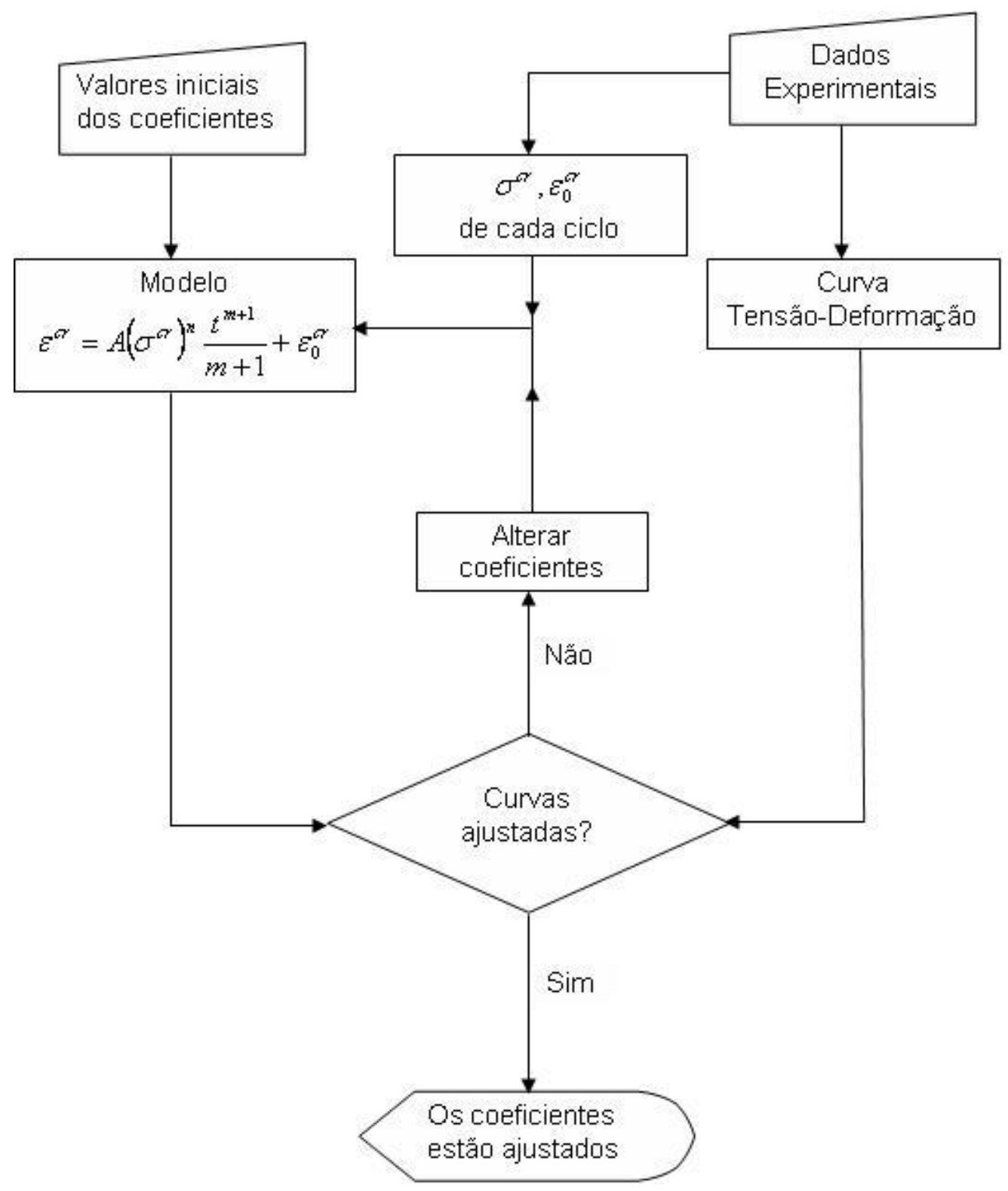

Figura 3.19 - Procedimento de ajuste dos coeficientes ao modelo de Drucker-Prager.

Para Drucker-Prager creep strain hardening, tem-se um modelo que é uma forma alternativa de representar o modelo anterior. O modelo para o strain hardening é expresso da seguinte forma:

$$
\dot{\varepsilon}^{c r}=\left[A \cdot\left(\sigma^{c r}\right)^{n}\left((m+1) \varepsilon^{c r}\right)^{m}\right]^{\frac{1}{1+m}} \rightarrow \varepsilon^{c r}=\left[A \cdot\left(\sigma^{c r}\right)^{n}\left((m+1) \varepsilon^{c r}\right)^{m}\right]^{\frac{1}{1+m}} \cdot t
$$


Sendo os coeficientes $A, n$ e $m$ ajustados para que a curva teórica levantada pelo modelo se aproxime o máximo possível da curva experimental. Esse ajuste se deu segundo o procedimento ilustrado pela Figura 3.19.

Para Drucker-Prager Singth-Mitchell, o modelo é expresso da seguinte forma:

$$
\dot{\varepsilon}^{c r}=A \cdot e^{\left(\alpha \sigma^{c r}\right)}\left(\frac{t_{1}}{t}\right)^{m} \rightarrow \varepsilon^{c r}=\frac{A \cdot e^{\left(\alpha \sigma^{c r}\right)} t_{1} \cdot t^{1-m}}{1-m}+\varepsilon_{0}^{c r}
$$

Sendo os coeficientes $A\left[s^{-1}\right], \alpha\left[N^{-1} m^{2}\right], m$ [cte] e $t_{1}[s]$ ajustados para que a curva teórica levantada pelo modelo se aproxime o máximo possível da curva experimental. Esse ajuste, também, deu-se segundo o procedimento ilustrado pela Figura 3.19. Destaca-se que o tempo inicial $\left(t_{1}\right)$ deve ser menor do que a soma dos tempos de duração de todos os patamares.

Em seguida foram realizadas outras simulações para a verificação do modelo viscoelástico existente no $A B A Q U S^{\circledR}$, para tais simulações foi necessário os seguintes dados:

a) As propriedades elásticas de tração, E e v;

b) Escolheu-se o modelo Viscoelástico no domínio do tempo, sendo que a outra opção era no domínio da freqüência;

c) Os dados de ensaio para implementação no programa, para simular o efeito viscoelástico, foram os tempos de duração de cada passo de carga e a flexibilidade (flexibilidade normalizada), a qual foi calculada segundo o ensaio de fluência à tração;

d) Os passos de carga da simulação foram configurados de acordo com a quantidade de passos realizados durante o ensaio, porém, para a análise dos 
resultados computacionais, consideraram-se apenas os passos dentro do regime viscoelástico, por causa do modelo utilizado.

\subsubsection{Metodologia empregada na simulação do ensaio de compressão}

Inicialmente o modelo de compressão era sólido, com elemento hexaédrico C3D8R, no qual a dimensão do modelo do CDP era 25,4 [mm] de altura e 12,7 [mm] de diâmetro. Porém, em virtude do gasto computacional e da simetria do CDP, optou-se por um modelo axissimétrico com elementos CAX4R (quadrilátero axissimétrico bilinear com 4 nós, que possui integração reduzida e controle de hourglass). O elemento CAX4R possui dois graus de liberdade por nó (translação na direção radial e na direção axial). Assim, o modelo possui simetria no eixo de giração, com 25,4 [mm] de altura e 6,35 [mm] de raio, como pode ser visto na Figura 3.20.

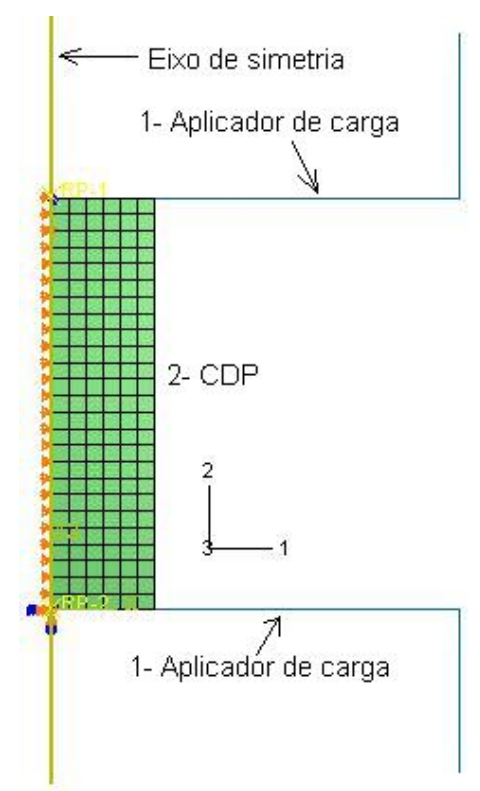

Figura 3.20 - Malha do modelo do CDP de compressão. 


\subsubsection{Metodologia empregada na simulação do ensaio monotônico de compressão}

Para a simulação do ensaio de compressão foram tomados os resultados provenientes dos ensaios monotônicos medidos com strain gages, para tanto, procedeu-se da seguinte forma para estabelecer os parâmetros necessários:

a) Encontrou-se o módulo de elasticidade à compressão " $E_{c}$ ", no limite viscoelástico, ou seja, na iminência em que a curva tensão-deformação perde completamente a linearidade, ponto "A" na Figura 3.21;

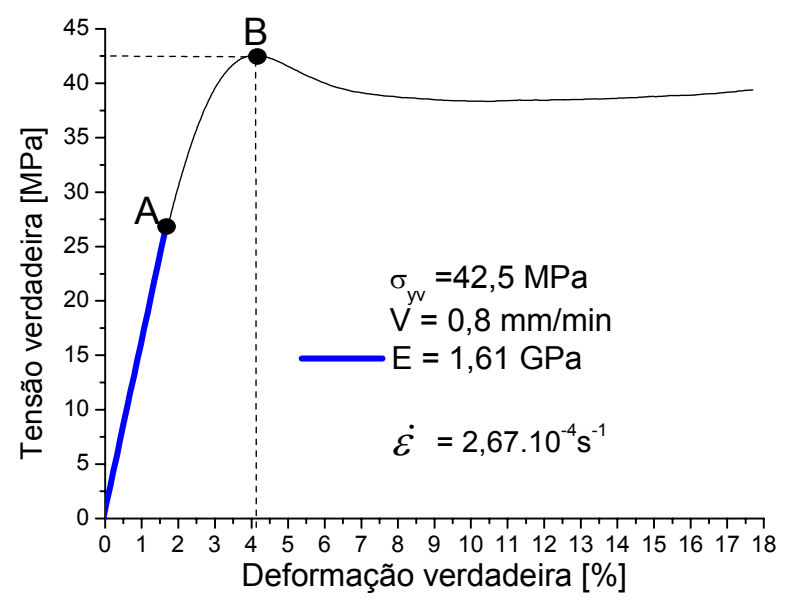

Figura 3.21 - Determinação do módulo de elasticidade.

b) O coeficiente de Poisson foi obtido por meio da razão entre a deformação transversal e a deformação longitudinal, as quais foram obtidas através dos strain gages; 
c) A determinação da deformação plástica de compressão se deu por meio da equação: $\varepsilon_{p}^{c}=\varepsilon_{t}-\varepsilon_{e}^{c}$. Onde $\varepsilon_{e}^{c}=\frac{\sigma_{y v}^{c}}{E_{c}}$. Onde $\sigma_{y v}^{c}$ (ponto B) é a tensão verdadeira de escoamento a compressão; $\varepsilon_{\mathrm{t}}$ é deformação verdadeira total;

d) O preenchimento da tabela de entrada de dados do ABAQUS refere-se à deformação plástica, com isso, seguiu-se a equação do item anterior, ou seja, preenche-se a tabela apenas com os dados plásticos escolhendo-se alguns pontos da curva tensão-deformação, excluindo a parcela do softening, essa curva foi idealizada como no Item 3.4.1.1.

As condições de contorno foram aplicadas nas devidas faces $(1,2,3,4,5)$ da Figura 3.22, para que as condições de simetria fossem válidas e não permitisse movimento de corpo rígido, assim, as condições de contorno foram distribuídas nas faces do CDP da seguinte forma:

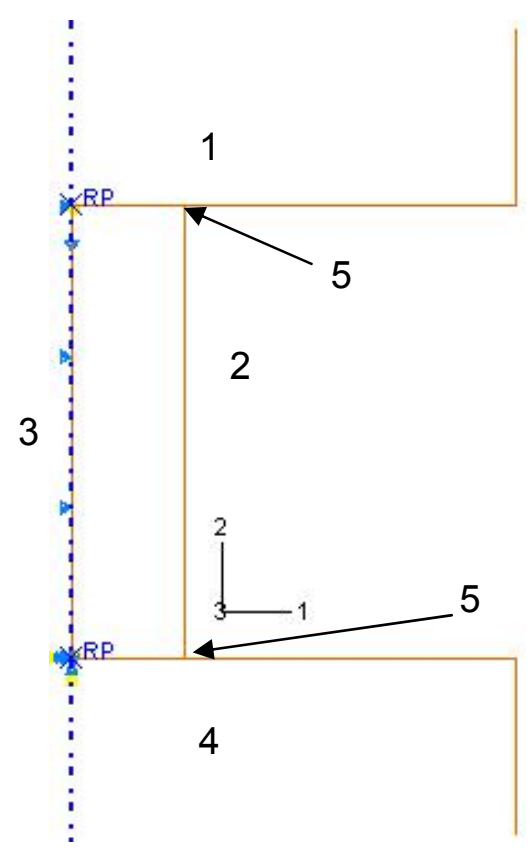

Figura 3.22 - Aplicador de carga, CDP de compressão e condições de contorno. 
a) $\mathrm{Na}$ face (1) do aplicador aplicou-se o deslocamento prescrito de -14 [mm] na direção (2) aplicado no ponto de referência e nas outras direções $(1,3)$ restringiuse o movimento, destaca-se também, que os aplicadores foram considerados como superfícies rígidas;

b) A face (2) foi isenta de restrição, podendo expandir na direção (1) e contrair na direção (2);

c) Na face (3) aplicou-se a condição de simetria e restrição de deslocamento na direção (1);

d) Na face (4) do aplicador, impôs-se deslocamento zero nas três direções;

e) $\mathrm{Na}$ interface (5), ou seja, entre o aplicador de carga e o CDP foi imposta uma condição de contato entre o modelo do CDP e os modelos dos aplicadores, ou seja, uma condição de contato tangencial que simulasse o atrito entre as partes. Com isso, foram configurados os coeficientes de atrito estático $(\mu \mathrm{e})$ e cinemático $(\mu \mathrm{c})$, bem como a taxa de decaimento de acordo com o modelo do coeficiente de atrito com decaimento exponencial, representado na equação (3.18) (Figura 3.23). Esses parâmetros do modelo de atrito foram determinados pelo método da tentativa-erro, ou seja, calibrou-se os valores desses parâmetros, analisando a resposta simulada qualitativamente, quanto ao embarrilamento. Porém, isso não é suficiente para a análise, uma vez que o objetivo são os dados mensuráveis, tais como tensão-deformação, força-deslocamento. Portanto, a determinação dos parâmetros de atrito da simulação seguiu a análise comparativa das curvas de força-deslocamento numéricos e experimentais, visando minimizar a diferença entre ambas.

$$
\mu=\mu_{c}+\left(\mu_{e}-\mu_{c}\right) e^{-d_{c} \gamma_{e q}}
$$




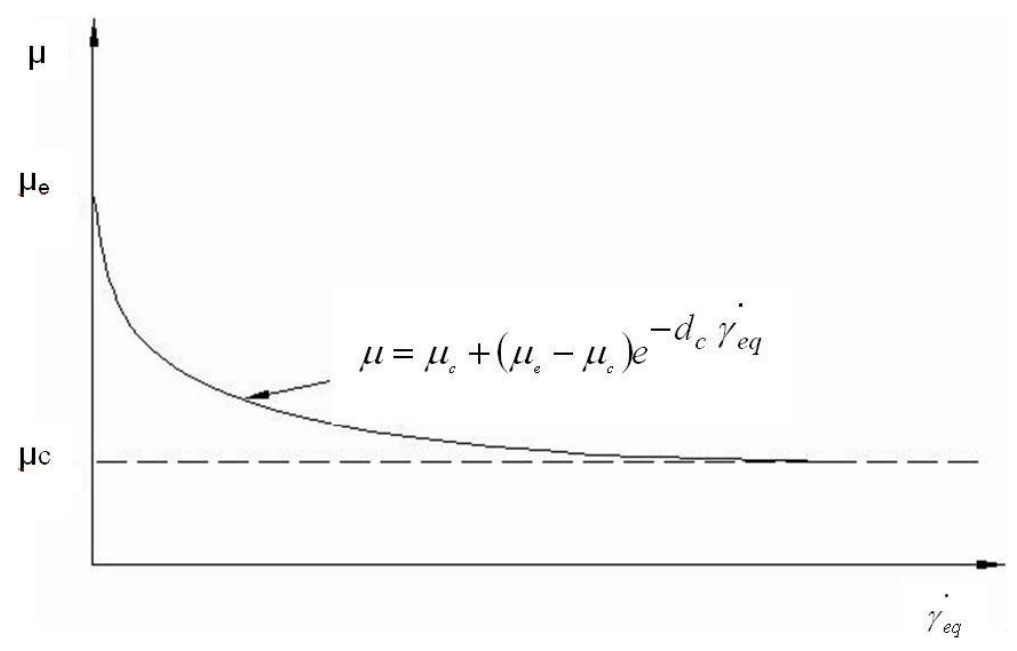

Figura 3.23 - Curva do coeficiente de atrito pela taxa de escorregamento; HIBBIT et al (2000).

\subsubsection{Metodologia empregada na simulação do ensaio cíclico de compressão}

Para a simulação do ensaio de fluência em compressão, primeiramente foram analisados os 3 modelos de Drucker-Prager creep implementados no programa ABAQUS:

1. Encruamento por tempo (Time hardening);

2. Encruamento por deformação (Strain hardening);

3. Singh-Mitchell.

Para a verificação de quanto esses modelos eram capazes de representar o comportamento do material frente às solicitações de fluência em compressão, necessitou-se dos seguintes dados:

1- As propriedades elásticas de compressão, $E_{c}$ e $v$;

2- Os parâmetros de Drucker-Prager, ou seja, o ângulo de atrito, a razão da tensão de fluxo (para o caso de fluência é indicado que a razão da tensão de 
fluxo "K" = 1) e o ângulo de dilatação, que no caso é igual ao ângulo de atrito para o caso de fluxo associado;

3- O critério de cisalhamento configurado para linear (que é a opção padrão) implica em ter o critério de plastificação de Drucker-Prager para escoamento linear, requerido na utilização do comportamento de fluência;

4- A excentricidade do potencial de fluxo igual a 0,1, para quando o modelo é exponencial e $\psi=\beta$, ou seja, o fluxo é associado. A excentricidade significa a taxa com que a curva se aproxima da assíntota.

Para Drucker-Prager creep time hardening, o modelo é expresso pela equação (3.15) como descrito no modelo de tração.

Para Drucker-Prager creep strain hardening, o modelo é descrito pela equação (3.16) e os seus parâmetros obtidos como no modelo para tração.

Para Drucker-Prager Singth-Mitchell, o modelo é expresso pela equação (3.17) e os seus parâmetros são obtidos como no modelo de tração.

Em seguida foram realizadas outras simulações para a verificação do modelo viscoelástico existente no ABAQUS, para tais simulações foi necessário os seguintes dados:

a) As propriedades elásticas de compressão, $E_{c}$ e $v$;

b) Escolheu-se o modelo Viscoelástico no domínio do tempo, sendo que a outra opção era no domínio da freqüência;

c) Os dados de ensaio para implementação no programa, para simular o efeito viscoelástico, foram os tempos de duração de cada passo de carga e a flexibilidade (flexibilidade normalizada), a qual foi calculada segundo o ensaio de fluência à compressão; 
d) Os passos de carga da simulação foram configurados de acordo com a quantidade de passos realizados durante o ensaio, porém, para a análise dos resultados computacionais, consideraram-se apenas os passos dentro do regime viscoelástico, devido ao modelo utilizado.

\subsubsection{Metodologia empregada na simulação do ensaio de flexão}

Com o intuito de simular os ensaios de flexão, baseou-se os dados aquisitados através do sistema de medição da flecha com LVDT na região entre os apoios do dispositivo (span) de flexão, os quais distavam um do outro 51 [mm] (Figura 3.12). O modelo apresentado tem as seguintes dimensões: comprimento de 127 [mm]; largura de 12,7 [mm] e a espessura de 3,2 [mm]. Com isso, as condições de contorno foram atribuídas considerando a realidade dos ensaios, a menos do deslizamento do CDP sobre os roletes de apoio (Figura 3.12), uma vez que as condições foram atribuídas nos nós do lado oposto ao de aplicação da carga, de modo a impedir que o modelo sofresse deslocamento de corpo rígido, ou seja, restringiu-se o movimento daqueles nós nas três direções principais. 0 modelo de flexão é constituído por elementos do tipo C3D8R, ou seja, são elementos tridimensionais que possuem 8 nós e 3 graus de liberdade cada um (translação em x, y e z), bem como, interpolação linear, Figura 3.24. 


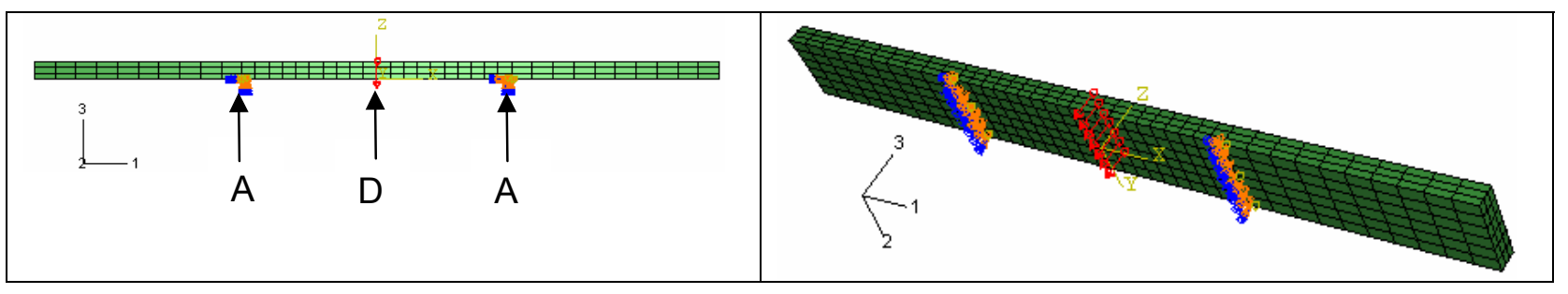

Figura 3.24 - Malha do modelo do CDP de Flexão.

Sendo:

A - representa os apoios;

D - o deslocamento prescrito aplicado.

\subsubsection{Metodologia empregada na simulação monotônica do ensaio de flexão}

Os dados de entrada do modelo foram os mesmos do ensaio monotônico de tração, tais como: Módulo de Elasticidade igual a 1,470 GPa; coeficiente de Poisson igual a 0,43 e alguns pontos da curva de plastificação. Como os modelos de von Mises e Drucker-Prager foram testados para simular o comportamento do biopolímero sob os carregamentos de tração e compressão monotônicos sem apresentarem convergência melhor que o modelo viscoplástico, por isso, resolveu-se empregar este último para representar o comportamento do material sob flexão. 


\subsubsection{Metodologia empregada na simulação cíclica do ensaio de flexão}

Para as simulações cíclicas de flexão foi utilizado o modelo viscoelástico existente no ABAQUS ${ }^{\circledR}$, para tais simulações foi necessário os seguintes dados:

a) As propriedades elásticas de tração, E e v;

b) Escolheu-se o modelo Viscoelástico no domínio do tempo, sendo que a outra opção era no domínio da freqüência;

c) Os dados de ensaio para implementação no programa, para simular o efeito viscoelástico, foram os tempos de duração de cada passo de carga e a flexibilidade (flexibilidade normalizada), a qual foi calculada segundo o ensaio de fluência à tração;

d) Os passos de carga da simulação foram configurados de acordo com a quantidade de passos realizados durante o ensaio, porém, para a análise dos resultados computacionais, consideraram-se apenas os passos dentro do regime viscoelástico, por causa do modelo utilizado. 


\section{Resultados e discussões}

Os ensaios experimentais constituíram parte essencial do presente trabalho, em virtude dos objetivos alcançados e de como obter parâmetros associados aos modelos a partir dos resultados experimentais obtidos. Deve-se destacar que serão discutidas e comentadas as dificuldades encontradas na realização dos ensaios, na instrumentação dos corpos-de-prova, bem como, no ajuste das máquinas (set-up).

Quanto às simulações computacionais, discute-se sobre a capacidade dos modelos de material em representar o comportamento do material sob solicitação de tração, compressão e flexão.

\subsection{Resultados dos ensaios de tração}

Os ensaios de tração foram realizados da seguinte maneira:

a) Ensaios monotônicos de tração;

b) Ensaios cíclicos de tração para avaliação do fenômeno de Relaxação;

c) Ensaios cíclicos de tração para avaliação do fenômeno de Fluência; 
d) Ensaios cíclicos de tração para avaliação da energia dissipada através da histerese do material.

\subsubsection{Ensaios de tração monotônico}

Inicialmente seguiu-se a norma ASTM D638M - 96 (Tipo I), como já mencionado no Capítulo 3, a qual sugere uma velocidade de ensaio de 5 [ $\mathrm{mm} / \mathrm{min}]$. Porém, com finalidade de encontrar uma velocidade específica, que melhor se adequasse e possibilitasse coletar os dados com mais facilidade, alguns ensaios com velocidades distintas foram realizados, como pode ser visto na Figura 4.1. Também, em virtude do comportamento do material viscoelástico o evento da estricção ("necking") do CDP poderia não ocorrer no centro do comprimento útil de medição da deformação (gage length), bem como, quando o travessão da máquina de ensaio (crosshead) atingia certo patamar de força ou elongação desejada, determinava-se a parada desse travessão para se fazer a aquisição dos dados naquela posição específica. Para esta situação de aquisição havia uma dificuldade, pois o CDP continuava a se deformar até a ruptura, podendo danificar o extensômetro. Dessa forma, o nível de deformação foi estipulado para um limite aquém do limite que o extensômetro poderia medir em virtude desses efeitos viscosos que o material apresentava.

Devido a essas características viscoelásticas (fluência e relaxação) a velocidade de $0,8[$ [mm $/ \mathrm{min}]$ foi escolhida. Mesmo essa velocidade sendo menor do que a sugerida pela norma, os efeitos viscoelásticos e viscoplásticos ainda estavam presentes, porém, pode-se coletar os dados adequadamente. No entanto, teve-se o cuidado com velocidades muito baixas para não desprezar os efeitos viscosos do polímero, como pode ser visto na Figura 4.1, quando a velocidade foi de 0,01 [mm/min] o comportamento do material se aproximou ao elastoplástico com encruamento, ou seja, verificou-se a ausência da fase de 
amolecimento. Ainda na Figura 4.1 é evidente que o material apresenta um comportamento dúctil, em virtude do nível de deformação exibido.

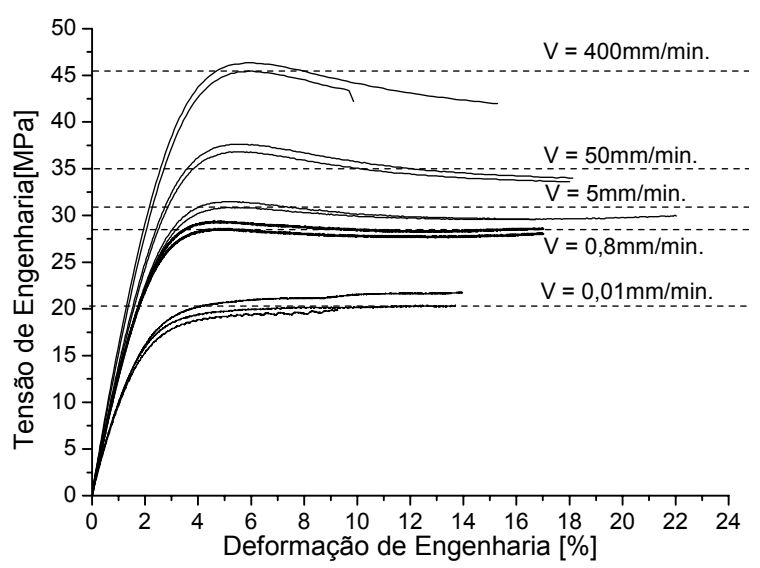

(a) Tensão de engenharia-Deformação de engenharia.

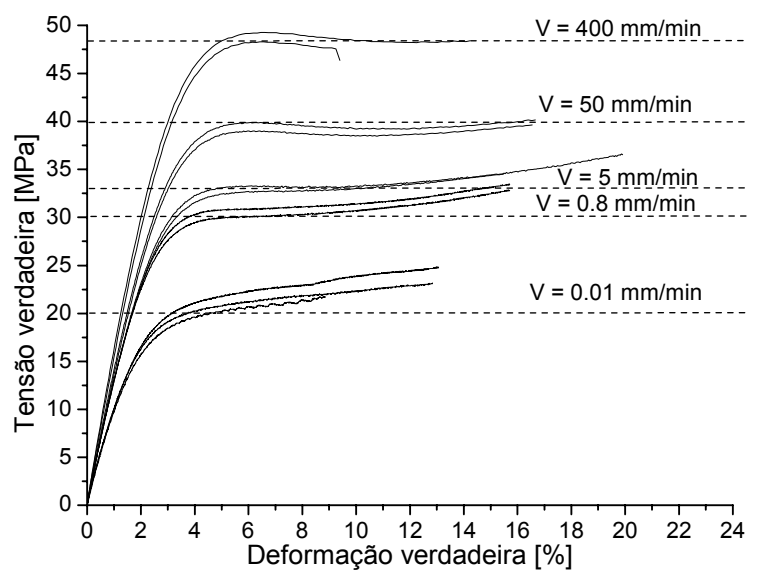

(b) Tensão verdadeira-Deformação verdadeira.

Figura 4.1 - Deformações medidas com extensômetro sob diferentes velocidades.

Uma vez estabelecidos os parâmetros para a realização dos ensaios, tais como: a velocidade de ensaio; a forma de aquisição e os dados a serem coletados. Partiu-se efetivamente para realização dos mesmos.

O ensaio monotônico ocorre quando o carregamento do CDP (através do deslocamento do travessão da máquina de ensaio) é efetuado em um único passo de carga, ou seja, aplica-se força ou deslocamento na velocidade estabelecida $(0,8[\mathrm{~mm} / \mathrm{min}])$ até a ruptura, ou até o nível de deformação que os instrumentos de medição são capazes de medir.

Ensaios monotônicos são empregados para determinação das propriedades elásticas (e/ou viscoelásticas) do material, bem como, o limite de escoamento, se o material é dúctil ou, o limite de ruptura se o material é frágil. Além disso, tem-se a classificação se o material é elastoplástico perfeito (sem encruamento), elastoplástico com encruamento, etc. Para o presente trabalho, determinaram-se as seguintes propriedades sob tração:

a) O módulo de elasticidade (E); 
b) Deformação de escoamento $\left(\varepsilon_{\mathrm{y}}\right)$;

c) A tensão de escoamento $\left(\sigma_{y}\right)$ e o limite de deformação elástica $\left(\varepsilon^{\mathrm{e}}\right)$, sem considerar a contribuição da parcela viscosa, apresentados na Figura 4.2.

Para o presente trabalho, os ensaios monotônicos de tração também foram empregados para ajustar os parâmetros do modelo de Drucker-Prager (juntamente com os ensaios monotônicos de compressão).

O cálculo para a obtenção das curvas tensão-deformação (tensão e deformação de engenharia) usou as equações que consideram a configuração inicial (área inicial da seção transversal e comprimento inicial), que segue:

$$
\begin{gathered}
\sigma_{e n g}=\frac{F}{A_{o}} \\
\varepsilon_{\text {eng }}=\frac{\Delta L}{L_{0}}
\end{gathered}
$$

Sendo que:

F -valor da força que atua na direção perpendicular à secção transversal do CDP;

$A_{\circ}$-valor inicial da área transversal do CDP;

$\mathrm{L}_{o}$-comprimento de abertura inicial do extensômetro utilizado (50 [mm]).

No entanto, valores de tensão e deformação determinados a partir da configuração inicial do CDP são válidos apenas para pequenas deformações, ou seja, valores que estejam no regime elástico. Porém, sob grandes deformações, torna-se necessário usar como referência valores atuais. Para tal, deve-se empregar o cálculo de tensões verdadeiras $\sigma_{v}$ e deformações verdadeiras $\varepsilon_{v}$, dadas por: 


$$
\begin{gathered}
\sigma_{v}^{a p r o x}=\sigma_{\text {eng }}\left(1+\varepsilon_{\text {eng }}\right) \\
\varepsilon_{v}^{a p r o x}=\int_{L_{o}}^{L_{f}} \frac{d L}{L}=\ln \frac{L_{f}}{L_{o}}=\ln \left(1+\varepsilon_{\text {eng }}\right)
\end{gathered}
$$

Sendo que:

A -área instantânea da seção transversal do CDP;

$L_{f}$-abertura instantânea do extensômetro.

Todavia, para o cálculo da tensão verdadeira é levada em consideração a deformação de engenharia, porque até então não havia a possibilidade de medir a variação da área apenas com um único extensômetro medindo em uma única direção. Ressalta-se também que a utilização da expressão (4.3) leva em conta a hipótese de conservação de volume durante o processo de deformação, ou seja, $\mathrm{AL}_{f}=\mathrm{A}_{o} \mathrm{~L}_{\circ}$ (isto é: $v=0,5$ ). Porém, os materiais poliméricos são compressíveis durante a plastificação (G'SELL et al, 2002) e segundo Williams (1973), a tensão de escoamento para esses materiais pode ser adotada quando há um pico de tensão (ponto A), Figura 4.2b. Para PU da mamona, este pico de tensão ocorre próximo aos $5 \%$ de deformação verdadeira.

Além disso, é importante acrescentar que após a ocorrência do pico de tensão, inicia-se um fenômeno denominado "necking", onde o CDP de tração sofre inicialmente uma estricção na sua largura ao longo do comprimento (chamado "necking" difuso) e posteriormente uma estricção na sua espessura (chamado "necking" localizado), provocando assim o surgimento de um estado triplo de tensões. 


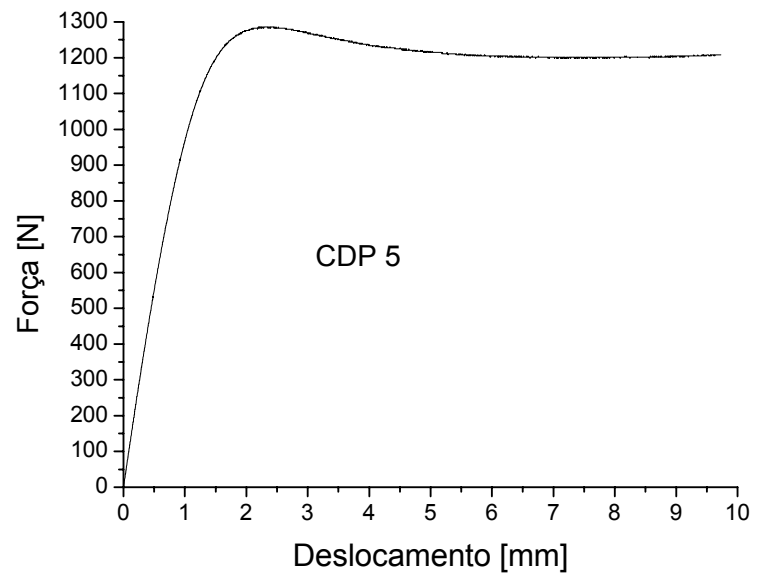

(a)

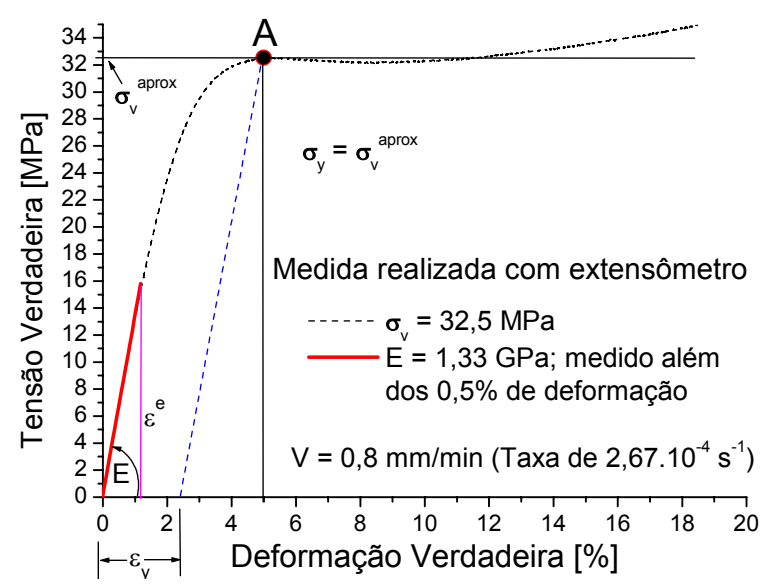

(b)

Figura 4.2 - Curvas (a) força-deslocamento e (b) tensão-deformação verdadeira (ensaio de tração).

A Figura 4.2 possibilitou também encontrar o módulo de elasticidade por meio do ajuste linear que está evidenciado na figura $\left(\sigma_{v}=15,88 \mathrm{MPa}, \varepsilon_{v}=1,17 \%\right)$, porém essa forma de encontrar o limite elástico não é a mais apropriada, uma vez que o ponto definido como limite elástico é escolhido de forma aleatória. Vale ressaltar que o módulo pode ser calculado pela seguinte equação:

$$
E=\frac{\sigma_{v}}{\varepsilon_{v}}
$$

Destaca-se também que após o pico de tensão (ponto A) a curva exibe o comportamento de amolecimento (softening) até aproximadamente $10 \%$ de deformação. Esse amolecimento caracteriza uma perda de rigidez, e após este nível de deformação o material apresenta ganho de rigidez devido ao encruamento, deformando-se até aproximadamente $18 \%$ sem ocorrer a ruptura do CDP.

Com esse nível de deformação (18\%) não se pode considerar que o CDP mantenha constante sua seção transversal, bem como a hipótese de volume constante. Com isso, fezse necessário o uso de instrumentos que medissem a deformação em pelo menos duas 
direções (longitudinal e transversal) do CDP. Assim, o uso de strain gages foi imprescindível, sendo comercialmente encontrados strain gages que mediam até $15 \%$ de deformação.

Entretanto, destaca-se que este não é o melhor ou mais eficiente sistema de aquisição de dados para ensaio em polímero, porque a localização do necking é incerta dentro do comprimento útil de medição (gage length). Quando os strain gages são colados na metade do comprimento está se elegendo uma provável posição de ocorrência do necking, com isso se torna incerta a aquisição de dados. Com o extensômetro, o grau de incerteza aumenta, uma vez que tem um volume de referência $(50[\mathrm{~mm}] \times 13[\mathrm{~mm}] \times 3,3$ [mm]) muito maior do que a zona afetada pelas instabilidades plásticas (necking difuso e necking localizado), implicando em uma medida que não representa a situação local do gage length e sim uma média da deformação que está acontecendo dentro desse comprimento. Destaca-se ainda, com relação ao extensômetro, que o seu clipe é uma possível fonte de início de falha (G'SELL et al, 2002), pois o mesmo tem uma lâmina afiada e uma mola com uma constante bem rígida, a fim de impedir o escorregamento do extensômetro em relação ao CDP. Devido a estas implicações é que, por muito tempo, o comportamento do polímero foi analisado pelos pesquisadores sob o aspecto de volume constante na plastificação. Um sistema que poderia acompanhar a formação e o desenvolvimento do necking seria um sistema de aquisição por imagem, no entanto, tal equipamento não estava disponível para uso no presente trabalho. Sendo assim, com os dados dos ensaios de tração utilizando extensômetros e "stain-gages" pode-se calcular:

1. O coeficiente de Poisson médio através da Equação (4.6);

$$
\nu=\frac{\varepsilon_{v}^{\text {trans }}}{\varepsilon_{V}^{\text {long }}}
$$

Sendo que: $\varepsilon_{v}^{\text {trans }}$ - deformação transversal verdadeira;

$\varepsilon_{V}^{\text {long }}$ - deformação longitudinal verdadeira. 
2. A variação da secção transversal do CDP, que possibilitou o cálculo da variação instantânea da área;

3. A tensão verdadeira (instantânea).

Destaca-se que o coeficiente de Poisson encontrado $(v=0,44)$ dentro da faixa viscoelástica (Figura 4.3) está próximo ao do elastômero $(v=0,49)$, que é considerado um material quase incompressível.

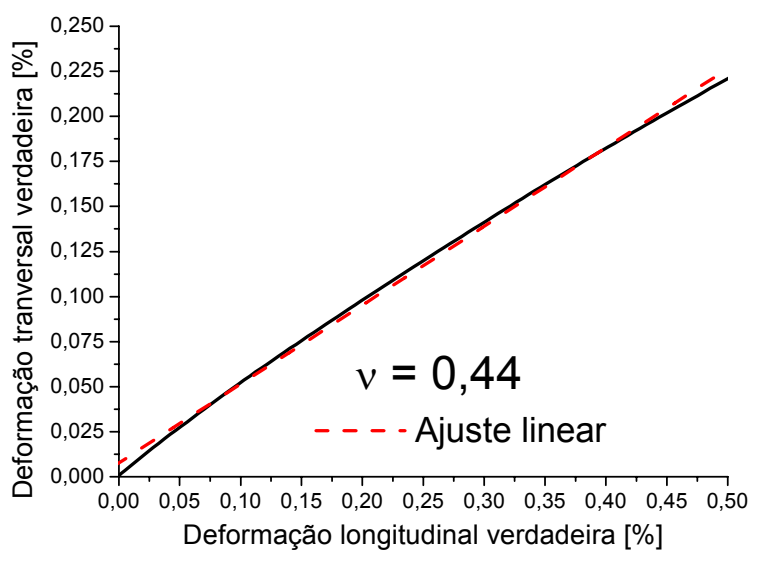

Figura 4.3 - Curva deformação transversal-verdadeira x deformação longitudinal verdadeira (Coeficiente de Poisson médio).

O cálculo das tensões e deformações verdadeiras foi possível devido ao uso das medidas de deformação nas duas direções, como já fora mencionado acima, que possibilitou o uso das equações a seguir:

$$
\begin{gathered}
\sigma_{v}=\frac{F}{A} \\
\varepsilon_{v}=\int_{L_{o}}^{L_{f}} \frac{d L}{L}=\ln \frac{L_{f}}{L_{o}}
\end{gathered}
$$




$$
A=w_{i} \cdot t_{i}
$$

Sendo que: $w_{i}$ - largura instantânea do CDP;

$t_{i}$ - espessura instantânea do CDP. As quais são calculadas da seguinte forma:

$$
\begin{aligned}
& w_{i}=w_{0} \cdot\left(1-\frac{\varepsilon_{v}^{\text {trans }}}{100}\right) \\
& t_{i}=t_{0} \cdot\left(1-\frac{\varepsilon_{v}^{\text {trans }}}{100}\right)
\end{aligned}
$$

Sendo que: $w_{0}$ - largura inicial;

$t_{0}$ - espessura inicial;

$\varepsilon_{v}^{\text {trans }}$ - deformação transversal.

Para a utilização da equação (4.10), considerou-se a hipótese de material transversalmente isótropo, porque não se pôde efetuar a medida no sentido da espessura do CDP.

A medição da variação da seção transversal também possibilitou calcular a diferença entre as tensões obtidas pelas Equações (4.3) e (4.4) com as obtidas pela Equação (4.7). A diferença foi comparada entre as tensões para o maior nível de deformação medido em cada CDP (Figura 4.4), de maneira que a mesma apresentou 10,5\%.

$\mathrm{Na}$ Figura 4.4, faz-se uma comparação entre as tensões de engenharia calculada com base na expressão (4.1) e a tensão verdadeira, calculada através da expressão (4.3) e da expressão (4.7). A curva da tensão verdadeira também foi calculada a partir da variação da área, Equação (4.11), considerando o coeficiente de Poisson médio. A Figura 4.4 também evidencia que enquanto a parcela linear não foi ultrapassada, as curvas apresentaram uma pequena diferença na rigidez. Porém, a partir da perda da linearidade, 
nota-se uma diferença mais acentuada, ou seja, quando o material atinge o nível das deformações plásticas (deformações permanentes). Isto implica em dizer que a fronteira viscoelástica (ponto A) foi ultrapassada e as medidas de tensão já não são mais coerentes com a hipótese de volume constante no regime plástico, pois, o coeficiente de Poisson $(0,44)$ evidencia que o material é quase incompressível no regime elástico.

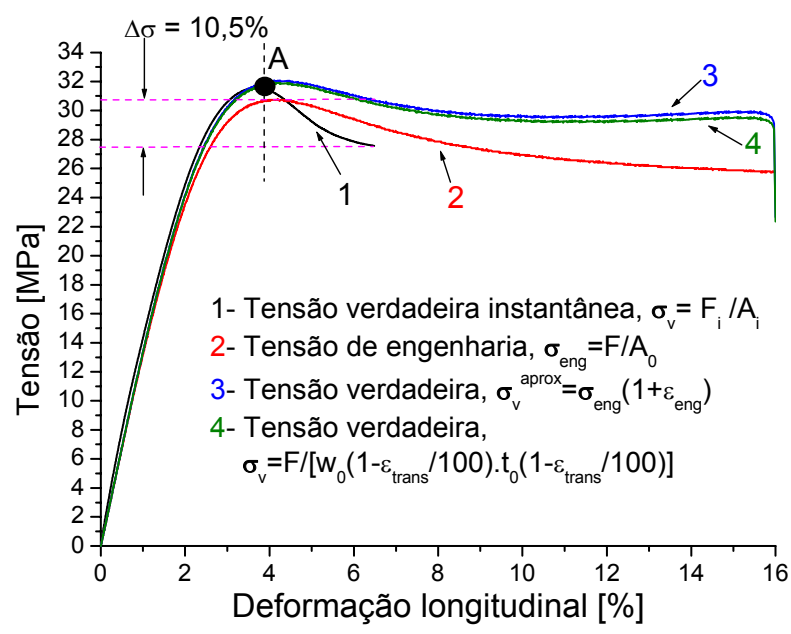

Figura 4.4 - Comparação entre as formas de cálculo das tensões.

A Tabela 4.1 exibe as propriedades relevantes ao limite elástico do material, as quais foram calculadas utilizando:

a) A aproximação que considera o volume constante e emprega a tensão de engenharia e a deformação de engenharia, $\sigma_{\text {eng }}\left(1+\varepsilon_{\text {eng }}\right)$;

b) A variação da área da seção transversal por meio da medição direta com strain gages e a variação da área da seção transversal medida através da aproximação do produto do Poisson médio com a deformação no sentido longitudinal (medida com extensômetro) para calcular a deformação transversal (Equação (4.6)). Com essas duas variações foi possível calcular a redução da largura e da espessura do CDP e, assim, calcular a área instantânea, (Equação (4.11) ) através da hipótese de material transversalmente isótropo. 


$$
\mathrm{A}_{\text {aprox }}=\mathrm{w}_{0} \cdot\left(1-\frac{v \cdot \varepsilon_{\mathrm{v}}^{\text {long }}}{100}\right) \cdot \mathrm{t}_{0}\left(1-\frac{v \cdot \varepsilon_{\mathrm{v}}^{\text {long }}}{100}\right)=\mathrm{w}_{\mathrm{i}} \cdot \mathrm{t}_{\mathrm{i}}
$$

Tabela 4.1 - Propriedades do material obtidas por tração obtidas por três métodos.

\begin{tabular}{|c|c|c|c|c|c|c|c|c|c|}
\hline \multirow{3}{*}{ CDP } & \multicolumn{6}{|c|}{ Medidas com extensômetro } & \multirow{2}{*}{\multicolumn{3}{|c|}{$\begin{array}{c}\text { Medidas com strain gages } \\
\sigma_{v}=\text { F/A } \\
\end{array}$}} \\
\hline & \multicolumn{3}{|c|}{$\sigma_{v}=\sigma_{\text {eng }}\left(1+\varepsilon_{\text {eng }}\right)$} & \multicolumn{3}{|c|}{$\sigma_{v}=F /\left(w_{0} t_{0}\left(1-v \varepsilon_{\text {long }} / 100\right)^{2}\right)$} & & & \\
\hline & $\begin{array}{c}\sigma_{y}^{v} \\
{[\mathrm{MPa}]}\end{array}$ & $\begin{array}{c}\mathrm{E}_{\mathrm{v}} \\
{[\mathrm{GPa}]}\end{array}$ & $\begin{array}{c}\varepsilon_{y}^{v} \\
{[\%]}\end{array}$ & $\begin{array}{c}\sigma_{y}^{v} \\
{[\mathrm{MPa}]}\end{array}$ & $\begin{array}{c}\mathrm{E}_{\mathrm{v}} \\
{[\mathrm{GPa}]}\end{array}$ & $\begin{array}{c}\mathcal{E}_{y}^{v} \\
{[\%]}\end{array}$ & $\begin{array}{c}\sigma_{y}^{v} \\
{[\mathrm{MPa}]}\end{array}$ & $\begin{array}{c}\mathrm{E}_{\mathrm{v}} \\
{[\mathrm{GPa}]}\end{array}$ & $\begin{array}{c}\mathcal{E}_{y}^{v} \\
{[\%]}\end{array}$ \\
\hline 1 & 32,98 & 1,30 & 4,6 & 32,79 & 1,35 & 4,26 & 32,59 & 1,54 & 4,18 \\
\hline 2 & 32,05 & 1,35 & 4,48 & 31,88 & 1,33 & 4,42 & 31,51 & 1,43 & 3,65 \\
\hline 3 & 29,10 & 1,31 & 4,64 & 28,90 & 1,32 & 4,46 & 28,1 & 1,44 & 2,57 \\
\hline Média & 31,38 & 1,32 & 4,57 & 31,19 & 1,33 & 4,38 & 30,73 & 1,47 & 3,47 \\
\hline
\end{tabular}

Sendo que:

$\sigma_{y}^{v}$-Tensão verdadeira de escoamento;

$\mathbf{E}_{\mathrm{v}}$ - Módulo de elasticidade;

$v$ - Coeficiente de Poisson;

$\varepsilon_{y}^{v}$ - Deformação verdadeira no início do escoamento.

Com os dados da Tabela 4.1, tem-se os valores médios para a tensão, deformação e módulo de elasticidade. Assim, optou-se pelos valores médios das medidas obtidas com os strain gages, pelo fato de estas medidas terem sido efetuadas diretamente dos CDPs, no sentido axial e transversal do carregamento. Com isso, obteve-se:

$$
\begin{aligned}
& \sigma_{y}^{v}=30,73 \mathrm{MPa} ; \\
& \mathbf{E}_{\mathrm{v}}=1,47 \mathrm{GPa} ; \\
& v=0,44 \\
& \varepsilon_{y}^{v}=3,47 \% .
\end{aligned}
$$


Vale ressaltar que para contabilizar a variação volumétrica, adotou-se como hipótese que a deformação é transversalmente isotrópica, ou seja, $\varepsilon_{22}=\varepsilon_{33}$. Isto ocorreu, devido a espessura do CDP (direção 3) não ter dimensão suficiente para a colagem de um strain gage (Figura 4.5), bem como, ausência de um outro sistema de medição de deformação (extensômetro) que comprovasse essa hipótese.

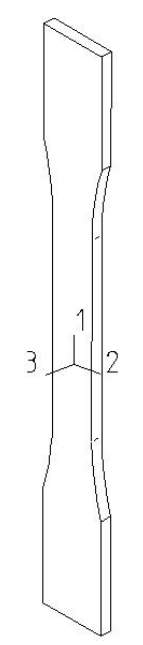

Figura 4.5 - Sistema de coordenada do CDP.

Como havia somente carregamento em uma direção (1) de acordo com a Figura 4.5 e considerando que o CDP não havia atingido o nível de deformação suficiente para produzir distorções angulares e gerar o necking localizado, consideram-se as seguintes parcelas de deformação:

$$
\begin{gathered}
\hat{\varepsilon}_{11}=\frac{1}{E}\left[\hat{\sigma}_{11}-v\left(\hat{\sigma}_{22}+\hat{\sigma}_{33}\right)\right], \rightarrow \hat{\varepsilon}_{11}=\ln \left(\frac{L_{f}}{L_{0}}\right) \\
\hat{\varepsilon}_{22}=\frac{1}{E}\left[\hat{\sigma}_{22}-v\left(\hat{\sigma}_{11}+\hat{\sigma}_{33}\right)\right], \rightarrow \hat{\varepsilon}_{22}=-v \hat{\varepsilon}_{11} \\
\hat{\varepsilon}_{33}=\frac{1}{E}\left[\hat{\sigma}_{33}-v\left(\hat{\sigma}_{22}+\hat{\sigma}_{11}\right)\right], \rightarrow \hat{\varepsilon}_{33}=\hat{\varepsilon}_{22}
\end{gathered}
$$


A variação do volume do CDP é decorrente das seguintes equações:

$$
\begin{gathered}
\varepsilon_{v}=\ln \left(\frac{V}{V_{0}}\right)=\ln \left(\frac{l_{i} W_{i} t_{i}}{l_{0} W_{0} t_{0}}\right)=\ln \left(\frac{l_{i}}{l_{0}} \frac{W_{i}}{W_{0}} \frac{t_{i}}{t_{0}}\right)=\ln \left(\frac{l_{i}}{l_{0}}\right)+\ln \left(\frac{W_{i}}{W_{0}}\right)+\ln \left(\frac{t_{i}}{t_{0}}\right) \\
\varepsilon_{v}=\hat{\varepsilon}_{11}+\hat{\varepsilon}_{22}+\hat{\varepsilon}_{33} \rightarrow \varepsilon_{V}=\hat{\varepsilon}_{11}(1-2 v)
\end{gathered}
$$

Para chegar a essas deformações foram utilizados CDPs que atingiram um nível de deformação considerável, como pode ser visto na Tabela 4.2, sendo que para o cálculo das deformações $\varepsilon_{22}$ e $\varepsilon_{33}$ foram utilizadas as Equações (4.13) e (4.14) com o Poisson médio $(v=0,44)$. Com isso foi possível expressar o tensor das deformações na seguinte forma matricial:

$$
\begin{gathered}
\varepsilon=\left[\begin{array}{lll}
\varepsilon_{11} & \varepsilon_{12} & \varepsilon_{13} \\
\varepsilon_{21} & \varepsilon_{22} & \varepsilon_{23} \\
\varepsilon_{31} & \varepsilon_{32} & \varepsilon_{33}
\end{array}\right]=\left[\begin{array}{ccc}
\hat{\varepsilon}_{11} & 0 & 0 \\
0 & \hat{\varepsilon}_{22} & 0 \\
0 & 0 & \hat{\varepsilon}_{33}
\end{array}\right] \\
\mathrm{J}_{1}=\hat{\varepsilon}_{11}+\hat{\varepsilon}_{22}+\hat{\varepsilon}_{33}
\end{gathered}
$$

Sendo que J1 é o primeiro invariante das deformações.

Tabela 4.2 - Resultado do cálculo da variação volumétrica.

\begin{tabular}{|c|c|c|c|c|}
\hline CDP & $\hat{\varepsilon}_{11}(\%)$ & $\hat{\varepsilon}_{22}(\%)$ & $\hat{\varepsilon}_{33}(\%)$ & $\varepsilon_{\mathrm{v}}(\%)=\mathrm{J}_{1}$ \\
\hline 1 & 12,31 & $-5,42$ & $-5,42$ & 1,48 \\
\hline 2 & 16,11 & $-7,09$ & $-7,09$ & 1,93 \\
\hline 3 & 11,42 & $-5,02$ & $-5,02$ & 1,37 \\
\hline 4 & 8,37 & $-3,68$ & $-3,68$ & 1,00 \\
\hline 5 & 14,86 & $-6,54$ & $-6,54$ & 1,78 \\
\hline \multicolumn{5}{|c}{ Média da variação volumétrica: } \\
\hline
\end{tabular}


A variação $J_{1}$ é de $1,51 \%$, para este caso em que o material foi considerado transversamente isotrópico e as deformações transversais foram calculadas pela relação com o Poisson médio. Vale ressaltar que o ideal seria que as medidas fossem efetuadas nas três direções, através de sistemas adequados de aquisição.

\subsubsection{Ensaios de tração cíclicos de fluência}

Os resultados a seguir são de ensaios nos quais a amostra sofreu vários ciclos de carregamento, descarregamento e recarregamento sob velocidade de 37,5 [N/s], ou seja, o controle do ensaio foi realizado por meio de aplicação de força a fim de simular uma máquina de fluência, a qual tem o princípio de aplicação instantânea de massas específicas. Assim, para chegar à velocidade de carregamento deste ensaio foi feita uma análise baseada na velocidade de deslocamento do ensaio monotônico, ou seja, com base a partir da curva do ensaio monotônico sob controle de deslocamento, determinou-se a curva forçatempo e, com isso encontrou-se uma velocidade média de carregamento.

Com os ensaios de fluência, pode-se verificar a flexibilidade (e o módulo de elasticidade) por meio das curvas isócronas, ou seja, curvas constantes no tempo. Isto facilita a determinação onde a curva perde a linearidade, ou seja, tem-se o método de determinação da viscoelasticidade linear do polímero através das curvas deformação-tensão em um tempo específico. Neste caso são deformações que ocorrem em tempos iguais. Os pontos destas curvas foram obtidos através de cada passo de carga estabelecida no ensaio, ou seja, extraiu-se a tensão e a deformação no início e no final de cada passo, Figura 4.6. Os valores de tensão e deformação são apresentados na Tabela 4.3. 


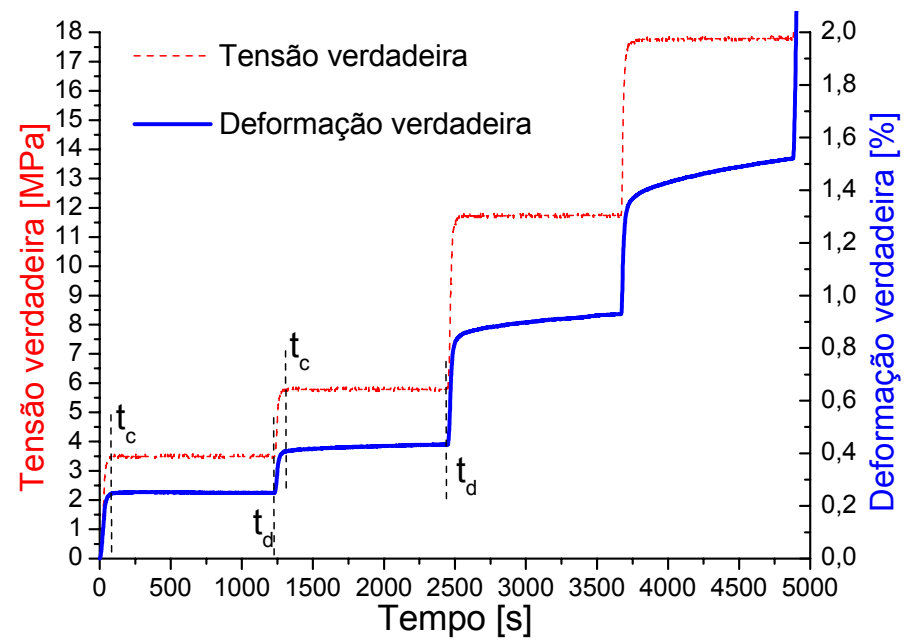

Figura 4.6- Curva tensão - tempo - deformação (Resposta viscoelástica linear para 4 passos de carga).

Deve-se destacar que, as isócronas na Figura 4.7, a tensão utilizada foi uma tensão média em virtude do controle de força da máquina não ser tão eficiente quanto uma máquina dedicada para ensaios de fluência. Contudo ainda se considera que a máquina utilizada apresentou um bom controle de força e de tensão, para o ensaio de tração como pode ser visto na Figura 4.8.

Tabela 4.3 - Propriedades do ensaio de fluência em tração para as curvas isócronas.

\begin{tabular}{|c|c|c|c|c|c|c|c|c|c|c|}
\hline \multirow{3}{*}{ Ciclo } & \multicolumn{5}{|c|}{ CDP1 } & \multicolumn{5}{|c|}{ CDP3 } \\
\hline & \multicolumn{2}{|c|}{ Tempo [s] } & \multirow{2}{*}{$\begin{array}{c}\text { Tensão } \\
\sigma_{\mathrm{m}}[\mathrm{MPa}]\end{array}$} & \multirow{2}{*}{$\begin{array}{c}\varepsilon_{\mathrm{i}} \\
{[\%]}\end{array}$} & \multirow{2}{*}{$\begin{array}{c}\varepsilon_{\mathrm{f}} \\
{[\%]}\end{array}$} & \multicolumn{2}{|c|}{ Tempo [s] } & \multirow{2}{*}{$\begin{array}{c}\text { Tensão } \\
\sigma_{\mathrm{m}}[\mathrm{MPa}]\end{array}$} & \multirow{2}{*}{$\begin{array}{c}\varepsilon_{\mathrm{i}} \\
{[\%]} \\
\end{array}$} & \multirow{2}{*}{$\begin{array}{c}\varepsilon_{\mathrm{f}} \\
{[\%]}\end{array}$} \\
\hline & $t_{c}$ & $t_{d}$ & & & & $t_{c}$ & $t_{d}$ & & & \\
\hline 1 & 100 & 212 & 5,69 & 0,44 & 0,48 & 100 & 1132 & 3,49 & 0,25 & 0,25 \\
\hline 2 & 314 & 205 & 11,52 & 0,93 & 1,01 & 1334 & 1102 & 5,79 & 0,41 & 0,43 \\
\hline 3 & 827 & 201 & 17,34 & 1,50 & 1,66 & 2592 & 1067 & 11,70 & 0,86 & 0,93 \\
\hline 4 & 1072 & 205 & 20,93 & 2,02 & 2,25 & 3818 & 1057 & 17,78 & 1,39 & 1,52 \\
\hline
\end{tabular}

Sendo que:

$t_{c}$ - tempo de corte;

$t_{d}$ - tempo de duração de cada passo $(P)$;

$\boldsymbol{\sigma}_{\mathrm{m}}$ - tensão média calculada entre a tensão do início e o fim do passo; 
$\varepsilon_{\mathrm{i}}$ - deformação no início do passo;

$\varepsilon_{\mathrm{f}}-$ deformação no final do passo.

As curvas isócronas foram elaboradas com os dados do ensaio de fluência até o quarto passo de carga. Cada passo foi mantido constante durante um dado tempo, sendo implementado um patamar de força por vez até o quarto patamar. Com isso, foram verificados os níveis de deformação a fim de comprovar ou não a afirmação encontrada em WILLIAMS (1973), segundo o qual os polímeros são viscoelásticos lineares até $0,5 \%$ de deformação. Considerando apenas a Figura 4.7a poder-se-ia incorrer no equívoco de afirmar que o material possui a visco-linearidade até $0,95 \%$ de deformação, pelo simples fato de coletar um ponto para $\sigma_{v}$ de $5,69 \mathrm{MPa} ; \varepsilon_{\mathrm{v}}$ de $0,44 \%$ e o outro ponto somente para $\sigma_{\mathrm{v}}$ de $11,52 \mathrm{MPa}$ e $\varepsilon_{\mathrm{v}}$ de $0,93 \%$. Como existe apenas um ponto abaixo de $0,5 \%$ de deformação e outro ponto acima deste, não foi possível verificar a perda da visco-linearidade porque seria necessário pelo menos dois pontos abaixo dos $0,5 \%$ deformação. Notado isto para o CDP1, fez-se um novo ensaio que contemplasse dois passos de carga dentro dos $0,5 \%$ de deformação a fim de comprovar ou não a perda da linearidade. Assim, foram implementados no roteiro de ensaio da máquina, o ponto "A" $(3,49 \mathrm{MPa} ; 0,25 \%)$ e o ponto "B" $(5,79 \mathrm{MPa}$; 0,41\%), conforme Figura $4.7 b$. Dessa forma foi possível identificar uma leve perda da viscolinearidade, o que comprova a teoria do WILLIAMS (1973). Fica caracterizado, então, que o material pode ser considerado viscoelástico linear, embora a inclinação dos segmentos de reta $A B\left(\theta_{1}=2,4^{\circ}\right)$ e $B C\left(\theta_{2}=2,8^{\circ}\right)$ não seja muito diferente (Figura $4.7 b$ ).

Portanto, este procedimento é mais razoável para verificar a perda de linearidade, pois se torna complicado determinar essa perda pelo ensaio monotônico (Figura 4.2), uma vez que é feito um ajuste linear, sendo este insuficiente para observar essa não-linearidade tão reduzida. 


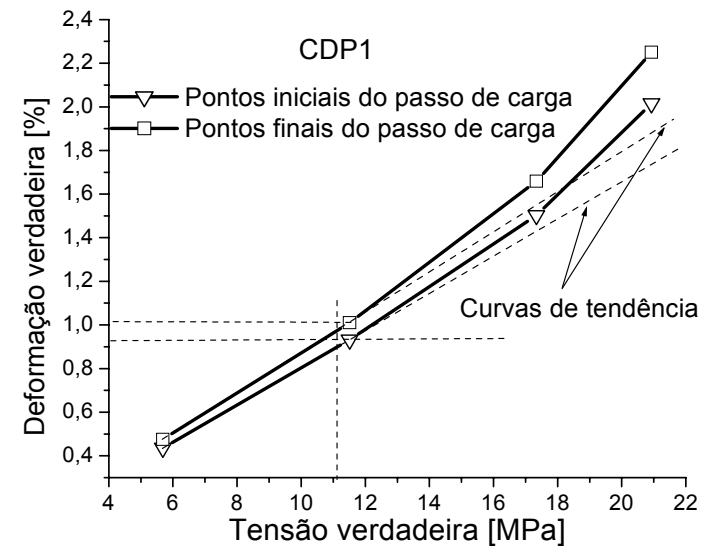

(a)

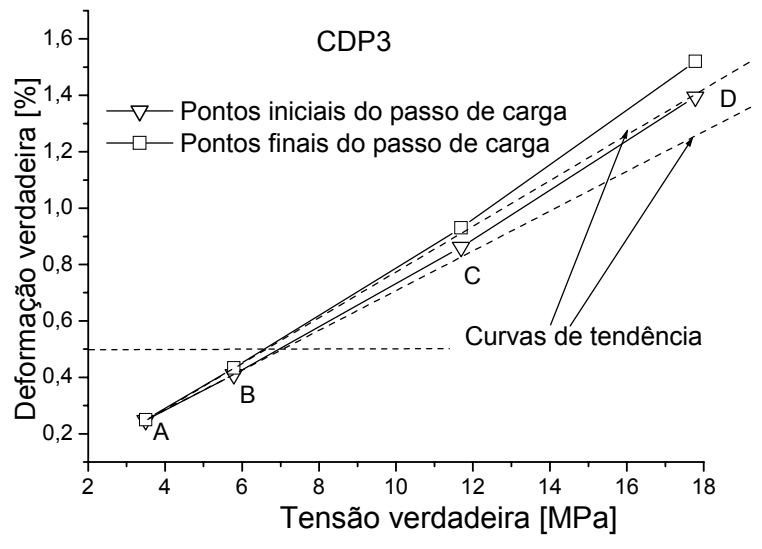

(b)

Figura 4.7 - Isócronas(deformação verdadeira-tensão verdadeira) para determinação da linearidade do material.

Neste ensaio é perceptível como o material altera seu comportamento ao passo que vai se afastando da fase elástica, sendo esta linear ou não-linear. A Figura 4.8 ilustra a curva de um ensaio completo com todas as fases, ou seja: ( I ) viscoelástica linear, ( II ) viscoelástica não-linear e ( III ) visco-elastoplástica. Percebe-se que ao ultrapassar a fronteira da fase II com III, ocorre um pequeno aumento de tensão para um grande aumento da deformação.

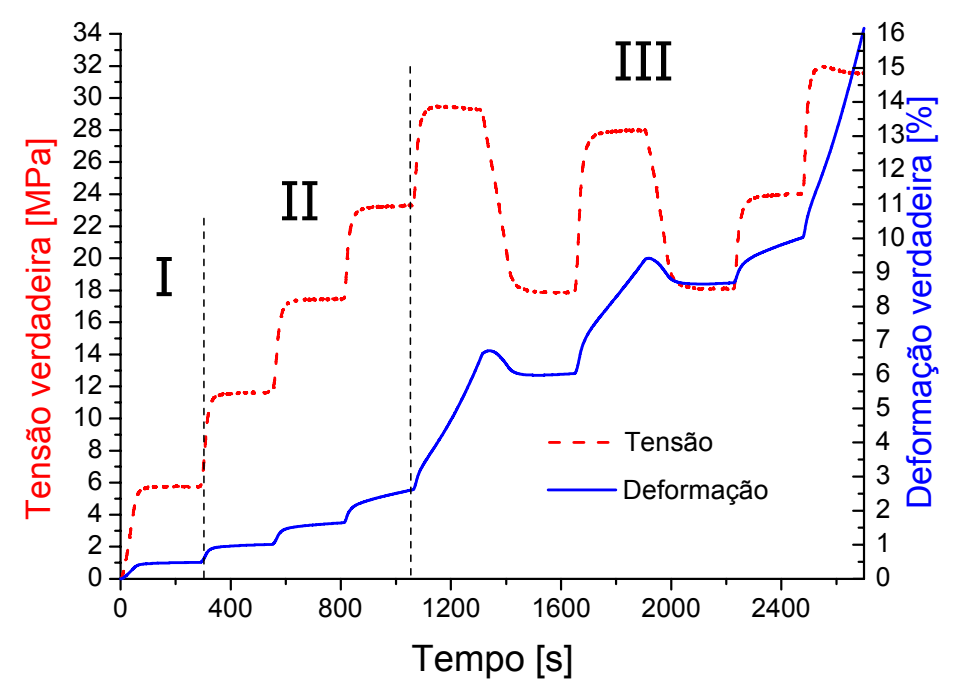

Figura 4.8 - Curva tensão-tempo-deformação, representando a mudança de fase do material. 
Com as fases identificadas, verifica-se que:

1- Na fase viscoelástica linear (fase I ) o material não sofre o efeito da fluência, ou seja, quando a carga atinge o patamar estabelecido para o primeiro passo e se estabiliza no decorrer do tempo estipulado, o CDP permanece com a deformação do início do passo que é a deformação proporcional à carga aplicada, caracterizando o comportamento viscoelástico linear;

2- Na fase viscoelástica não-linear (fase II ), o material já sofre o efeito da fluência, ou seja, a tensão permanece constante, mas o CDP continua se deformando. Com essa variação de comportamento de resposta entre a fase I e a fase II, tornou-se possível a determinação da parcela viscoelástica, como já foi mencionado anteriormente;

3- Na fase visco-elastoplástica (fase III ), o primeiro patamar foi idealizado para que o CDP ultrapassasse da fase II para fase III, ou seja, foi aplicada uma força suficientepara ultrapassar a fase II (viscoelástica) e que fizesse com que o CDP atingisse níveis de deformação permanentes. Esse nível de força foi definido por meio do ensaio de tração monotônico, no qual foi possível determinar a tensão de escoamento e o nível de deformação que essa tensão produziu. Assim, com esses dois parâmetros definidos, pôdese planejar os passos de carga de modo a contemplar a parte viscoelástica e viscoelastoplástica (Figura 4.8), verificando, assim, o quanto o material se recuperava (Fase III ) mesmo quando estava em níveis de deformação permanente.

Destaca-se ainda, que o tempo estabelecido para fluência nesta fase foi insuficiente, pois, observando a curva de deformação (Figura 4.9), percebeu-se que a mesma não se estabilizou, demonstrando que o material continuaria a se deformar caso permanecesse mais tempo no passo de carga.

Este tipo de ensaio além de ser empregado para avaliar as curvas cargadeslocamento, tensão-deformação, também é utilizado para definir mais precisamente o módulo de elasticidade e a flexibilidade à tração. 
Com respeito às curvas carga-deslocamento (Figura 4.9), destaca-se o fato de que quando o CDP atinge o escoamento há uma perda de rigidez (passo $\mathrm{V}$ ), de maneira que o mesmo não suporta a carga estabelecida para aquele patamar. Destaca-se também, que o mesmo ocorre no descarregamento (recovery, patamares VI e VII), por isso o CDP continuou a se deformar. É suposto que a deformação apresentada pelo CDP é residual devido ao valor da força do patamar "V" e que a redução do carregamento nos passos subseqüentes não foi suficiente para fazer com que o fluxo do escoamento estagnasse ou diminuísse. Porém, nota-se que houve uma diminuição da taxa de deformação quando se reduziu a força no patamar "VII", pelo fato da inclinação da curva de deformação neste patamar ser menor do que a anterior. Portanto, quando o CDP atinge certo nível de deformação a rigidez é drasticamente reduzida, aumentando a flexibilidade.

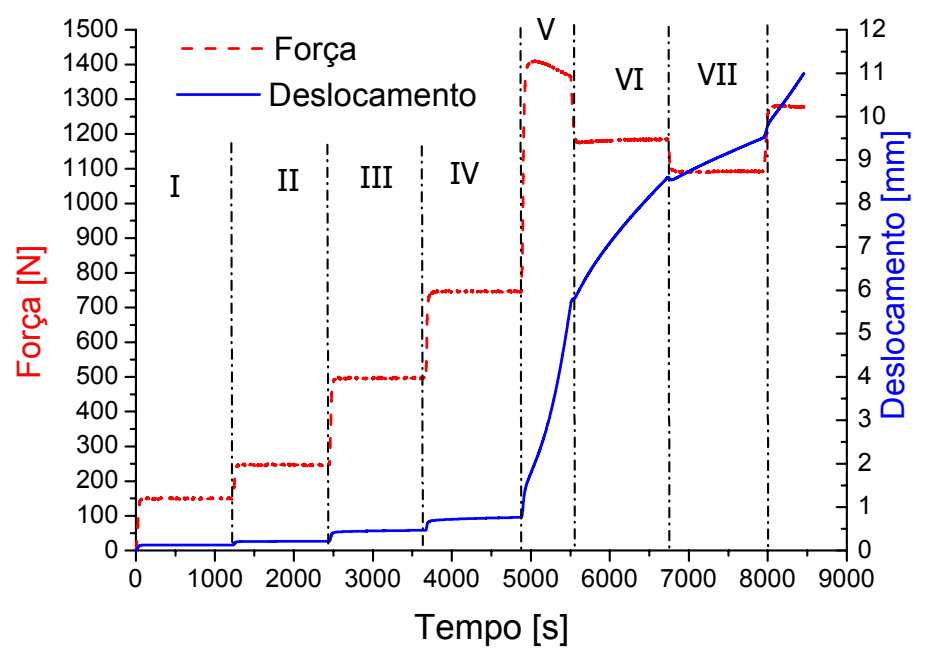

Figura 4.9 - Curvas força-tempo versus deslocamento-tempo. 


\subsubsection{Ensaios de tração cíclicos de relaxação de tensão}

Como nos ensaios de fluência, os ensaios de relaxação de tensão também sofreram vários ciclos de carregamento, descarregamento e recarregamento. Porém, a velocidade de ensaio foi controlada pelo deslocamento configurada para 0,8 [mm/min], Figura 4.10.

$\mathrm{Na}$ Figura 4.10, nota-se como a tensão depende do tempo e o quão difícil foi controlar os patamares de elongação para que fosse mantido o nível de deformação estabelecido para cada patamar de relaxação. Essa dificuldade se deu pelo fato do controle da máquina não ser capaz de compensar o efeito viscoso do CDP. Essas observações podem ser notadas entre os dois primeiros patamares (fase I) de elongação e os restantes (fase II). Quando a fronteira viscoelástica linear foi rompida não foi mais possível submeter o CDP apenas à relaxação de tensão sem a presença da fluência. Para este tipo de ensaio o ideal seria que cada patamar de elongação estabelecido se mantivesse constante e houvesse apenas a relaxação de tensão.

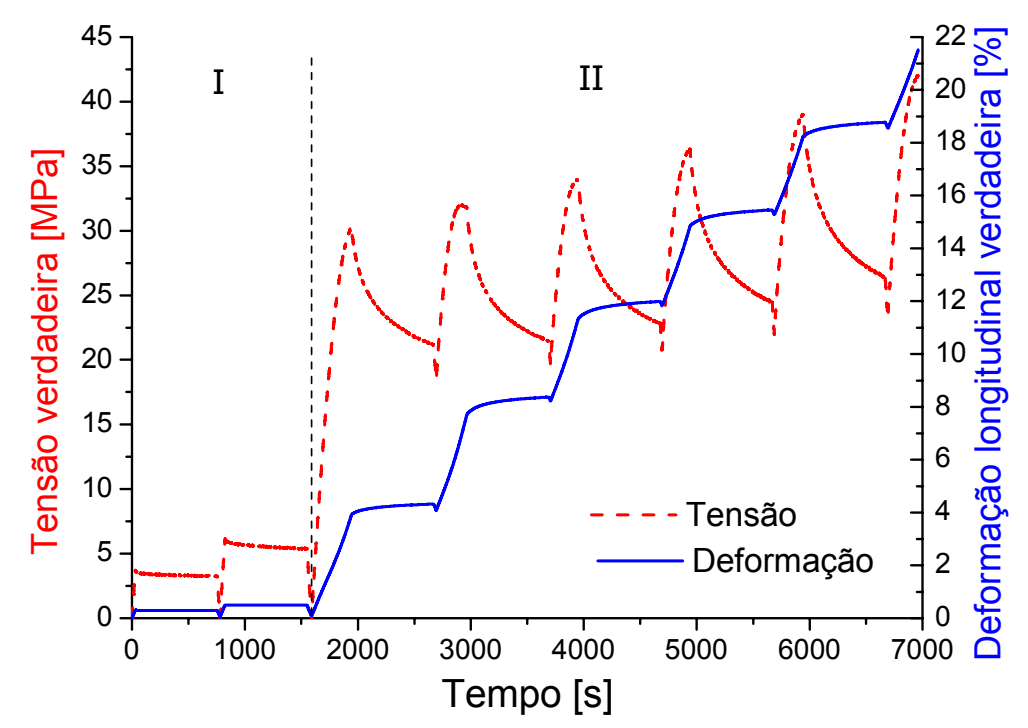

Figura 4.10 - Curvas tensão -tempo- deformação com ciclos de relaxação de tensão. 
Este ensaio também facilita a determinação do módulo de elasticidade por meio das curvas isócronas que demonstram a perda da linearidade do material. Os pontos destas curvas foram obtidos através de cada passo de elongação estabelecido no ensaio, ou seja, capturou-se a tensão e a deformação no início e no final de cada passo, respectivamente, Figura 4.10. Os valores de tensão e deformação são apresentados na Tabela 4.4.

A Figura 4.11 exemplifica melhor o que foi colocado no parágrafo anterior, porque evidencia o comportamento da deformação e da elongação. Verifica-se quando o travessão da máquina pára no nível de elongação estabelecido, o efeito viscoso do material faz com que o CDP continue a se deformar, mesmo sob a relaxação da tensão, sendo que o nível de tensão está diminuindo (diminuição do nível de força). Infere-se ainda sobre Figura 4.11 que se o descarregamento continuasse, como ilustrado, a curva de descarregamento exibiria uma inclinação semelhante à curva I.

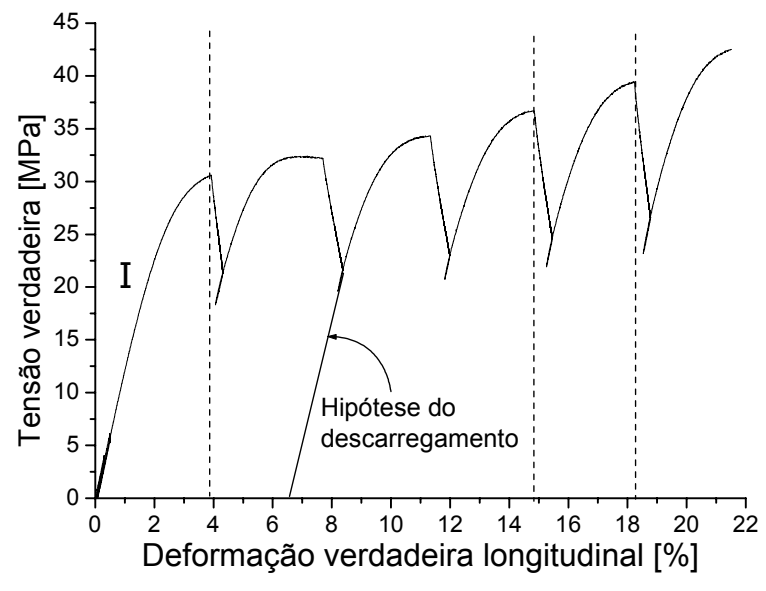

(a) Curva tensão-deformação.

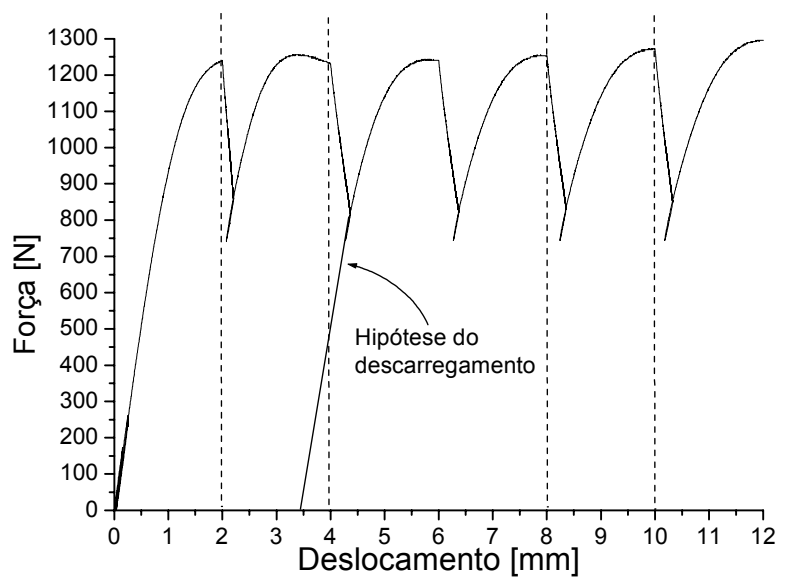

(b) Curva força-deslocamento.

Figura 4.11 - Ciclos de relaxação de tensão sob tração.

Deve-se destacar que, as isócronas na Figura 4.12, para relaxação de tensão, a deformação utilizada foi uma deformação média, em virtude do controle de deslocamento da máquina não ser eficiente para compensar os efeitos do retardo da deformação. 
Tabela 4.4 - Propriedades de relaxação de tensão na tração para as curvas isócronas.

\begin{tabular}{|c|c|c|c|c|c|c|c|c|c|c|}
\hline \multirow[b]{3}{*}{ Ciclo } & \multicolumn{5}{|c|}{ CDP6 } & \multicolumn{5}{|c|}{ CDP7 } \\
\hline & \multicolumn{2}{|c|}{ Tempo [s] } & \multirow{2}{*}{$\begin{array}{c}\varepsilon_{\mathrm{m}} \\
{[\%]}\end{array}$} & \multicolumn{2}{|c|}{ Tensão } & \multicolumn{2}{|c|}{ Tempo [s] } & \multirow{2}{*}{$\begin{array}{l}\varepsilon_{\mathrm{m}} \\
{[\%]}\end{array}$} & \multicolumn{2}{|c|}{ Tensão } \\
\hline & $t_{c}$ & $t_{d}$ & & $\begin{array}{c}\sigma_{\mathrm{i}} \\
{[\mathrm{MPa}]}\end{array}$ & $\begin{array}{c}\sigma_{\mathrm{f}} \\
{[\mathrm{MPa}]}\end{array}$ & $t_{c}$ & $t_{d}$ & & $\begin{array}{c}\sigma_{\mathrm{i}} \\
{[\mathrm{MPa}]}\end{array}$ & $\begin{array}{c}\sigma_{\mathrm{f}} \\
{[\mathrm{MPa}]}\end{array}$ \\
\hline 1 & 61,9 & 737,4 & 0,2954 & 3,73 & 3,27 & 40,8 & 736,8 & 0,30 & 4,03 & 3,42 \\
\hline 2 & 843,4 & 1545,4 & 0,4946 & 5,95 & 5,41 & 825,2 & 1536,7 & 0,50 & 6,18 & 5,41 \\
\hline 3 & 2003,8 & 2638,8 & 4,1849 & 30,07 & 21,37 & 1988,5 & 2669,5 & 4,18 & 30,84 & 21,45 \\
\hline 4 & 2994,3 & 3686,3 & 8,1000 & 32,26 & 21,70 & 2991,0 & 3686,5 & 8,08 & 32,48 & 21,69 \\
\hline
\end{tabular}

Sendo que:

$t_{c}$ - tempo de corte;

$t_{d}$ - tempo de duração de cada passo;

$\varepsilon_{\mathrm{m}}$ - deformação média calculada entre a deformação do início e do fim do passo;

$\sigma_{i}-$ tensão no início do passo;

$\sigma_{f}-$ tensão no final do passo.

A Figura 4.12 exibe curvas isócronas referentes ao ensaio de relaxação de tensão na tração com a finalidade de determinar o módulo de elasticidade e a perda da linearidade. Por isso, nos ensaios foram realizados dois ciclos de deformação abaixo de $0,5 \%$ de deformação verdadeira e os demais ciclos estão acima deste limite, como mostrado na Tabela 4.4. Este procedimento facilitou a determinação do módulo elástico e da perda de linearidade porque os quatro pontos coletados para determinar essas curvas são bem distintos e, assim, acentuam a diferença entre as inclinações das curvas, além de evidenciar a perda de rigidez. 


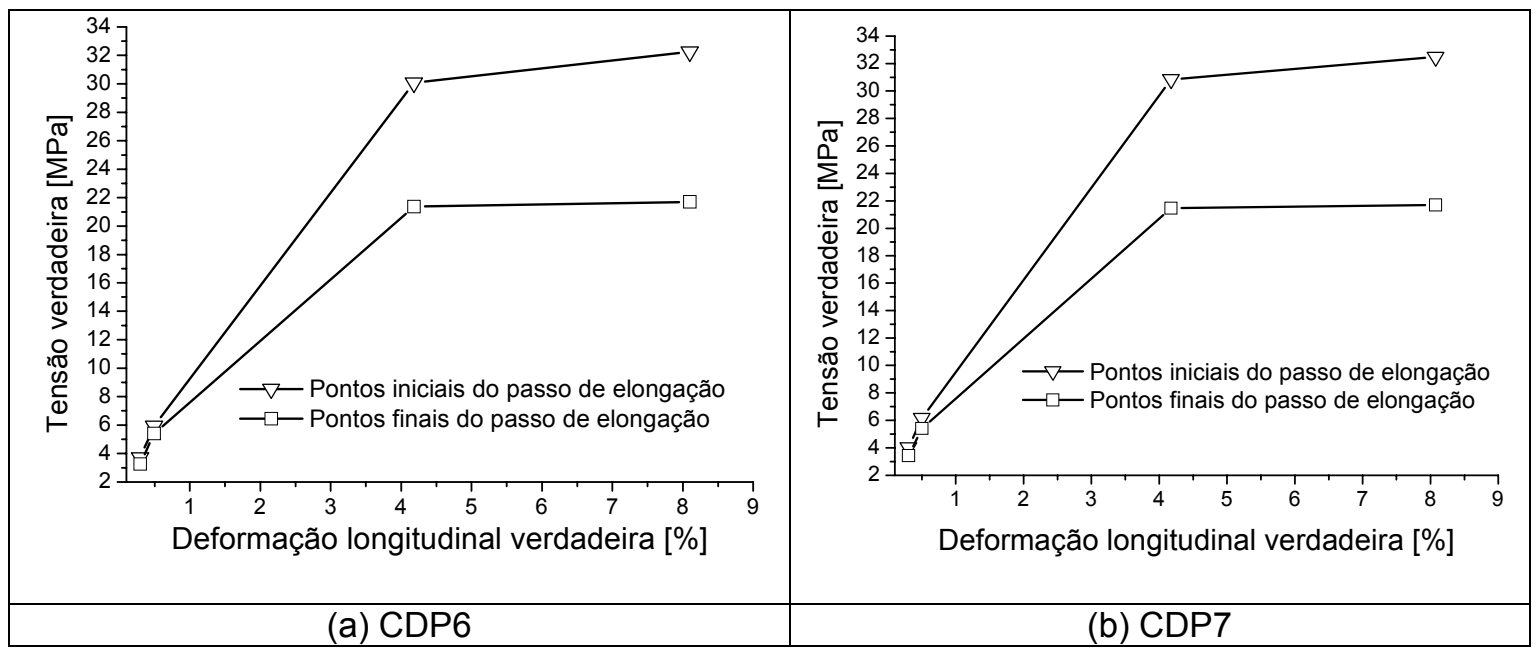

Figura 4.12 - Isócronas do material sob relaxação de tensão.

\subsubsection{Ensaios cíclicos de tração para avaliação da energia dissipada}

Segundo Timoshenko e Gere (1998), os conceitos de energia de deformação e energia complementar formam a base de alguns métodos extremamente poderosos de análise estrutural, sendo estes aplicáveis a estruturas lineares e não-lineares, como é o caso do Princípio dos Trabalhos Virtuais (PTV).

Com isso, verificou-se o comportamento do material realizando ciclos de carregamento, descarregamento e recarregamento (sem que o material sofresse fluência ou relaxação de tensão) a fim de revelar a histerese do material e, consequentemente, a área dos laços histeréticos fosse quantificada, Figura 4.13. As áreas desses laços revelam a perda de energia por unidade de volume em cada ciclo $\left(Q^{*}\right.$, energia dissipada à tração), segundo Meyers e Chawla (1999), Bai e Wang (2003) e essa energia pode ser calculada pela expressão (4.19) a seguir:

$$
Q^{*}=\oint \sigma \cdot d \varepsilon
$$




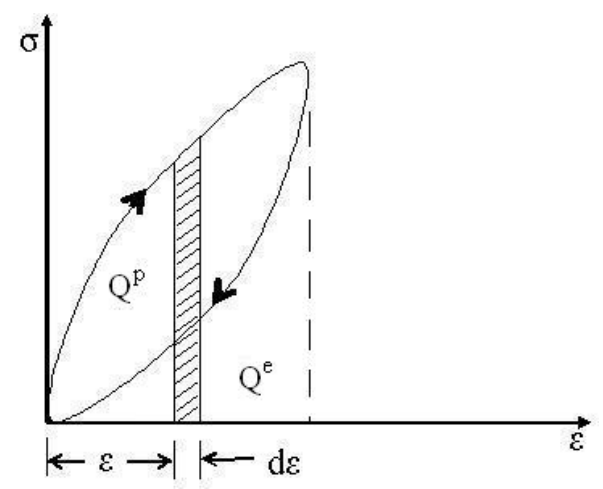

Figura 4.13 - Histerese no ciclo de carregamento e descarregamento.

Assim, para fazer o cálculo da energia dissipada do CDP, escolheu-se o ciclo entre os pontos "A" e "B" da Figura 4.14a.

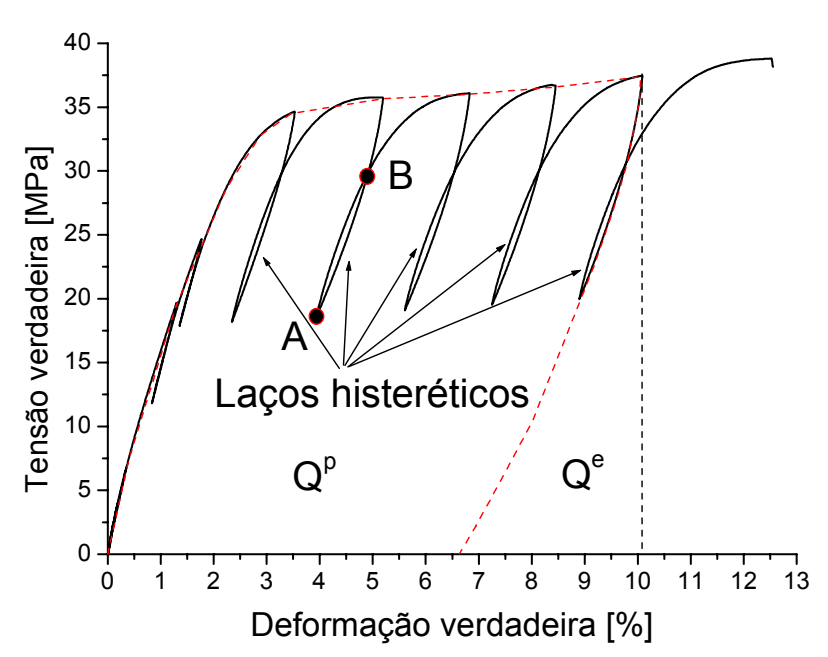

(a) Ensaio completo

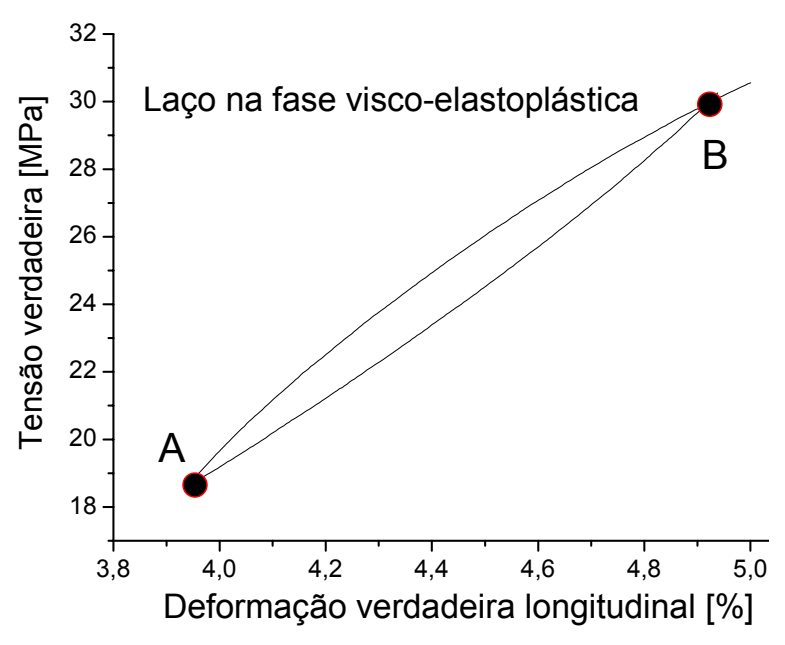

(b) Detalhe do ciclo escolhido

Figura 4.14 - Curvas tensão-deformação para determinação da energia dissipada.

A Figura 4.14 mostra que a histerese acontece de forma mais acentuada quando o limite viscoelástico é superado, pois até então, a trajetória de carregamento era praticamente a mesma trajetória do descarregamento. Com isso, a energia dissipada por unidade de volume $\left(Q^{*}\right)$ pode ser medida de forma mais generalizada por meio da aproximação da curva hipotética tracejada (Figura 4.14a), como se o ensaio fosse realizado por um único ciclo de carregamento e descarregamento completo. Outra forma mais restrita 
é a utilização do laço, como evidenciada na Figura 4.14b, por meio dos laços de descarregamento e recarregamento. Destaca-se, que o descarregamento não foi efetuado até zero em virtude do tempo destinado a cada ensaio. Vale ressaltar ainda que na Figura 4.14a, verifica-se que o nível de tensão (38 MPa) alcançado foi mais elevado do que no ensaio monotônico (32 MPa). Acredita-se que isto tenha ocorrido devido ao nível de deformação atingido (viscoplástico) e ao efeito cíclico do ensaio, possibilitando assim, o material ter uma resistência maior devido ao encruamento sofrido.

O procedimento do cálculo da energia dissipada consiste em ajustar uma equação para a parte superior do laço referente ao carregamento (Figura 4.14b, sentido A-B) e outra para a parte inferior da curva referente ao descarregamento (Figura 4.14b, sentido B-A). Uma vez tendo as duas equações, subtrai-se uma equação da outra conforme a equação (4.22), tendo-se a energia dissipada ao se realizar a integração.

A curva de ajuste para o carregamento é:

$$
\sigma_{1}(\varepsilon)=-99,77745+45,1093 \varepsilon-3,81022 \varepsilon^{2}
$$

A curva de ajuste para o descarregamento é então dada por:

$$
\sigma_{2}(\varepsilon)=19,12679-9,40594 \varepsilon+2,35669 \varepsilon^{2}
$$

A equação da energia dissipada na tração é:

$$
Q^{p}=\int_{A}^{B} \sigma_{1}(\varepsilon) d \varepsilon-\int_{A}^{B} \sigma_{2}(\varepsilon) d \varepsilon
$$

Assim, a energia plástica dissipada para o laço selecionado é de $Q^{p}$ igual a $1,04.10^{4} \mathrm{~J} / \mathrm{m}^{3}$. Destaca-se também que esse valor da energia dissipada foi calculado para apenas um laço histerético, Figura 4.14b. 
Vale salientar que as condições para este ensaio não foram as melhores, em virtude do descarregamento não ser realizado "livremente", ou seja, o CDP estava ligado à máquina através de dois mordentes (garras) tanto para aplicação do carregamento (quando o travessão aplica força no sentido de tracionar o CDP), quanto para o descarregamento (quando o travessão aplica força no sentido de comprimir), Figura 4.15. Há um mordente fixo na base da máquina e outro no travessão de aplicação de deslocamento. Então, quando ocorre o descarregamento neste ensaio, não ocorre a abertura do mordente para que haja a recuperação do material por meio da energia residual armazenada, decorrente dos esforços sofridos pelo CDP.

Portanto, neste momento é impossível mensurar o quanto esse procedimento de descarregamento influenciou na resposta do material, por não permitir que o material sofresse uma recuperação natural, ou seja, em função apenas da parcela elástica residual no material (energia armazenada). Um outro fator que pode ter afetado a energia dissipada foi a diminuição da velocidade de ensaio de $5[\mathrm{~mm} / \mathrm{min}]$ para $0,8[\mathrm{~mm} / \mathrm{min}]$, haja visto que a velocidade de ensaio exerce papel fundamental na resposta do material.

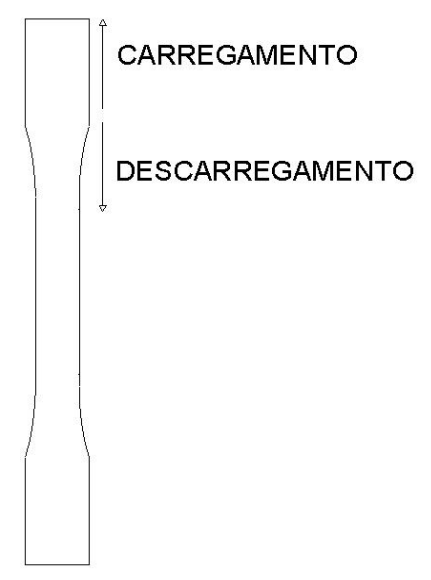

Figura 4.15 - Sentido de carregamento e descarregamento no CDP de tração. 


\subsection{Resultados dos ensaios de compressão}

Para o ensaio de compressão foi seguida a ASTM D695-96, a qual sugere o corpode-prova cilíndrico de 12,7 [mm] de diâmetro e 25,4 [mm] de comprimento, Figura 3.8, como mencionado no CAPITULO 3. Porém, a velocidade configurada em $0,8[\mathrm{~mm} / \mathrm{min}]$ devido às dificuldades de aquisição e controle da resposta viscoelástica do material.

Os ensaios de compressão foram realizados de forma a evitar o problema de "embarrilamento", por meio de um aplicador de carga direcionado para atender esta necessidade. Para a coleta de dados foram utilizados strain gages biaxiais ligados a um sistema de aquisição da HBM, como citado no CAPÍTULO 3. Como nos ensaios de tração os ensaios de compressão foram divididos em:

1- Ensaios monotônicos de compressão;

2- Ensaios cíclicos para avaliação do fenômeno de Fluência;

3- Ensaios cíclicos para avaliação do fenômeno de Relaxação;

4- Ensaios cíclicos de compressão para avaliação da energia dissipada.

\subsubsection{Ensaios de compressão monotônico}

Ensaios monotônicos foram realizados com o intuito de determinar as propriedades elásticas (viscoelásticas) do material, limite de escoamento, ductilidade ou fragilidade do material, bem como, classificar se o material é elastoplástico perfeito, elastoplástico com encruamento, etc. Para o presente trabalho, os ensaios monotônicos também serviram para ajustar os parâmetros do modelo de Drucker-Prager (juntamente com os ensaios monotônicos de tração). Para tanto, determinaram-se as seguintes propriedades compressivas: 
1. o módulo de elasticidade a compressão $\left(E_{c}\right)$;

2. deformação de escoamento a compressão $\left(\varepsilon_{\mathrm{c}}^{\mathrm{y}}\right)$;

3. a tensão de escoamento $\left(\sigma_{\mathrm{c}}^{\mathrm{y}}\right)$ e o limite de deformação elástica a compressão $\left(\varepsilon_{\mathrm{c}}^{\mathrm{e}}\right)$, apresentados na Figura 4.16.

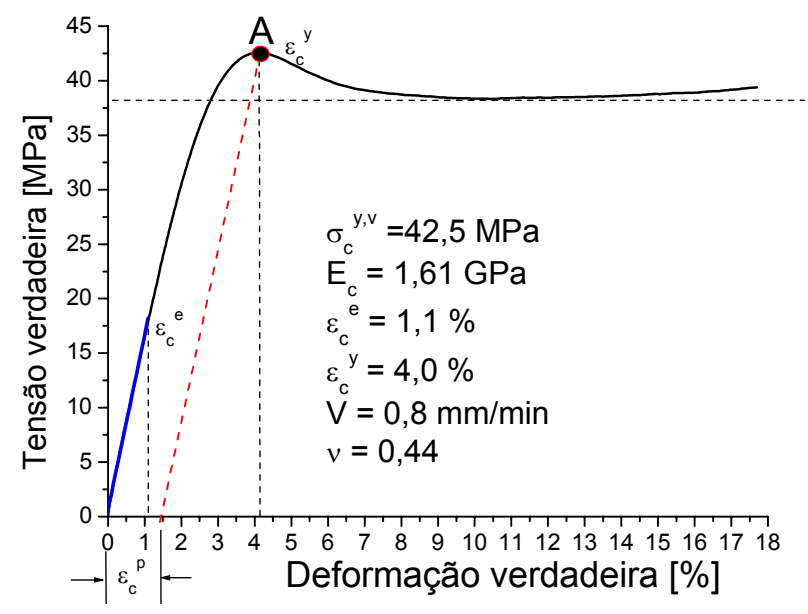

Figura 4.16 - Curva tensão verdadeira-deformação verdadeira.

Analogamente ao ensaio de tração, o material apresenta, após o pico de tensão (ponto A), o comportamento de amolecimento (softening) até aproximadamente $10 \%$ de deformação. Esse amolecimento caracteriza uma perda de rigidez, em seguida o material apresenta ganho de rigidez devido ao encruamento, o qual atingiu aproximadamente $18 \%$ de deformação sem apresentar ruptura. Essa deformação foi medida com strain gages, apesar do fabricante estabelecer que a capacidade máxima de medição é de $15 \%$ de deformação.

Entretanto, estes ensaios também foram instrumentados com LVDT (Transdutor de deslocamento linear variável) a fim de medir a redução do comprimento do CDP juntamente com o strain gage (Figura 4.17). 


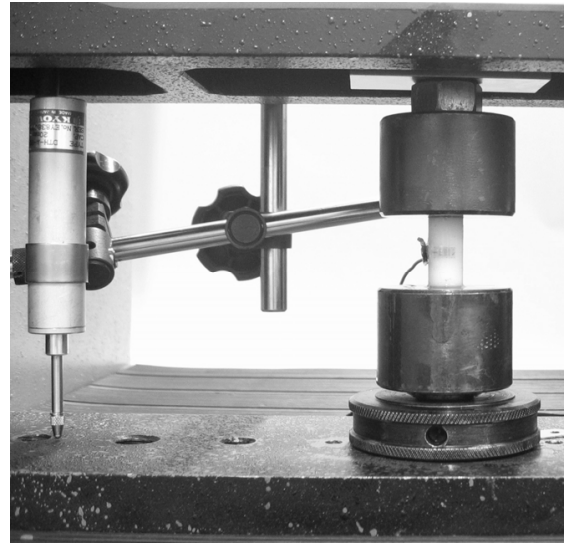

(a) Antes do ensaio;

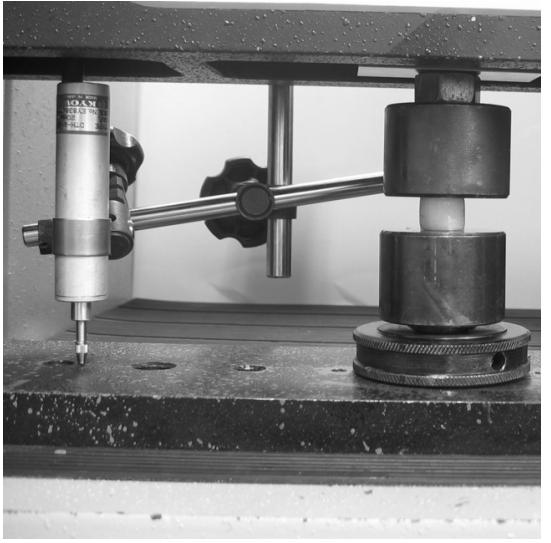

(b) Depois do ensaio.

Figura 4.17 - Representação da redução do comprimento do CDP.

Estas medidas (com LVDT) chegaram a aproximadamente 11,32 [mm] sem que o CDP fraturasse. Essa redução do comprimento equivale a aproximadamente $59,6 \%$ de deformação verdadeira calculada pela Equação 4.23:

$$
\varepsilon_{\text {long }}^{c, v}=100 \cdot \ln \left(\frac{h_{0}-\Delta h}{h_{0}}\right)
$$

Sendo que: $h_{0}$ - altura inicial do CDP de compressão;

$\Delta h$ - variação da altura do CDP de compressão.

O cálculo das tensões seguiu duas formas distintas: 1) considerando as medidas de deformações obtidas pelo LVDT (Equação (4.24)); 2) obtidas pelos strain gages (Equação(4.25)).

1) Pelo LVDT $\quad \sigma_{y, v}^{c}=\frac{4 F}{\pi\left(D_{0}\left(1+\frac{v \varepsilon_{\text {long }}^{c, v}}{100}\right)\right)^{2}}$

2) Pelo Strain gage

$$
\sigma_{y, v}^{c}=\frac{4 F}{\pi\left(D_{0}\left(1+\frac{\varepsilon_{\text {trans }}^{c, v}}{100}\right)\right)^{2}}
$$


Dessa forma, puderam-se comparar essas duas formas de obtenção (via strain gage e via LVDT) das curvas do material sob solicitação compressiva, Figura 4.18, somado a isso, verificou-se o quanto o material ainda poderia se deformar visco-plasticamente sem se romper. Para tanto, para melhorar os resultados, necessitar-se-ia de um sistema de aquisição que medisse o nível de deformação atingido na direção longitudinal e transversal simultaneamente. Porém, dispunha-se apenas do sistema com strain gage, assim, o material foi caracterizado até o nível de deformação medido com este dispositivo.

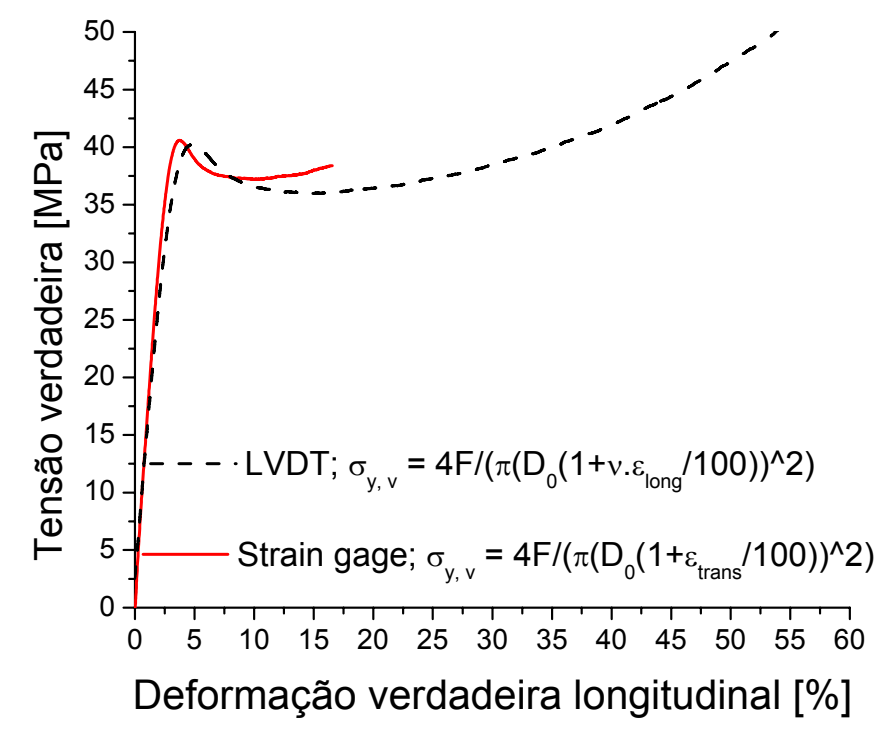

Figura 4.18 - Curvas tensão-deformação compressiva obtidas de duas formas.

A Tabela 4.5 exibe as propriedades relevantes ao limite elástico do material, as quais foram calculadas utilizando:

1- A variação da área da seção transversal por meio da medição com LVDT (Equação (4.24)), a qual se utiliza do princípio de que o material é isotrópico para que o coeficiente de Poisson seja empregado no cálculo da deformação no sentido diametral;

2- A variação da área da seção transversal por meio da medição direta com strain gages (Equação(4.25)) e com as medidas da variação diametral foi possível calcular a expansão da área instantânea. 
Tabela 4.5 - Propriedades do material sob compressão.

\begin{tabular}{|c|c|c|c|c|c|c|}
\hline \multirow{3}{*}{$\mathrm{CDP}$} & \multicolumn{3}{|c|}{ Medidas com LVDT } & \multicolumn{3}{c|}{ Medidas com strain gages } \\
\cline { 2 - 7 } & $\sigma_{\mathrm{c}, \mathrm{v}}=4 \mathrm{~F} /\left(\pi\left(\mathrm{D}_{0}\left(1+\mathrm{v} \varepsilon_{\text {long }} / 100\right)\right)^{2}\right)$ & \multicolumn{3}{|c|}{$\sigma_{\mathrm{c}, \mathrm{v}}=\mathrm{F} / \mathrm{A}$} \\
\cline { 2 - 7 } & $\sigma_{c, y}^{v}$ & $\mathrm{E}_{\mathrm{c}}$ & $\varepsilon_{c, y}^{v}$ & $\sigma_{y}^{v}$ & $\mathrm{E}_{\mathrm{v}}$ & $\varepsilon_{y}^{v}$ \\
& {$[\mathrm{MPa}]$} & {$[\mathrm{GPa}]$} & {$[\%]$} & {$[\mathrm{MPa}]$} & {$[\mathrm{GPa}]$} & {$[\%]$} \\
\hline 1 & 42,13 & 1,18 & 5,66 & 42,50 & 1,61 & 4,06 \\
\hline 2 & 40,16 & 1,30 & 5,07 & 40,60 & 1,80 & 3,75 \\
\hline Média & 41,15 & 1,24 & 5,37 & 41,55 & 1,71 & 3,91 \\
\hline
\end{tabular}

Com os dados da Tabela 4.5, tem-se os valores médios para a tensão, deformação e módulo de elasticidade. Assim, optou-se pelos valores médios das medidas obtidas com os strain gages, pelo fato das medidas terem sido efetuadas diretamente dos CDPs, no sentido axial e transversal do carregamento. Com isso, tem-se:

$\sigma_{c, y}^{v}=41,55 \mathrm{MPa}$-Tensão verdadeira de escoamento em compressão;

$E_{c, v}=1,71 \mathrm{GPa}$ - Módulo de elasticidade em compressão;

$v=0,44-$ Coeficiente de Poisson;

$\varepsilon_{c, y}^{v}=3,91 \%$ - Deformação verdadeira de compressão no início do escoamento.

Com respeito à variação volumétrica no CDP de compressão, tem-se $\varepsilon_{22}=17,7 \% \mathrm{e}$ $\varepsilon_{11}=\varepsilon_{33}=9,98 \%$, (Figura 4.19), e utilizando as equações (4.16) e (4.18) consegue-se verificar o quanto o CDP varia de volume.

$$
\begin{gathered}
\varepsilon_{v}=\hat{\varepsilon}_{11}+\hat{\varepsilon}_{22}+\hat{\varepsilon}_{33} \rightarrow \varepsilon_{V}=\hat{\varepsilon}_{11}(1-2 v) \\
\mathrm{J}_{1}=\hat{\varepsilon}_{11}+\hat{\varepsilon}_{22}+\hat{\varepsilon}_{33}
\end{gathered}
$$




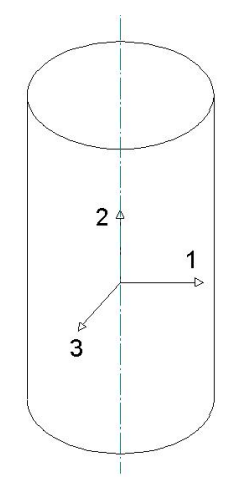

Figura 4.19 - Sistema de orientação das deformações principais.

Segundo Young e Lovell (1996, p. 367), certos polímeros são passíveis de suportar uma forma localizada de deformação plástica. Para tal é necessário um estado de tensão hidrostática que promova um aumento significativo no volume.

Dessa forma, chega-se à variação volumétrica do CDP de compressão pelo primeiro invariante de deformação, como foi determinado nos ensaios de tração. Porém, sem usar a aproximação do coeficiente de Poisson, uma vez que se conseguiu medir com strain gages, chegou-se aos valores expressos na Tabela 4.6.

Tabela 4.6 - Resultado do cálculo da variação volumétrica no CDP de compressão.

\begin{tabular}{|c|c|c|c|c|}
\hline $\operatorname{CDP}$ & $\varepsilon_{11}(\%)$ & $\varepsilon_{22}(\%)$ & $\varepsilon_{33}(\%)$ & $\varepsilon_{\mathbf{V}}(\%)$ \\
\hline 1 & 9,98 & $-17,70$ & 9,98 & 2,26 \\
\hline 2 & 9,33 & $-16,55$ & 9,33 & 2,11 \\
\hline \multicolumn{4}{|r}{ Média da variação volumétrica: } \\
\hline
\end{tabular}

\subsubsection{Ensaios de compressão cíclicos de fluência}

Os resultados a seguir são de ensaios nos quais a amostra sofreu vários ciclos de carregamento, descarregamento e re-carregamento sob velocidade de 37,5 [N/s], conforme mencionado no Capítulo 3 (Figura 3.5). 
Como mencionado na Seção 4.1.2, os ensaios de fluência facilitam a determinação da flexibilidade por meio das curvas isócronas. Porém, os dados obtidos nestes ensaios de compressão foram medidos acima de $0,5 \%$ de deformação. Portanto, para obter as isócronas, fez-se uma generalização do limite viscoelástico até aproximadamente $2,4 \%$ de deformação, ou seja, sem a distinção de viscoelasticidade linear e viscoelasticidade nãolinear (Fase I), Figura 4.20. A Fase II é facilmente determinada com auxílio do ensaio monotônico, pois o nível de deformação atingido é sabido, uma vez que o material começa a escoar e, assim, tem-se o início da visco-elastoplasticidade.

Os pontos das isócronas foram obtidos através de cada passo de carga estabelecida no ensaio, ou seja, extraiu-se a tensão e a deformação no início e no final de cada passo, Figura 4.20, respectivamente. Os valores de tensão e de deformação utilizados são apresentados na Tabela 4.7.

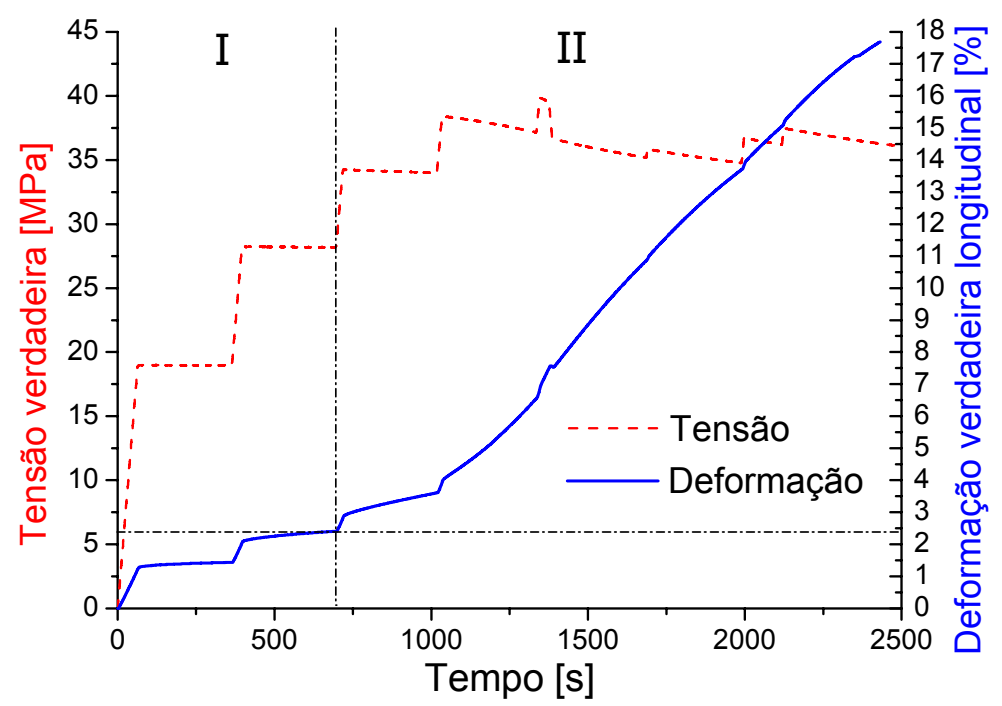

Figura 4.20 - Resposta viscoelástica não-linear de uma série de passos de carga de compressão.

Sendo que, no gráfico das isócronas, a tensão utilizada foi uma tensão média em virtude do controle de força da máquina não ser tão eficiente quanto numa máquina para ensaios de fluência. Contudo houve um bom controle de força, no instante em que a tensão variava quando o material começava a escoar. Portanto, ao atingir o limite de escoamento, a 
máquina controlava o nível de força estabelecido, porém a tensão não permanecia constante no patamar especificado. Isto pode ser visto na Figura 4.22.

Tabela 4.7 - Propriedades compressivas do ensaio de fluência para as curvas isócronas.

\begin{tabular}{|c|c|c|c|c|c|c|c|c|c|c|}
\hline \multirow[b]{3}{*}{ Ciclo } & \multicolumn{5}{|c|}{ CDP1 } & \multicolumn{5}{|c|}{ CDP4 } \\
\hline & \multicolumn{2}{|c|}{ Tempo [s] } & \multirow{2}{*}{$\begin{array}{c}\text { Tensão } \\
\sigma \mathrm{c}, \mathrm{m} \\
{[\mathrm{MPa}]}\end{array}$} & \multirow[b]{2}{*}{$\begin{array}{l}\varepsilon \mathrm{c}_{, \mathrm{i}} \\
{[\%]}\end{array}$} & \multirow[b]{2}{*}{$\begin{array}{l}\varepsilon \mathrm{c}, \mathrm{f} \\
{[\%]}\end{array}$} & \multicolumn{2}{|c|}{ Tempo [s] } & \multirow{2}{*}{$\begin{array}{c}\text { Tensão } \\
\sigma c,_{\mathbf{m}} \\
{[\mathrm{MPa}]}\end{array}$} & \multirow[b]{2}{*}{$\begin{array}{r}\varepsilon \mathrm{C}_{, \mathrm{i}} \\
{[\%]}\end{array}$} & \multirow[b]{2}{*}{$\begin{array}{l}\varepsilon \mathrm{c}_{, \mathrm{f}} \\
{[\%]}\end{array}$} \\
\hline & $\mathbf{t}_{\mathrm{c}}$ & $\mathbf{t}_{d}$ & & & & $\mathbf{t}_{\mathrm{c}}$ & $t_{d}$ & & & \\
\hline 1 & 67 & 294,5 & 18,96 & 1,295 & 1,437 & 69 & 168,0 & 18,92 & 1,436 & 1,585 \\
\hline 2 & 397,5 & 297 & 28,19 & 2,097 & 2,415 & 277,5 & 171,0 & 28,05 & 2,326 & 2,721 \\
\hline 3 & 720,5 & 294 & 34,1 & 2,92 & 3,614 & 483 & 166,5 & 33,84 & 3,214 & 4,121 \\
\hline 4 & 1035,5 & 297,5 & 37,76 & 3,983 & 6,62 & 684 & 166,5 & 37,26 & 4,683 & 7,535 \\
\hline
\end{tabular}

Sendo que:

$t_{c}$ - tempo de corte;

$t_{d}$ - tempo de duração de cada passo;

$\boldsymbol{\sigma}_{c, m}$ - tensão compressiva média calculada entre a tensão do início e o fim do passo;

$\varepsilon_{c, i}$ - deformação de compressão no início do passo;

$\varepsilon_{\mathrm{c}, \mathrm{f}}$ - deformação de compressão no final do passo.

Assim, as curvas isócronas foram elaboradas com os dados de ensaio de fluência até o quarto passo de carga. Estes passos foram variados em seus níveis de força e, conseqüentemente, nos níveis de deformação. Dessa forma, considerando a Figura 4.21 pode-se afirmar que o material perdeu a viscoelasticidade a partir dos $2,415 \%$ de deformação. Com isso, caracterizou-se que até este valor o material pode ser considerado viscoelástico. 


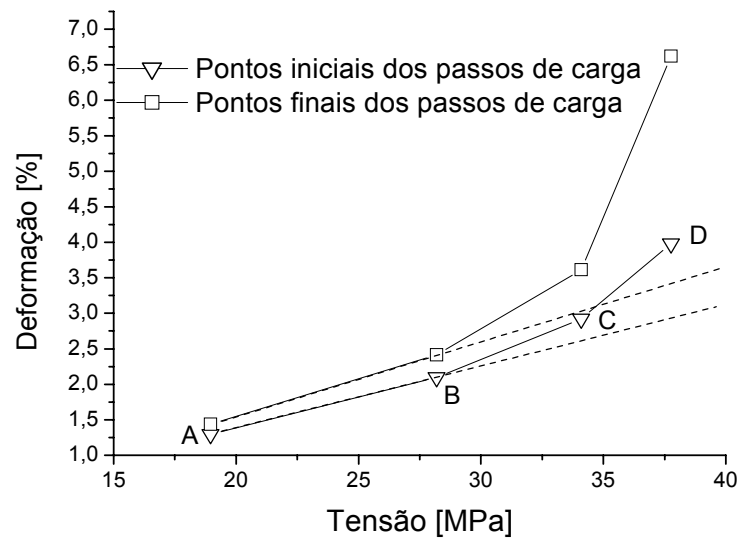

Figura 4.21 - Curvas isócronas de compressão para determinação da viscoelasticidade (Deformação -Tensão).

Neste ensaio é perceptível como o material muda de comportamento ao passo que vai se afastando da fase elástica. A Figura 4.22 ilustra a curva de um ensaio completo que contempla as parcelas: ( I ) viscoelástica e ( II ) visco-elastoplástica.

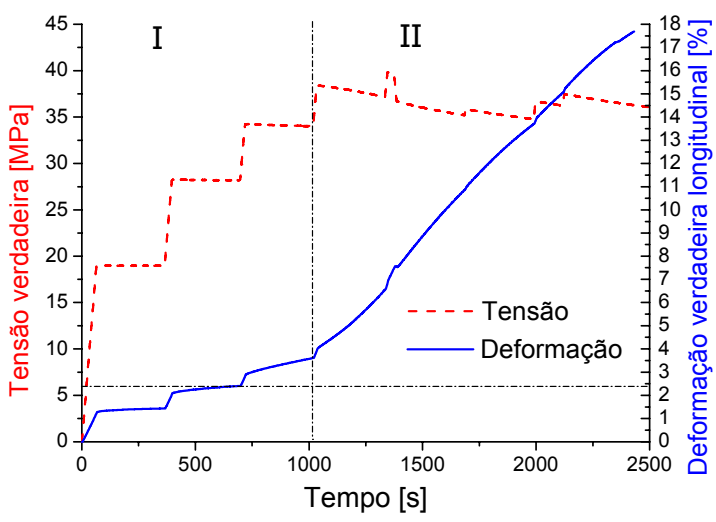

(a) Curva tensão - tempo - deformação

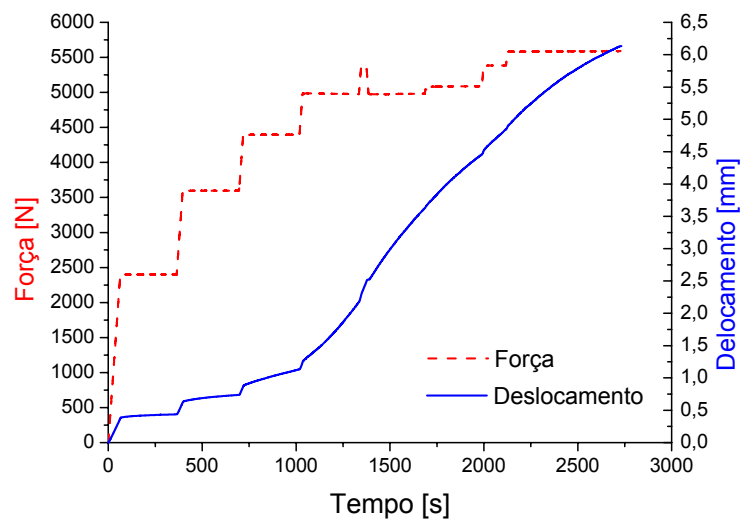

(b) Curva força - tempo - deslocamento

Figura 4.22 - Curvas de fluência para ensaio de compressão.

Com as fases identificadas, deve-se perceber que:

1- Na fase viscoelástica (fase I), a qual compreende a parcela viscoelástica não-linear, o material sofreu o efeito da fluência, ou seja, a tensão permanece constante, mas o CDP demonstrou certo nível de deformação decorrente da parcela viscosa, ou seja, seu comportamento não é mais linear com o carregamento; 
2- Na parcela visco-elastoplástica (fase II), no primeiro patamar o material demonstrou que não mais suportava o carregamento imposto, pelo fato de apresentar escoamento. Com isso, o terceiro patamar foi idealizado para que o CDP ultrapassasse do regime viscoelástico não-linear para o regime visco-elastoplástico. Assim, foi aplicada uma força capaz de ultrapassar a fase I (viscoelástica) e que fizesse com que o CDP atingisse níveis de deformação permanentes. Em seguida, fez-se um descarregamento a um patamar mais baixo a fim de verificar se o material se recuperaria e continuaria com o ensaio de fluência. Porém, não se obteve êxito, porque o material entrou num processo de escoamento acentuado, superando o limite de medição do sistema de aquisição de dados.

Em vista desses problemas foram feitas algumas alterações nos ciclos de ensaio, de modo que o CDP tivesse mais alguns patamares de recuperação antes de começar um novo re-carregamento no regime visco-elastoplástico, Figura 4.23. Com isso, melhorou-se um pouco a resposta, porém não houve um ensaio de fluência ideal, uma vez que para este ensaio é requerido um nível constante de tensão. Desta forma, investigou-se a variação da secção transversal e foi constatado que enquanto a célula de carga mantinha a força constante a secção transversal aumentava bastante ao ultrapassar o limite de escoamento. Portanto, com a força constante e a área aumentando, a tensão passou a diminuir de forma muito rápida, de modo que a máquina não conseguia controlar o nível de tensão. Isto fez com que o ensaio não fosse tão bem sucedido quanto o ensaio de tração. 


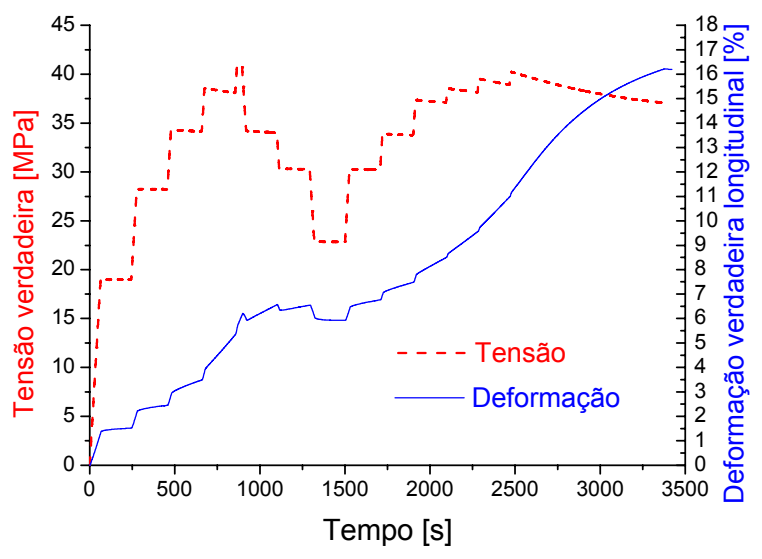

(a) Tensão - tempo - deformação longitudinal.

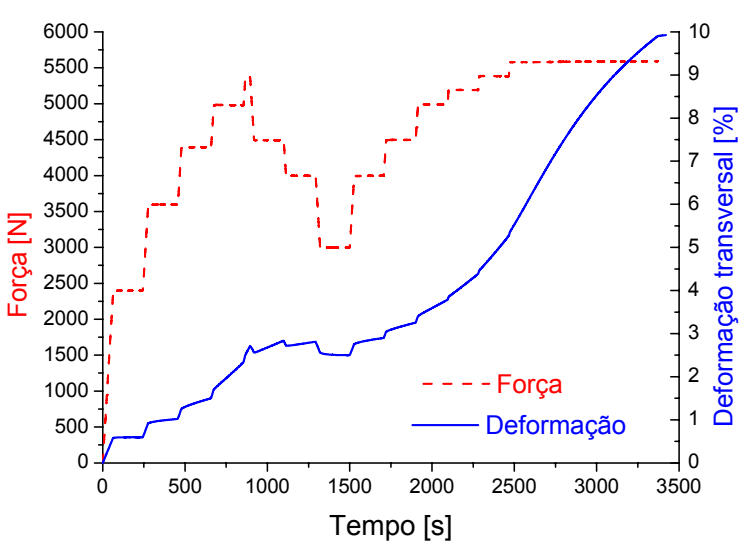

(b) Força - tempo - deformação transversal.

Figura 4.23 - Curvas do ensaio em fluência compressiva, com patamares de recuperação.

\subsubsection{Ensaios de compressão cíclicos de relaxação}

Como nos ensaios de relaxação de tensão na tração, na compressão, seguiu-se o mesmo procedimento de vários ciclos de carregamento, descarregamento e recarregamento para compressão, como pode ser visto na Figura 4.24a. Quanto à manutenção do nível de elongação, o CDP de compressão se comportou diferentemente do CDP de tração, havendo apenas um overshoot no início do patamar e no decorrer do ensaio estes patamares de deformação se estabilizaram. Na Figura $4.24 b$, pode ser visto que a deformação é praticamente constante enquanto que a tensão reduz drasticamente (para o maior pico de tensão a queda é da ordem de $53 \%$ ), esse fato evidencia que o material sofreu apenas relaxação de tensão. Sendo esta uma outra diferença do ensaio de tração, no qual o material se comportava com uma diminuição de tensão e aumento na deformação, Figura 4.11b.

Ainda na Figura 4.24a, percebe-se como a tensão depende do tempo, principalmente quando o material se afasta do regime viscoelástico e se aproxima do regime viscoelastoplástico, quando o material entra neste regime ele exibe (Fase II) uma relaxação 
elevada. No descarregamento, o CDP diminuía um pouco o nível de deformação ou elongação, devido à parcela elástica residual. Isto pode ser notado mais precisamente por meio das curvas força-deslocamento (Figura 4.24b), sendo que após um período de relaxação, realizava-se um descarregamento. Caso este descarregamento fosse mantido, havia uma pequena recuperação do material em virtude da parcela elástica residual, porém a maior parcela de deformação era permanente, para o caso em que o CDP sofresse deformações além do limite elástico.

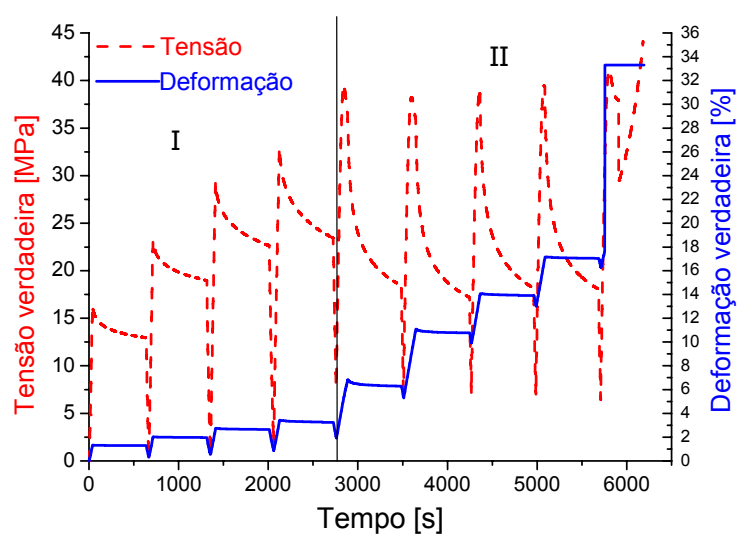

(a) Curvas tensão-tempo-deformação.

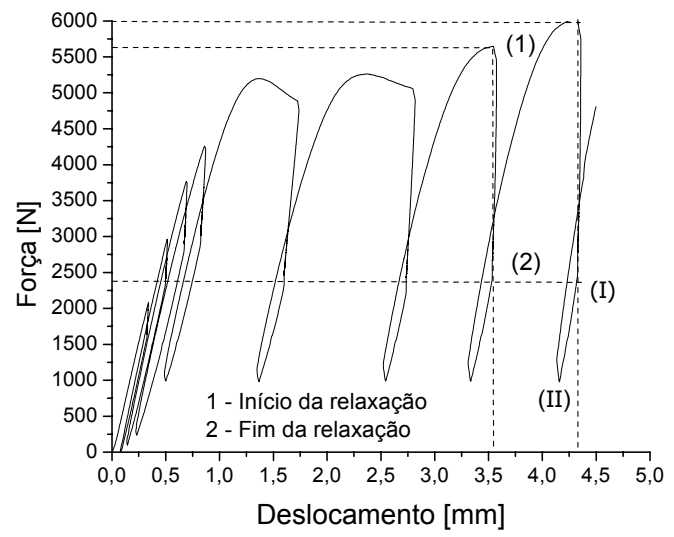

(b) Curvas força-deslocamento.

Figura 4.24 - Relaxação de tensão na compressão.

Vale ressaltar que este ensaio também facilita a determinação do módulo de elasticidade por meio das curvas isócronas, facilitando a determinação da perda da linearidade. Os pontos destas curvas foram obtidos através de cada passo de elongação estabelecida no ensaio, ou seja, extraiu-se a tensão e a deformação no início e no final de cada passo, respectivamente, Figura 4.24a. Os valores de tensão e deformação são apresentados na Tabela 4.8.

No gráfico das isócronas para relaxação de tensão na compressão, a deformação utilizada foi uma deformação média, em virtude do controle de deslocamento da máquina não ser tão eficiente para compensar os efeitos do retardo da deformação. 
Tabela 4.8 - Propriedades do material na relaxação de tensão na compressão.

\begin{tabular}{|c|c|c|c|c|c|}
\hline \multirow{2}{*}{ Ciclo } & \multicolumn{3}{|c|}{ CDP6 } \\
\cline { 2 - 4 } & \multicolumn{2}{|c|}{ Tempo [s] } & \multirow{2}{*}{$\boldsymbol{\varepsilon}_{\mathbf{m}}$} & \multicolumn{2}{c|}{ Tensão } \\
\cline { 2 - 5 } & $\mathbf{t}_{\mathbf{c}}$ & $\mathbf{t}_{\mathbf{d}}$ & $\mathbf{[ \% ]}$ & $\begin{array}{c}\mathbf{\sigma}_{\mathbf{i}} \\
{[\mathbf{M P a}]}\end{array}$ & $\begin{array}{c}\mathbf{\sigma}_{\mathbf{f}} \\
{[\mathbf{M P a}]}\end{array}$ \\
\hline 1 & 43,5 & 588 & 1,3093 & 15,5118 & 12,9552 \\
\hline 2 & 727,5 & 588,5 & 1,9554 & 23,0729 & 18,9937 \\
\hline 3 & 1427 & 577 & 2,6905 & 29,2430 & 22,6576 \\
\hline 4 & 2138,5 & 578 & 3,3289 & 32,9188 & 23,454 \\
\hline
\end{tabular}

Sendo que:

$t_{c}$ - tempo de corte;

$t_{d}$ - tempo de duração de cada passo;

$\varepsilon_{\mathrm{m}}$ - deformação média calculada entre a deformação do início e do fim do passo;

$\sigma_{i}$ - tensão no início do passo;

$\sigma_{\mathrm{f}}=$ tensão no final do passo.

A Figura 4.25 exibe curvas isócronas, as quais determinam o ponto onde o material perde a linearidade. Estas curvas foram determinadas com dois pontos de deformação até $2,1 \%$ e os outros dois pontos acima deste valor, como mostrado na Tabela 4.8. Com isso, pode-se determinar o limite viscoelástico linear e o módulo de elasticidade dentro da faixa de 0 a 2,1\% de deformação. Porém, o ideal seria que os pontos iniciais estivessem dentro da faixa de 0 a $0,5 \%$ de deformação para caracterizar melhor o ponto limite de elasticidade, bem como, o módulo de Young mais coerente. 


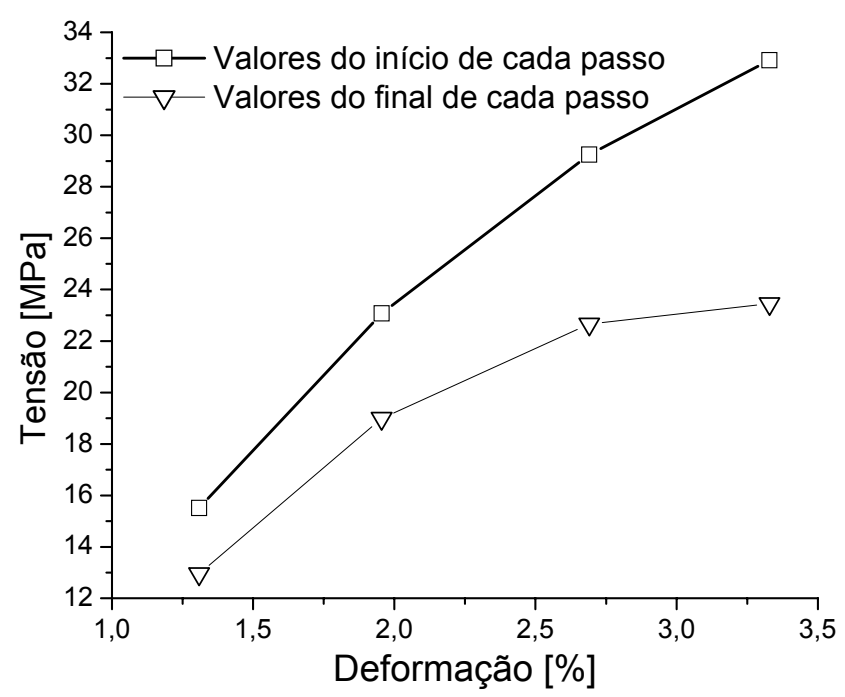

Figura 4.25 - Isócronas do material sob relaxação de tensão (tensão-Deformação).

\subsubsection{Ensaios cíclicos de compressão para avaliação da energia dissipada}

Como mencionado no item 4.1.4, o cálculo da energia dissipada na compressão procedeu-se da mesma forma como no ensaio de tração, ou seja, através do gráfico de carregamento, descarregamento e recarregamento do CDP. De modo a ajustar uma equação que represente a parte superior do laço e uma outra que represente a parte inferior do mesmo laço. Definidas as curvas, é possível calcular as áreas sob as mesmas e com isso determinar a energia total que é composta da energia dissipada e da energia de armazenamento (energia elástica). Então, subtraindo da energia total a energia elástica, tem-se a energia dissipada pelo CDP quando solicitado por compressão.

Ressalta-se que o aplicador de carga, quando do descarregamento, realmente não induz nenhum carregamento extra ao CDP, pelo fato do mesmo aliviar a pressão no sentido de perder o contato com o CDP, uma vez que neste ensaio o espécime não é preso à máquina como no ensaio de tração, Figura 4.26. Assim, no ensaio de tração, o descarregamento pode induzir uma flexão ou compressão no CDP, em virtude do CDP estar 
ligado à máquina por meio dos mordentes de aplicação de força. Por isso, o ensaio de compressão pode ser melhor para avaliar esse tipo de comportamento do material. Porém, seria ainda melhor caso o aplicador liberasse completamente o CDP para que a recuperação se desse, tão somente, pela energia elástica do material.
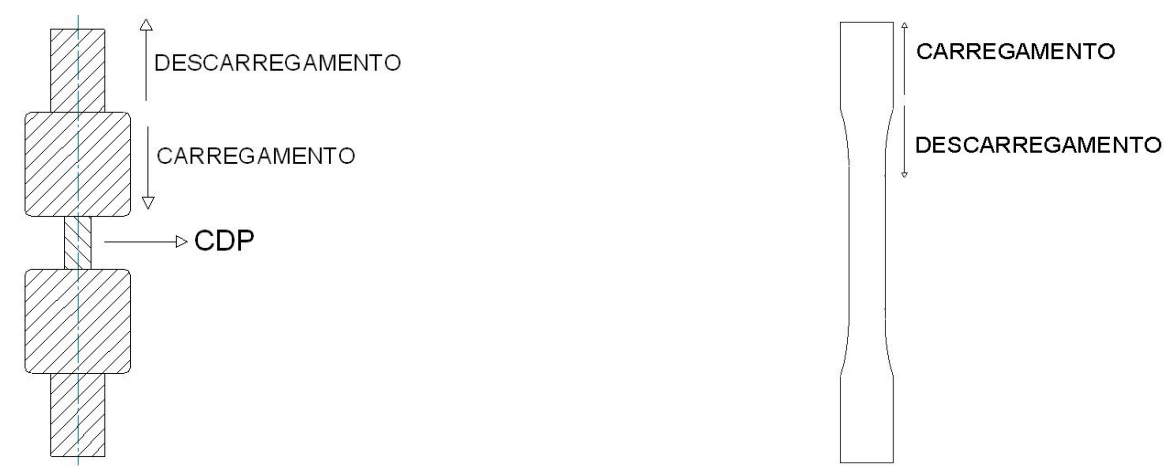

Figura 4.26 - Comparação entre a forma de carregamento e descarregamento dos ensaios de compressão e tração.

Assim, para fazer o cálculo da energia dissipada pelo CDP no ensaio de compressão, escolheu-se o ciclo entre os pontos "A" e "B" da Figura 4.27 e, seguiu-se o mesmo procedimento do Item 4.1.4, encontrando uma quantidade de energia dissipada para o ciclo escolhido $\left(Q^{p}=1,79.10^{4}\left[\mathrm{~J} / \mathrm{m}^{3}\right]\right)$. Salienta-se que essa quantidade de energia dissipada foi obtida por uma aproximação de um único ciclo, no entanto o ideal para a plena caracterização do material quanto à energia dissipada seria deformar o material até próximo ao seu limite de ruptura e em seguida realizar o descarregamento completo, ou seja, nível zero de força. Assim, ter-se-ia o nível de plastificação do material. 


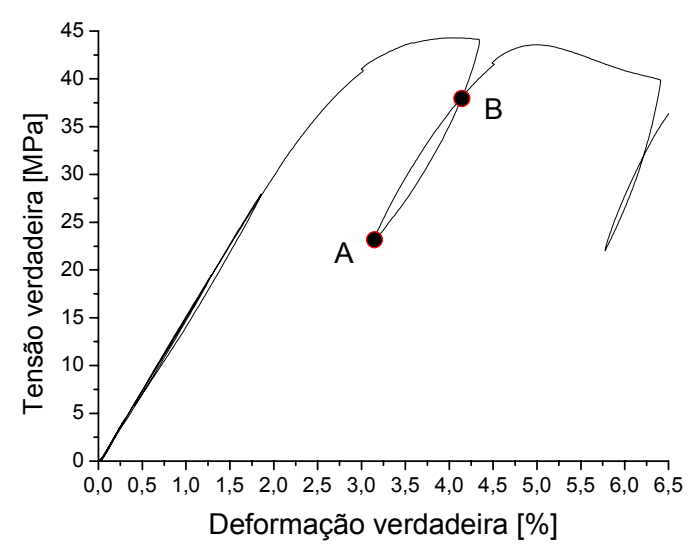

(a) Curva completa

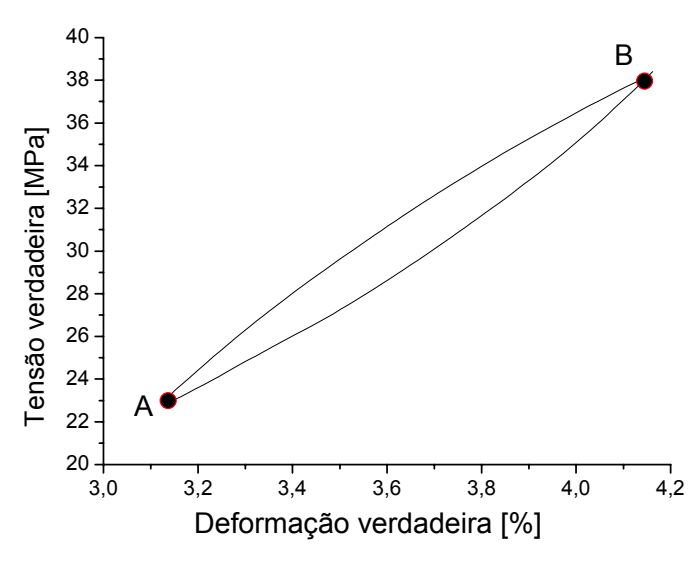

(b) Detalhe do ciclo escolhido.

Figura 4.27 - Curvas tensão-deformação para determinação da energia dissipada.

\subsection{Resultados dos ensaios de flexão}

Para o ensaio de flexão três pontos foram adotadas as dimensões especificadas pela ASTM D790-96a (Método I), a qual sugere o corpo-de-prova prismático de acordo com a Figura 3.11, porém a velocidade do ensaio foi de $0,8[\mathrm{~mm} / \mathrm{min}]\left(\dot{\varepsilon}=2,67.10^{-4}\left[\mathrm{~s}^{-1}\right]\right)$.

A realização dos ensaios de flexão é um pouco controversa, em virtude dos deslocamentos dos apoios, ou seja, quanto mais o CDP sofre flexão mais os pontos de apoio mudam de posição. Este fato é bastante significativo para ensaios em materiais poliméricos, pois os apoios são fixos e com a flexão do material a distância diminui, devido a mudança da posição do ponto de contato, Figura 4.28. Tentou-se encontrar uma solução para esse problema em que o dispositivo se auto-ajustasse, porém não se obteve êxito, porque o CDP sofria grande flexão, o que impossibilitava a estabilização dos apoios durante a realização dos ensaios, o que obrigou a que fossem deixados fixos. Portanto, os ensaios foram realizados com dispositivo de apoio fixo e distância inicial entre os apoios de 51 [mm], como fora mencionado. Percebeu-se, também, que durante a aquisição dos dados, o atrito entre os apoios, o CDP e o aplicador de força estava interferindo nas curvas respostas, com 
isso resolveu-se aplicar lubrificante, evitando a presença do comportamento serrilhado característico, proveniente do atrito excessivo, Figura 4.29.

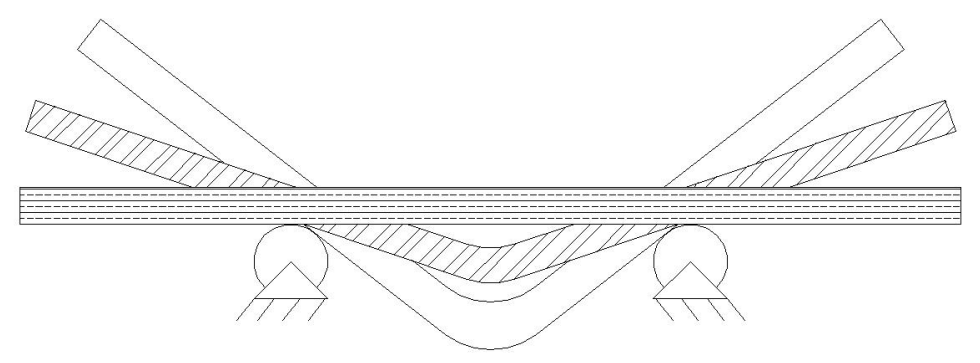

Figura 4.28 - Esquema do dispositivo de flexão.

Os ensaios de flexão foram realizados segundo os mesmos procedimentos dos ensaios de tração e compressão, ou seja:

1- Ensaios monotônicos de flexão;

2- Ensaios cíclicos para avaliação da fluência em flexão;

3- Ensaios cíclicos para avaliação da relaxação em flexão.

\subsubsection{Ensaios de flexão monotônico}

A Figura 4.29a mostra que as curvas carga-deslocamento apresentam uma resposta altamente não-linear, caracterizando o comportamento viscoelastoplástico proveniente do deslocamento imposto $(14,00[\mathrm{~mm}])$. Destaca-se que até certo nível da flecha a parcela nãolinear é uma conseqüência da não-linearidade geométrica. Mas para o nível de deslocamento empregado a não-linearidade é também uma conseqüência física. A Figura 4.29b apresenta as curvas tensão-deformação, com as quais obtém-se o módulo de elasticidade à flexão $E^{f}$ igual a 1,22 GPa para o nível de deformação de $\varepsilon^{f}$ igual a $0,5 \%$ e de tensão de flexão $\sigma^{f}$ igual a 6,13 MPa. 


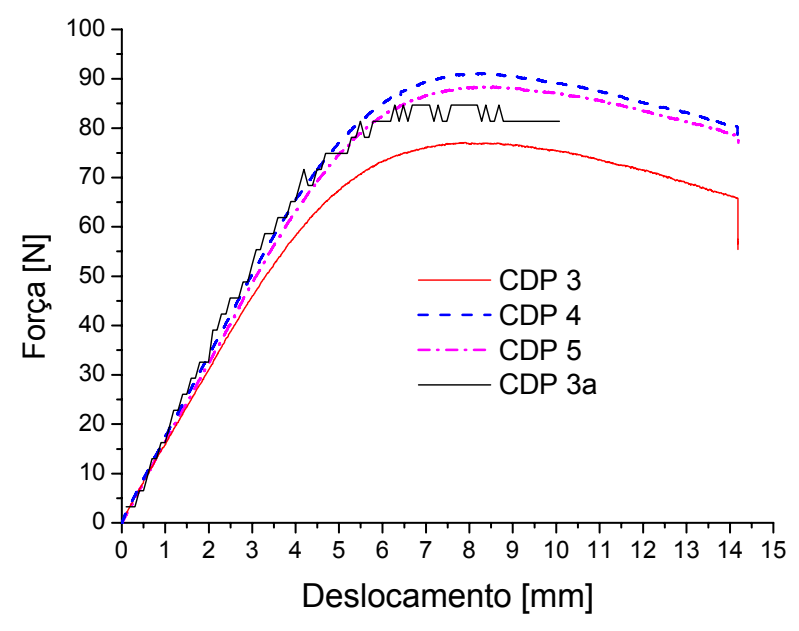

(a)

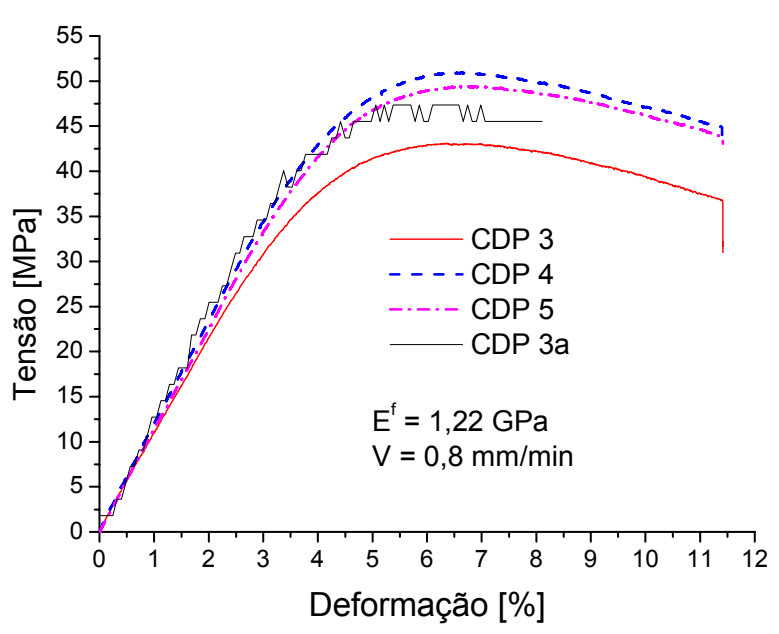

(b)

Figura 4.29 - Curvas de (a) força-deslocamento e (b) tensão-deformação sob flexão.

Com as devidas considerações, que a sessão inicialmente plana permanece plana e ortogonal ao eixo deslocado, pode-se aplicar a teoria de cálculo das parcelas das tensões de tração (abaixo da linha neutra) e compressão (acima da linha neutra) no CDP de flexão (WILLIAMS, 1973).

Deve-se relembrar que o CDP quando está sob tração, o arranjo das cadeias poliméricas acontece no sentido do carregamento, no caso no sentido uniaxial. Ao passo que no carregamento compressivo, as cadeias poliméricas estão se deformando e se rearranjando de forma planar, ou seja, perpendicular ao sentido de carregamento. Dessa forma, a linha neutra da viga não coincide com a linha média geométrica, pois o material possui diferentes módulos de elasticidade à tração (1,52 [GPa]) e à compressão (1,71 [GPa]), devido ao diferenciado processo de deformação sob tração e sob compressão. Percebe-se que o nível de tensão ( 50 [MPa]) que o CDP de flexão atingiu é maior do que o de tração. Porém, destaca-se que apesar do nível de tensão na flexão ser maior do que na tração, quando se verifica o nível de força o contrário é ocorre. Acredita-se que essa diferença entre o nível de tensão ocorre devido à aplicação das fórmulas utilizada na flexão, uma vez que a mesma é aplicável para o regime elástico e, também, pelo fato de considerar 
constante (nas equações) a distância $(L)$ entre os apoios. Vale ressaltar que na realidade a distância "L" é variável, como a Figura 4.28 ilustra a mudança do ponto de contato entre o CDP e os apoios à medida que o mesmo sofre flexão.

\subsubsection{Ensaios de relaxação de tensão sob flexão}

Neste ensaio foi considerado o mesmo procedimento dos ensaios de tração e de compressão, ou seja, vários ciclos de carregamento, descarregamento e recarregamento, foram aplicados, Figura 4.30. Pode-se notar por meio da Figura 4.30b que desde o primeiro passo de deformação ( 0,19\%), há uma resposta com relaxação.

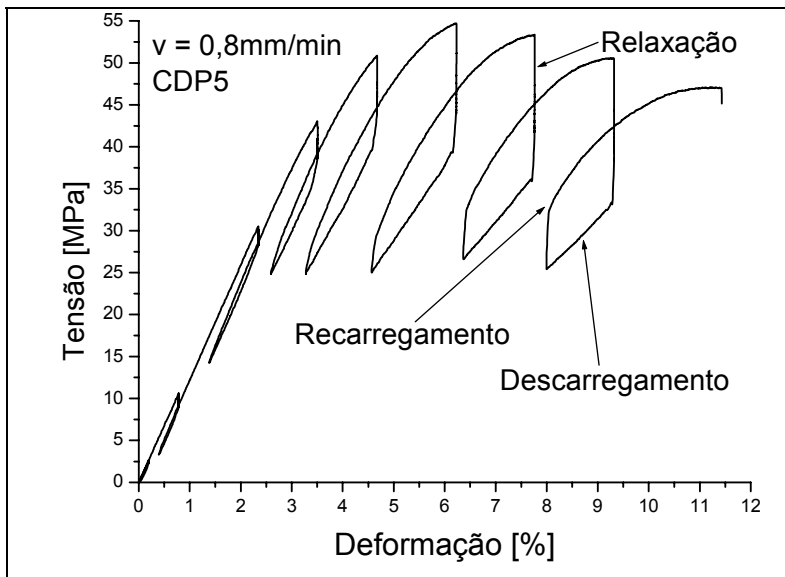

(a)

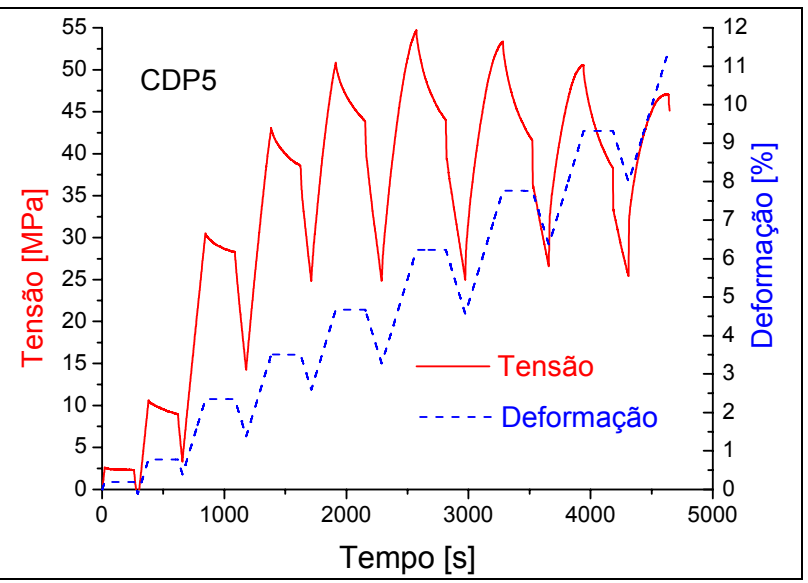

(b)

Figura 4.30 - Curvas (a) Tensão-deformação, (b) Tensão-tempo-deformação em flexão.

Vale destacar que o controle dos patamares de deformação prescrita neste ensaio manteve-se estável, ao contrário dos ensaios de tração e compressão que ao atingir determinado nível de deformação não conseguiram a manutenção do nível de deformação prescrito para a verificação da relaxação no período de tempo estabelecido para cada patamar. Assim, havia aumento da deformação com o tempo. O termo deformação prescrita 
vem da condição que a máquina de ensaio realizava os ensaios segundo um roteiro préestabelecido, no qual é definido cada nível de deformação, o tempo de duração de cada nível e se haverá descarregamento ou recarregamento.

Quanto à relaxação de tensão, percebe-se que quanto mais o material se afasta do regime elástico mais acentuada fica a relaxação nos patamares. Isto evidencia a parcela viscosa do material que necessita de tempo para que o material entre em equilíbrio e, assim, o material apresente um nível de tensão compatível com a deformação aplicada.

\subsection{Resultados dos ensaios de DMA}

Os testes de DMA foram realizados sob um carregamento cíclico senoidal de freqüência igual a $1[\mathrm{~Hz}]$, com o intuito de determinar as propriedades viscoelásticas associadas ao biopolímero.

A Figura 4.31 exibe o módulo de elasticidade (E') em função do tempo, bem como o módulo de perda (E”) do módulo de elasticidade em função do tempo, ou seja, a parcela viscosa. Verifica-se que, inicialmente, a parcela elástica é igual a 1,2 [GPa], sendo que nos ensaios quase-estáticos de tração constatou-se um valor igual a 1,52 [GPa]. No entanto, deve-se ressaltar que, durante o ensaio de DMA, a amostra é submetida a um carregamento de flexão e, por isso, o módulo de elasticidade do material sob flexão $\left(E^{f}=1,22\right.$ [GPa]) é igual ao obtido pelo ensaio de DMA, isto evidencia que a obtenção das propriedades elásticas por meio dos ensaios de flexão é válida.

Nota-se também que a parcela elástica reduz em função do tempo ao passo que a parcela viscosa começa a aumentar gradativamente e atinge um valor máximo de 0,1 [GPa]. Após este valor, constata-se a redução da parcela viscosa juntamente com a parcela elástica, porém ao longo de todo tempo analisado, a parcela elástica praticamente domina a 
resposta, uma vez que a parcela elástica é aproximadamente 10 (dez) vezes maior que a parcela viscosa. Portanto, conclui-se que o biopolímero possui uma resposta mais elástica do que viscosa sob temperatura ambiente.

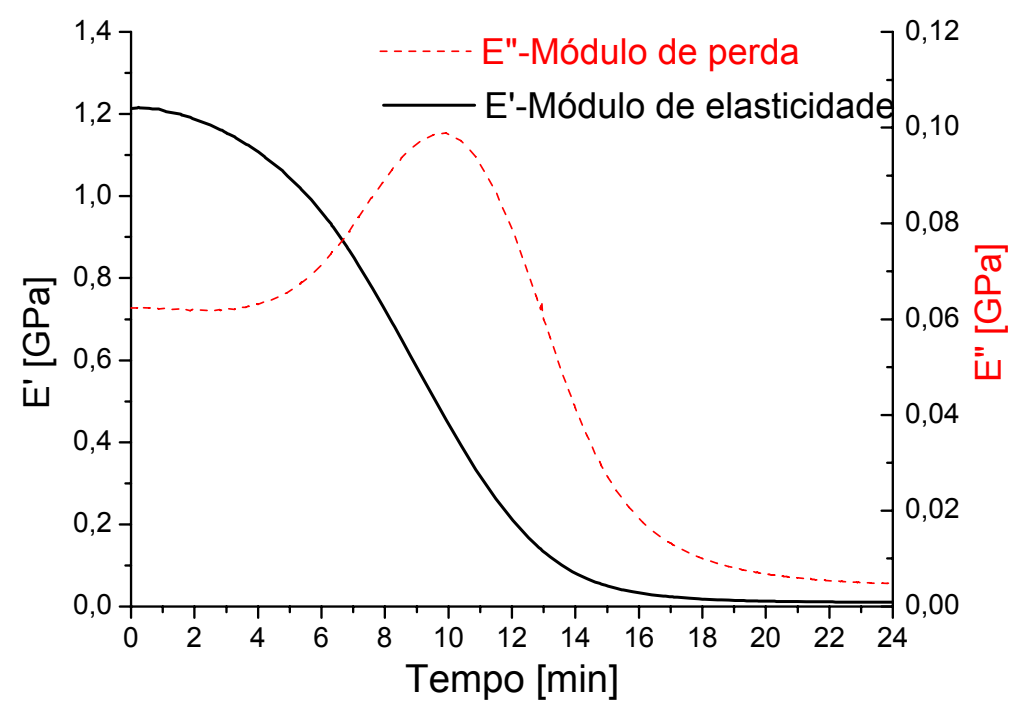

Figura 4.31 - Módulo de elasticidade: curvas parcela elástica (E')-Tempo e parcela viscosa (E”)Tempo.

O módulo de elasticidade complexo é formado pela composição da parcela viscosa (parte imaginária) com a parcela elástica (parte real), como pode ser visto na Figura 4.32.

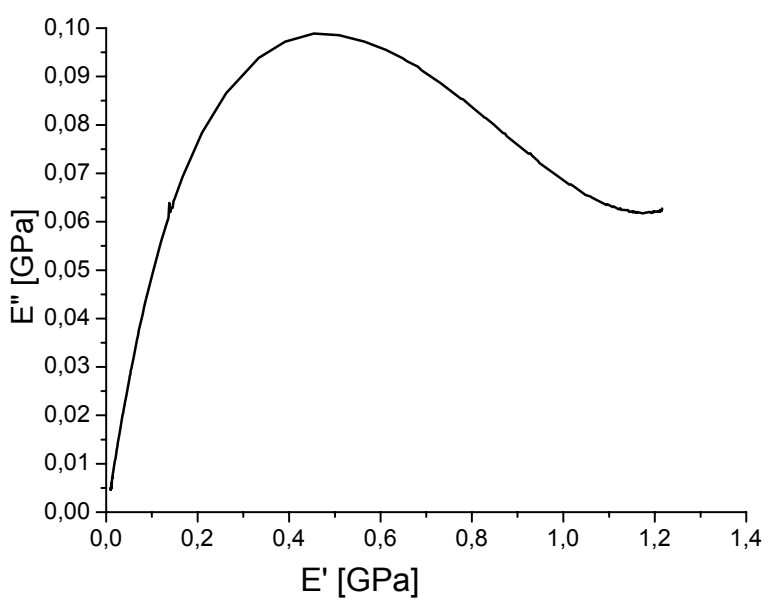

Figura 4.32 - Módulo de elasticidade complexo $\left(E^{*}\right)$ : curva parcela viscosa-parcela elástica. 
A Figura 4.33 apresenta o Fator de Amortecimento $(\tan \delta)$ em função do tempo. Destaca-se, que este fator está associado principalmente com a viscosidade do material. Portanto, até 5 minutos, este valor é pequeno e permanece praticamente constante em 0,05 , porém a partir deste instante, o fator aumenta consideravelmente chegando a atingir valor máximo de 0,55 em 16 minutos. Ressalta-se que o valor de tan $\delta$ é dado pela relação E’/E' que é proporcional a razão existente entre a energia dissipada pela energia armazenada pelo sistema.

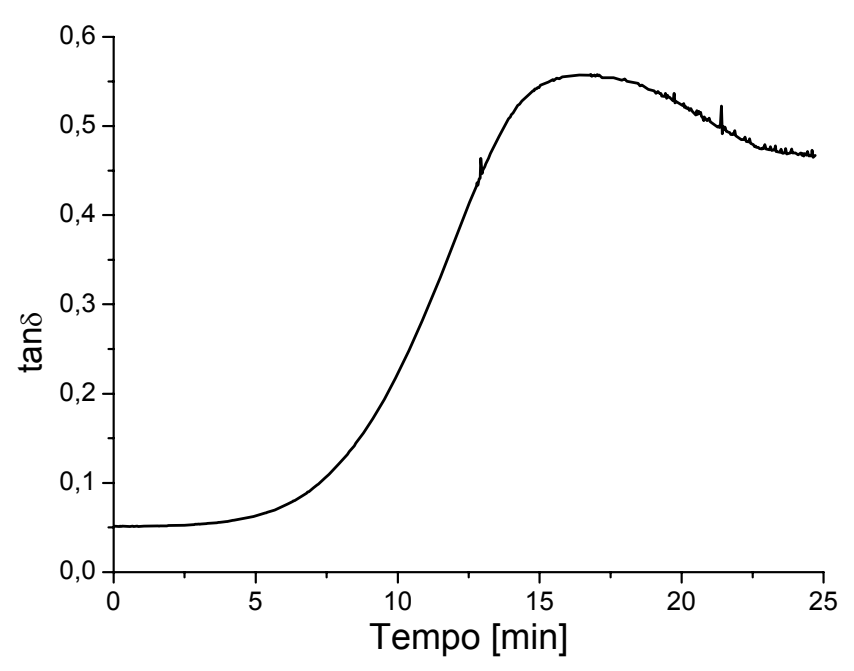

Figura 4.33 - Fator de amortecimento (tan $\delta)$-tempo.

A Figura 4.34 exibe as curvas de comportamento do módulo elástico cisalhante (G') no tempo, bem como a parcela viscosa do módulo ao cisalhamento (G") em função do tempo. Verifica-se que inicialmente a parcela elástica é igual a 420 [MPa] e a parcela viscosa é igual a 21 [MPa]. Com base nos ensaios quase-estáticos de tração, nos quais o módulo de elasticidade é igual a 1,52 GPa e o coeficiente de Poisson é igual a 0,44, calculase o módulo elástico ao cisalhamento, encontrando um valor de $528 \mathrm{MPa}$. No entanto, devese ressaltar que durante o ensaio de DMA, o CDP é submetido a um carregamento de flexão. 
Nota-se também que a parcela elástica diminui com o tempo, ao passo que a parcela viscosa começa a aumentar gradativamente a partir de 5 minutos, atingindo um valor máximo de 34 [MPa] em 10 minutos. Isto é aceitável, pois o polímero é composto de duas parcelas: sólido e líquido viscoso. Após os dez minutos, constata-se a redução da parcela viscosa juntamente com a parcela elástica, porém a parcela elástica é dominante em relação à viscosa.

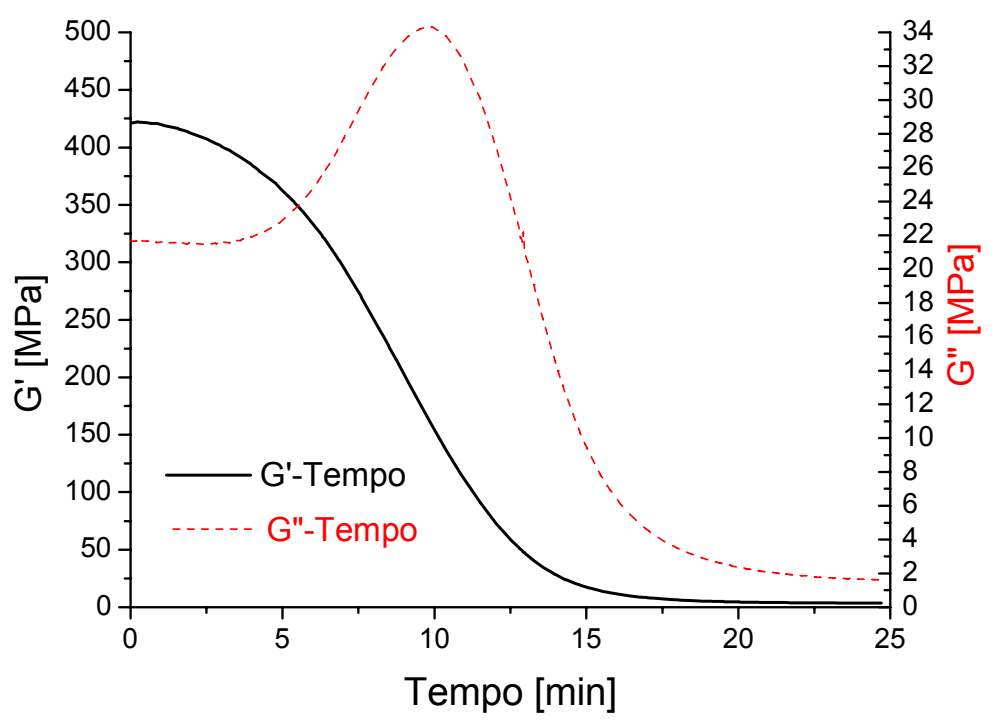

Figura 4.34 - Módulo de cisalhamento: parcela elástica e parcela viscosa.

Finalmente, a combinação da parcela viscosa ao cisalhamento (parte imaginária) com a parcela elástica ao cisalhamento (parte real) fornece o Módulo de Cisalhamento Complexo mostrado pela Figura 4.35. 


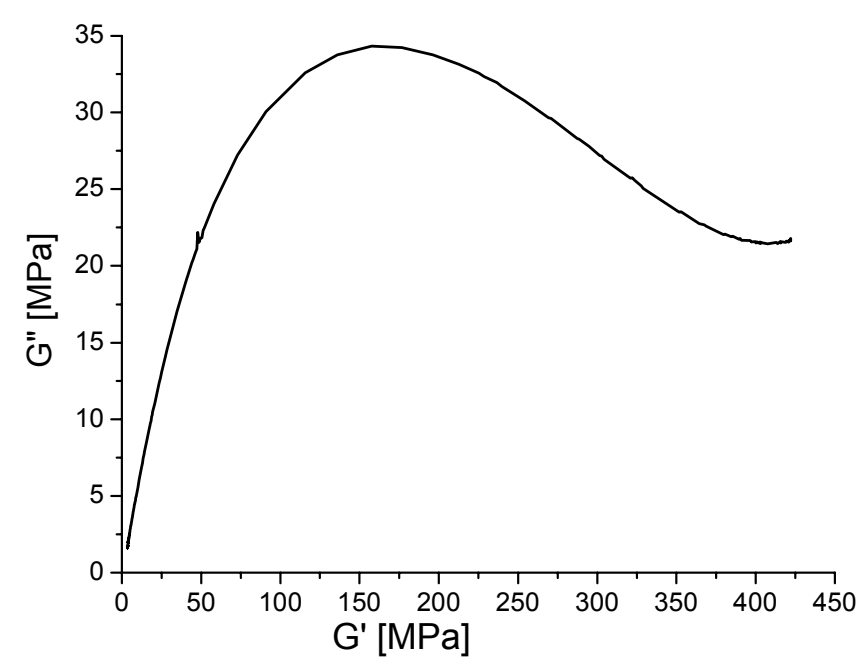

Figura 4.35 - Módulo de cisalhamento complexo $\left(\mathrm{G}^{*}\right)$.

\subsection{Resultados computacionais}

Deve-se ressaltar que todos os modelos computacionais foram desenvolvidos empregando o programa ABAQUS ${ }^{\circledR}$, via Método dos Elementos Finitos. Vale destacar que o programa possui formulação de modelo viscoelástico, viscoplástico, elastoplástico entre outros implementados (HIBBIT et al, 2002).

\subsubsection{Cálculo dos parâmetros de Drucker-Prager}

Com base nos resultados experimentais sob velocidade de 0,8 [mm/min], determinaram-se os parâmetros associados ao modelo de Drucker-Prager, que foi apresentado no Item 3.4.1.1. Destaca-se que para melhor determinar esses parâmetros seriam necessários mais alguns outros tipos de ensaio para que mais pontos fossem determinados. Assim, ter-se-ia a curva de plastificação do material no plano das tensões hidrostáticas e desviadoras. No presente trabalho, a curva de plastificação foi determinada 
com os dados dos ensaios de tração e compressão. Assim, por meio de pares de pontos ( $p$, q), tensão hidrostática e desviadoras respectivamente, foram obtidos parâmetros (Tabela 4.9) de Drucker-Prager:

Tabela 4.9 - Valores dos parâmetros de Drucker-Prager.

\begin{tabular}{|c|c|}
\hline Parâmetros & Valor \\
\hline Ângulo de atrito $(\beta)$ & $25,7^{\circ}$ \\
\hline Coesão (d) & $34,81[\mathrm{MPa}]$ \\
\hline Ângulo de dilatação $(\psi)($ Associatividade $\psi=\beta)$ & $25,7^{\circ}$ \\
\hline
\end{tabular}

Os valores da Tabela 4.9 estão dispostos na Figura 4.36 que representa a superfície de plastificação de Drucker-Prager para o material em questão.

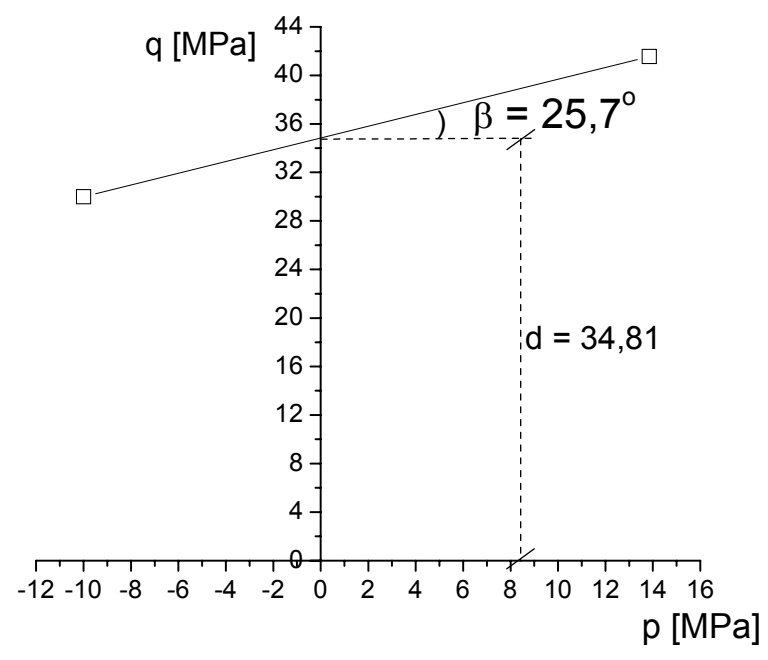

Figura 4.36 - Superfície de plastificação de Drucker-Prager.

\subsubsection{Resultados computacionais dos ensaios de tração monotônico}

Inicialmente, fez-se um levantamento bibliográfico com o intuito de verificar na literatura modelos capazes de reproduzir o comportamento do material. Em seguida, 
buscou-se explorar as potencialidades e limitações desses modelos que estão implementados no programa Abaqus ${ }^{\circledR}$, tais como:

1- Modelo elastoplático de von Mises;

2- Modelo de plasticidade de Drucker-Prager;

3- Modelo viscoplástico de von Mises.

Assim, foram realizadas as primeiras simulações com os modelos elastoplástico de von Mises e de Drucker-Prager com encruamento, embora o modelo de von Mises seja para materiais metálicos e o material em análise tenha parcela viscosa, verificou-se o resultado do modelo frente às propriedades deste material. A Figura 4.37 exibe uma comparação entre o resultado dos modelos elastoplástico com os resultados experimentais.

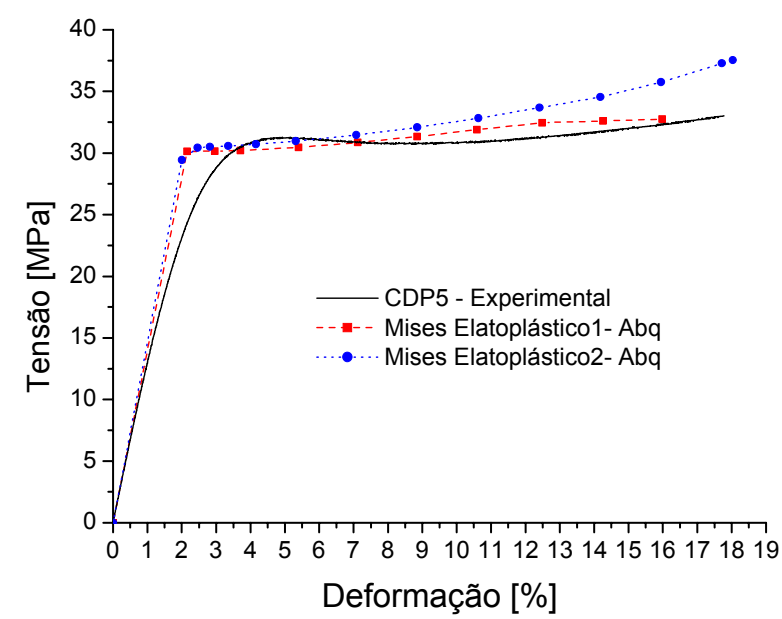

(a) Modelo de plasticidade de Mises

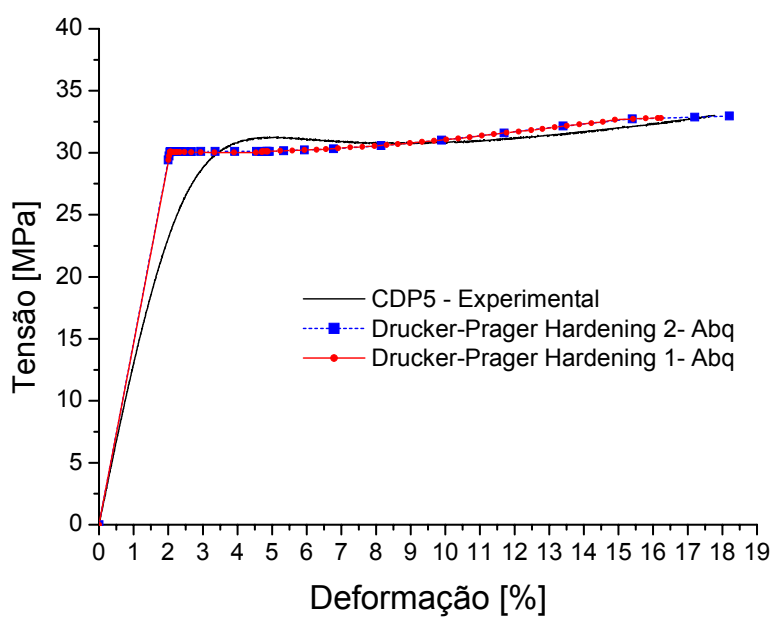

(b) Modelo de plasticidade de Drucker-Prager Figura 4.37 - Curvas de tensão-deformação elastoplástica.

Percebe-se pela Figura 4.37a que o resultado obtido através do modelo elastoplástico (linha tracejada em vermelho) apresenta um erro de 3,3\% no nível de tensão na fase viscoplástica $\left(\sigma^{p}=31,2[\mathrm{MPa}] ; \varepsilon^{p}=11,8 \%\right)$, desconsiderando que há um erro na região de escoamento do material, enquanto que na Figura 4.37b o erro apresentado é de $2,13 \%$ na fase viscoplástica $\left(\sigma^{p}=31,87[\mathrm{MPa}] ; \varepsilon^{p}=14,64 \%\right)$ e na região do escoamento o 
comportamento é similar ao anterior. Devido aos resultados obtidos com os modelos elastoplásticos, procurou-se abordar os modelos que tratam especificamente da parte viscosa do material. Com essa abordagem, conseguiu-se boa aproximação do comportamento do material, com o modelo viscoplástico de Mises, como pode ser visto na Figura 4.38b. No qual verifica-se que no ponto "A", para o mesmo nível de tensão, tem-se diferente nível de deformação (4,184\% - experimental; 5,049\% - teórica), implicando em um erro de $20,7 \%$ no nível de deformação. Enquanto que no ponto "B", para o mesmo nível de deformação tem-se diferentes níveis de tensão (30,78 [MPa] - experimental; 30,97 [MPa] teórico) implicando em um erro de $0,61 \%$ no nível de tensão.

Assim, avaliando a resposta do modelo viscoplástico através da Figura 4.38, percebe-se que o mesmo subestima o comportamento do material desde o limite de escoamento até as proximidades do pico de tensão ao escoamento, o que é favorável quando da utilização do modelo para simular o comportamento do material em forma de produtos acabados. Isto implica na utilização do material aquém do que o mesmo é capaz de suportar no regime viscoelástico não-linear, garantindo assim uma margem de segurança para o projeto. No ponto "B" (Figura 4.38b) o comportamento do modelo é muito similar ao do material, haja visto que o erro é de $0,61 \%$ até o limite de softening. Após este limite, o modelo praticamente representa o comportamento do material sob carregamento uniaxial monotônico quase estático.

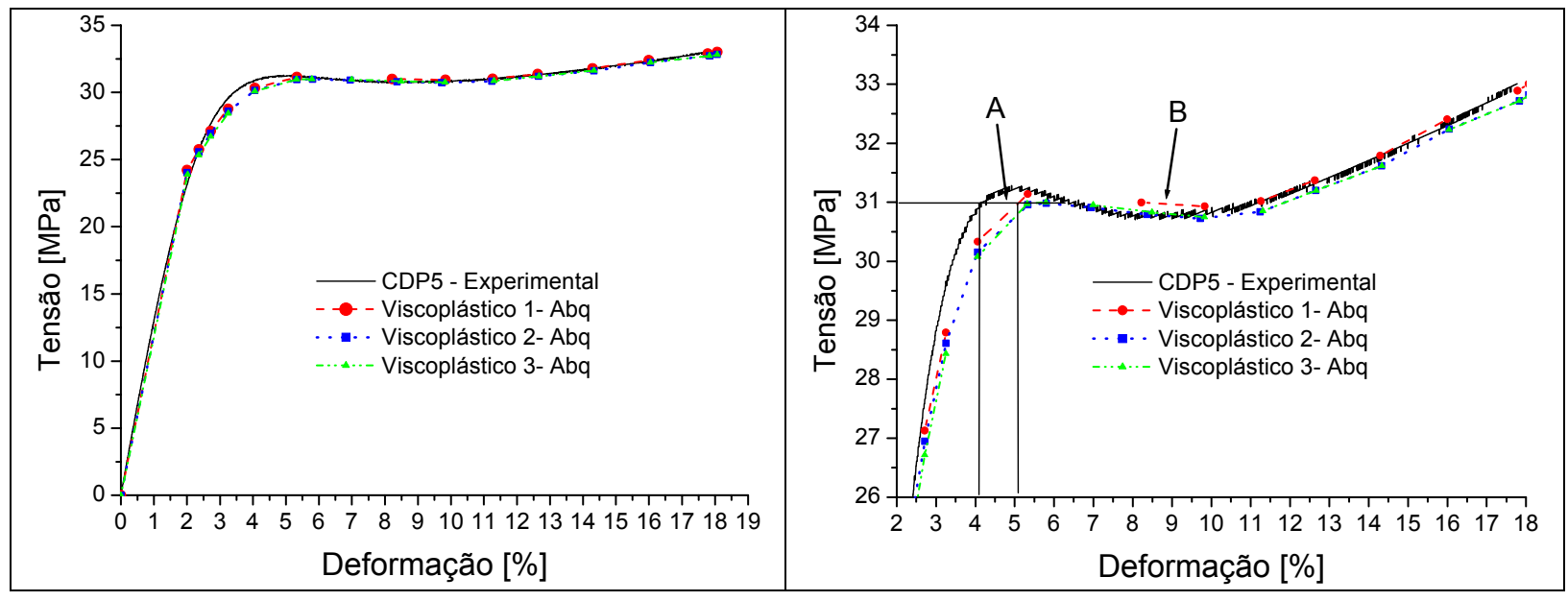

$\begin{array}{ll}\text { (a) Curva completa } & \text { (b) Curva detalhada }\end{array}$

Figura 4.38 - Cuvas de tensão-deformação viscoelastoplástica. 
Os parâmetros de entrada do modelo foram calibrados da seguinte forma: "A" igual a 0,18; "n" igual a 2,8; "m" igual a zero e "f" igual a 0,15205

\subsubsection{Resultados computacionais dos ensaios de tração cíclicos de fluência}

O procedimento para realização desta simulação se deu de acordo com o já mencionado (Item 3.4.2.2), para isto foram utilizados os modelos de Drucker-Prager e o de viscoelasticidade com von Mises. Para os modelos de Drucker-Prager, necessita-se da calibração dos parâmetros "A", "n", "m" e "a". A Figura 4.39 mostra um comparativo entre os modelos de Drucker-Prager time hardening (encruamento no tempo) e Drucker-Prager Singh Mitchell. O modelo de Drucker-Prager time hardening tem sua reposta mostrada na Figura 4.39a, o qual teve seus parâmetros ajustados da seguinte forma: $A=2,5.10-6 ; n=1,5 ; m=-$ 0,$42 ; v=0,44$ e o módulo de elasticidade médio $E=1,47$ [GPa]. Enquanto que a Figura 4.39b, mostra o comportamento do modelo de Drucker-Prager Singh Mitchell, com os parâmetros ajustados da seguinte forma: $A=8,5.10-7 ; \alpha=0,1 ; m=0,6 ; v=0,44$ e o módulo de elasticidade médio $\mathrm{E}=1,47 \mathrm{GPa}$.

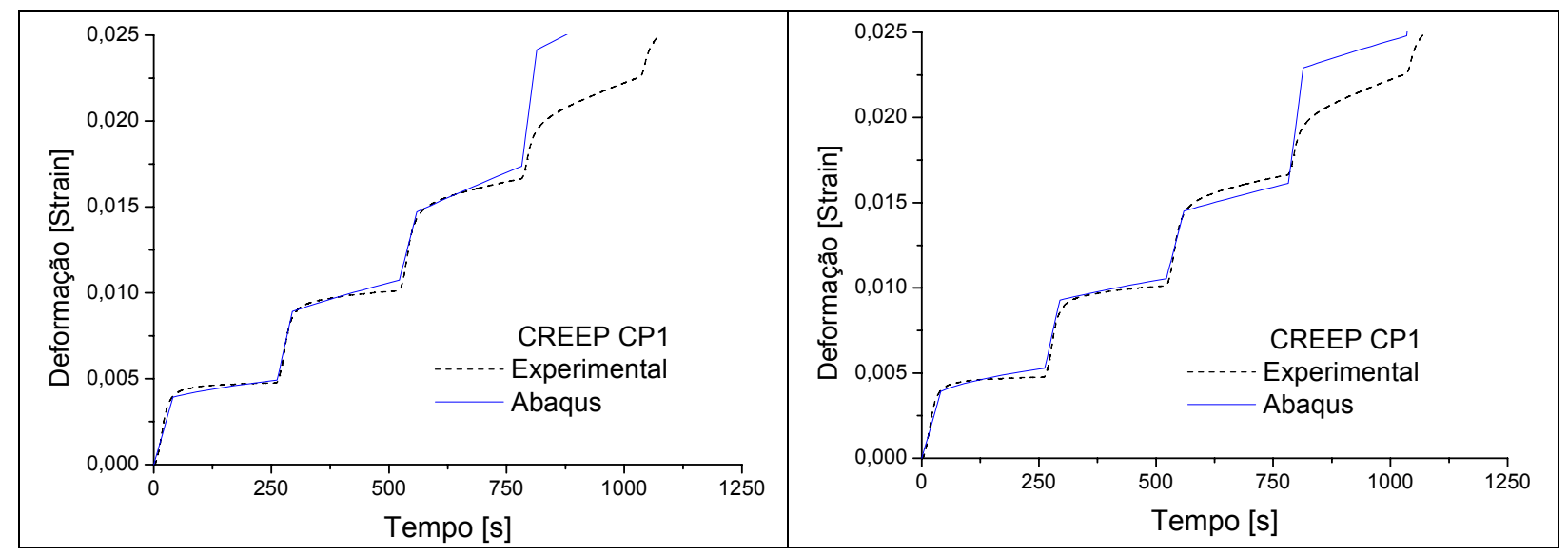

(a) Modelo Drucker-Prager time hardening

(b) Modelo Drucker-Prager Singh Mitchell

Figura 4.39 - Comparação das curvas deformação-tempo teórico-experimental. 
A Figura 4.39 evidencia que os modelos de Drucker-Prager se aproximam da resposta experimental. Porém, essa aproximação é mais nítida para pequenas deformações. No entanto, quando a deformação aumenta, o modelo converge para determinados níveis de deformação em detrimento de outros. Assim, ajusta-se o modelo para um patamar, desajustando para outro. Isto acontece devido aos parâmetros do modelo, entre os quais há um de grande influência linear (parâmetro A).

Para tanto, foram realizadas várias simulações para as duas leis de encruamento e o mais próximo da resposta experimental é mostrado na Figura 4.39, procurou-se ajustar os modelos para os primeiros passos, dentre os quais a partir do terceiro passo, o modelo apresentou uma tendência de divergência do resultado experimental. Isto levou o modelo a divergir do experimental aproximadamente $6,96 \%$ no primeiro patamar, $6,06 \%$ no segundo patamar e 4,4\% no terceiro patamar, Figura 4.39a. A divergência da resposta do modelo na Figura $4.39 \mathrm{~b}$, atingiu aproximadamente $9,22 \%$ no primeiro patamar, $4,07 \%$ no segundo patamar e $3,4 \%$ no terceiro patamar, subestimando o comportamento do material.

Continuando com a análise da fluência, pesquisou-se a resposta do modelo viscoelástico, tendo em vista que o material em questão é um biopolímero, portanto não se poderia deixar de verificar se o modelo viscoelástico avaliado seria capaz de representar o comportamento do material. Para tanto, necessita-se do módulo de flexibilidade normalizado, do tempo e de especificar o domínio (tempo ou freqüência). Neste caso, a simulação foi realizada no domínio do tempo com os dados do ensaio de fluência (flexibilidade e tempo). Para isso, foram utilizados como dados de entrada a flexibilidade e o tempo de duração de todos os patamares, a fim de verificar qual se ajustava ao modelo. Outra solução encontrada foi a utilização dos dados de ensaio de DMA, os quais, também, foram testados a fim de verificar a resposta do modelo.

Os dados elásticos de entrada, como o módulo de elasticidade a flexão e o coeficiente de Poisson, são: $E^{f}=1,220$ [GPa] e v = 0,44. A Figura 4.40 exibe a comparação entre a curva teórico-experimental de deformação-tempo com uma pequena diferença na 
resposta, pois a Figura 4.40 a até o terceiro patamar superestima o comportamento do material, enquanto que na Figura 4.40b, o modelo se distingue do experimental a partir do terceiro patamar. Isto resulta nos seguintes erros do modelo para representar o comportamento do material: para a Figura $4.40 \mathrm{a}$, no primeiro patamar aproximadamente $5,19 \%$ e no segundo patamar de $2,99 \%$; para a Figura $4.40 \mathrm{~b}$, no primeiro patamar aproximadamente $2,8 \%$ e no terceiro patamar $4,19 \%$.

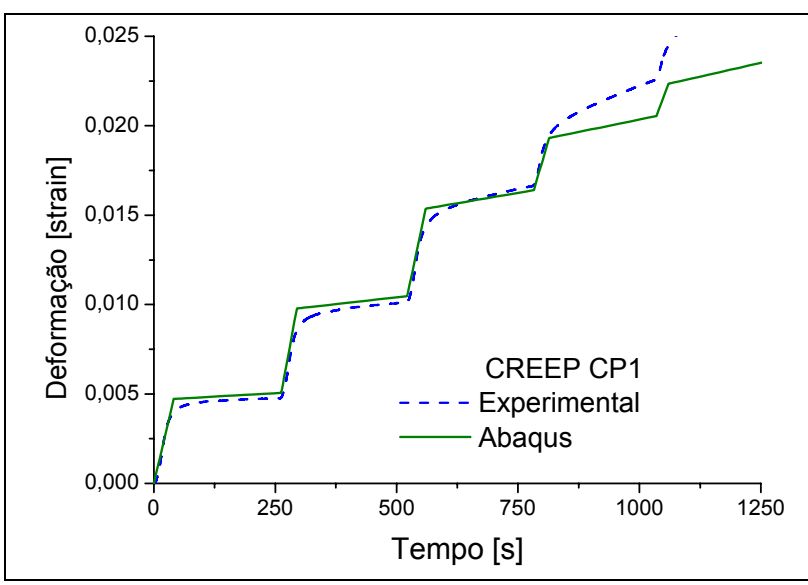

(a)

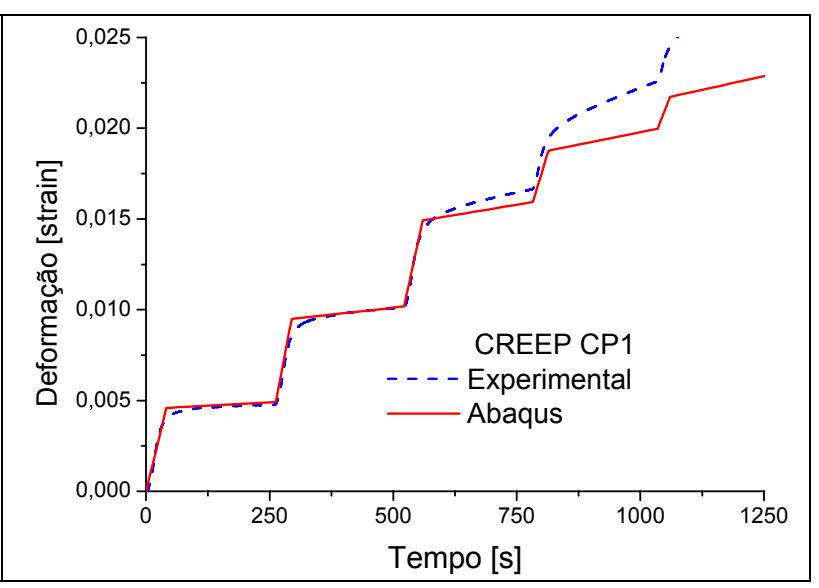

(b)

Figura 4.40 - Comparação teórico-experimental de curvas deformação-tempo.

\subsubsection{Resultados computacionais dos ensaios de compressão monotônico}

Para a simulação do comportamento do material sob compressão, adotou-se o mesmo procedimento empregado na simulação do ensaio de tração. Assim, analisando os resultados obtidos com o modelo elastoplástico de Mises (linha cheia em azul) Figura 4.41a apresenta um erro aproximado de $1,20 \%$ na região do softening, sem considerar que na região do limite de escoamento até o início do amolecimento, o modelo diverge do comportamento do material. Enquanto que o modelo de Drucker-Prager apresenta erro máximo de $1,70 \%$ na extremidade da curva da Figura $4.41 \mathrm{~b}$, sem considerar que o mesmo 
modelo apresenta comportamento similar ao de von Mises, ou seja, diverge do comportamento do material, quanto ao nível de tensão. Isso caracteriza que os modelos não representam adequadamente o comportamento do material, pelo menos no intervalo entre o início do escoamento e o final do softening. Isto é coerente, porque o modelo não contempla o efeito viscoso do material.

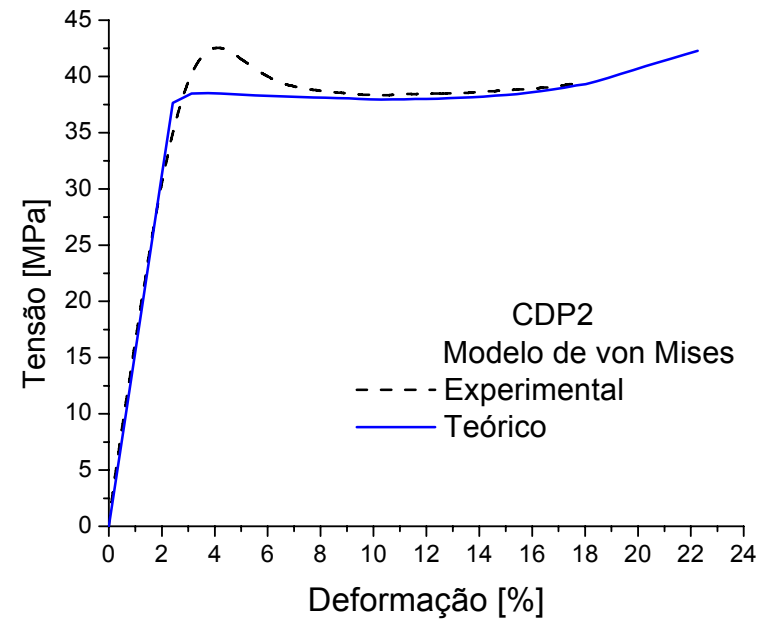

(a) Modelos elastoplástico de von Mises

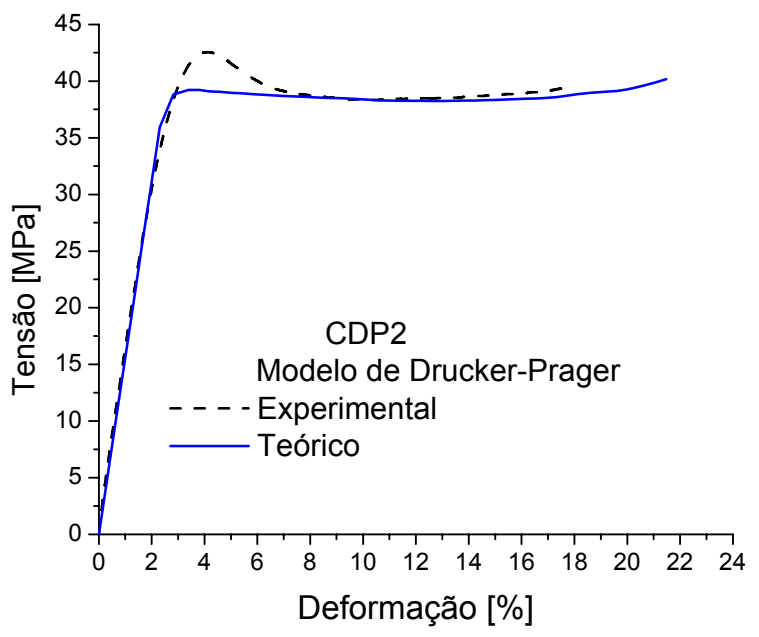

(b) Modelo elastoplástico de Drucker-Prager

Figura 4.41 - Curvas tensão-deformação.

Assim, continuando a investigação, passou-se a utilizar o modelo viscoso com von Mises. Os resultados obtidos não foram tão satisfatórios, como podem ser visto na Figura 4.42. Apesar de muitas tentativas de ajuste dos parâmetros não se obteve êxito, isto pode ter ocorrido devido ao softening ser mais acentuado no ensaio de compressão do que no ensaio de tração. A Figura 4.42 apresenta três curvas, uma curva experimental e duas teóricas. As curvas teóricas representam duas formas de ajustes dos dados de entrada, como visto na Tabela 4.10. Além desses ajustes exibidos, realizaram-se outros ajustes nos parâmetros do modelo viscoso $(A, n)$. Vale destacar que este procedimento também foi realizado no ensaio de tração. 
Tabela 4.10 - Propriedades do material para entrada no Abaqus.

\begin{tabular}{|c|c|c|c|c|c|}
\hline & \multirow[b]{2}{*}{ Dados elásticos } & \multicolumn{3}{|c|}{ Dados plásticos } & \multirow[b]{2}{*}{ Dados viscosos } \\
\hline & & & Início & Fim & \\
\hline \multirow{4}{*}{ 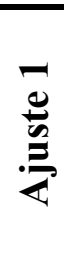 } & \multirow[t]{2}{*}{$\mathrm{E}^{\mathrm{c}}=1,71 \mathrm{GPa}$} & \multirow[t]{2}{*}{$\sigma$} & \multirow[t]{2}{*}{$25,381 \mathrm{MPa}$} & \multirow[t]{2}{*}{$43,000 \mathrm{MPa}$} & $\mathrm{A}=1,13673.10-4$ \\
\hline & & & & & $\mathrm{n}=0,3$ \\
\hline & \multirow[t]{2}{*}{$v=0,44$} & \multirow[t]{2}{*}{$\varepsilon$} & \multirow[t]{2}{*}{0,000} & \multirow[t]{2}{*}{0,170} & $\mathrm{~m}=0$ \\
\hline & & & & & $\mathrm{f}=1,934 \cdot 10-4$ \\
\hline \multirow{4}{*}{ 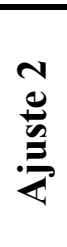 } & \multirow[t]{2}{*}{$\mathrm{E}^{\mathrm{c}}=1,71 \mathrm{GPa}$} & \multirow[t]{2}{*}{$\bar{\sigma}$} & \multirow[t]{2}{*}{$39,683 \mathrm{MPa}$} & \multirow[t]{2}{*}{$39,400 \mathrm{MPa}$} & $\mathrm{A}=1,13673 \cdot 10-4$ \\
\hline & & & & & $\mathrm{n}=0,3$ \\
\hline & \multirow[t]{2}{*}{$v=0,44$} & \multirow[t]{2}{*}{$\varepsilon$} & \multirow[t]{2}{*}{0,000} & \multirow[t]{2}{*}{0,161} & $\mathrm{~m}=0$ \\
\hline & & & & & $\mathrm{f}=1,934 \cdot 10-4$ \\
\hline
\end{tabular}

\section{Sendo que:}

A ,m e n - parâmetros de material;

f - razão do módulo viscoelástico pelo módulo instantâneo.

Assim, avaliando a resposta do modelo, o mesmo subestima o comportamento do material desde o limite de escoamento até as proximidades do pico de tensão ao escoamento (ponto A). Na região do softening, o modelo diverge um pouco na representação do comportamento do material, aproximadamente $1,5 \%$ no nível de tensão (no ponto B da Figura $4.42 \mathrm{~b}$ ).

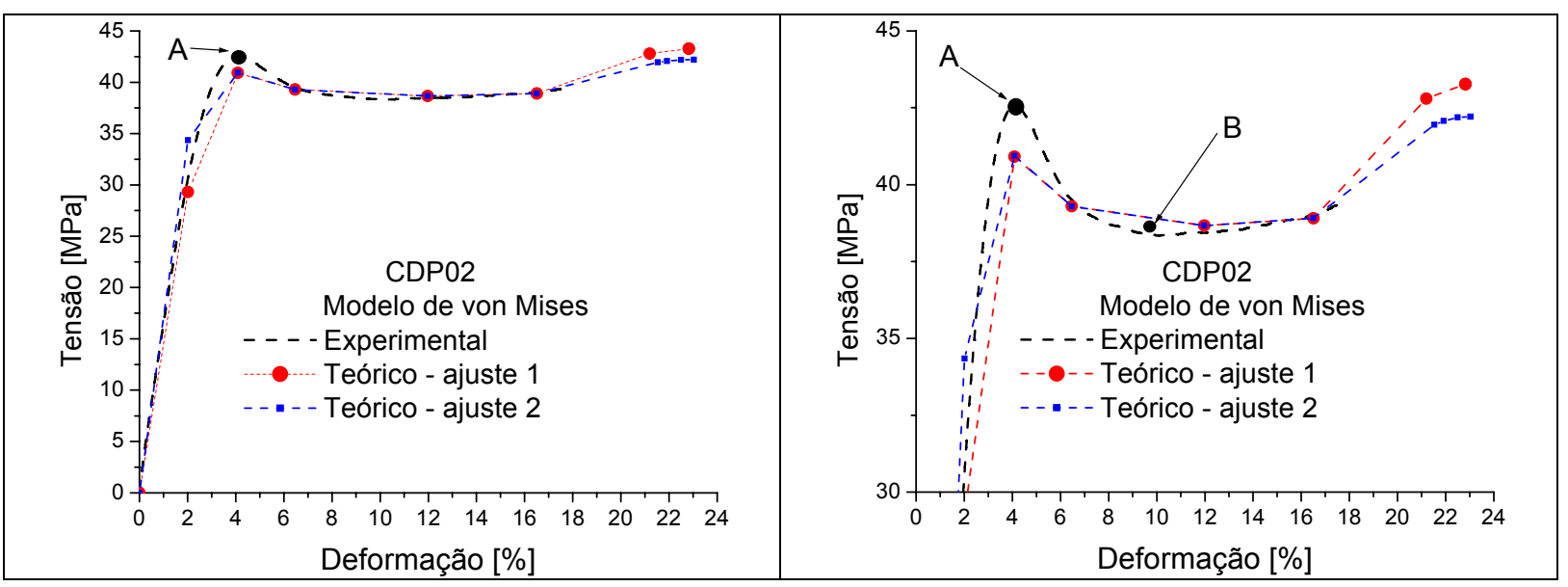

(a) Resposta do modelo viscoso de von Mises

(b) Detalhe da curva do modelo viscoso de von Mises

Figura 4.42 - Comparação das curvas tensão-deformação teórico-experimental em compressão. 


\subsubsection{Resultados computacionais dos ensaios de compressão cíclicos de fluência}

O procedimento para realização desta simulação se deu de acordo com o já mencionado (Item 3.4.2.2), para isto foram utilizados os modelos de Drucker-Prager. Para os modelos de Drucker-Prager, necessita-se da calibração dos parâmetros "A", "n" e "m". A Figura 4.43 exibe o quanto o modelo de Drucker-Prager creep law strain (encruamento por deformação) é capaz de representar o comportamento do material. Para este modelo, a lei de encruamento por deformação possui os seguintes valores da calibração dos parâmetros: $A=6,5 \cdot 10^{-6} ; n=0,95 ; m=-0,42 ; v=0,44$ e o módulo de elasticidade médio $E=1,71$ [GPa].

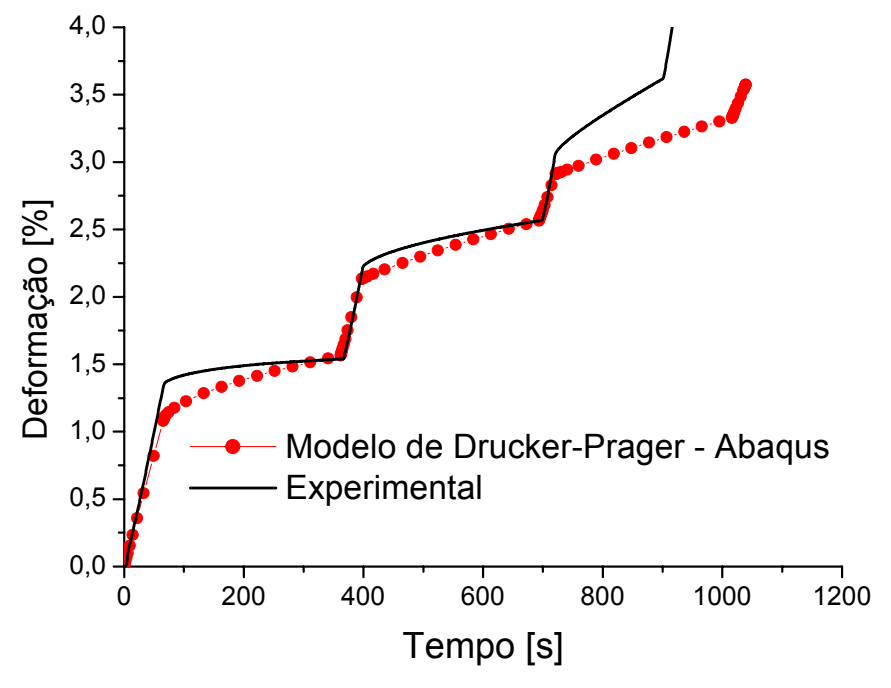

Modelo Drucker-Prager creep law strain

Figura 4.43 - Comparação das curvas deformação-tempo teórico-experimental de compressão.

A Figura 4.43 evidencia que o modelo de Drucker-Prager converge para a resposta experimental. Porém, essa convergência é mais nítida para pequenas deformações, no entanto, quando a deformação aumenta, o modelo converge para determinados níveis de deformação em detrimento de outros. Assim, quando se ajusta o modelo para um patamar a resposta do modelo diverge para o outro patamar. Isto acontece devido aos parâmetros do 
modelo, entre os quais há um de grande influência linear (parâmetro "A"). Para chegar a essa resposta, foram realizadas várias simulações para as leis de encruamento que se encontram no modelo de Drucker-Prager avaliados. Buscou-se a melhor convergência entre o computacional e o experimental, exibida na Figura 4.43. Assim, os modelos foram ajustados para os primeiros passos, sendo que a partir do terceiro passo o modelo apresentou uma tendência de divergência do resultado experimental.

\subsubsection{Resultados computacionais dos ensaios de flexão monotônico}

A Figura 4.44 mostra que os resultados obtidos através do modelo viscoplástico de Mises não convergiram para os resultados experimentais. Acredita-se que essa nãoconvergência se deve à natureza do carregamento, bem como pelas condições impostas ao modelo não representarem de fato as condições de ensaio. Outra explicação para a nãoconvergência se deve a forma de cálculo das deformações experimentais através da hipótese de Bernoulli-Navier, a qual é aplicável para pequenas deformações.

Para estas simulações foram utilizados os seguintes parâmetros: "A" igual a 0,18 ; " $n$ " igual a 3,0; "m" igual a zero, "f" igual a 0,15205, "E" igual 1,220GPa e "v" igual a 0,44. 


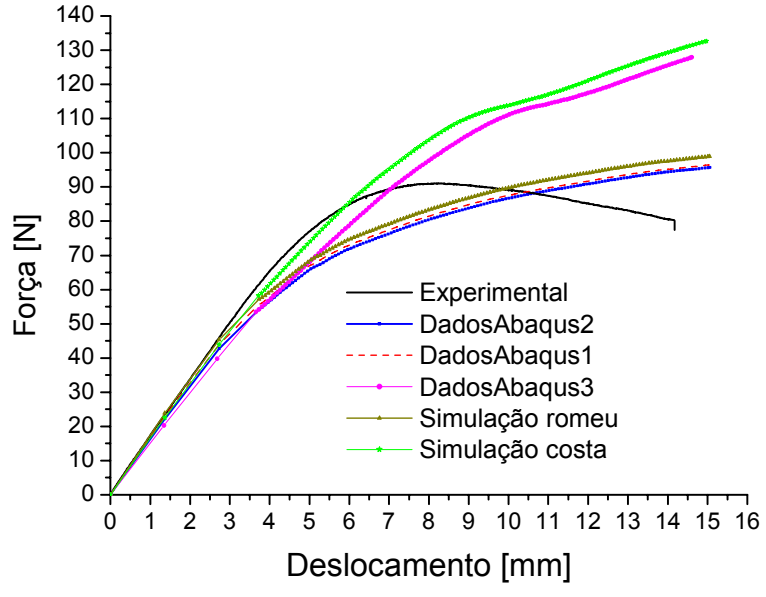

(a) Curva força-deslocamento

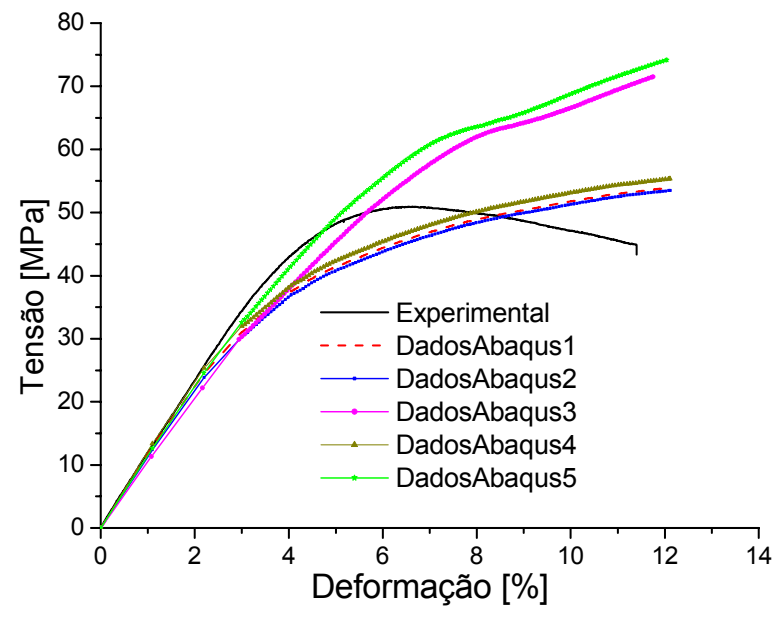

(b) Curva tensão-defomação

Figura 4.44 - Comparação das curvas teórico-experimental em flexão monotônica.

\subsubsection{Resultados computacionais dos ensaios de flexão cíclicos de relaxação}

A Figura 4.45a mostra as curvas força-tempo e deslocamento-tempo as quais demonstram a necessidade de ajuste do modelo viscoelástico. Também, pode-se notar que os dois primeiros patamares da Figura $4.45 a$ como na Figura $4.45 \mathrm{~b}$ estão próximos da convergência, em virtude da resposta elástica ser preponderante para os níveis de tensãodeformação empregados. Mas não se pode afirmar que os resultados convergiram. Os resultados podem ter sido influenciados pelas diferenças entre as condições de ensaio e as condições de contorno empregadas no modelo.

A Figura $4.45 \mathrm{~b}$ mostra a resposta numérica do modelo de flexão comparada ao resultado experimental quando empregado o modelo visco-elástico de Relaxação (tensãotempo e deformação-tempo). Verifica-se que o modelo diverge em níveis de tensãodeformação além do regime elástico o que é coerente com o modelo utilizado 
Para estas simulações foram utilizados os seguintes dados " $E$ ", igual 1,220 [GPa], " $v$ " igual a 0,44 e a flexibilidade ao cisalhamento normalizada tabular adquirida através do ensaio de DMA.

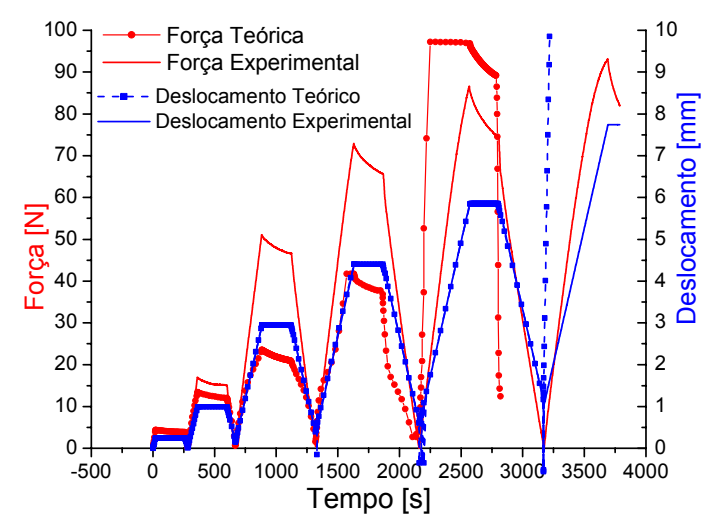

(a) Curva força-tempo x deslocamento-tempo

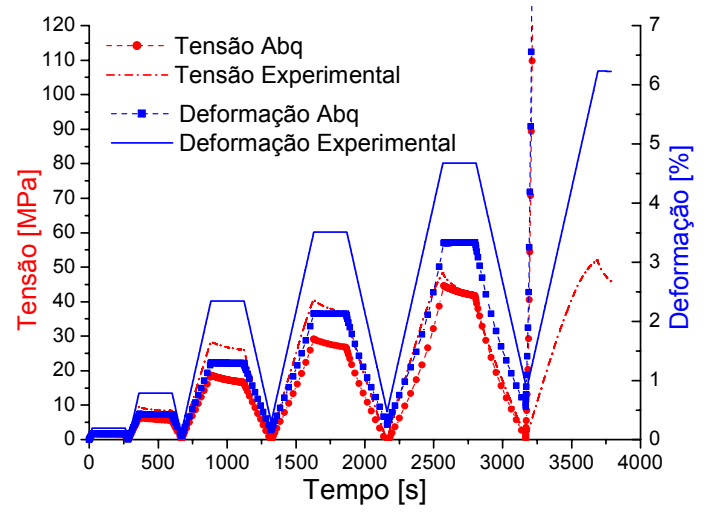

(b) Curva tensão-tempo x defomação-tempo Figura 4.45 - Comparação das curvas teórico-experimental em flexão cíclica. 


\section{Considerações finais}

Os ensaios de tração, compressão, flexão e DMA são de fundamental importância para a caracterização do material para carregamentos quase-estáticos e dinâmicos. Essa caracterização facilita o fornecimento dos parâmetros de entrada dos modelos constitutivos, a fim de verificar se os mesmos são capazes de representar o comportamento do material. Como destacado no objetivo, esse material foi analisado sob o ponto de vista físico-químico e no regime elastoplástico. Portanto, a proposta inicial (um pouco ousada) deste trabalho consistia na realização de todos os ensaios supracitados e verificação da existência de modelos constitutivos que representassem o comportamento de material. Porém, durante a realização dos ensaios, perceberam-se as dificuldades na aquisição de dados consistentes e coerentes com estado de tensão em cada estágio de solicitação dos CDPs. Inicialmente com os ensaios de tração, quando da escolha da velocidade de ensaio, em virtude das dificuldades encontradas para a aquisição dos dados devido o efeito viscoso do material, por isso optou-se por trabalhar com a velocidade de 0,8 [mm/min]. Em seguida, as dificuldades na realização dos ensaios de compressão, devido ao atrito entre os aplicadores de força e o CDP. Isto demandou tempo para se chegar a uma forma de minimizar o efeito do atrito no estado de tensão, que promovia o embarrilamento do CDP e, com isso, o estado de tensão deixava de ser uniaxial para ser um estado triplo de tensão. Após investigação de como 
outros pesquisadores minimizavam o problema do atrito na interface aplicador de força/ CDP, para a realização deste idealizou-se uma forma própria que gerou a solicitação de patente.

\subsection{Conclusões}

\subsubsection{Conclusões referentes aos ensaios experimentais}

Os resultados dos ensaios são fortemente influenciados pela velocidade de ensaio (taxa de deformação) empregada, principalmente no que diz respeito ao nível de tensão de escoamento, bem como o módulo de elasticidade quando as taxas de deformação são superiores à velocidade de $0,8[\mathrm{~mm} / \mathrm{min}]$ (igual a taxa de deformação de $2,67.10^{-4}\left[\mathrm{~s}^{-1}\right]$ ), como visto na Figura 4.1.

Os resultados dos ensaios monotônicos de tração demonstraram que o biopolímero possui uma parcela elástica elevada, ou seja, uma característica de recuperar seu estado inicial. Os gráficos tensão-deformação verdadeira demonstraram que a redução da velocidade de ensaio de $5,0[\mathrm{~mm} / \mathrm{min}]$ para $0,8[\mathrm{~mm} / \mathrm{min}]$ apresentou uma pequena alteração do módulo de elasticidade (1,47 [GPa]). Além disso, os ensaios com velocidade de 0,8 [mm/min] apresentaram o softening menos acentuado do que os ensaios sob velocidades de 5 [mm/min], esta minimização do softening facilitou o modelo implementado no Abaqus $₫$ representar melhor o comportamento do material quando submetido aos esforços de tração. Conclui-se, portanto, que o biopolímero apresenta comportamento distinto a cada taxa de deformação empregada. 
Por fim, os ensaios monotônicos de tração tanto via extensômetros como via straingages forneceram um coeficiente de Poisson que oscilou entre 0,44 e 0,45.

Os resultados dos ensaios monotônicos de compressão, realizados somente sob a velocidade de 0,8 [mm/min] mostraram que os níveis de deformação atingidos são bem superiores aos níveis de deformação atingidos pelos ensaios de tração. Além disso, tanto o fenômeno de softening como de encruamento são mais acentuados do que nos testes de tração. As curvas tensão-deformação, obtidas com o auxílio do deslocamento do travessão da máquina, forneceram o módulo de elasticidade aproximadamente igual a 1,1 [GPa] e tensão de escoamento igual a 49 [MPa]. Posteriormente, a deformação do CDP no sentido axial foi medida por um strain-gage colado na direção longitudinal e a variação da área foram obtidas através do strain-gage colado na direção transversal do CDP, isso possibilitou o cálculo da tensão instantânea atuante. O valor do módulo de elasticidade foi superior (1,71 [GPa]), o que evidenciou a influência da rigidez da máquina nas medidas realizadas através do travessão. Por fim, deve-se destacar que o valor da tensão de escoamento foi reduzido (42,5 [MPa]), devido ao cálculo do valor instantâneo da tensão atuante ser feito através da variação da área da seção transversal medida com o auxílio do strain-gage transversal. Vale destacar que estes resultados somente foram obtidos após o desenvolvimento do processo de tratamento superficial nos aplicadores de força compressiva, os quais minimizaram bastante o efeito do embarrilamento que atingia a região onde se colava os strain-gages, como já mencionado no item próprio sobre compressão. Esse procedimento de tratamento da rugosidade superficial e dureza dos aplicadores foi objetivo de solicitação de patente.

Tanto os resultados dos ensaios de tração como os de compressão com ciclos de carregamento-descarregamento e re-carregamento demonstraram onde o comportamento do material deixa de ser viscoelástico linear e passa a ser viscoelástico não-linear através das isócronas do ensaio de fluência (Figura 4.7) e com essas determina a flexibilidade do material. 
Também através das isócronas do ensaio de relaxação de tensão (Figura 4.12) consegue-se determinar o módulo de elasticidade com mais facilidade, porque fica mais perceptível o ponto em que o comportamento do material perde a linearidade. A viscoelastoplasticidade do material é demonstrada através dos laços histeréticos (Figura 4.14), os quais evidenciam a energia dissipada pelo material, ou seja, a deformação permanente (plástica).

Para obtenção dos resultados dos ensaios de flexão o ideal seria que o dispositivo mantivesse a distância dos apoios (span) constante durante todo o ensaio, pois como a Figura 4.28 mostrou que os pontos de contato do CDP com os apoios variam durante a realização do ensaio. Outro problema no tratamento dos dados foi a utilização da fórmula de Bernoulli-Navier, a qual contempla o regime elástico e, para tanto, o necessário seria utilizar a equação da viga de Timoshenko que envolve grandes deformações. Contudo, determinouse o módulo de elasticidade à flexão $\left(E^{f}\right)$ igual a 1,22 [GPa] para o nível de deformação $\left(\varepsilon^{f}\right) a ̀ ~$ flexão igual a 0,5\% e uma tensão $\left(\sigma^{f}\right)$ igual a 6,13 [MPa]. Os ensaios de flexão também evidenciam o comportamento viscoelastoplástico do biopolímero através da não-linearidade apresentada pelas curvas carga-deslocamento.

Os resultados dos testes de DMA mostraram que a parcela elástica do módulo de elasticidade foi igual a 1,2 [GPa], o que evidencia que o cálculo utilizado pela fórmula de Bernoulli-Navier aplicada nos resultados do ensaio de flexão não estão muito fora da realidade, uma vez que o módulo de elasticidade à flexão é igual a 1,22 [GPa]. Ressaltando que durante o teste de DMA, a amostra foi submetida a um carregamento de flexão. Nota-se também que a parcela elástica reduz-se em função do tempo ao passo que a parcela viscosa começou a aumentar gradativamente e atingiu um valor máximo de 0,1 [GPa] em 10 minutos (Figura 4.31). Após este valor, constatou-se a redução da parcela viscosa juntamente com a parcela elástica, porém a parcela elástica quase sempre foi dominante em relação à viscosa. Portanto, conclui-se que a parcela elástica da resposta é maior do que a parcela viscosa. Além disso, os testes de DMA permitiram determinar o Fator de 
Amortecimento $(\tan \delta)$ em função do tempo, sendo que até o tempo igual a 5 minutos este valor era pequeno e permaneceu praticamente constante em 0,05 , porém a partir deste instante, o fator aumentou consideravelmente chegando a atingir um valor máximo de 0,55 em 16 minutos.

Conclui-se com isso a caracterização mecânica deste biopolímero derivado do óleo da mamona.

\subsubsection{Conclusões referentes às simulações computacionais}

Foram realizadas simulações que contemplaram os efeitos elastoplásticos, viscoelásticos e visco-elastoplásticos, tanto para tração, para compressão como para flexão.

O modelo viscoplástico para representar o comportamento do biopolímero sob tração apresentou um erro de $0,61 \%$ no nível de tensão. Assim, avaliando a resposta do modelo viscoplástico através da Figura 4.38, percebe-se que o mesmo subestima o comportamento do material desde o limite de escoamento até as proximidades do pico de tensão ao escoamento, o que é favorável quando da utilização do modelo para simular o comportamento do material em forma de produtos acabados. Isto implica na utilização do material aquém do que o mesmo é capaz de suportar no regime viscoelástico não-linear, garantindo assim uma margem de segurança para o projeto. Porém, conclui-se que o modelo viscoplástico conseguiu representar o comportamento do material com certa exatidão, em virtude do pico de escoamento não ser muito acentuado, como no caso do emprego de velocidade mais elevada. Os resultados computacionais para simulação dos ensaios de tração monotônica utilizando os modelos de von Mises e Drucker-Prager não representaram muito bem o comportamento do biopolímero. Ou seja, o modelo de von Mises apresentou um erro de 3,3\% no nível de tensão na fase viscoplástica (Figura 4.37a), 
desconsiderando que há um erro na região de escoamento do material; enquanto que o modelo de Drucker-Prager (Figura 4.37b) apresentou um erro de 2,13\% na fase viscoplástica e na região do escoamento o comportamento é similar ao anterior.

Para os resultados das simulações do comportamento do material sob carregamentos cíclicos de fluência em tração, o modelo viscoelástico de Mises apresentou divergência no primeiro patamar aproximadamente de 2,8\% e no terceiro patamar 4,19\%. Tendo o modelo viscoelástico representado a curva com melhor perfil do que os modelos de Drucker-Prager. Com estes, procurou-se ajustar seus parâmetros para os primeiros passos, dentre os quais a partir do terceiro passo, o modelo apresentou uma tendência de divergência do resultado experimental da ordem de 6,96\% no primeiro patamar, $6,06 \%$ no segundo patamar e 4,4\% no terceiro patamar, Figura 4.39a. A divergência da resposta do modelo na Figura 4.39b, atingiu aproximadamente $9,22 \%$ no primeiro patamar, $4,07 \%$ no segundo patamar e $3,4 \%$ no terceiro patamar, subestimando o comportamento do material.

Para os resultados das simulações do comportamento do material sob compressão monotônica, adotou-se o mesmo procedimento empregado na simulação do ensaio de tração. Assim, utilizou-se o modelo viscoplástico de von Mises, o qual não apresentou resultados tão satisfatórios quanto os obtidos para tração, como podem ser visto na Figura 4.42. Isto ocorreu devido ao softening ser mais acentuado no ensaio de compressão do que no ensaio de tração. Esta divergência entre a resposta teórica e a resposta experimental evidencia que o modelo não consegue representar o comportamento do material frente à solicitação de compressão. Analisando os resultados obtidos com o modelo elastoplástico de von Mises (Figura 4.41a) a divergência apresentada foi de aproximadamente $1,20 \%$ na região do softening, sem considerar que na região do limite de escoamento até o início do amolecimento, o modelo diverge do comportamento do material. Enquanto que o modelo de Drucker-Prager apresenta divergência máxima de $1,70 \%$ na extremidade da curva da Figura $4.41 \mathrm{~b}$, sem considerar que o mesmo modelo apresenta comportamento similar ao de von Mises, ou seja, diverge do comportamento do material, 
quanto ao nível de tensão. Isso caracteriza que os modelos não representam adequadamente o comportamento do material, pelo menos no intervalo entre o início do escoamento e o final do softening. Isto é coerente, porque o modelo não contempla o efeito viscoso do material.

Os resultados das simulações do comportamento do material sob carregamentos cíclicos de fluência em compressão, utilizando os modelos de Drucker-Prager, apresentaram o mesmo comportamento do ensaio de tração.

Os resultados das simulações de flexão monotônica e cíclica também foram bastante divergentes (Figura 4.44 e Figura 4.45). Por tanto, segue-se as seguintes sugestões para trabalhos futuros.

\subsection{Sugestões para trabalhos futuros}

- Colocar os apoios e o aplicador de carga como superfícies rígidas, com isso colocar as condições de contato, conforme utilizado na compressão;

- Utilizar a viga de Timoshenko na análise dos resultados de flexão;

- Desenvolver um modelo que represente o comportamento do material, tanto na tração como na compressão;

- Desenvolvimento de UMAT (user's materials) para implementação do modelo no pacote Abaqus ${ }^{\circledR}$;

- Verificação desse possível modelo sob carregamento de flexão e sob um modelo de um produto, além do modelo de CDPs.

- Explorar mais a técnica DMA/ DMTA. 



\section{Referências bibliográficas}

AN, Y. G., VEGTER, H. Analytical and experimental study of frictional behavior in throughthickness compression test. Journal of Materials Processing Technology. 160; p148-155, 2005.

ARA, C. A. Fijacion cervical con polimero vegetal. Revista de Neurocirurgía. 2(3); p103107, 1999.

ASTM D 638 - 96. Standard test method for tensile properties of plastics. West Conshohocken, 1996.

ASTM D 695 - 96. Standard test method for compressive properties of rigid plastics. West Conshohocken, 1996.

ASTM D 790-96a. Standard test method for flexural properties of unreinforced and reinforced plastics and electrical insulating materials. West Conshohocken, 1996.

BAI, S. -L.; WANG, M. Plastic damage mechanisms of polypropylene/polyamide 6/polyethelene-octane elastomer blends under cyclic tension. Polymer, 44, p. 6537-47, 2003.

BARDELLA, L. A phenomenological constitutive law for the nonlinear viscoelastic behaviour of expoxy resins in the glassy state. European Journal of Mechanics A/Solids, 20, p. 907-924, 2001.

BARDENHAGEN, S.G.; STOUT, M.G.; Gray, G.T. Three-dimensional, finite deformation, viscoplastic constitutive models for polymeric materials. Mechanics of Materials, v.25, p.235253, 1997.

BONINI, S. Estudo comparativo da resistência transversal, resistência à compressão, dureza superficial e comportamento visco-elástico da resina poliuretana em relação à resina acrílica usada para prótese dental. Ribeirão Preto, 127p. Tese (Doutorado). FORP - Faculdade de Odontologia de Ribeirão Preto. 2004.

BOYCE, M.C. \& ARRUDA, E.M. An experimental and analytical of the large strain compressive and tensile response of glassy polymers. Polymer Engineering and Science, v.30, n.20, p.1288-1298, 1990. 
BRIDGMAN, P. W. Studies in large plastic flow and fracture. Harvard University Press, Cambridge-Massachusetts, 1964.

CABEZAS, E. E.; CALENTANO, D. J. Experimental and numerical analysis of the tensile test using sheet specimens. Finite Elements in Analysis and Design. V. 40, p 555-575. February, 2004.

CHEN, W. H. Necking f a bar. International Journal Solids Structures. V. 7, p. 685-717. 1971.

CLARO NETO, S. Caracterizações físico-química de um poliuretano derivado de óleo de mamona utilizado para implantes ósseos. São Carlos, 127p. Tese (Doutorado) - Instituto de Química de São Carlos, Universidade de São Paulo, 1997.

DONTOS, A. C. "Fio lifting biológico" (fio serrilhado de poliuretana do óleo de mamona) Avaliação de sua biocompatibilidade e eficácia no rejuvenescimento facial. São Carlos, 70p. Dissertação de mestrado. Escola de Engenharia de São Carlos, Universidade de São Paulo, 2005.

DROZDOV, A.D.; CHRISTIANSEN, J.C. Modelling the viscoplastic response of polyethylene in uniaxial loading -unloading tests. Mechanics Research Communications, v.30, p.431-442, 2003.

DROZDOV, A.D.; GUPTA, R.K. Constitutive equations in finite viscoplasticity of semicrystalline polymers. International Journal of Solids and Structures, v.40 p. 6217-6243, 2003.

FRACHON, A. Modélisation et Simulation Numérique de la Compression en Matrice de Poudres Métalliques. Grenoble. 252p. Thèse (Doctorat). Institut National Polytechnique de Grenoble. 2002.

FERNEDA, A. B. Estudo Teórico-experimental do Comportamento Elastoplástico do Poliuretano Derivado do Óleo de Mamona (Ricinus Communis). 135p. Tese (Doutorado) Escola de Engenharia de São Carlos, Universidade de São Paulo, São Carlos, 2006.

G'SELL, C.; HIVER, J.M.; DAHOUN, A. Experimental characterization damage in solid polymers under tension, and its enterrelation with necking. International Journal of Solids and Structures, v.39, p.3857-3872, 2002.

GILLIS, P. P. and Jones, S. E. Tensile deformation of a flat sheet. International Journal of Mechanics Science. V. 21, p. 109-117, 1979.

HART, E. W. A uniaxial strain model for a Luder's band. Acta Metallurgica, v. 3, p 146-149, 1955.

HIBBIT, KARLSSON; SORENSEN. ABAQUS Theory Manual. v2 Version 6.1. 2002.

IGNÁCIO, H. Avaliação da poliuretana da mamona nas formas compacta e porosa no preenchimento de falha óssea. Estudo experimental em cães. Ribeirão Preto, 92p. Tese (Doutorado) - Faculdade de Medicina de Ribeirão Preto, Universidade de São Paulo. 1999. 
IGNÁCIO, H.; MAZZER, N.; BARBIERI, C. H.; CHIERICI, G. Estudos sobre a aplicabilidade médica da poliuretana derivada da mamona. Resenha Ortopédica. 6(2); p10 $12,1996$.

IGNÁCIO, H.; MAZZER, N.; BARBIERI, C. H.; CHIERICI, G. Uso da poliuretana derivada do óleo de mamona para preencher defeitos ósseos diafisários segmentares do rádio. Revista Brasileira de Ortopedia.v 32(10); Outubro; p815-822, 1997.

JESUS, J. M. H.; CALIL JÚNIOR, C.; CHIERICE, G. O. Adesivo a base de óleo de mamona para madeiras. Curitiba. p.2063-2971. Congresso Brasileiro de Engenharia e Ciência dos Materiais, 13. Anais Curitiba, 1998.

KHAN, A.; ZHANG, H. Finite deformation of a polymer: experiments and modeling. International Journal of Plasticity. 17; p.1167-1188, 2001.

KYOWA. Adesivo CC-36 - Manual de instruções. Código: IM-G-052b '99.10. Kyowa Electronic Instuments Co., Ltd. Tokyo, Japão. 2004b.

KYOWA. Strain gages: A complete lineup of high performance strain gages and acessories (catálogo). Código: Cat. No. 101E-U1. Kyowa Electronic Instuments Co., Ltd. Tokyo, Japão. 2004a.

LEMAITRE, J.; CHABOCHE, J. -L. Mechanics of solid materials. Traduzido para o inglês por SHRIVASTAVA, B. Cambridge University Press, 1990.

LING, Y. Uniaxial true stress-strain after necking. AMP Journal of Technology, v.5, p.37-48, 1996.

MALVERN, L.E. Introduction to the mechanics of a continuous medium. Prentice-Hall, Inc: New Jersey, 1969.

McCRUM, N. G.; BUCKLEY, C. P.; BUCKNALL, C. B. Principles of polymer engineering. Oxford Science Publications. Oxford University Press, INC: New York, 1992.

MEYERS, M. A.; CHAWLA, K. K. Mechanical behavior of materials. Prentice-Hall, Inc, 1999.

MIKKELSEN, L. P. Necking in rectangular tensile bars approximated by a 2-D gradient dependent plasticity model. Eur. J. Mech A/ Solids. pp 805-818. V. 18. February, 1999.

MURAKAMI, C.R. Aplicações das resinas poliuretanas derivadas do óleo de mamona, como materiais isolantes elétricos. São Carlos. 123p. Tese (Doutorado) - Escola de Engenharia de São Carlos, Universidade de São Paulo, 2002.

NEEDLEMAN, A. A numerical study of necking in circular cylindrical basrs. Journal of the Mechanics and Physics of Solids. V. 20, p. 111-127, 1972.

NIKOLOV, S.; DOGHRI, I. A micro/macro constitutive model for the small-deformation behavior of polyethylene. Polymer, v.41, p.1883-1891, 2000. 
NORRIS Jr., D. M.; MORAN, B.; SCUDDER, J. K.; QUIÑONES, D. F. A computer simulation of the tension test. Journal of the Mechanics and Physics of Solids. V. 26, p. 1-19, 1978.

ODOM, E. M.; ADAMS, D. F. Development of an improved compression specimen geometry for unreinforced polymers. Journal of Testing \& Evaluation. V. 22(2); p104-110, 1994.

OHARA, G. H.; KOJIMA, K. E.; ROSSI, J. C.; TELlES, M.; SOARES, T. V. C.; SALOMÃO, C.; SANDA, M. Estudo experimental da biocompatibilidade do polímero poliuretano da mamona implantada intra-óssea e intra-articular em coelhos. Acta Ortopédica Brasileira. V.3 (2). Abr/Jun. p62-68, 1995.

PASCON, E. A. Projeto biocompatibilidade dos materiais endodonticos: Biocompatibilidade da resina poliuretana derivada da mamona. Ribeirão Preto, 167p. Tese (Doutorado) Faculdade de Odontologia de Ribeirão Preto, Universidade de São Paulo. 1999.

RAVI-CHANDAR, K.; MA, Z. Inelastic Deformation in Polymers under Multiaxial Compression. Mechanics of Time-Dependent Materials. V 4(4); p333-357, 2000.

SHACKELFORD, J.F. Introduction to materials science for engineers, 4th edition. PrenticeHall, Inc: New Jersey. 1996.

SILVA, I. J. Contribuição ao estudo da utilização da resina poliuretana a base de óleo de mamona na construção civil. São Carlos. 163p. Dissertação (Mestrado) - Escola de Engenharia de São Carlos, Universidade de São Paulo, 1996.

SILVA, R. V. Compósito de resina poliuretano derivado de óleo de mamona e fibras vegetais. São Carlos. 139p. Tese (Doutorado) - Escola de Engenharia de São Carlos, Universidade de São Paulo, 2003.

SILVESTRE FILHO, G.D. Comportamento mecânico do poliuretano derivado de óleo de mamona reforçado por fibra de carbono: contribuição para o projeto de hastes de implante de quadril. São Carlos. 136p. Dissertação (Mestrado) - Escola de Engenharia de São Carlos, Universidade de São Paulo, 2001.

TIMOSHENKO, S. P.; GERE, J. M. Mecânica dos sólidos. Tradutores: CARVALHO, J. R.; CAPSKI, L. R. LTC - Livros Técnicos e Científicos Editora S. A., 1998.

VAN DER SLUIS, O; SCHREURS, P. J. G.; MEIJER, H.E.H. Effective properties of a viscoplastic constitutive model obtained by homogenisation. Mechanics of Materials, v.31 p.743-759, 1999.

VIANNA, D. L. Estudo comparativo da resistência mecânica da poliuretana derivada de óleo vegetal submetida à ensaios de tração. Ribeirão Preto e São Carlos, 67p. Dissertação (Mestrado) - Faculdade de Medicina de Ribeirão Preto e Escola de Engenharia de São Carlos, Universidade de São Paulo. 1997.

WILLIAMS, J.G. Stress analysis of polymers. Longman Group Limited. London. UK. 1973. 
WU, J. Z.; DONG, R. G.; SCHOPPER, A. W. Analysis of effects of friction on the deformation behavior of soft tissues in unconfined compression tests. Journal of Biomechanics. V 37; p147-155, 2004.

YOUNG, R.J.; LOVELL, P.A. Introduction to polymers. Second edition. Chapman \& Hall: London, 1991.

ZHANG, Z.L.; ODERGARD, J.; SOVIK, O.P. Determining true stress-strain curve for isotropic and anisotropic materials with rectangular tensile bars: method and verifications. Computational Materials Science, v.20, p.77-85, 2001. 